\title{
sustainability
}

\section{Port Strategy \\ for Sustainable \\ Development}

Printed Edition of the Special Issue Published in Sustainability 


\section{Port Strategy for Sustainable Development}





\section{Port Strategy for Sustainable Development}

Editor

Elvira Haezendonck 
Editor

Elvira Haezendonck

Vrije Universiteit Brussel

België

Editorial Office

MDPI

St. Alban-Anlage 66

4052 Basel, Switzerland

This is a reprint of articles from the Special Issue published online in the open access journal Sustainability (ISSN 2071-1050) (available at: https://www.mdpi.com/journal/sustainability/ special_issues/port_strategy).

For citation purposes, cite each article independently as indicated on the article page online and as indicated below:

LastName, A.A.; LastName, B.B.; LastName, C.C. Article Title. Journal Name Year, Volume Number, Page Range.

ISBN 978-3-0365-0090-4 (Hbk)

ISBN 978-3-0365-0091-1 (PDF)

Cover image courtesy of pixaby user pexels.

(C) 2021 by the authors. Articles in this book are Open Access and distributed under the Creative Commons Attribution (CC BY) license, which allows users to download, copy and build upon published articles, as long as the author and publisher are properly credited, which ensures maximum dissemination and a wider impact of our publications.

The book as a whole is distributed by MDPI under the terms and conditions of the Creative Commons license CC BY-NC-ND. 


\section{Contents}

About the Editor $\ldots \ldots \ldots \ldots \ldots \ldots \ldots \ldots \ldots \ldots \ldots$ vii

Elvira Haezendonck

Port Strategy for Sustainable Development: Circularization and Value Creation—Introduction to a Special Issue

Reprinted from: Sustainability 2020, 12, 9914, doi:10.3390/su12239914 . . . . . . . . . . . . . .

\section{Elvira Haezendonck and Karel Van den Berghe}

Patterns of Circular Transition: What Is the Circular Economy Maturity of Belgian Ports?

Reprinted from: Sustainability 2020, 12, 9269, doi:10.3390/su12219269 . . . . . . . . . . . . 5

Peter W. de Langen, Henrik Sornn-Friese and James Hallworth

The Role of Port Development Companies in Transitioning the Port Business Ecosystem;

The Case of Port of Amsterdam's Circular Activities

Reprinted from: Sustainability 2020, 12, 4397, doi:10.3390/su12114397 . . . . . . . . . . . . 21

Karel Van den Berghe, Felipe Bucci Ancapi and Ellen van Bueren

When a Fire Starts to Burn. The Relation Between an (Inter)nationally Oriented Incinerator

Capacity and the Port Cities' Local Circular Ambitions

Reprinted from: Sustainability 2020, 12, 4889, doi:10.3390/su12124889 . . . . . . . . . . . . 37

Marta Mańkowska, Izabela Kotowska and Michał Pluciński

Seaports as Nodal Points of Circular Supply Chains: Opportunities and Challenges for Secondary Ports

Reprinted from: Sustainability 2020, 12, 3926, doi:10.3390/su12093926 . . . . . . . . . . . . 55

Ling Yu, Pengfei Xu, Jia Shi, Jihong Chen and Hong Zhen

Driving Mechanism of Port-City Spatial Relation Evolution from an Ecological Perspective:

Case Study of Xiamen Port of China

Reprinted from: Sustainability 2020, 12, 2857, doi:10.3390/su12072857 . . . . . . . . . . . . . 77

\section{Michael Stein and Michele Acciaro}

Value Creation through Corporate Sustainability in the Port Sector: A Structured

Literature Analysis

Reprinted from: Sustainability 2020, 12, 5504, doi:10.3390/su12145504

Magali Geerts and Michaël Dooms

Sustainability Reporting for Inland Port Managing Bodies: A Stakeholder-Based View on Materiality

Reprinted from: Sustainability 2020, 12, 1726, doi:10.3390/su12051726 . . . . . . . . . . . . 113

Yuyan Zhou, Yan Zhang, Dong Ma, Jun Lu, Wenbin Luo, Yu Fu, Shanshan Li, Junlan Feng, Cheng Huang, Wangqi Ge and Hong Zhu

Port-Related Emissions, Environmental Impacts and Their Implication on Green Traffic Policy in Shanghai

Reprinted from: Sustainability 2020, 12, 4162, doi:10.3390/su12104162 . . . . . . . . . . . . 131

Geoffrey C. Preston, Phillip Horne, Maria Paola Scaparra and Jesse R. O’Hanley

Masterplanning at the Port of Dover: The Use of Discrete-Event Simulation in Managing

Road Traffic

Reprinted from: Sustainability 2020, 12, 1067, doi:10.3390/su12031067 . . . . . . . . . . . . 149 
Vytautas Paulauskas, Ludmiła Filina-Dawidowicz and Donatas Paulauskas

The Method to Decrease Emissions from Ships in Port Areas

Reprinted from: Sustainability 2020, 12, 4374, doi:10.3390/su12114374 . . . . . . . . . . . . . 169 


\section{About the Editor}

Elvira Haezendonck (PhD) is Full Professor at the University of Brussels (VUB), Visiting Professor at the University of Antwerp (UA) since 2004, and Guest Professor at Erasmus University of Rotterdam (MEL) since 2005. Her research covers various topics in the field of sustainable management, strategy, and policy applied to ports and (large) infrastructure projects: environmental strategy, competitive strategy, and the circular economy. She recently co-authored a Palgrave McMillan book on Sustainable Port Cluster and Economic development. She is particularly passionate about applied research and has been involved in over 60 national and international research projects on, for example, social cost-benefit, economic impact as well as value-added analysis, and on strategic port and infrastructure developments. Since 2010, she has consecutively held three research chairs, two on public-private partnerships and one currently on infrastructure asset management. 



\title{
Port Strategy for Sustainable Development: Circularization and Value Creation-Introduction to a Special Issue
}

\author{
Elvira Haezendonck ${ }^{1,2}$ \\ 1 Faculty of Social Sciences and Solvay Business School, Vrije Universiteit Brussel (VUB), \\ 1050 Brussels, Belgium; elvira.haezendonck@vub.be \\ 2 Faculty of Business Economics, Universiteit Antwerpen (UA), 2000 Antwerp, Belgium
}

Received: 24 November 2020; Accepted: 25 November 2020; Published: 27 November 2020

Today, most large port hubs embrace the circular economy (CE) transformation challenge, and include this together with smart digitalization and the Internet of Things (IoT) in their strategic priorities. The $\mathrm{CE}$ transition is particularly challenging because it is complex: ports do not only have to reconsider their own core activities within their port boundaries, but also their role in the supply chain of shippers [1], to lift themselves out of the linear lock-in. Developing business models with allied partners and intensified stakeholder co-creation will be key to this successful strategic change. The articles in this special issue support port strategists and managers by demonstrating and explaining different aspects that ports should consider for their circular economy transformation and advanced sustainability.

Importantly, the CE transition should not merely be focussing on its potential threat to the volume of handled goods, because CE also creates opportunities for new and different flows. The CE transition is understood to imply shortened and more regional streams of goods, and potentially also inversed material trades [2]. Hence, collaboration and data-exchange with key customers of ports on their change of flows, are crucial to be able to seize these opportunities. In this sense, a successful CE transition of ports implies smart digitalization and more data control on its flows and customers.

However, it also implies financial or business sustainability of this change process. Non-business' (for example government, city, cluster organisations, etc.) initiatives and support are most often behind current circular projects. Much as this support can serve as an engine for innovation towards sustainable port development, in the end port authorities as well as port businesses need to embrace circular learning and turn these projects into sustainable business models, i.e., the design of the value creation, delivery and capture mechanisms employed [3]. Hence, this CE-oriented strategic change requires new insights in innovative governance and business frameworks and further developing the link between strategy and commercially viable business models.

Moreover, ports need to initiate and foster CE-related networks. Through intensified stakeholder collaboration and co-creation, they will together be more powerful in ensuring a business model and form a larger resource pool for developing CE projects and traffic segments.

Finally, ports may have to reconsider their investment policy and landowner role and provide dedicated space, in view of hosting more CE opportunities and enabling related infrastructure in the area and connection regions. Space for pilot projects, labs and pipelines, among other things, can accelerate the $\mathrm{CE}$ transition. In this context, port alliances and networks need to exploit their synergies for accommodating CE-activities and their mutual benefits from connecting infrastructural links.

\section{Special Issue Content}

This special issue in Sustainability on "Port Strategy for Sustainable Development: circularization and value creation" attracted ten interesting academic papers, which each contribute in 
a particular way to support sustainable port management, and enrich the insights in the domain of port value creation through sustainability and in the rather novel domain of $\mathrm{CE}$.

Basically, the ten contributions of this special issue can be grouped into three themes which they address and study: (1) the importance of metrics and data sharing; (2) the salience of space attribution and organization; and (3) ensuring the survival of CE investments through solid business cases.

Within the first theme, the subjects addressed in five papers are:

1. Measures of port value creation and corporate sustainability (CS) metrics: a rigorous CS measurement framework is developed.

2. Emission control policy and use of accurate data as key to reduce emissions in ports and the air quality of neighbouring residential areas.

3. Better manoeuvring of captains and pilots in ports, given appropriate training and knowledge transfer, can substantially reduce emissions in port areas.

4. Circular supply chains and role of secondary ports depend on data sharing and coordination, among others, and is negatively affected by the linear mindset of port authorities. In secondary ports, stevedores play a key role in developing circular supply chains.

5. Disclosure of data to stakeholders and sustainability reporting for inland ports: expected content of reports is viewed differently for various stakeholders and should unite all views to create a transparent account of the contributions of ports.

The second topic is studied in three papers, on:

1. The importance of less focus on 'negative' $\mathrm{CE}$ operational capacity, such as landfills and incinerator capacity: a cap in this capacity encourages port cities to become more circular.

2. Managing port-city distances and in-between areas in a coordinated way is critical to the capacity enhancement and sustainable and ecological development of both ports and cities.

3. Port design and flexible space is important to minimize the impact of road traffic in ports, and simulation can be used for more sustainable 'green' port master planning.

The third topic is specifically addressed in one paper on the business model of port authorities to engage in and foster $\mathrm{CE}$, usually involving new logistical (but fewer international) services that create input-output synergies, and industrial ecology synergies.

Finally, one paper covers all three topics in one: mapping CE initiatives in different port settings and hence benchmarking the CE project portfolios, based on available data, their location or territorial interaction, and the budget and subsidies involved.

\section{Suggestions for a Future Research Agenda}

While these special issue articles address current CE transition concerns, such as first strategic changes towards circular ports, building awareness on the importance of sustainability data and available space, and how port authorities can develop circular business models, several areas remain open to further research.

1. Considerable resources and funding are currently attributed to the $\mathrm{CE}$ transformation of ports. But how does the CE investment pay off? Ports need to measure and monitor the performance of their CE activities. The development of an optimal monitoring system, a "CE dashboard" including the regular measurement of value added, jobs, return on investment, emission reduction, etc., could serve internal and external reporting, and investment valuation. In addition, this monitoring should provide feedback on missing links and/or processes. This is certainly a promising future research endeavour.

2. In the short term, measuring the direct value added and jobs of CE efforts and CE-dedicated space developments is meaningful for port authorities, policy makers and stakeholders. Given the frequent opposition to the expansion of port capacity in terms of the societal costs versus benefits, 
any changing strategy towards CE should prepare for these broader economic effects as soon as possible.

3. Given most CE initiatives are heavily funded or subsidized, it is salient to study how and with whom these projects can become a new business line for port firms as well as for port authorities. What is in it for whom, and how can port authority business models embed CE in their renewed and more comprehensive business model?

4. Alliances and networks have been pointed out as enabling mechanisms and relationships to accelerate circularity in ports. But how inter-port collaboration and stakeholder co-creation should be organised and how it effectively impacts the transition is currently under-researched.

5. Another future stream of research should establish an integrated sustainability strategy for port managers, reconciling their current corporate social responsibility (CSR) projects such as solar and wind turbine projects, their modal shift ambitions, and their CE transition projects. There may in fact be potential trade-offs complicating this integrated strategic focus. For example, when ports try to shift cargo from road to rail transport, they encourage cargo bundling over longer distances so as to make rail transport a viable alternative. However, the CE transition of ports may imply shorter, more regional and local flows of goods, which may then become, because of their inherent shorter distances, less economically favourable when using environmentally friendly modes of transport.

6. As a final reflection of this editorial, some intriguing research questions can be obtained from a governance perspective: What is the role of each actor in a CE coalition; and how are the ambitions aligned among partners and in relation to their competences and their infrastructure and space capacity?

Funding: This research received no external funding.

Conflicts of Interest: The author declares no conflict of interest.

\section{References}

1. de Langen, P.; Sornn-Friese, H. Ports and the circular economy. In Green Ports; Elsevier: Amsterdam, The Netherlands, 2019; pp. 85-108.

2. Fusco, G.L. Toward a smart sustainable development of port cities/areas: The role of the "Historic Urban Landscape" approach. Sustainability 2013, 5, 4329-4348. [CrossRef]

3. Teece, D.J. Business models, business strategy and innovation. Long Range Plan. 2010, 43, 172-194. [CrossRef]

Publisher's Note: MDPI stays neutral with regard to jurisdictional claims in published maps and institutional affiliations.

(C) 2020 by the author. Licensee MDPI, Basel, Switzerland. This article is an open access article distributed under the terms and conditions of the Creative Commons Attribution (CC BY) license (http://creativecommons.org/licenses/by/4.0/). 



\title{
Patterns of Circular Transition: What Is the Circular Economy Maturity of Belgian Ports?
}

\author{
Elvira Haezendonck $^{1,2, *}$ and Karel Van den Berghe ${ }^{3}$ \\ 1 Department of Business, Faculty of Social Sciences and Solvay Business School, Vrije Universiteit Brussel, \\ Pleinlaan 2, 1050 Brussels, Belgium \\ 2 Department of Management, Faculty of Business Economics, University of Antwerp, Prinsstraat 13, \\ 2000 Antwerp, Belgium \\ 3 Department of Management in the Built Environment, Faculty of Architecture and the Built Environment, \\ Delft University of Technology, Julianalaan 134, 2628 BL Delft, The Netherlands; \\ K.B.J.VandenBerghe@tudelft.nl \\ * Correspondence: Elvira.Haezendonck@vub.be; Tel.: +32-495-808-408
}

Received: 30 September 2020; Accepted: 5 November 2020; Published: 8 November 2020

\begin{abstract}
Large seaport hubs in Northwestern Europe are aiming to develop as circular hotspots and are striving to become first movers in the circular economy (CE) transition. In order to facilitate their transition, it is therefore relevant to unravel potential patterns of the circular transition that ports are currently undertaking. In this paper, we explore the CE patterns of five Belgian seaports. Based on recent (strategy) documents from port authorities and on in-depth interviews with local port executives, the circular initiatives of these ports are mapped, based on their spatial characteristics and transition focus. The set of initiatives per port indicates its maturity level in terms of transition towards a circular approach. For most studied seaports, an energy recovery focus based on industrial symbiosis initiatives seems to dominate the first stages in the transition process. Most initiatives are not (yet) financially sustainable, and there is a lack of information on potential new business models that ports can adopt in view of a sustainable transition. The analysis of CE patterns in this paper contributes to how ports lift themselves out of the linear lock-in, as it demonstrates that ports may walk a different path and at a diverging speed in their $\mathrm{CE}$ transition, but also that the Belgian ports so far have focused too little on their cargo orchestrating role in that change process. Moreover, it offers a first insight into how integrated and sustainable the ports' $\mathrm{CE}$ initiatives currently are.
\end{abstract}

Keywords: circular economy; ports; strategy; maturity; patterns; transition; process; circular initiative; case studies; Belgium

\section{Introduction}

The circular economy (CE) poses a challenge to ports around the world. In general, the business models of ports and (semi-)independent port authorities (PAs) are based on volume and financial growth, whereby the PAs at least break even, preferably making profits [1,2]. Landlord ports and their PAs increasingly incorporate activities beyond the maintenance of infrastructure as their core business, and now also include the development of the local economy, business integration, urban development and environmental protection [3-6]. However, the main source of income for PAs is still the leasing of land and port dues on incoming and outgoing cargo. In other words, the business models of PAs are based on the expansion of their port area and increasing throughput volumes. Considering the pollution, decrease in wetlands, congestion and many other external effects of core port activities, the environmental impact of this business model is apparent [4,7-9].

The CE is seen as a new business model whereby economic growth is decoupled from environmental impact. The CE implies cleaner production patterns at the company level and 
the use of renewable materials as much as possible [10,11]. However, the CE is only in its early stages as an industry or business line, and a lot is still uncertain [12,13]. Nevertheless, if a CE is the main or only sustainable business for the future, beyond what we already do "circular" today, a significant amount of innovation is necessary $[11,14]$. The CE in practice currently seems to focus primarily on (re)production, but also in terms of product design, logistical processes (cf. collection and treatment of waste), management and production networks, a lot of innovations and potential benefits can be generated [1,15-17].

While in the first instance, a decoupling of economic growth and environmental pressure poses a problem to the landlord PAs' prevailing business model, at the same time port areas have the potential to become essential places in fostering a CE. The European Parliament as well as European port organizations, such as the European Federation of Inland ports (EFIP) and the European Sea Ports Organisation (ESPO) [18-20], have stressed the enormous potential of ports to play a leading role in the context of the CE transition. Indeed, ports are crossings of transport modes and waste flows, but also accommodate industrial sites and/or unlock urban areas and economies. Ports operate within a competitive and clustering (industrial) environment, which may offer opportunities to treat residual flows and products in a circular way. Furthermore, ports close to urban areas may offer the necessary space for recycling activities of all wastes created by the city or help in their energy transition. In addition, ports are essential nodes wherein and whereby (global to local) production networks are possible, in terms of established technologies and processes, and in terms of incremental innovation. Especially the combination of extensive, specialized industrial and logistical maritime areas with urban economies, explains why ports are attractive for circular activities [21,22]. These circular activities are broad and can vary from small companies or start-ups focusing on new management processes, the establishment of new educational programs training the circular skills of tomorrow [23,24], engineering bureaus dealing with product design, new (spatial) policies encouraging circular activities, new infrastructure connecting companies whereby existing material flows become connected, and the creation of circular consortia and think thanks [5] (e.g., [12]), to large-scale projects involving the construction of new circular industrial plants or labs. Hence, for the identification of circular actions or activities within ports, we focus in this paper on hard investments (plants, space allocation and other infrastructure) as well as on soft commitments such as networks and skill development.

In this paper, we focus on the CE initiatives of ports from the viewpoint of the port cluster managers, most often PAs. Besides smart digitalization and Internet of Things (IoT), the CE is high on the strategic agenda of PAs. PAs regard the CE as a (potential) solution to many of their problems, for example, the increased congestion and environmental impact, the need for added value and job employment, and the need to remain competitive. Yet, PAs are struggling to develop an integrated CE strategy and find their role in this transition. Hence, the relevant research questions addressed in this paper are: "How are ports facing the CE transition in relation to an integrated approach, and what can port cluster managers learn from CE port patterns?"

To answer these questions, this paper uses a cross-case analysis with primary and secondary data on the portfolio of CE activities in five Belgian ports, a sample consisting of an interesting variety of port clusters, ranging from large hubs, medium-sized diversified ports, a niche port and an inland port. The paper is organized as follows. In the next section, we give a brief overview of the origin of the concept and theoretical foundations of CE. We will show how "circularity" originates from within (applied) industrial ecology, and therefore the majority of existing studies relate to material flows and stocks but lack a connection to (port) business models and socioeconomic processes $[7,16,17,20]$. In the third section, we develop a framework presenting a potential CE development path based on the nature and (spatial) impact of circular projects within ports. We then present our method, data collection and empirical results in the fourth section. We end this paper with a discussion section, and finally some concluding remarks and future research suggestions. 


\section{Circular Economy Concept}

Circular economy has its origins within industrial ecology and goes back to the 1980s with the waste hierarchy concepts, better known as the 3 Rs, 4 Rs, etc. $[14,16,17,25]$. The circular economy concept was initially introduced by Stahel [26] in his paper 'The product life factor', where he described it as a spiral system with the aim of reducing the used inputs, waste flows and ecological detriment, without limiting economic, social and technological advances [27]. He also claimed that the circular economy impacts products as well as processes, and primary as well as secondary materials. Peace and Turner [28] added to Stahel [26] that a circular economic system is the only sustainable future for production, based on the laws of thermodynamics, saying that energy and material can neither be created nor destroyed. Instead, they can be reduced to a non-valuable quality. In 2002, McDonough and Braungart [29] presented their cradle-to-cradle process, which was seen as a first step towards new processes including upcycling or upgrading the value of outputs into new inputs. In the aftermath, researchers focused on decoupling growth and welfare [30,31], and on internalizing external costs [26,32]. We could argue that most classic frameworks of reducing, reusing and recycling are far from being ambitious. A currently prevailing definition of $C E$ [33-36] proclaims $C E$ is a new model for industrial organization, which enables us to decouple growing welfare from using more raw materials and which goes beyond efficiency gains and realizes a transformation change (regenerative by design). In fact, waste from industries becomes valuable input for other processes, and products can be reused or upcycled.

As the CE concept is trending, especially in industry-wide management practice and policy, the concept tends to diffuse [18,22]. Several literature reviews on this topic have been conducted, and a more recent systematic and comprehensive one by Kirchherr et al. [18] concludes that the CE definition of van Buren et al. [33] is complete and yet understandable, and therefore recommended the use of this one out of hundreds as a basic concept to build upon.

While in the past two decades $\mathrm{CE}$ was very much directed at industrial and product environments, more attention in recent years has been given to CE in services (examples can be found in $[15,16,23,37]$ ). Van Buren et al. [33] developed their concept for the Dutch logistics industry, a typical sector offering services, which they saw as "a genuine enabler (so for other industries as well) to implement a successful and sustainable circular strategy". Ports are salient nodes in logistic networks, and therefore, the present paper builds upon their definition of CE: "A circular economy aims for the creation of economic value (the economic value of materials or products increases), the creation of social value (minimization of social value destruction throughout the entire system, such as the prevention of unhealthy working conditions in the extraction of raw materials and reuse) as well as value creation in terms of the environment (resilience of natural resources)" [33].

\section{A CE Transition Framework for Port Clusters}

\subsection{Three Pillars of a Strategic CE Port Vision}

According to van Buren et al. [33], a distinction can be made between options or levels of circularity when applying CE. Although different levels are used, commonly one refers to the $\mathrm{R}$ hierarchy here, such as the 9Rs model. These are (1) Refuse (preventing the use), (2) Reduce (using less materials), (3) Reuse (second-hand), (4) Repair, (5) Refurbish, (6) Remanufacture (new products by assembling old parts), (7) Repurpose, (8) Recycle (reuse of materials) and (9) Recover energy (incineration of residual flows) [27,33]. In line with this, van Buren et al. [33] suggest that "recovering energy" is the final option for extracting value from resources as it ends the resource cycle. Recycling, as the eighth $R$, is the one before the last option to extract value. Recycling is a process that often degrades the materials and makes secondary resources of a lower quality [33]. In the R model, the degree of increasing circularity is considered inversely related to the number of the R strategy, so where recovering energy (R9) is "less circular" than recycling materials (R8), which is then again "less circular" than for example repair (R4) etc. [27]. As sectors and industries attempt to gradually move from linear to circular 
economic models, it can be assumed that "increased circularity" indicates a higher maturity level in this change process.

Applying this to the port industry, R9 and R8 in the circular R model are in line with the concepts of reusing materials and energy of de Langen and Sornn-Friese [38]. These authors argue that a circular supply chain does not end with waste nor just with reusing it. Hence, these activities are preceding a more advanced CE transition of ports. In fact, the activity of reusing energy and materials could be considered as the first stages of a port's CE transition. Van Buren et al. [33] add to this that a circular economy should be much more than recycling and energy recovery, because in focusing too much on these two aspects, it would result in a so-called "economy with feedback loops", rather than a serious circular economy. In a recycling-based economy or an "economy with feedback loops", the reuse of materials or resources is regarded as a separate (or secondary) optimization step [33]. As such, it is seen as a potentially interesting new business line, next to or maybe less important than "business as usual", and nice to communicate to stakeholders sensitive to environmental issues. Within port clusters, (industrial) energy consumption is for example primarily based on the large-scale use of oil and gas, which may be partly offset when these industries connect to waste-to-energy plants where steam is turned into electric energy, for example in the Ecluse project in the Antwerp seaport (The Ecluse project is a port heating network in the Waasland part of the Antwerp seaport, where steam is sluiced from the Indaver and SLECO waste-to-energy plants to industrial (mainly oil) companies in the port. More details on the Ecluse project can be found via http:/www.ecluse.be). Although the Ecluse project is considered as a showcase circular project by the port of Antwerp, the initial choices of the industries partnering in this project are not circular. The primary choices made in the phase of design and production should be integrated as well. In sum, if a port takes the circular challenge seriously, it should therefore not only consider recycling and energy recovery, but also consider the flows following the initial choices of firms. This would therefore indicate a more advanced level of maturity in a port's CE change process.

The problem with this advanced CE transition is that any port is only partly able to influence those (industrial) companies within or beyond their port area, and for which the port operates as a nodal point in their logistics chain. Ports actually depend on the circular transition in those industries using port services, and their transition thus requires simultaneous changes in many port subsystems, or (trans)port demanding clusters. So, the challenge for ports is also in how much they can actually put pressure on their clients and leverage subsystems to become circular in their design and production, or collaborate with shippers to facilitate their transition and control the changing flows of goods, because it ultimately affects the circular strategy of ports as well.

Many industries using port facilities operate beyond the port boundaries, so a circular port is also one that impacts products and processes beyond the port cluster demarcations [38]. A port should therefore be looking at "valuable new inputs", as already suggested by Peace and Turner in 1989 [28], in terms of new cargo flows for example. A simple look into the strategy reports of most European ports, disclosing information on their circular initiatives, intuitively indicates that most ports do not yet address this third essential pillar of circularity, besides energy recovery (pillar one) and recycling (pillar two). In fact, we may even question whether ports at all recognize this advanced yet crucial stage in their CE transition. Here, the Ellen MacArthur Foundation (2017) [36] was right in stating that some circularity models may not be ambitious enough, and this may also be the case for ports.

\subsection{Territorial Level of CE in Ports and Space as an Accelerator}

Given the challenge of reaching out beyond port borders to realize the huge circular ambition, ports should also collaborate with actors outside the port area itself. Fusco Girard [39] researched how port areas can circularize from a territorial perspective. He suggested that three levels of symbiosis, or mutually beneficial relationships, can interestingly take place between three different spatial levels, as depicted in Figure 1, which he named: industrial symbiosis (IS), urban symbiosis (US) and city-territorial symbiosis (CTS) [39]. 


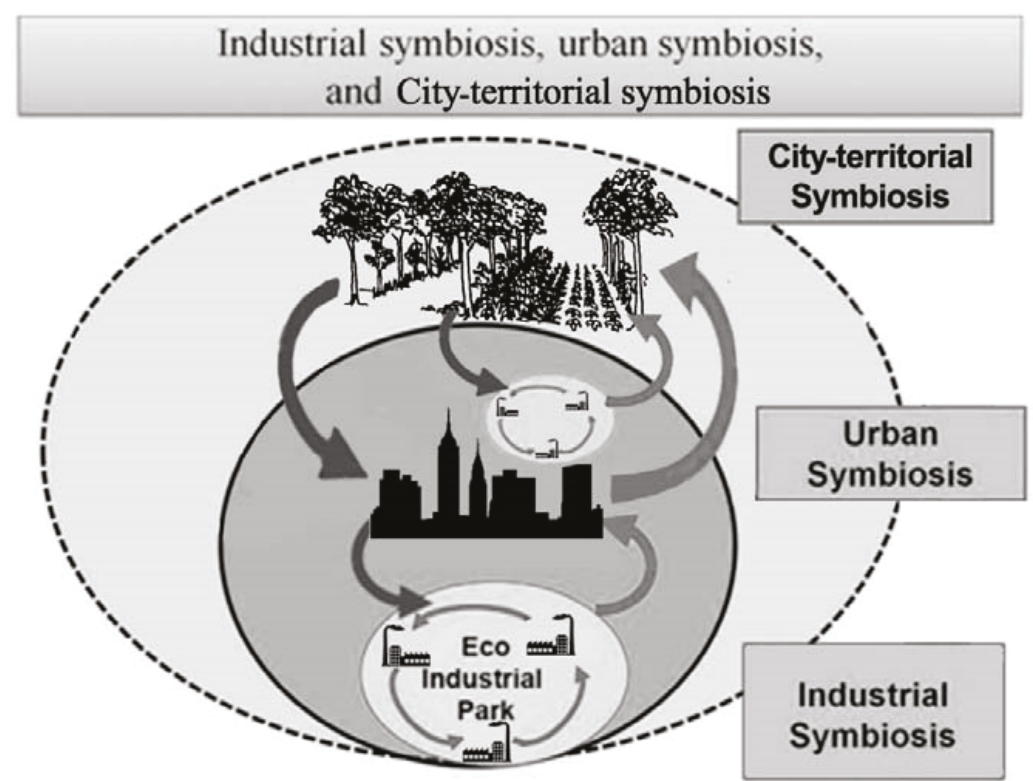

Figure 1. Port area/urban circularization [39].

The earlier argued three pillars for the CE transition of ports are in line with the proposed relations of Fusco Girard [39]. He [39] actually links the geographical level to the strategic CE pillars of ports, where industrial symbiosis mainly reflects the energy recovery potential, urban symbiosis creates a huge opportunity for recycling activities, and territorial symbiosis points at relationships with the hinterland to organize new cargo streams. Moreover, this implicitly suggests which actors in that geographical dimension can become interesting partners, may have innovative ideas and/or may possess CE know-how. In turn, the (landlord) port may be the best partner and location to provide space to develop CE knowledge, relations, products and processes. These symbiosis levels add another dimension to the dual CE transition of ports as argued by de Langen and Sornn-Friese [38], beyond "renewable energy" and "renewed materials for products", which we earlier suggested to complete a third CE transition pillar or strategic focus.

In line with the work of Fusco Girard [39], more recently, Salomone et al. [30] have argued that in order to effectively achieve a sustainable development, it is necessary to relate the CE concept to the concept of industrial symbiosis (IS), especially to understand the crucial social and organizational aspects of the circular transition. IS is namely a business-focused approach to promote sustainability by recovering residues from one entity for use in another [3]. In recent years, IS has become a sub-field of the $\mathrm{CE}$, rising to become the primary concept in relation to sustainable development [19], and referring to the first strategic CE pillar, as explained in the previous section.

Urban symbiosis reflects the relationship a port, and city-ports in particular, may develop with its surrounding or adjacent urban environment. Recycling activities in city or inland ports, being faced with huge waste issues, were already developed decades ago as the first port CE projects.

City-territorial symbiosis may take place in the wider hinterland of ports, so this symbiosis level reflects the starting point of a new "port-logistics provider/forwarder-customer/shipper" relationship, bringing larger parts of the supply chain into a circular transition. It may also result in more local or regional freight flows and supply chains, different cargo types to handle, and opportunities for new (reversed) logistics. 
Finally, CE should today be applied in an even broader sense. It should not only deal with the design of products, but also with processes and infrastructure. Because $\mathrm{CE}$ has been rapidly brought to the forefront by many public and private organizations [6,19], it is only gradually being linked from operational to also more organizational aspects [20,21]. Actually, it also influences the different planning initiatives, e.g., spatial planning and product design $[16,17]$. The CE era is still in its early stages, and multiple issues and trade-offs related to spatial, temporal and scale impacts have not yet been extensively explored [30]. For example, CE strategies can aim for degrowth and thus a reduced demand for (and flow of) new goods. Ports are still mainly aiming at maximizing cargo volumes, so it may feel contradictory to invest in CE strategies at the same time. On what scale such degrowth will happen, and if maybe on other levels more (regional and local) growth will consequently be triggered, is yet to be explored [12,34]. Crucial hereby will be to understand if and how existing global production networks will be reconfigured, or in other words, what (re)consumption and/or (re)productive elements of proximity, tangible or intangible [1,21], will be more or less important. Especially for ports, being core locations within the current local to global production networks, this could be a true game changer.

A recent Belgian study commissioned by OVAM (OVAM stands for Openbare Afvalstoffenmaatschappij (translated as "Public Waste Organization"). OVAM is a Flemish government agency making sure that Flanders (Belgium) treats its waste, materials and soil in an environment-friendly way) [40], "Circular City Ports", revealed indeed how proximity and spatial aspects, within and beyond the port cluster area, are intertwined with the symbiosis opportunities of ports. The development of ports towards a more circular economy depends on qualitative coalitions between the PA, businesses, the city, knowledge institutes, federations and policy makers. This study also revealed how the PA can gradually use its own space or land as an accelerator of the symbiosis levels. Indeed, ports may host eco-industrial parks or other important colocation spaces, ideal for accommodating CE initiatives. Moreover, PAs have the potential, through their sites, to unlock urban areas and to organize test-phase sites and recycle hubs for urban mining. Proximity is key to qualitative coalitions here.

\subsection{An Integrated Framework for Circular Maturity of Ports}

\subsubsection{Scope of Circular Economy-Related Port Projects}

In previous sections, we have elaborated on the CE strategic goal for ports, based on three pillars "energy recovery", "recycling" and "orchestrating valuable new cargo streams". We continued with how symbiosis levels are linked to those strategic pillars, and how spatial aspects can contribute to these levels of a port's CE transition. In this section, the scope and key characteristics of CE initiatives in ports contributing to one or more of the three CE pillars for ports are described.

Building upon the results of OVAM's "Circular City Ports" [40], presented in a Workbook, a non-exhaustive set of several European city-port CE practices was explored. All practices were structured according to three categories of aspects of the initiative, which contributed most to the $\mathrm{CE}$ transition in that project: "orgware", referring to the organization, platform or collaboration type, "framework", referring to the process in the port, and "materials", which are the tangible products or resources that are impacted through the initiative, see Figure 2. 


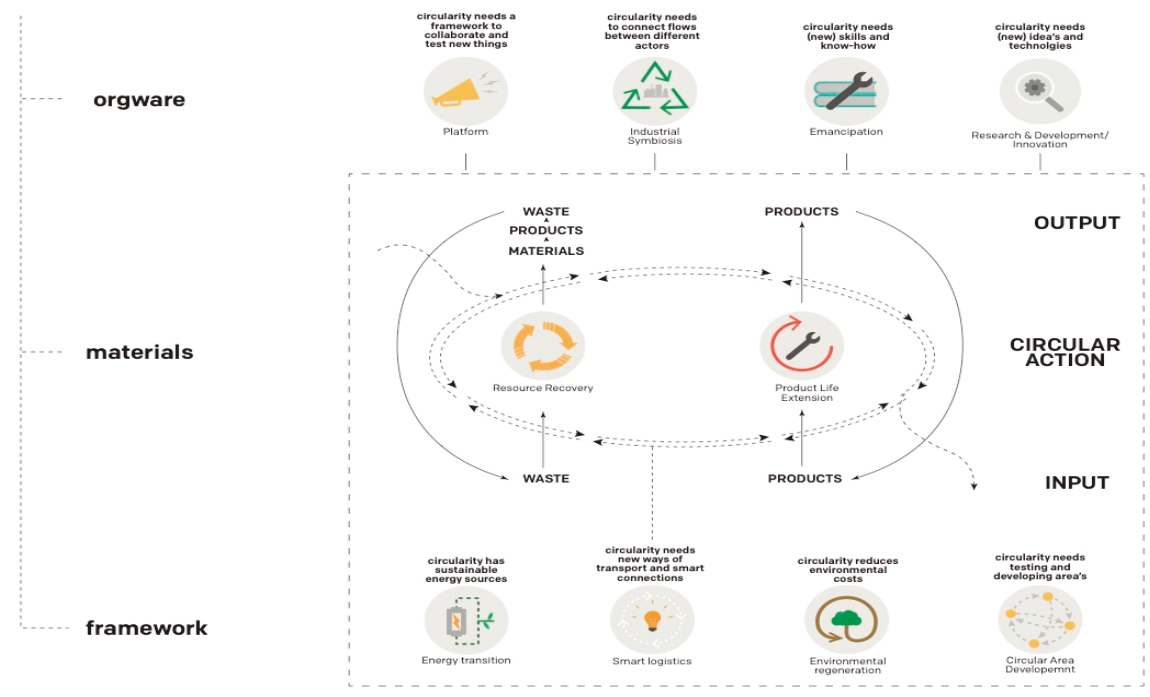

Figure 2. Types of initiatives and circular economy (CE) building blocks [40].

Other valuable variables for each initiative are the location where the initiative takes place or is developed, which stakeholder took the initiative and who are the other partners involved (cf. role of actors in line with de Langen, Sornn-Friese and Hallworth [41]), when was the initiative started and what collaborative steps have been taken since the start, to more comprehensively understand the evolution of the involved actors. Together, these characteristics enable us to map port CE initiatives according to their strategic goal (for PAs, especially when they are initiating the CE project), location and territorial collaboration.

\subsubsection{An Analytical Framework to Map a Port's Strategic Transition to CE}

The above information explains what the CE transition for ports should entail, but does not tell us how ports or PAs should or can implement this. To adopt a new strategy, organizations often rely on a maturity model that includes all steps to consider towards the implementation of an innovation process $[9,42]$, in this case CE transition in ports. A maturity model for strategic change is based on the levels of maturity or developed capabilities as set out by Crosby [43]. The evolutionary process consists of succeeding levels of maturity, and provides the prerequisites for improvements that lead to the next stage [42]. Sehnem et al. [42] added that these levels guide growth based on continuous improvement and incremental changes, rather than radical transformations. Hence, maturity levels lead the organization to identify and evaluate its current state in the pursuit of excellence [42,44]. In line with the $\mathrm{R}$ hierarchy model for CE transition, as discussed in Section 3.1, the succeeding levels of CE maturity for ports, in relation to the ambitious three strategic pillars of a CE transition process, are (1) energy recovery, (2) recycling materials and (3) orchestrating new cargo streams. With maturity levels in the context of this paper, we do not aim to measure the progress of CE transition in terms of results or business success, but to outline what potential patterns or CE project dynamics characterize ports, which may help them in view of the next step in their change process.

It is important to stress that a circular transition is not only characterized by disruptive changes, but is also complemented by incremental sustainability innovations. Even more so, scientists warn that counting too much on disruptive innovation may slow down the incremental processes, because the disruption is supposed to solve all issues later anyway [45]. The paradigm shift through innovation then risks leaving the linear lock-in optimizations [46]. On the contrary, both ways for a sustainable 
transition should be embraced in parallel. Therefore, individual CE projects can be considered as interesting indicators to observe the pathway of a port's development in its CE transition.

Mapping the individual port CE initiatives or projects in such a way that shows how ports innovate towards a CE paradigm shift can be interestingly done by combining the scale or symbiosis level with the strategic focus (or stages of circularity) of the particular initiative.

This leads us to our analytical framework. In the framework, we combine two axes as described before. On the Y-axis, we map the scale on which the circular activity unfolds. This axis is based on the work of Girard [39], which we translated into, from small to large: intra-port, port-city and territorial levels. The higher the level, the more complex it becomes to organize these, as more and more actors are involved [47]. On the X-axis, we map the type of circular activity, based on the three pillars of a circular transition strategy for ports. Linked to the maturity stages of this circular transition, ports are assumed (from left to right on the X-axis) to first start with energy recovery, then initiate additional, new projects in recycling, and then orchestrate new cargo streams. These two axes lead to our analytical framework in Figure 3, which enables us to plot our empirical results.

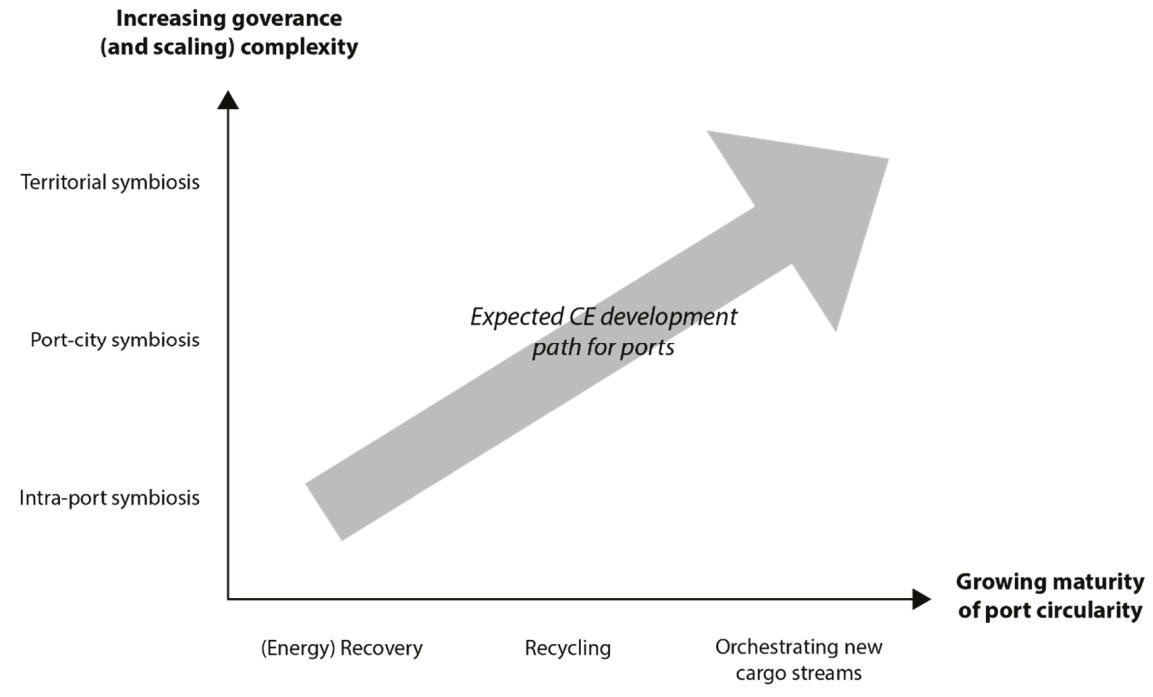

Figure 3. Development path for CE in ports (source: compiled by authors).

\section{Empirical Analysis of CE Patterns in Five Belgian Ports}

\subsection{Multiple Case-Study Method and Data Collection}

Because our research is problem-driven and we are, in particular, searching for circular activities within ports related to their strategy and geographical scale of symbiosis, we turn towards a multiple case-study method. The research is explorative in nature, and little research currently exists on the CE transition of ports. A cross-case analysis is suitable in this context and enables the discovery of a variety of transition processes based on ports' CE initiatives and in quite different port contexts. The choice of the cases will be discussed in the next section. A cross-case analysis enabled us to focus on an individual port's results, but also on results in reference to each other. As for the data, we first collected all available secondary information on the different CE activities of the ports, with port sustainability and annual reports, information retrieved from the PA websites and all specific websites existing for some CE initiatives. In the first instance, we limited ourselves to the most recent 5 -year period because CE has only recently been added to the strategy of port authorities. However, some circular initiatives existed before 2015; thus, in the second instance we also looked at the important circular projects 
initiated before that date and still active (e.g., recycling of ships). Our first dataset was cross-checked with the sustainability manager and/or CE project responsible of each port under study, and finetuned together with the authors. For each initiative, we collected data on the strategic focus, the territoriality and relationship with actors, the role of the port authority, and the investment amount and level of subsidies (if available). In using these data for our mapping, we especially focus on the level of circularity (energy, recycling, new cargo streams), the scaling and the involved budget. For the latter, if available, we differ the amount of public and private budgets. Lastly, we look at the involvement of the port authority within the several activities. In what follows, we first describe our results per port and finally bring our results together.

\subsection{The Case Selection of Five Belgian Ports}

The selection of the five Belgian ports, namely, the ports of Antwerp, Zeebrugge, Ostend, Brussels and North Sea Port, is based on the size, function and diversification of these port clusters, including two large hubs, a medium-sized diversified port, a niche port and an inland port. These five selected ports are all important ports active in the same region of Flanders in Belgium, yet diverse in their size, operations or traffic scope. The case selection includes an inland port (Brussels) and a cross-border merged port cluster (North Sea Port), two coastal ports of different size and focus (Zeebrugge and Ostend), and a large seaport hub (Antwerp) considering closer cooperation with the port of Zeebrugge. This variety of cases enables us to obtain rich insights into their patterns of CE initiatives, linking to their unique position and clustering dynamics, yet all operating in the same area and under similar regulations and policies.

The port of Antwerp counts no less than 65 circular initiatives, of which almost half are initiated by the PA and publicly subsidized. There is a clear imbalance in the number of activities related to energy recovery (47), recycling (14) and new cargo streams (4). The energy focus may be embedded in the long-term development of the Antwerp port hub, with a large industrial cluster of petrochemical and chemical companies. Given these businesses' environmental impact, many of them have been triggered a long time ago to invest in ways to reduce and recover waste and energy. For the majority of these initiatives the budget is unknown, yet for those where it is known, the public subsidies are quite high. Recycling activities seem to mainly occur in relation to port companies within the port hub, but not in relation to the adjacent city for example. Organizing new cargo streams seems to be the newest activity developed and remains very explorative at this stage.

The Dutch/Flemish North Sea Port exists since the merger in 2018 between the Dutch port of Zeeland Seaport, being a merger itself between the ports of Flushing and Terneuzen, and the Belgian port of Ghent. We found 18 relevant circular activities. These are almost equally distributed over the different circular activities, with six related to energy, seven to recycling and five to orchestrating new cargo streams. Looking at the involved budget, there are more clear differences. Most of the focus is on energy. The most important activities here are the approved hydrogen factory in Flushing (around $100 \mathrm{M} €$ ) and the factory in Steelanol (around $160 \mathrm{M} €$ ). The latter project strives to transform the $\mathrm{CO}_{2}$ of the steel plant of ArcelorMittal into bio-ethanol. Currently, the project is within the demonstration phase, the last one before the potential upscaling. Another point is that these relative large projects go beyond the port area and relate to the whole territory. Next, the recycling activities are mostly related to existing companies, some for more than a century. Here, no relevant important investments have been made. Lastly, and most recently, activities focus on creating an industrial symbiosis within the port. Here, the most relevant is the ongoing Steel2Chemicals project. This project strives to convert the $\mathrm{CO}_{2}$ of the steel plant of ArcelorMittal into naphtha, which can be used as an input commodity by the chemical plant of DOW Terneuzen. Here, the port authority is an important partner because ArcelorMittal is located within Ghent, while DOW is located across the border. Hence, cross-border infrastructure (cf. pipelines) is needed. Most likely, within the near future, these industrial symbiosis projects linked to circularity will only increase in impact. The question remains, though, if it will also go beyond the port area and connect to the region. 
For the port of Zeebrugge, our analysis did only find four relevant circular activities. On the one hand this is not really surprising, because Zeebrugge is foremost a throughput port, focusing on logistical processes and less on manufacturing processes. In Zeebrugge, three companies are related to recycling activities, linked to their historical presence going back more than a century. More recently, the port authority is building wind turbines within its port area, explaining the one activity related to the intra-port level or area, and energy recovery as a focus.

Considering the port of Ostend's small size in cargo throughput, this port developed quite a few initiatives, mainly in energy recovery and recycling. Little is known about the investment size or subsidy levels of these projects, but it is clear from the initiator perspective that most projects are privately embedded and facilitated by the PA in its area.

As an inland port, but capable of receiving maritime vessels and therefore legally categorized as a seaport, the port of Brussels is characterized by a large number of CE initiatives, both initiated by its companies and by the PA itself. Most initiatives are situated in the recycling activity and in relationship with the city of Brussels and its region, which reflect an urban mining focus, but intra-port and port-city energy recovery projects are also well developed.

\subsection{Results: Mapping of CE Initiatives of Five Ports in the Transition Framework}

In Table 1, some key figures (throughput and port area) and the main CE variables collected per port are presented.

Table 1. Overview of circular initiatives of Belgian ports.

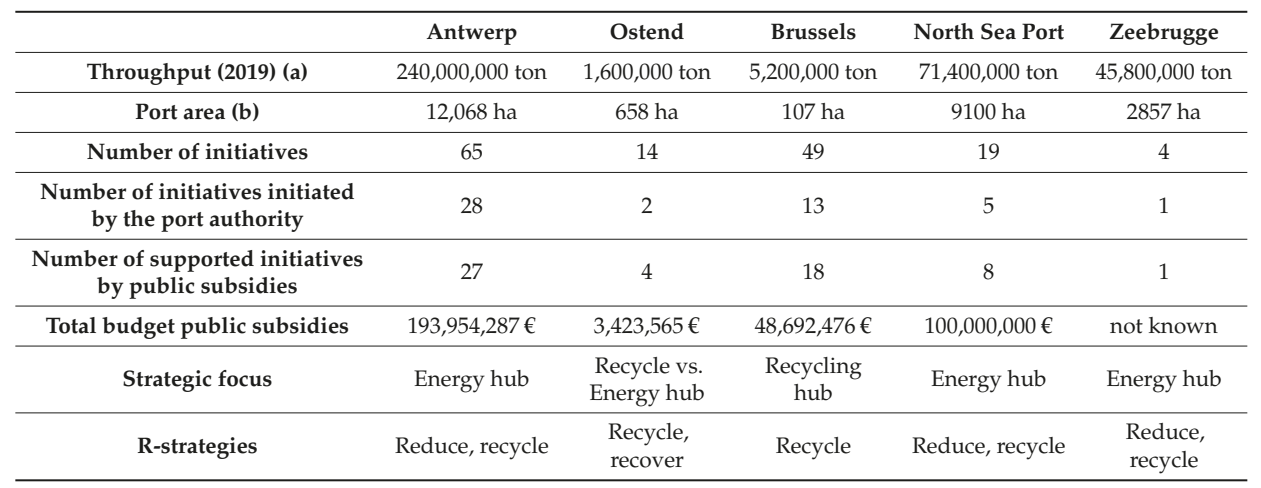

Sources: (a) [48], (b) [49].

Taking all results together, as shown in Table 1, it is clear that the larger diversified port hubs, Antwerp and North Sea Port, have more CE activities in absolute number, as well as in relative size. The medium-sized port of Zeebrugge has as few as four initiatives to report. The port of Ostend, a small niche port amongst others involved in off-shore windmill projects, has a relatively large number of initiatives, almost all situated in the port area itself. The inland port of Brussels also has a large number of CE projects, and here we observe a more balanced spread over the three strategic pillars, which is also geographically more extended.

Translating these results to our framework, most ports concentrate their CE initiatives in the lower-left side of the framework in Figure 4. Within the colored circles and squares in Figure 4, the mentioned numbers are referring to the found number of different initiatives or projects existing in the ports. 


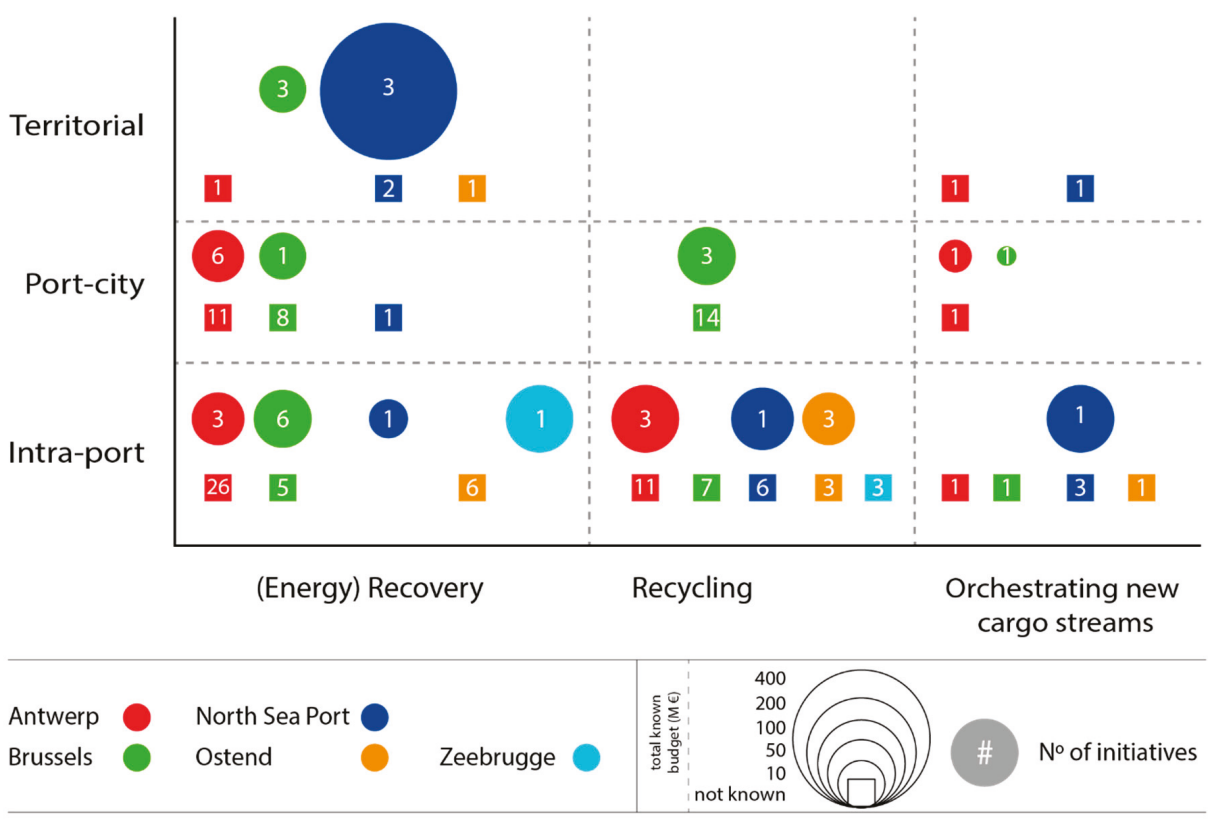

Figure 4. Mapped circular initiatives for five Belgian (sea)ports (source: compiled by authors).

\section{Discussion}

Considering the fact that larger port hubs have more means and firms to support initiatives, taking all the results together, as shown in Table 1, it is clear that larger diversified ports have more CE activities in absolute number as well as in relative size. However, it is apparent that for many projects the total budget is unknown, and for approximately a quarter of the projects, at least, public subsidies are keeping them alive.

Arguably, the port of Brussels stands out, especially considering its small size. We detected many circular activities, although they are in most cases on a relatively small scale and related to existing cargo streams within and between port and city. This is not a surprise, taking into account that the port of Brussels is a true urban port, understood as being located in a dense urbanized region. This lends itself to more cooperation between urban processes (e.g., building materials, bio-based flows) and the logistical and processing processes in the port areas. The CE will bring increasingly localized and closed material flows, coming with a considerable logistical challenge to make this possible, especially in spatial terms. Hence, the city of Brussels, having a maritime port area at its heart, has many advantages to really develop the more urban centered circular processes. This is confirmed by the type of circular activities. In Brussels, the majority of circular activities deal with recycling activities, while in the other Belgian ports, energy is more important, which deals with larger-scale processes and industrial activities.

What we also see is that ports that focus on energy activities tend to deal with higher budgets. This is to some level quite logical, because these energy activities are on a larger scale and involve more (capital-powerful) actors. Nonetheless, Brussels does not have the smallest budget involved—on the contrary. The city of Brussels is the largest city in Belgium (around 1 million inhabitants) and the capital of Belgium and Europe. Hence, the potential for urban circular activities is relatively higher than in the other Belgian cities. In other words, although we found that recycling activities tend to involve less money than energy and industrial symbiosis activities, following the large amount of recycling activities in Brussels, they account for the third largest budget involved in Belgian ports. 
Overall, the port of Antwerp takes the lead in number of activities, activities that are supported, as well as the involved budget. Second is North Sea Port, then Brussels, Ostend and finally Zeebrugge. Zeebrugge is a greenfield port, focusing on logistical processes, cross-channel feedering and trans-shipment, and so far did not manage to attract nor initiate many CE initiatives.

What clearly differs thus is the overall focus of the different ports. Brussels and to a smaller extent Ostend focus on recycling, while the largest Flemish seaports of Antwerp, North Sea Port and Zeebrugge focus much more on energy activities. However, increasingly-following the more recent date of the respective initiatives of our dataset-activities are moving towards the lower- and mid-right side of the framework. In other words, this confirms our hypothesis that slowly the circular transition is getting more mature and will—most likely—increasingly cross port areas and borders and reach out to the surrounding urban environments, similar to what occurred with energy activities. It is however very clear for every port that the orchestration of new CE-based cargo streams is still a lower priority or evolved at a slower pace. The fact that many of the studied ports do not control many information links on their cargo flows, or develop strong data-relationships with their shippers in their hinterland, may be a bottleneck for developing these more complex, yet important and sustainable CE initiatives.

The observation that limited information is available on the budget and on the extent and prospected timing of subsidies does raise some questions on the funding continuity and the sustainability of these initiatives in the longer run. In fact, very few initiatives are confirmed as building upon a positive business case today.

\section{Conclusions}

In this paper, we developed a framework to indicate the maturity level of the circular transition of ports, through their portfolio of circular initiatives in which the port authority either takes the lead, partners or facilitates by offering space. We mapped all current CE initiatives based on the strategic focus of the project in the CE transition, and on the symbiosis level and geographical outreach of each initiative or project. We find that the studied Belgian ports almost all focus on the lower-left side of the framework. This is rather natural for seaports with a large industrial development area. Only the inland port of Brussels has a stronger focus on recycling, but being close to a large metropolitan area, this is also a more expected development for this port. In line with this observation, we could conclude that the CE provides especially interesting new strategies for urban ports such as Brussels. During recent decades, the growth and success of ports were mostly based on a growth of throughput and land leasing. However, this is problematic for ports that have a lack of space or are locked-in in a densely populated area, such as Brussels. The CE transition provides a way to turn this disadvantage of being located within or close to large urban metropoles into an advantage. The CE strives for more closed, but also more local material flows. Hence, urban areas with industrial and logistical (maritime) areas within their centers have a clear advantage to realize their CE potential. For Brussels, we thus expect, based on their context and front runner position in $\mathrm{CE}$, that increasingly they will be able to move more quickly towards the right side of the framework, but still very much linked to urban activities.

For the larger-scale circular activities, ports that already host huge industrial and energy processes have more intrinsic potential for intensified symbioses [50]. We observed that so far the focus has been on pure energy processes (e.g., transforming $\mathrm{CO}_{2}$ into fuels). However, these energy processes will increasingly blend into more 'clear' circular processes, whereby waste from one organization becomes input for another, without the current intermediary step of transforming waste into energy before being used by a new actor, such as in the Ecluse project in Antwerp. The Steel2Chemical project in the North Sea Port can be seen as an example here, whereby $\mathrm{CO}_{2}$ is not being transformed into fuels which only then can be used by actors, but is directly being transformed into a commodity (cf. naphtha) that can be used to make plastics. As a result, new cargo streams in and through the port will occur, and hence we foresee that circular activities within ports will move towards the right side of the framework.

Of course, we should not underestimate the crucial role of the port authority in facilitating the emergence of circular activities within their ports. Despite the fact that the CE potential may depend 
on the present type of activities, it is still important that actors are networked, ideas are exchanged and funding is provided to proceed. The port authority plays an important role in this process. From this perspective, we can conclude that the ports of Brussels and Ostend really 'jumped' on the circular bandwagon and have successfully put themselves on the map as circular ports. Zeebrugge, on the other hand, and although it is a clear logistical greenfield port, until now has not succeeded in doing the same. Next, both North Sea Port and the port of Antwerp are increasingly positioning themselves as places where circular activities can-and should-emerge. The question, however, remains how sustainable the initiatives are in terms of their business case, and how the PAs also realize the importance of the third CE pillar of orchestrating new CE cargo streams. Their history and economic profile play to their advantage. Different than for example the port of Zeebrugge, North Sea Port and the Antwerp seaport are more industrial ports, already having many industrial clusters and related supporting infrastructure. The potential to further increase circular symbioses is there; the question is if this potential is fully recognized and exploited. To conclude, all ports can embrace more partnerships and clustering, as well as benefit from better understanding the importance of data and capturing information on their traffic flows to and from their hinterland. Hence, they could co-create with shippers and other actors the cargo streams of tomorrow and play a lead role in the CE transition.

Despite these insightful results, our study also indicated future research is necessary on the role of each actor, on the developed business models for the CE initiatives, and on how the results for Belgian ports relate to the CE transition in other ports in Europe and beyond.

Author Contributions: E.H. had the initial idea for the paper and set out the main lines and structure, and subsequently with K.V.d.B. wrote the paper. All authors have read and agreed to the published version of the manuscript.

Funding: This research received no external funding.

Acknowledgments: OVAM/Circular Flanders commissioned a study in 2018 to Architecture Workroom Brussels (AWB) and 1010au to explore circular projects undertaken by multiple city ports in Northwestern Europe. The results have been widely communicated and will lead to more specific valorization studies together with ports and business partners from summer 2020. The initial explorative study and the workshops organized during this trajectory, under the leading project role of Walter Tempst, were an important source of inspiration to both authors for this research paper.

Conflicts of Interest: The authors declare no conflict of interest.

\section{References}

1. Burger, M.; Stavropoulos, S.; Ramkumar, S.; Dufourmont, J.; van Oort, F. The heterogeneous skill-base of circular economy employment. Res. Policy 2019, 48, 248-261. [CrossRef]

2. van der Lugt, L.; Dooms, M.; Parola, F. Strategy making by hybrid organizations: The case of the port authority. Res. Transp. Bus. Manag. 2013, 8, 103-113. [CrossRef]

3. Chertow, M.R. INDUSTRIALSYMBIOSIS: Literature and Taxonomy. Annu. Rev. Energy Environ. 2000, 25, 313-337. [CrossRef]

4. de Langen, P. Governance in Seaport Clusters. Marit. Econ. Logist. 2004, 6, 141-156. [CrossRef]

5. Monios, J. Polycentric port governance. Transp. Policy 2019, 83, 26-36. [CrossRef]

6. COM. Communication on The European Green Deal. Retrieved from Brussels. Available online: https: //ec.europa.eu/info/strategy/priorities-2019-2024/european-green-deal_en (accessed on 8 November 2020).

7. Merk, O. The Competitiveness of Global Port-Cities: Synthesis Report; OECD Regional Development Working Papers; OECD: Paris, France, 2013.

8. RLI. Mainports Voorbij; RLI: Den Haag The Netherlands, 2016.

9. Demir, F. A Strategic Management Maturity Model for Innovation. Technol. Innov. Manag. Rev. 2018, 8, $13-21$. [CrossRef]

10. Deutz, P.; Ioppolo, G. From Theory to Practice: Enhancing the Potential Policy Impact of Industrial Ecology. Sustainability 2015, 7, 2259-2273. [CrossRef]

11. Ghisellini, P.; Cialani, C.; Ulgiati, S. A review on circular economy: The expected transition to a balanced interplay of environmental and economic systems. J. Clean. Prod. 2016, 114, 11-32. [CrossRef] 
12. Heshmati, A. A Review of the Circular Economy and Its Implementation; Institute of Labor Economics: Bonn, Germany, 2016.

13. Van den Berghe, K.; Ancapi, F.B.; van Bueren, E. When a Fire Starts to Burn. The Relation Between an (Inter)nationally Oriented Incinerator Capacity and the Port Cities' Local Circular Ambitions. Sustainability 2020, 12, 4889. [CrossRef]

14. PBL. Outline of the Circular Economy. 2019. Available online: https://www.pbl.nl/sites/default/files/ downloads/pbl-2019-outline-of-the-circular-economy-3633.pdf (accessed on 8 November 2020).

15. Heyes, G.; Sharmina, M.; Mendoza, J.M.F.; Gallego-Schmid, A.; Azapagic, A. Developing and implementing circular economy business models in service-oriented technology companies. J. Clean. Prod. 2018, 177, 621-632. [CrossRef]

16. Johannsdottir, L. Transforming the linear insurance business model to a closed-loop insurance model: A case study of Nordic non-life insurers. J. Clean. Prod. 2014, 83, 341-355. [CrossRef]

17. Van den Berghe, K.; Vos, M. Circular Area Design or Circular Area Functioning? A Discourse-Institutional Analysis of Circular Area Developments in Amsterdam and Utrecht, The Netherlands. Sustainability 2019, 11, 4875. [CrossRef]

18. Kirchherr, J.; Reike, D.; Hekkert, M. Conceptualizing the circular economy: An analysis of 114 definitions. Resour. Conserv. Recycl. 2017, 127, 221-232. [CrossRef]

19. Korhonen, J.; Honkasalo, A.; Seppälä, J. Circular Economy: The Concept and its Limitations. Ecol. Econ. 2018, 143, 37-46. [CrossRef]

20. Korhonen, J.; Nuur, C.; Feldmann, A.; Birkie, S.E. Circular economy as an essentially contested concept. J. Clean. Prod. 2018, 175, 544-552. [CrossRef]

21. Lieder, M.; Rashid, A. Towards circular economy implementation: A comprehensive review in context of manufacturing industry. J. Clean. Prod. 2016, 115, 36-51. [CrossRef]

22. Van den Berghe, K.; Jacobs, W.; Boelens, L. The relational geometry of the port-city interface: Case studies of Amsterdam, the Netherlands, and Ghent, Belgium. J. Transp. Geogr. 2018, 70, 55-63. [CrossRef]

23. Mendoza, J.M.F.; D'Aponte, F.; Gualtieri, D.; Azapagic, A. Disposable baby diapers: Life cycle costs, eco-efficiency and circular economy. J. Clean. Prod. 2019, 211, 455-467. [CrossRef]

24. Vona, F.; Marin, G.; Consoli, D.; Popp, D. Green Skills; National Bureau of Economic Research: Cambridge, MA, USA, 2015. [CrossRef]

25. Reike, D.; Vermeulen, W.J.; Witjes, S. The circular economy: New or Refurbished as CE 3.0?-Exploring Controversies in the Conceptualization of the Circular Economy through a Focus on History and Resource Value Retention Options. Resour. Conserv. Recycl. 2018, 135, 246-264. [CrossRef]

26. Stahel, W.R. An Inquiry into the Nature of Sustainable Societies: The Role of the Private Sector (Series: 1982 Mitchell Prize Papers), NARC. In The Product Life Factor; Mitchell Energy and Development Corp: Houston, Texas, USA, 1982.

27. Potting, J.; Hekkert, M.P.; Worrell, E.; Hanemaaijer, A. Circular Economy: Measuring Innovation in the Product Chain; PBL (netherlaznds Environmental Assessment Agency): The Hague, The Netherlands, 2017; Available online: https://www.pbl.nl/en/publications/circular-economy-measuring-innovation-in-productchains (accessed on 8 November 2020).

28. Segerson, K.; Pearce, D.W.; Turner, R.K. Economics of Natural Resources and the Environment. Land Econ. 1991, 67, 272. [CrossRef]

29. McDonough, W. Design for the Triple Top Line: New Tools for Sustainable Commerce. Corp. Environ. Strat. 2002, 9, 251-258. [CrossRef]

30. Salomone, R.; Cecchin, A.; Deutz, P.; Raggi, A.; Cutaia, L. Industrial Symbiosis for the Circular Economy. In Operational Experiences, Best Practices and Obstacles to a Collaborative Business Approach; Springer: Berlin/Heidelberg, Germany, 2020.

31. Jackson, T.; Senker, P. Prosperity without Growth: Economics for a Finite Planet. Energy Environ. 2011, 22, 1013-1016. [CrossRef]

32. Panayotou, T. Economic growth and the environment. In The Environment in Anthropology; NYU Press: New York, NY, USA, 2016; pp. 140-148.

33. van Buren, N.; Demmers, M.; Van Der Heijden, R.; Witlox, F. Towards a Circular Economy: The Role of Dutch Logistics Industries and Governments. Sustainbility 2016, 8, 647. [CrossRef] 
34. Van den Berghe, K.; Ersoy, A.; Dabrowski, M.; Wandl, A.; van Bueren, E. The Circular Economy as Re-Emerging Industry and the Importance of the Role of Space [Working Paper]; Delft University of Technology: Delft, The Netherlands, 2020.

35. Preston, F. A Global Redesign? Shaping the Circular Economy; The Royal Institute of International Affairs: London, UK, 2012.

36. Ellen MacArthur Foundation. What Is a Circular Economy? Ellen Macarthur Foundation: Cowes, UK, 2017.

37. Yip, A.W.; Bocken, N.M. Sustainable business model archetypes for the banking industry. J. Clean. Prod. 2018, 174, 150-169. [CrossRef]

38. de Langen, P.; Sornn-Friese, H. Chapter 5-Ports and the Circular Economy. In Green Ports; Bergqvist, R., Monios, J., Eds.; Elsevier: Amsterdam, The Netherlands, 2019; pp. 85-108.

39. Girard, L.F. Toward a Smart Sustainable Development of Port Cities/Areas: The Role of the "Historic Urban Landscape" Approach. Sustainbility 2013, 5, 4329-4348. [CrossRef]

40. OVAM. Circular City Ports. In Synthesis; OVAM: Brussels, Belgium, 2020.

41. de Langen, P.; Sornn-Friese, H.; Hallworth, J. The Role of Port Development Companies in Transitioning the Port Business Ecosystem; The Case of Port of Amsterdam's Circular Activities. Sustainability 2020, 12, 4397. [CrossRef]

42. Sehnem, S.; Campos, L.M.; Julkovski, D.J.; Cazella, C.F. Circular business models: Level of maturity. Manag. Decis. 2019, 57, 1043-1066. [CrossRef]

43. Crosby, P.B. Quality is Free: The Art of Making Quality Certain; McGraw-Hill: New York, NY, USA, 1979; Volume 94.

44. Barra, G.M.J. Modelo de Maturidade Para Processos Certificados em Sistemas Agroindustriais", Tese (Doutorado em Administração); Universidade Federal de Minas Gerai: Belo Horizonte, Brazil, 2016; p. 179.

45. Anderson, K.; Peters, G. Act now, not tomorrow. New Sci. 2016, 232, 20-21. [CrossRef]

46. Ellen MacArthur Foundation; McKinsey Center for Business and Environment. Growth within: A Circular Economy Vision for a Competitive Europe; Ellen MacArthur Foundation: Cowes, UK, 2015.

47. Verbeke, A.; Merchant, H.; Greidanus, N. The end of the opportunism versus trust debate: Bounded reliability as a new envelope concept in research on MNE governance. In Handbook of Research on International Strategic Management; Edward Elgar Publishing: Cheltenham, UK, 2013; pp. 31-63.

48. NBB. Economic Importance of the Belgian Maritime and Inland Ports-Report 2018; National Bank of Belgium: Brussels, Belgium, 2020.

49. De Vlaamse, H. De Vlaamse Havens: Feiten, Statistieken En Indicatoren Voor 2018; Flemish Government: Brussels, Belgium, 2019.

50. Van den Berghe, K. Planning the Port City. A Contribution to and Application of the Relational Approach, Based on Five Case Studies in Amsterdam (The Netherlands) and Ghent (Belgium); Ghent University: Ghent, Belgium, 2018.

Publisher's Note: MDPI stays neutral with regard to jurisdictional claims in published maps and institutional affiliations.

(C) 2020 by the authors. Licensee MDPI, Basel, Switzerland. This article is an open access article distributed under the terms and conditions of the Creative Commons Attribution (CC BY) license (http://creativecommons.org/licenses/by/4.0/). 



\title{
The Role of Port Development Companies in Transitioning the Port Business Ecosystem; The Case of Port of Amsterdam's Circular Activities
}

\author{
Peter W. de Langen ${ }^{1, *}$, Henrik Sornn-Friese ${ }^{2}$ and James Hallworth ${ }^{3}$ \\ 1 Copenhagen Business School, 2000 Frederiksberg, Denmark \\ 2 Copenhagen Business School \& Lee Kong Chian School of Business, Singapore Management University, \\ Singapore 188065, Singapore; hs.si@cbs.dk \\ 3 Port of Amsterdam, Circular \& Renewable Industry, 19406 Amsterdam, The Netherlands; \\ James.Hallworth@portofamsterdam.com \\ * Correspondence: pdl.si@cbs.dk
}

Received: 20 April 2020; Accepted: 25 May 2020; Published: 27 May 2020

\begin{abstract}
There is a gradual but clear transition towards a circular economy (CE) that will potentially have significant impacts on ports, both in their function as transport nodes and as locations for logistics and manufacturing activities. A rough appraisal of new investments in circular manufacturing activities in ports in Europe drawn from organizational reports and official webpages illustrates the (slow) development of circular activities in ports. This paper is to our knowledge the first paper which deals with the implications of $\mathrm{CE}$ for the business model of the port development company. We assess if and how the circularity transition affects the role and business model of port authorities as developers of port clusters. We outline a framework for analyzing the consequences of $\mathrm{CE}$ on the business model of the port authority. We then apply this framework to get a detailed understanding of the emerging CE ecosystem in the Port of Amsterdam, which is clearly a frontrunner in the transition, and the role of the government-owned Port of Amsterdam port development company (PoA) in developing this ecosystem. In Amsterdam, a CE 'business ecosystem' has emerged and continues to evolve with three types of synergies between the companies in this ecosystem: logistics infrastructure and services synergies, input-output synergies and industrial ecology synergies. We find that the spatial scale of the CE value chains in the port varies between segments and that they are generally less international than 'linear' value chains. The development of CE activities occupies a central place in PoA's strategy, and PoA assumes new and active roles in advancing the circular business ecosystem, most notably through developing industrial ecology synergies and nurturing and attracting new, innovative CE companies. Finally, the circularity transition leads to changes in PoA's business model, with an increasing focus on new services that create synergies, and a decreasing importance of the share of port dues in the total revenue mix.
\end{abstract}

Keywords: circular economy; ports; port of Amsterdam; case study; circular economy ecosystem

\section{Introduction}

There is a clear transition towards a circular economy (CE), a gradual and incremental process of structural societal change where materials and components are increasingly reused or recycled at the end of their lifecycle (EOL). This transition, which may, on the one hand, be understood as a subcategory of a more general sustainability transition [1] and on the other be seen as a development that pushes the frontier of sustainability [2], has important consequences for supply chains, ranging from the way products are designed to the business models of companies [3]. The trend towards circular supply chains is partly driven by profit potential for companies and partly by societal pressure 
to increase the sustainability of the local or national economy, which leads to policies to promote sustainability and 'green purchasing' of consumers and companies. Recycling is already advanced for materials such as glass, steel and paper, while for others, such as construction and demolition waste, considerable efforts are made to increase recycling rates [4]. However, recycling of food waste, e-waste, tires and textiles is still limited. The volumes of waste that are still generated at the product EOL represent an enormous loss of material and energy resources. Thus, an increasing number of companies focus on creating value through advancing the circularity of supply chains.

Ports as transport nodes and as locations for logistics and manufacturing activities will be affected by the transition towards CE. Ports handle huge volumes of non-renewable primary resources. The trend towards CE will likely lead to a decline in these volumes [5]. The majority of non-fossil imports and exports furthermore consist of products in linear supply chains, and these flows will be impacted as well, especially when supply chains move from current globalized and linear structures to more localized and circular ones. The CE transition also offers an opportunity for ports to diversify into circular economy activities as alternative lines of business [6].

In most ports, an autonomous but government-owned port development company (PDC) is responsible for port development [7]. While such a publicly owned company operates commercially, it is generally not oriented towards maximizing profit but towards creating value for society [8]. Thus, on top of the commercial logic of attracting CE as it provides growth opportunities, government ownership of a PDC may increase the focus on attracting sustainable activities to the port complex, especially given the fact that ports are under pressure from stakeholders to mitigate the social, economic and ecological harms caused by the commercial, tourist and industrial activities localized in the port [9].

Notwithstanding the advances in the understanding of the role and business model of the PDC $[10,11]$, the role of the PDC in transitioning the port towards a circular model has not received detailed attention. This paper is to our knowledge the first paper which deals with the implications of CE for the business model of the port development company.

We first provide a cursory overview of new investments in circular manufacturing activities in European ports based on primary data collected from their organizational reports and official webpages. This allows us to map the transition towards CE and show the relevance for ports.

Second, we provide a framework for analyzing the role of the port development company in transitioning the port business ecosystem, based on a review of the relevant literature. We then provide an in-depth analysis of the role of Port of Amsterdam (PoA) in developing circular activities. The case of Amsterdam is particularly interesting as it is clearly a frontrunner in the CE transition in ports and has the highest number of CE activities of all European ports. We describe the emerging CE activities in detail and assess the changing role of PoA. We finalize the paper with a concluding section.

\section{CE Activities in European Ports}

We first explore CE activities in the entire population of European Core and Comprehensive ports, as listed by the EU Commission, except the ports in the United Kingdom (UK). UK ports are excluded as they are developed mainly by private companies, which each operate a group of ports and, to the best of our knowledge, report very limited data on specific ports. We rely on primary data from the port's organizational reports and official webpages. Organizational reports are generally accepted for studying the interaction of organizations with their environments [12], and port authorities are usually keen to reveal their environmental measures [13], thus reflecting the tendency of environmentally high-performing organizations to disclose environmental management information [14]. In sustainability reports, the relevant information is stated clearly and is generally easy to find. However, only some ports provide such reports, of which several are accessible only in the official languages in the respective countries. We supplement this with information from annual reports, although here, $\mathrm{CE}$ information tends to be veiled within broader financial and strategic statements. Finally, we analyze CE statements contained in mission and strategy descriptions disclosed through the ports' webpages. A drawback is that such information may differ greatly among the 
ports. For example, an earlier study found great variation in the extent and content of corporate social responsibility (CSR) reporting on the webpages of 186 European ports [15]. Finally, some ports do not have an official webpage and others provide incomplete information. We specifically assess new investments in CE activities in the period 2010-2017, as these are most likely to be reported in annual reports, news items or other publications. The data collection was executed from May 2018 to March 2019.

Our assessment covers a total of 280 European ports. Broadly in line with [16], we include the generation of renewable energy (mainly wind, solar and biomass) in ports as a circular activity, as well as activities in collecting and processing materials at the end of a lifecycle (i.e., materials that have previously been used) for a form of reuse. This material may be conventionally treated as waste, (i.e., burned/landfilled), but may also already often be recycled (e.g., scrap). We include activities that mainly use agricultural by-products for other purposes than food/feed. Food/feed processing is excluded because it has always relied on agricultural products. Thus, the use of agricultural products cannot be considered an alternative for using scarce natural resources. As an example, we consider using biomass for making plastics as circular, while we do not regard a flour mill as circular.

We acknowledge the shortcomings of these population-level data. The detailed analysis of the case of Amsterdam presented in this paper allows for a check on the composed population data. While for Amsterdam, the actual number of new CE establishments in the period 2010-2017 was 11 , our broad-based assessment of publicly available sources revealed eight of these (around 73\%). Thus, while our quantifiable population data are incomplete, they suffice to draw out the bigger picture of the transition towards CE among European ports. Hence, the data are only used to provide a global picture of $\mathrm{CE}$ activities in European ports. Tables 1 and 2 show the results.

Table 1. New CE activities in European ports 2010-2018.

\begin{tabular}{ccccc}
\hline Country & $\begin{array}{c}\text { Number of Ports } \\
\text { in Database }\end{array}$ & $\begin{array}{c}\text { Number of Ports } \\
\text { With at Least 1 } \\
\text { New CE Activity }\end{array}$ & $\begin{array}{c}\text { \% Ports With at } \\
\text { Least 1 New CE } \\
\text { Activity }\end{array}$ & $\begin{array}{c}\text { Average Number } \\
\text { of New CE } \\
\text { Activities in Ports }\end{array}$ \\
\hline Belgium & 4 & 4 & $100 \%$ & 3.8 \\
Slovenia & 1 & 1 & $100 \%$ & 3.0 \\
The Netherlands & 12 & 7 & $58 \%$ & 2.3 \\
Latvia & 3 & 1 & $33 \%$ & 1.0 \\
Finland & 15 & 4 & $27 \%$ & 0.6 \\
Sweden & 25 & 6 & $24 \%$ & 0.4 \\
France & 26 & 6 & $23 \%$ & 0.6 \\
Ireland & 5 & 1 & $20 \%$ & 0.6 \\
Germany & 20 & 4 & $20 \%$ & 0.4 \\
Denmark & 22 & 4 & $18 \%$ & 0.4 \\
Croatia & 7 & 1 & $14 \%$ & 0.1 \\
Estonia & 8 & 1 & $8 \%$ & 0.1 \\
Greece & 25 & 2 & $3 \%$ & 0.2 \\
Italy & 39 & 1 & $0 \%$ & 0.0 \\
Bulgaria & 2 & 0 & $0 \%$ & 0.0 \\
Cyprus & 2 & 0 & $0 \%$ & 0.0 \\
Lithuania & 1 & 0 & $0 \%$ & 0.0 \\
Malta & 4 & 0 & $0 \%$ & 0.0 \\
Poland & 4 & 0 & $0 \%$ & 0.0 \\
Portugal & 13 & 0 & $0 \%$ & 0.0 \\
Romania & 5 & 0 & 0.0 \\
Spain & 37 & 0 & 0.0 \\
\hline
\end{tabular}

Source: authors based on publicly available information on websites of the ports.

Our observations on the broad population of European Core and Comprehensive ports allow us to state the following conclusions. First, in about one out of three European ports, at least one activity can be classified as circular. Second, there is a clear concentration of CE activities in the ports 
in West Europe, especially in Belgium and The Netherlands, and to a lesser extent, North Europe (Scandinavia and the Baltic States). Virtually no CE activities were identified in East and South Europe. This is partly due to the fact that ports in The Netherlands and in Belgium are also industrial complexes. In some other countries, industrial activities are not formally (or functionally) part of the port complex; as one example, the Port of Sines (Portugal) only encompasses the terminal and logistics activities, whereas the industrial park is located outside of the port area. In addition, the central locations of Dutch and Belgian ports in Europe make them attractive as hubs for waste collection and processing.

Table 2. Ports with 3 or more CE initiatives.

\begin{tabular}{cc}
\hline Port & Number of CE Initiatives \\
\hline Amsterdam & 8 \\
Nantes-St Nazaire & 6 \\
Antwerp & 5 \\
Oostende & 5 \\
Helsinki & 5 \\
Delfzijl/Eemshaven & 5 \\
Zeebrugge & 4 \\
Thessaloniki & 4 \\
Rotterdam & 4 \\
Copenhagen-Malmö & 3 \\
Le Havre & 3 \\
Marseille & 3 \\
Hamburg & 3 \\
Dublin & 3 \\
Ventspils & 3 \\
Moerdijk & 3 \\
Koper & 3 \\
Aalborg & 3 \\
\hline
\end{tabular}

Source: authors based on publicly available information on websites of the ports.

Third, investments in CE are only loosely related to cargo volumes. The three largest European ports in volume terms (Rotterdam, Antwerp and Hamburg) have CE activities, but ports with relatively small volumes, like Oostende and Groningen Seaports also have managed to develop a leading role in $\mathrm{CE}$ activities. Given the demonstrated development of circular activities in ports and the expectation that ports will attract more $\mathrm{CE}$ activities as the transition towards CE advances, it is relevant to assess if and how the circularity trend affects the role and business model of the port development company.

\section{The Port as a Business Ecosystem and the Role of the PDC in Transitioning This Ecosystem;}

\section{A Review}

In most ports, an autonomous but government-owned PDC aimed at financial sustainability and creating broader societal value is responsible for port development. The central concept in assessing the role and business model of the port development company is the concept of the port as a 'business ecosystem' [17]. This aligns well with various studies that also analyze circular economic activities with a business ecosystem perspective [18].

In management studies, the ecosystem metaphor is often utilized without a clear definition, and several partially overlapping concepts such as industrial, business and innovation ecosystems have been introduced [19]. In the broadest definition, an ecosystem refers to a group of interacting firms that depend on each other's activities. More precise definitions have been proposed, partially with the aim to distinguish ecosystems from related concepts such as networks and hierarchical, vertically integrated firms. In such definitions, the focus is on the complementarity of products for users. Cennamo et al. [20] define ecosystems as 'a set of actors with varying degrees of multi-lateral, non-generic complementarities that are not fully hierarchically controlled'. It is the non-generic nature 
of complementarities, which necessitates some degree of customization, that generates the uniqueness of an ecosystem.

In this approach, so-called 'complementors' (i.e., firms that offer complementary products) make their own decisions (e.g., in terms of design choices or price setting), while still forming part of an interdependent product or service. In this definition, ecosystems differ from integrated supply chains through more limited hierarchical control, while they differ from networks in the sense that ecosystem members may simply adhere to standards or common infrastructure without having developed network ties. There is competition between ecosystems (i.e., all members benefit from the success of the ecosystem as a whole). Firms in an ecosystem can be direct competitors, and in addition compete for capturing a share of the profits generated in the ecosystem.

Management research on ecosystems focuses largely on the analysis of digital ecosystems and consequently has so far not addressed cases where complementarities are derived from co-location in space. Ports (as well as airports [21]) can be considered as ecosystems in which different types of users benefit from complementarities and shared infrastructures [22,23]. For instance, shipping lines purchase various complementary services in a port, such as cargo handling, bunkering, towage, waste collection, inland transport and others. These are non-generic in the sense that they become more attractive if the firms in the ecosystem coordinate their activities. Likewise, shippers also purchase various complementary services in a port, ranging from warehousing to inland distribution. The same applies for manufacturing firms that purchase transport, storage, energy and related services. For such companies, purchasing some services within the spatially delimited ecosystem is more valuable than purchasing them from outside of the ecosystem.

\subsection{The Port Business Ecosystem and the PDC}

The emerging concept of a 'port business ecosystem' [17] considers ports as localized business networks in which individual companies strongly depend on the development of the ecosystem as a whole. The business ecosystem perspective provides relevant insights for the role and business model of the port development company (PDC). The literature on business ecosystems distinguishes between different stylized roles in the ecosystem; the main distinction is between that of niche players (or complementors) and the focal firm—also known as a hub firm [24] or an architect [25] —that leads the development of the ecosystem. Helfat and Raubitschek [26] have recently argued that innovation capabilities and integrative capabilities are critical for ecosystem developers.

Iansiti and Levien [27], while not confining their focus to geographically bounded systems (such as ports or airports), distinguish three potential strategies for an ecosystem developer: distinguish three potential strategies for an ecosystem developer: a landlord strategy, a dominator strategy and a keystone strategy. They argue that for key actors, who possess crucial assets in the ecosystem and depend strongly on the prospering of the ecosystem as a whole, a keystone strategy generally is most suitable for the long-run development of the ecosystem. Keystones play a more active role in shaping the ecosystem than landlords, which are more passive. Compared to dominators, keystones are more oriented on creating value for and capturing value from third parties in the ecosystem. Keystones aim at providing a proper level of diversity within the ecosystem (which sometimes means removing parts of the system that do not contribute to raising system level productivity) and create platforms (services, tools, or technologies) that allow other ecosystem members to be successful. Such a strategy has proven extremely successful for companies such as Wal-Mart in the retail industry and Microsoft Corporation in the computing business ecosystem [27].

\subsection{The Strategy and Business Model of the PDC}

The keystone strategy advocated by Iansiti and Levien is in line with the strategies developed by many port development companies [28]. PDCs increasingly operate with a landlord business model, i.e., they attract third parties to their ecosystem. Port reform in various countries has led to a shift from 
'operating ports', in which the PDC provides port operations in-house (a dominator strategy, in the vocabulary of Iansiti and Levien [27]). Most PDCs remain state-owned.

By operating a land lease model, the PDC leaves a substantial part of the port operations in the ecosystem to third parties and focuses on improving the quality of the port as a platform. On the other hand, many of those PDCs that traditionally operated as landlords have shifted away from a passive role, in which they focused mainly on the provision of port infrastructure such as quays and basins (the passive landlord strategy in the terms of Iansiti and Levien). Increasingly, PDCs develop a more active role, which is described with different labels such as cluster manager [29], orchestrator [30] or matchmaker, and is in line with the keystone strategy. In this strategy, PDCs develop services and tools to make the port as a whole more productive and competitive.

Ports are special compared to other (digital) ecosystems in the sense that the ecosystem developer is often state-owned. In line with the developing body of knowledge on SOEs, a state-owned PDC is expected to behave differently from a private PDC. Two differences are relevant in the context of the keystone strategy [17]. First, the state-owned PDC is expected to have a higher commitment than a private PDC to investments in the ecosystem with benefits that are partly external to the PDC (i.e., cannot be fully captured by the PDC). Second, the state-owned PDC is expected to have a higher commitment to reducing negative externalities and creating positive externalities (especially in R\&D and training and education) than a private PDC. The state ownership is relevant for the firms in the port business ecosystem as risks of niche firms in ecosystems are partly related to exogenous developments but also partly to the actions of the core firm in the ecosystem [31]. These theoretical considerations are taken into account in the questions addressed in the case of Amsterdam, which are detailed in the next paragraph.

\section{The Transition Towards CE; the Case of Port of Amsterdam}

\subsection{Research Questions and Methods}

This paper applies a case study strategy $[32,33]$ to the study of the role of PDCs in port business ecosystem transitions. Following [34], we see the case study as a research strategy that employs a variety of data sources to examine a particular phenomenon in its natural context and in this process relate theories and concepts with practice. Following [35], we furthermore understand case studies as the thorough study of a single unit for the purpose of understanding a larger class of similar units. The particular phenomenon that we investigate is the role of PDCs in port ecosystem transition, as exemplified by the transition to $\mathrm{CE}$, and the formal unit chosen for intensive investigation is the Port of Amsterdam (PoA).

In line with the emerging stream of research on PDCs as developers of the port business ecosystem, described above, and the focus of this paper on CE activities, four broad questions are addressed. First, there is the question of whether synergies and complementarities in Amsterdam's port business ecosystem are relevant for circular activities. This question is relevant as it sheds light on the (ir)relevance of the ecosystem perspective for $\mathrm{CE}$ activities in ports. Second, we address the question of how the transition towards circularity is incorporated in the strategy of Port of Amsterdam, the developer of Amsterdam's business ecosystem. This sheds light on the relevance of this transition for port development companies. Third, we assess whether PoA's approach in developing CE activities incorporates an ecosystem logic. Finally, we assess whether the transition towards CE has implications for the business model of PoA. This question is relevant given previous research that shows that the circularity transition often leads to changes in business models [36].

Our study relies on both interview and non-interview data. A number of interviews were held during December 2019 and January 2020 with the head of PoA's commercial team 'Circular \& Renewable Industry' and a commercial manager of this team, the latter of whom is also one of the authors of the present article. What started as an interview with the PoA by the other two authors of the paper to discuss the transition to $\mathrm{CE}$ in the port evolved into a collaborative undertaking. This led 
to a deep shared understanding of the context of decision-making in PoA and better data (for the advantages and disadvantages of participant observation, see [37]).

Regarding non-interview data, we have analyzed accessible documents published by PoA that reveal its approach to $\mathrm{CE}$, including its long-term strategy paper, annual reports, and other external communication. The circular activities in Port of Amsterdam were identified from the port's own list of $\mathrm{CE}$ activities, which is available through the website of PoA [38]. The activities of the identified circular activities in Amsterdam were analyzed to get a deeper understanding of the activities, the spatial scale of the value chains and the co-location synergies. In this step, it was also verified that these activities meet the criteria for CE activities deployed in this paper. PoA provided data on the firms involved in circular activities as well as volumes and land use of the circular activities and PoA revenues related to $\mathrm{CE}$.

\subsection{Amsterdam's Port Business Ecosystem and PDC}

Amsterdam's port complex covers over 1400 companies, located in a port area of over 4500 hectares. These companies have over 65,000 employees [39]. The PDC of Amsterdam is called 'Port of Amsterdam' (PoA). PoA is a publicly owned corporate entity (fully owned by the municipal government of Amsterdam) that operates with a landlord business model: land in the port is leased to private companies. PoA became a commercial entity on the first of April 2013; previously, it was a department of the public municipal administration. All shares are held by the municipality of Amsterdam.

The municipality of Amsterdam has a common shareholder policy for all municipal participation. This policy specifically addresses the objectives for the Port of Amsterdam. While sufficient return on investment is a key policy principle, the municipality does not aim for profit maximization but, in line with other government-owned PDCs, aims to create value for society. The shareholder policy of Amsterdam specifically mentions sustainability as a key interest for its municipally owned corporations [40]. The municipality of Amsterdam has an ambitious strategy with regard to circularity: it aims to become fully circular in 2050, with intermediate targets such as achieving a separated waste delivery rate of $65 \%$ in 2020 (up from 19\% in 2013) and a strong economic contribution from new circular activities [40]. The municipality of Amsterdam identifies two of its public corporations as central players in advancing circularity: the municipal waste company (Afval EnergieBedrijf, AEB, Amsterdam, The Netherlands) and Port of Amsterdam (PoA).

PoA has a supervisory board with five members, all of whom are independent (i.e., there are no politicians or senior civil servants on the board that specifically represent the municipality of Amsterdam). The supervisory board approves major decisions, and the shareholder has a more limited direct influence: shareholder approval is only needed for strategically important decisions, for instance, regarding mergers, take-overs and very large investments.

\subsection{Circular Activities in Amsterdam's Port Complex}

PoA uses a formal classification of the activities in the port into different segments, as the account management and commercial contacts of different segments are handled by different teams. PoA currently classifies 22 establishments as circular. However, one of these, the headquarter of Avantium, a stocklisted circular company, does not meet the criteria applied in this paper, as no circular activities are carried out within Amsterdam's port business ecosystem, and the headquarter is also not located inside the formal port area. The remaining 21 circular establishments, of which 11 were created in the period 2010-2017, all have a contractual relation with PoA and can be divided into five segments (see Table 3). For each of these, we also assessed whether the activities entail a full transformation of waste into a new product (for instance biofuel) or whether activities involve collecting, sorting and/or processing waste which is then sold to other companies in the circular system (for instance, metal scrap that is sorted, processed and exported as scrap).

In demolition waste and metals, the activities in the port are focused on sorting and processing waste, not on turning scrap into new metals. On the contrary, the recycling of food and agricultural 
residues leads to a new product, in the majority of cases bioenergy. In general, the most common end product of the circular activities in Amsterdam's port is energy (either biofuels or electricity). However, the number of firms that create feedstocks or new products from waste has increased over the last years.

Table 3. Circular activities in Amsterdam's port.

\begin{tabular}{ccc}
\hline Categories of CE Activities & Number of Companies & Of Which Full Transformation \\
\hline Recycling of plastics and rubber & 5 & 3 \\
Demolition waste recycling & 2 & 0 \\
Recycling of food and agricultural residues & 7 & 7 \\
Metals recycling & 4 & 0 \\
General waste processing & 3 & 1 \\
\hline
\end{tabular}

Source: own analysis based on Port of Amsterdam (PoA)'s own list of circular activities.

\subsection{Synergies and Complementarities of CE Activities in Amsterdam}

To make an assessment of the synergies between CE activities and other companies in Amsterdam's port business ecosystem, we have made a distinction between three types of synergies, based on previous work on co-location synergies [41-43]. First, companies can benefit from a logistics infrastructure and services synergy: companies have relatively cheap inbound and outbound logistics flows because other firms in the ecosystem provide logistics services, enabled by logistics infrastructure [44]. This synergy is due to the location of CE activities in the port, and it can be considered the most general type of synergy: only companies that have local or no inbound/outbound material flows do not benefit from this synergy type.

Second, companies can benefit from input-output synergy when they sell products or purchase resources from other firms in the port business ecosystem. Third, companies can benefit from what we term industrial ecology synergy, in which the exchange of (by)products is enabled by dedicated infrastructure. Only this third type of synergy can be considered as non-generic in the definition of [20]. Table 4 provides a case of each of the three synergy types for the CE activities in Amsterdam's port and the number of firms that benefit from each synergy type.

Table 4. Types of synergy of circular activities in ports and examples for Port of Amsterdam.

\begin{tabular}{ccc}
\hline & Example CE in Amsterdam & $\begin{array}{c}\text { Number of Firms Benefitting } \\
\text { from This Synergy Effect }\end{array}$ \\
\hline $\begin{array}{c}\text { Logistics infrastructure and } \\
\text { services synergy } \\
\text { Input Output Synergy }\end{array}$ & $\begin{array}{c}\text { Scrap recycling company exports scrap in containers } \\
\text { overseas, using the container terminal in Amsterdam. } \\
\text { Oils and fats recycling company sources its fats from a } \\
\text { nearby waste collection company. }\end{array}$ & 20 \\
Industrial ecology synergy & $\begin{array}{c}\text { A producer of bioelectricity uses dedicated electricity } \\
\text { connection to put the electricity in the grid. }\end{array}$ & 20 \\
\hline
\end{tabular}

Source: own analysis based on publicly available data, interviews and insider participant observation.

All firms but one benefit from the logistics infrastructure and services synergy. This is straightforward: the presence of logistics infrastructure and services is the reason for locating in Amsterdam's port complex. Twenty out of 21 firms also benefit from input-output synergy, meaning that virtually all firms either source from or sell material to another firm in the port business ecosystem. This shows the strong interrelations between the CE activities in Amsterdam's port complex. The co-location benefits apply within Amsterdam's port business ecosystem as a whole (4500 hectares), but a couple of hotspots have been developed where companies are co-located at the same site to maximize synergies. Most importantly, a site in the eastern part of the port of around 100 hectares hosts five circular companies, with land reserved for another 4-5 CE companies.

The number of firms that benefit from dedicated infrastructure that enables synergies is four (less than 20\%). The clearest example is a fruit juice company that sends it sugar-rich wastewater (from washing the fruit) to a biogas conversion plant that converts food waste into electricity and heat 
while also cleaning the water. There are currently a number of projects in various phases (from idea to operation) to further create synergies through investing in dedicated facilities/infrastructures. The most advanced is a dedicated pipeline to transport the heat generated by the major waste processing company to a biodiesel refinery.

In addition, together with one waste processing company, the Port of Amsterdam is (as of March 2020) investing in a public berth on the southern bank of the Aziëhaven capable of receiving coaster vessels and inland barges and serving the recycling companies located in this area. The geographical situation of this new quay, combined with its public character (i.e., it can be reserved and used by any company, making use of both mobile quay cranes and floating cranes) will allow many different CE businesses in the immediate vicinity to transship both feedstocks and semi-finished or finished products. AEB, SUEZ and BioEnergyNetherlands (BEN), which are all located directly adjacent to the new quay, have expressed their intention to use this facility for the loading and unloading of both dry bulk (i.e., wood chips) and liquid bulk (i.e., liquified $\mathrm{CO}^{2}$ ) cargoes. The realization of this multi-user and multi-cargo infrastructure is expected to stimulate further growth in the number and type of CE activity in this area of the port and generate revenues for PoA in the form of quay rental and port dues.

\subsection{CE in the Strategy of the PDC}

The relevance of CE in the Port of Amsterdam's strategy is assessed based on three relevant documents of PoA: first, the long-term port development vision, termed Vision 2030, which was published in 2015; second, the strategy 2017-2021, which translates this vision into actions for a 5 -year period; and third the annual report of 2018, which reports on the progress in 2018. The vision 2030 aims to develop the port as a 'dynamic, diverse, adaptive and metropolitan port business ecosystem' [45] (p.5 -this and other quotes from Port of Amsterdam are the author's translation from Dutch). PoA distinguishes three roles for PoA: first, creating an attractive location climate, second, a role as matchmaker that connects organizations and sectors around business opportunities and shared challenges; and third, which PoA clearly states, its role as active developer of new activities that strengthen the business ecosystem (or co-creator, in the terminology of PoA). The vision 2030 explicitly mentions the transition towards circularity and the ambition of PoA to attract new circular economic activities. In the strategy 2017-2021, published in 2016, the circularity ambition is strengthened and translated into clear objectives. Four strategic roadmaps are defined: energy transition, circular economy, logistics accessibility and digitalization. The aim is to lease 22.5 hectares of land in the port to biobased and circular companies. Finally, the annual report 2018 reports the progress in achieving the vision. In the message of the executive board, it is stated that '2018 was a turning point [ ... ]. There is a broad societal awareness that change is needed. In the port, sustainable development took off. There were substantial investments in energy transition and circular economy' [46] (p.5). In addition, the statement of the supervisory board is also focused on circularity: 'the supervisory board compliments the port businesses and Port of Amsterdam with strong cargo handling volumes and a clear transition towards more circular activities' [46] (p. 8). Overall, CE clearly occupies a central role in PoA's strategy; PoA aims to change and diversify the port business ecosystem by attracting decisively circular activities. PoA also states that given the scarcity of port land, the contribution of tenants to advancing the transition towards circularity and/or sustainable energy is an important factor in land allocation decisions [46] (p. 34).

\subsection{PoA's Emerging Ecosystem Approach}

PoA uses the term ecosystem for the CE activities: 'From waste, raw materials and port logistics to established demo plants and innovative circular businesses, everything comes together in Port of Amsterdam's ecosystem' [46]. Beyond the terminology, PoA applies three instruments to develop the CE ecosystem. Each of these instruments demonstrates that PoA is taking on a more active role than simply acting as a landlord, much in line with the emerging theories on keystone strategies of ecosystem developers as discussed in Section 3, and in tune with other PDCs [28]. 
First, PoA aims to maximize synergies through promoting co-siting and co-location. For instance, in a specific area in the port, where various CE activities are already established, vacant land is reserved for CE activities; PoA would not sign lease agreements with linear activities, even if they would prove more attractive from a strictly commercial viewpoint. Second, PoA invests in infrastructure that creates synergies between all players. As a first example, PoA is currently investing in a public berth adjacent to various $\mathrm{CE}$ activities. Through this investment, PoA enables these companies to bundle volumes. As another example, PoA invested in the pipeline that enables sending the sugar-rich wastewater to the processing company, creating savings as well as environmental benefits. The third active role of PoA to strengthen the ecosystem is by supporting innovation and incubation. PoA provides an incubation facility (Prodock) where companies develop demo projects for circular processes, with support from PoA. In addition, PoA actively supports some new ventures; in one specific case, PoA decided to invest venture capital in a CE start-up. All in all, these cases show that PoA invests to attract and support innovative new CE companies.

\subsection{Implications of the Circularity Transition for the Business Model of PoA}

Like most PDCs, PoA currently has two principal revenue streams: port dues and land rents. One central issue is the extent to which a transition to a circular economy goes hand in hand with lower cargo volumes, which would have direct effects for PoA's revenue streams from port dues. In order to assess the maritime transport flows associated with CE activities, the spatial scale of circular value chains is assessed.

In our analysis of spatial scale, we distinguish between continental and overseas, not between national and international, as this allows us to more easily and clearly distinguish cargo flows within mainland Europe (not including the UK) and cargo flows travelling overseas. This is because of the importance of overseas flows for the port and because Belgium and to a lesser extent Germany are relatively close to Amsterdam, thus limiting the relevance of the national vs. international distinction. We furthermore analyze the spatial scale for the five segments, not for the individual CE activities, as the precise origins and destinations change rapidly; many waste products are traded as commodities (see Table 5).

Table 5. Spatial scale of inputs and outputs of CE activities in Amsterdam's port.

\begin{tabular}{|c|c|c|}
\hline Segment & Spatial Scale Inputs & Spatial Scale Outputs \\
\hline Recycling of plastics and rubber & $\begin{array}{l}\text { Mainly continental. There are no } \\
\text { substantial overseas import flows of } \\
\text { plastics waste; there are overseas imports } \\
\text { of used car tires from small niche markets } \\
\text { such as Iceland. }\end{array}$ & $\begin{array}{l}\text { Mainly continental, even though some } \\
\text { products, such as fuels and tiles made } \\
\text { from plastics, are traded internationally. }\end{array}$ \\
\hline Demolition waste recycling & $\begin{array}{l}\text { Continental, and mainly local. Demolition } \\
\text { waste is not traded internationally. }\end{array}$ & $\begin{array}{l}\text { Continental. The demolition waste is } \\
\text { generally sorted by waste companies and } \\
\text { further processed by other firms in } \\
\text { Amsterdam's CE ecosystem. }\end{array}$ \\
\hline Recycling of food and agri residues & $\begin{array}{l}\text { Mostly continental. Imported flows of } \\
\text { food and agri residues from overseas are } \\
\text { limited; commodities like used cooking } \\
\text { oil (UCO) are imported from overseas. }\end{array}$ & $\begin{array}{l}\text { In case of biofuels, the market is } \\
\text { international. High value products may } \\
\text { export overseas; currently, volumes } \\
\text { exported overseas are limited. }\end{array}$ \\
\hline Metals recycling & $\begin{array}{c}\text { Continental, and mainly local. Metal } \\
\text { waste is not traded or shipped over } \\
\text { long distances. }\end{array}$ & $\begin{array}{l}\text { Mainly international. Scrap (in various } \\
\text { qualities) is often traded internationally, } \\
\text { e.g., to India or Turkey where the metal } \\
\text { scrap is either rerolled or melted } \\
\text { for recycling. }\end{array}$ \\
\hline General waste processing & $\begin{array}{l}\text { Mostly local, even though the } \\
\text { state-owned waste processing installation } \\
\text { imports waste from the UK. }\end{array}$ & $\begin{array}{l}\text { Mostly local. The processed waste is } \\
\text { mainly sold to other companies in } \\
\text { Amsterdam's ecosystem. }\end{array}$ \\
\hline
\end{tabular}

Source: own analysis based on publicly available data, interviews and insider participant observation. 
Table 5 shows that, in the current situation, CE material flows are much more local than the traditional end-of-lifecycle flows. Only the scrap flow and liquid biofuels are traded internationally. The maritime volumes generated by the CE activities in Amsterdam are limited to about 3\% of total maritime volumes. However, the share of CE activities in the total land use of the port is much higher at $11.6 \%$ in 2019 [46]. Figure 1 shows the evolution of the revenues from circular activities in the period 2013-2019 (for the port dues that come from CE activities the year 2010 is added; for the other two, these figures were not available).

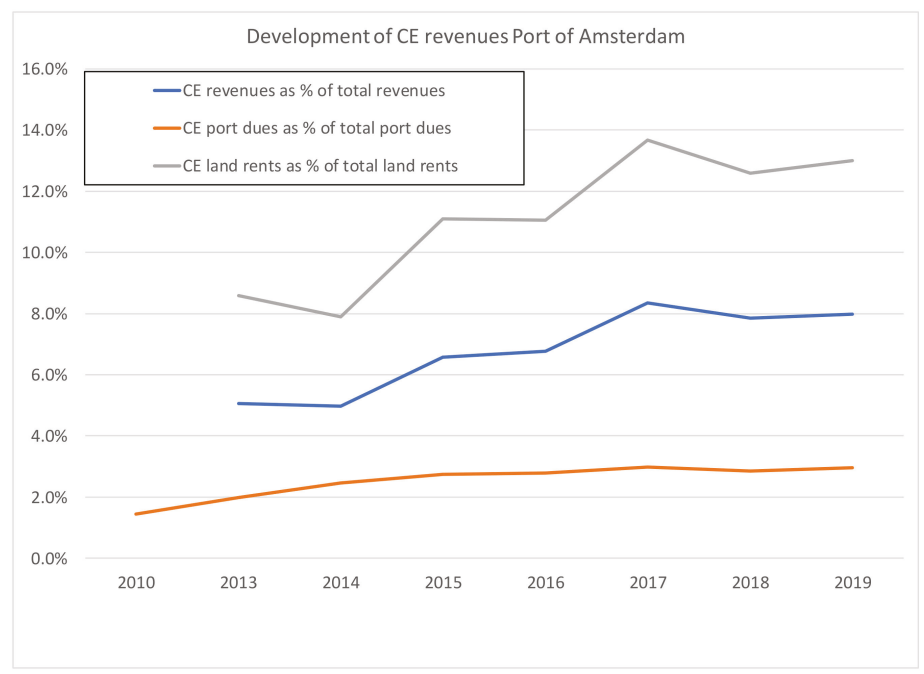

Figure 1. The development of cicular economy (CE)-related revenues in the PoA. Source: own elaboration based on data from Port of Amsterdam.

Figure 1 shows that revenues from $\mathrm{CE}$ activities have grown rapidly over the last years. CE activities now account for more than $8 \%$ of PoA's total revenues. In terms of growth contribution, the relevance of CE activities is larger: one-fifth of PoA's revenue growth between 2013 and 2019 stems from CE activities.

In line with the overview above, the data show that land lease revenues are much more important than port dues. For the CE activities, land revenues are 7.5 times higher than port dues, compared to less than 1.5 for total land revenues compared to port dues. This suggests that the transition to CE will go hand in hand with lower throughput volumes and thus lower revenues from port dues. This may explain why PoA mentions in its strategy 2017-2021 that the transition from linear to circular has implications for its business model: land lease revenues become much more dominant compared to port dues. In this respect, it is worth mentioning that so far, the transition towards a circular economy, at least for PoA, has not led to a decline in total throughput volumes. Instead, volumes based on linear flows have grown from about 70 million ton to about 85 million ton in the period 2013-2019. However, a decline of these linear volumes may well be on the horizon: 15 million tons of Amsterdam's total throughput consists of coal, and 50 million tons consists of oil products. Further progress of the CE transition is likely to further reduce the importance of port dues (which in 2019 accounted for 36\% of PoA's total revenues). Figure 2 shows the evolution of the land rent incomes per hectare, for both the $\mathrm{CE}$ activities and the traditional linear activities. 


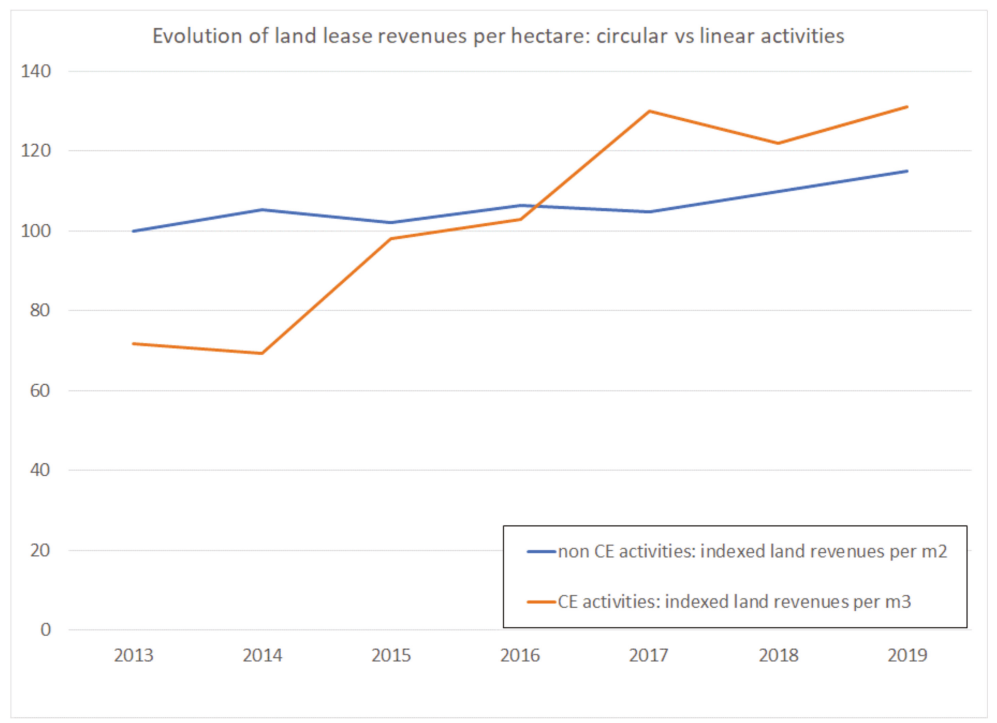

Figure 2. The evolution of the land rent incomes per hectare of PoA, for CE and linear activities. Source: own elaboration based on data from Port of Amsterdam.

Figure 2 shows that while initially the land lease incomes per hectare for CE activities were about $30 \%$ lower than for linear activities in 2013, in 2019 they were $15 \%$ higher. This is a significant development in a relatively short period. Two relevant factors to consider in this regard are, first, the use and continuous development of tenant incentives, which were introduced by Port of Amsterdam as a commercial instrument to attract CE companies, and second, the increasing attractiveness of Port of Amsterdam's circular and renewable industry business ecosystem.

Many of the new CE activities are only able to generate revenue once they have secured a location, secured (environmental) permits, invested in processing facilities and tested these processes. The substantial time lag between signing a lease contract, receipt of permits and the first revenues poses a challenge for the companies aiming to commercially exploit innovative recycling and upcycling technologies. Without a suitable physical location (either rented for the short-term or in a long-term lease from Port of Amsterdam), it is not possible to apply for an environmental permit. In turn, investors and banks are reluctant to commit to financing a project that is not yet environmentally permitted. To overcome this stalemate (no location, thus no permit, thus no financing, thus no means for a rent/lease agreement), the Port of Amsterdam has developed a series of tenant incentives, which allow new CE companies to lay claim to a plot of land (either in option or fully contracted) without high levels of expenditure (either capital expenditure-CAPEX—or operational expenditure-OPEX) in the start-up phase.

PoA uses the following methods, all of which abide by EU competition policy prohibiting state aid, to facilitate the establishment of CE activities in the port area:

1. Paid option on a plot of land in the port. If a company is not yet able to sign a long-term rental or long-term lease contract, it can take a paid option ( $25 \%$ of the normal price) on the plot of land it is looking to develop. The company cannot start physically developing the plot, but it can make plans and start the permitting procedure in the knowledge that the land will not be rented out or leased to a third party.

2. Start-up discounts. A new company does not start generating revenue until its activity is (environmentally) permitted, designed, built, commissioned and up and running. The Port of Amsterdam can provide temporary discounts to new tenants to reduce OPEX until a new activity is operational and revenue streams have started flowing. 
3. Delayed payment. For companies that plan to scale up processing capacity (i.e., in the case of phased increase in production from, say, 100 tons per day to 600 tons per day), the initial revenue streams may not be enough to sustain full lease payments. For these parties, PoA offers delayed payment of the land rental or lease fees. Like the above-mentioned growth agreement, this method reduces OPEX for the activity in the startup and/or growth phase of the operation. The delayed payment is paid back to Port of Amsterdam at a later date or spread out across the duration of the land rental or land lease contract. To ensure that this incentive tool adheres to is EU state-aid regulation, PoA charges a market conform interest over the amount for which payment is delayed.

4. Subordinated loans. Port of Amsterdam occasionally provides new companies and activities with subordinated loans, in partnership with local investment funds. These loans provide the funding to get a new activity built and operational. Like with the other mechanisms, the interest is market-based to adhere to EU legislation. One of the reasons for partnering with public investment funds is their expertise in due diligence and contractual agreements.

These instruments were used to attract CE activities. Thus, initial lease revenues were low and have grown over time.

As for the second key factor to explain the increase in land lease income for circular activities, the expanding circular and renewable industry business ecosystem in Port of Amsterdam has enabled PoA to negotiate higher land lease fees in the most recent land lease agreements. Overall, this evolution suggests that the tenant incentives developed for attracting circular and renewable industry activities, with competitive prices to develop a CE ecosystem that can sustain higher income in the longer run, have been successful.

\section{Conclusions}

This paper has provided an overview of CE activities in European ports and provided a detailed overview of circular activities in Amsterdam's port complex. Seven conclusions were found.

1. Our population-level assessment of CE activities in European Core and Comprehensive ports shows that ports in Europe do indeed attract $\mathrm{CE}$ activities. However, there are huge differences between the ports, and large ports in linear activities do not automatically also attract circular activities. Furthermore, there are important regional disparities in Europe regarding the speed of the $\mathrm{CE}$ transition in ports.

2. Amsterdam is a frontrunner in the $\mathrm{CE}$ transition in ports, with over 20 circular activities across five segments and substantial growth in CE activity over the past couple of years.

3. A circular and renewable industry business ecosystem has emerged in Port of Amsterdam and continues to evolve. Three types of synergies between the companies in this ecosystem can be distinguished. The vast majority of CE companies benefit from a logistics infrastructure and services because other firms in the ecosystem provide logistics services, enabled by logistics infrastructure. Almost all CE companies also benefit from input-output synergy that arises through sales to or purchases from other firms in the port business ecosystem. Finally, less than $20 \%$ of Amsterdam's CE companies also benefit from industrial ecology synergies, in which the exchange of (by)products is enabled by dedicated infrastructure.

4. The spatial scale of the $\mathrm{CE}$ value chains varies between segments but is in general less international than linear value chains; resources (in the form of waste) are often confined to the hinterland of the port, and often transported to the port by truck. Outputs of CE activities, either in the form of new products or in the form of sorted waste, are in some cases traded internationally, but often mainly reach continental markets within the European trading bloc. Amsterdam's maritime circular volumes amount to about 2.5 million tons, around $3 \%$ of total volumes, while CE activities account for around $11.5 \%$ of the total land use in Amsterdam's port. 
5. PoA, the government-owned landlord port development company, gives developing CE activities a central place in its strategy. Circularity is mentioned frequently in PoA's long-term vision, its five-year corporate strategy and its recent annual reports. PoA also reports land use for CE activities and has allocated a part of the port area for CE activities. PoA's focus on CE is in line with the ambitions and policies of its shareholder, the municipality of Amsterdam, which also includes the challenge to shift to a circular economy in its shareholder policy.

6. PoA takes on new and active roles in advancing the circular business ecosystem. Most notable are PoA's active role in developing industrial ecology synergies through investments in infrastructure to better connect the companies in the ecosystem and its role in nurturing and attracting new companies through an incubator facility as well capital provision (through loans and in one specific case equity).

7. The transition towards CE goes hand in hand with a transition of PoA's business model, with an increasing focus on new services that create synergy and a decreasing importance of the share of port dues in the total revenue mix.

These conclusions deepen our understanding of the impact of the circularity transition on ports. However, the findings from our study of Port of Amsterdam, as well as a limited number of other case studies on CE in ports [47-49], are context-dependent and conjunctural, and hence other ports may achieve similar outcomes in terms of $\mathrm{CE}$, even if their conditions (e.g., the stage of business ecosystem development or the apposition with the visions of main shareholders) are different than those of PoA.

Three further research themes on circularity and port development are particularly relevant: first, developing detailed datasets on circular activities in ports, to allow cross-section and analysis of drivers of CE in ports; second, comparative research, or even comparative-historical analysis [50] sensitive to contextual differences, addressing the emergence of port related incubation and start-up support services in ports and the further role of port development companies in the transitioning towards CE is called for. Many ports have embraced innovation as a key mechanism to transition the port business ecosystem towards more circular and sustainable ecosystems (as manifested by the innovation initiatives in various ports, often under the label 'smartport'). More comparative research on the efforts to nurture CE firms can shed light on its impact on the transition of ports. Finally, more detailed research on the effect of public ownership [17,51], and especially mechanisms through which public ownership may translate in more focus into attracting circular activities to the port, would yield important insights.

Author Contributions: Conceptualization, methodology, data analysis, all authors; writing-original draft preparation, P.W.d.L.; writing - review and editing, H.S.-F., J.H. All authors have read and agreed to the published version of the manuscript.

Funding: This research was supported by the Social Sciences and Humanities Research Council of Canada Green Shipping Partnership Project [\#895-2017-1003].

Conflicts of Interest: The authors declare no conflict of interest.

\section{References}

1. Sullivan, A.; White, D.D.; Larson, K.L.; Wutich, A. Towards Water Sensitive Cities in the Colorado River Basin: A Comparative Historical Analysis to Inform Future Urban Water Sustainability Transitions. Sustainability 2017, 9, 761. [CrossRef]

2. Nasi, M.H.A.; Genovese, A.; Acquaye, A.A.; Koh, S.C.L.; Yamoah, F. Comparing linear and circular supply chains: A case study from the construction industry. Int. J. Prod. Econ. 2017, 183, 443-457. [CrossRef]

3. Bocken, N.M.P.; de Pauw, I.; Bakker, C.; van der Grinten, B. Product design and business model strategies for a circular economy. J. Ind. Prod. Eng. 2016, 33, 308-320. [CrossRef]

4. Graedel, T.E.; Allwood, J.; Birat, J.P.; Rech, B.K.; Sibley, S.F.; Sonnemann, G.; Buchert, M.; Gaheluken, C. Recycling Rates of Metals-A Status Report; A Report of the Working Group on the Global Metal Flows to International Resource Panel; United Nations Environment Programme: Nairobi, Kenya, 2011. 
5. De Langen, P.; Sornn-Friese, H. Ports and the Circular Economy. In Green Ports. Inland and Seaside Sustainable Strategies; Bergqvist, R., Monios, J., Eds.; Elsevier: Amsterdam, The Netherlands, 2018.

6. Carpenter, A.; Lozano, R.; Samalisto, K.; Astner, L. Securing a port's future through Circular Economy: Experiences from the Port of Gävle in contributing to sustainability. Mar. Pollut. Bull. 2018, 128, 539-547. [CrossRef] [PubMed]

7. De Langen, P.W.; Heij, C. Corporatisation and performance: A literature review and an analysis of the performance effects of the corporatisation of port of Rotterdam authority. Transp. Rev. 2014, 34, 396-414. [CrossRef]

8. De Langen, P.W.; van der Lugt, L.M. Institutional reforms of port authorities in The Netherlands; the establishment of port development companies. Transp. Bus. Manag. 2017, 22, 108-113. [CrossRef]

9. Ezzat, A.M. Sustainable Development of Seaport Cities through Circular Economy: A Comparative Study with Implications to Suez Canal Corridor Project. Eur. J. Sustain. Dev. 2016, 5, 509-522. [CrossRef]

10. Kringelum, L.T.B. Transcending Organizational Boundaries: Exploring Intra-and Inter-Organizational Processes of Business Model Innovation in a Port Authority. Ph.D. Thesis, Aalborg Universitetsforlag, Aalborg, Denmark, 2017.

11. Kringelum, L.T.B. Reviewing the challenges of port authority business model Innovation. World Rev. Intermodal Transp. Res. 2019, 8, 265-291.

12. Duriau, V.J.; Reger, R.K.; Pfarrer, M.D. A Content Analysis of the Content Analysis Literature in Organization Studies. Research Themes, Data Sources, and Methodological Refinements. Organ. Res. Methods 2007, 10, 5-34. [CrossRef]

13. Puig, M.; Wooldridge, C.; Darbra, R.M. Identification and selection of Environmental Performance Indicators for sustainable port development. Mar. Pollut. Bull. 2014, 81, 124-130. [CrossRef]

14. Clarkson, P.M.; Li, Y.; Richardson, G.D.; Vasvan, F. Revising the relation between environmental performance and environmental disclosure: An empirical analysis. Accounting, Organ. Soc. 2008, 33, 303-327. [CrossRef]

15. Santos, S.; Rodrigues, L.L.; Branco, M.C. Online sustainability communication practices of European seaports. J. Clean. Prod. 2016, 112, 2935-2942. [CrossRef]

16. Lewandowski, M. Designing the Business Models for Circular Economy-Towards the Conceptual Framework. Sustainability 2016, 8, 43. [CrossRef]

17. Van der Lugt, L.M.; de Langen, P.W. Value creation and value capture in the port's business. In Port Management, Cases in Port Geography, Operations and Policy; Petitt, S., Beresford, A., Eds.; Kogan Page: London, UK, 2018; pp. 13-27.

18. Martins, N.O. Ecosystems, strong sustainability and the classical circular economy. Ecol. Econ. 2016, 129, 32-39. [CrossRef]

19. Valkokari, K. Business, innovation, and knowledge ecosystems: How they differ and how to survive and thrive within them. Technol. Innov. Manag. Rev. 2015, 5, 17-24. [CrossRef]

20. Cennamo, C.; Gawer, A.; Jacobides, M.G. Towards a theory of ecosystems. Strateg. Manag. J. 2018, 39, 2255-2276.

21. Power, T.; Jerjian, G. Ecosystem: Living the 12 Principles of Networked Business; Financial Times Management: London, UK, 2001.

22. Bichou, K.; Gray, R. A critical review of conventional terminology for classifying seaports. Transp. Res. Part A Policy Pract. 2005, 39, 75-92. [CrossRef]

23. Dhanaraj, C.; Parkhe, A. Orchestrating innovation networks. Acad. Manag. Rev. 2006, 31, 659-669. [CrossRef]

24. Gulati, R.; Puranam, P.; Tushman, M. Meta-organization design: Rethinking design in interorganizational and community contexts. Strateg. Manag. J. 2012, 33, 571-586. [CrossRef]

25. De Langen, P.W.; Visser, E.J. Collective action regimes in seaport clusters: The case of the Lower Mississippi port cluster. Transp. Geogr. 2004, 13, 173-186. [CrossRef]

26. Helfat, C.E.; Raubitschek, R.S. Dynamic and integrative capabilities for profiting from innovation in digital platform-based ecosystems. Res. Policy 2018, 47, 1391-1399. [CrossRef]

27. Iansiti, M.; Levien, R. Strategy as Ecology. Harv. Bus. Rev. 2004, 82, 68-78. [PubMed]

28. van der Lugt, L.; De Langen, P.W.; Hagdorn, L. Beyond the landlord: Worldwide empirical analysis of port authority strategies. Int. J. Shipp. Transp. Logist. 2015, 7, 570-596.

29. De Langen, P.W. The Performance of Seaport Clusters; a Framework to Analyze Cluster Performance and an Application to the Seaport Clusters of Durban, Rotterdam and the Lower Mississippi 2004 (No. ERIM PhD 
Series; EPS-2004-034-LIS). Available online: https://www.erim.eur.nl/smartporterasmus/publications/books/ detail/2597-the-performance-of-seaport-clusters-a-framework-to-analyze-cluster-performance-and-anapplication-to-the-seaport-clusters-of-durban-rotterdam-and-the-lower-mississippi/ (accessed on 20 February 2020).

30. Verhoeven, P. A review of port authority functions: Towards a renaissance? Marit. Policy Manag. 2010, 37, 247-270. [CrossRef]

31. Teece, D.J. Explicating dynamic capabilities: The nature and microfoundations of (sustainable) enterprise performance. Strateg. Manag. J. 2007, 28, 1319-1350. [CrossRef]

32. Gerring, J. What is a case study and what is it good for? Am. Political Sci. Rev. 2004, 98, 341-354. [CrossRef]

33. Eisenhardt, K.M. Building theories from case study research. Acad. Manag. Rev. 1989, 14, 532-550. [CrossRef]

34. Ridder, H.-G. The theory contribution of case study research designs. Bus. Res. 2017, 10, 281-305. [CrossRef]

35. Piekkari, R.; Welsh, C.; Paavilainen, E. The Case Study as Disciplinary Convention. Evidence from International Business Journal. Organ. Res. Methods 2009, 12, 567-589. [CrossRef]

36. Lopez, F.J.D.; Bastein, T.; Tukker, A. Business model innovation for resource-efficiency, circularity and cleaner production: What 143 cases tell us. Ecol. Econ. 2019, 155, 20-35. [CrossRef]

37. Flick, U. An Introduction to Qualitative Research, 5th ed.; Sage: London, UK, 2019.

38. Port of Amsterdam. Circular Companies in Port of Amsterdam. Available online: https://myport. portofamsterdam.com/en/portle/service/industries?f\%5B0\%5D=services\%3A41). (accessed on 20 February 2020).

39. Port of Amsterdam. Feiten en Cijfers 2018. Available online: https://www.portofamsterdam.com/sites/poa/ files/media/pdf-nl/feiten-en-cijfers-2018-port-of-amsterdam.pdf (accessed on 20 February 2020).

40. Gemeente Amsterdam. Uitvoeringsplan. 2016. Available online: https://www.amsterdam.nl/bestuurorganisatie/volg-beleid/afval-en-schoon/ (accessed on 19 March 2020).

41. Port of Amsterdam. Visie 2030, Port of Amsterdam, Port of Partnerships. 2015. Available online: https://www.portofamsterdam.com/nl/havenbedrijf/visie-2030 (accessed on 15 February 2020).

42. Jonsson, D. Sustainable infrasystem synergies: A conceptual framework. Urban Technol. 2000, 7, 81-104. [CrossRef]

43. Van den Heuvel, F.; Van Donselaar, K.; De Langen, P.; Fransoo, J. Co-Location Synergies: Specialised Versus Diverse Logistics Concentration Areas. Tijdschr. Voor Econ. Soc. Geogr. 2016, 107, 331-346. [CrossRef]

44. Williams, J. Circular cities. Urban Stud. 2019, 56, 2746-2762. [CrossRef]

45. Sheffi, Y. Logistics Clusters: Delivering Value and Driving Growth; MIT Press: Cambridge, MA, USA, 2012.

46. Port of Amsterdam. Corporate Information. 2020. Available online: https://www.portofamsterdam.com/en/ business/settlement/port-amsterdam-perfect-hub-circular-economy (accessed on 27 March 2020).

47. Hollen, R.M.A.; van den Bosch, F.A.J.; Volberda, H.W. Strategic levers of port authorities for industrial ecosystem development. Marit. Econ. Logist. 2015, 17, 79-96. [CrossRef]

48. Lozano, R.; Fobbe, L.; Carpenter, A.; Sammalisto, K. Analysing sustainability changes in seaports: Experiences from the Gävle Port Authority. Sustain. Dev. 2019, 27, 409-418. [CrossRef]

49. Bahers, J.B.; Tanguy, A.; Pincetl, S. Metabolic relationships between cities and hinterland: A political-industrial ecology of energy metabolism of Saint-Nazaire metropolitan and port area (France). Ecol. Econ. 2020, 167, 106-447. [CrossRef]

50. Mahoney, J.; Rueschemeyer, D. Comparative Historical Analysis in the Social Sciences; Cambridge University Press: Cambridge, UK, 2003.

51. Zhang, Q.; Zheng, S.; Geerlings, H.; El Makhloufi, A. Port governance revisited: How to govern and for what purpose? Transp. Policy 2019, 77, 46-57. [CrossRef]

(C) 2020 by the authors. Licensee MDPI, Basel, Switzerland. This article is an open access article distributed under the terms and conditions of the Creative Commons Attribution (CC BY) license (http://creativecommons.org/licenses/by/4.0/). 


\title{
When a Fire Starts to Burn. The Relation Between an (Inter)nationally Oriented Incinerator Capacity and the Port Cities' Local Circular Ambitions
}

\author{
Karel Van den Berghe ${ }^{1,2, *}$, Felipe Bucci Ancapi ${ }^{1}$ and Ellen van Bueren ${ }^{1}$ \\ 1 Department of Management in the Built Environment, Delft University of Technology, \\ 2628 BL Delft, The Netherlands; F.E.BucciAncapi@TUDelft.nl (F.B.A.); E.M.vanBueren@TUDelft.nl (E.v.B.) \\ 2 Department of Geography, Ghent University, Krijgslaan 281, 9000 Gent, Belgium \\ * Correspondence: K.B.J.VandenBerghe@TUDelft.nl; Tel.: +31-(0)1-5278-4159
}

Received: 29 May 2020; Accepted: 12 June 2020; Published: 15 June 2020

\begin{abstract}
This paper assesses the potential of the circular economy (CE) policy ambitions of the port cities of Ghent (Belgium) and Amsterdam (The Netherlands). Both Ghent and Amsterdam are municipalities that potentially lend themselves ideally to set up a more local-oriented circular (re)production and (re)consumption system. Subsequently, both have the ambition that, in 2050, the $\mathrm{CE}$ will have become an achieved public value that influences all activities to be more circular in comparison with today. However, while having ambitious policies is important, we explain that a public value also requires alignment with the operational capacity used or needed to achieve this policy ambition. In this paper, we focus on the 'negative' CE operational capacity: landfills and incinerators. Our results show that the CE ambitions of Ghent are more realistic than Amsterdam. During the last few decades, Dutch waste management has been largely privatized. This led to a significant increase in incinerator capacity and a lowering of the incineration price. This differs from Flanders, which has a deliberate capping on the allowed incinerator capacity, keeping the price for incineration high. This increases the incentive for urban and maritime actors to climb the waste hierarchy, eventually thus making the port city (potentially) more circular as a whole.
\end{abstract}

Keywords: circular economy; port cities; public value; strategic management; incinerator capacity

\section{Introduction}

This paper assesses the potential of the circular economy (CE) policy ambitions of port cities, specifically, the policy ambitions of their urban and their port authorities. To do so, it, however, does not focus primarily on port cities, but on the institutional and socioeconomic structures they are part of. We do this to avoid a bias towards success, in geography also known as the so-called 'territorial trap.' Hereby, the outcome of the research is being predefined by the idealizing of a given territorial bordered object [1]. Originally, the territorial trap was developed during the dawn of the post-cold war globalization to criticize research using territorial variables to explain the (non-) success of states to accommodate international businesses without focussing on the business itself or take into account international relations that would shape territorial spaces [2]. Arguably, to assess the (non-) success of the $\mathrm{CE}$, the 'danger' of the bias towards success is relevant (again). Although the $\mathrm{CE}$ is a relatively new concept, it has experienced an enormous hype among public and private actors [3,4]. The CE is increasingly seen as one of the key strategic societal goals towards sustainable development [5]. While being a strategic goal in China since the late 1990s [6], more recently it has been adopted by the United Nations [7], the Organisation for Economic Co-Operation and Development (OECD) [8] and the European Union $[9,10]$ among others. Within Europe, both Belgium (for this paper we focus on the region of Flanders) [11] and The Netherlands [12] have set the ambition to become fully circular 
in 2050. All of these policies are, however, arguably difficult to assess, as they all in essence are the same: having a full CE in 2050. Said otherwise, only in 2050 will we be able to assess the (non-) success of the policies and their ambitions today. Therefore, to make it more concrete, policy reports or research, e.g., [13], focus on best practices to assess the results of CE policy ambitions [14]. However, a recent study in The Netherlands revealed that the best practices of CE innovations only represent a very small amount of the total amount of $\mathrm{CE}$ innovations. The vast majority innovate the highest recycling activities but no higher R-steps of the waste prevention hierarchy $[15,16]$. This is a concern, as in reality, the world is increasingly less circular [17]. Today, $8.6 \%$ is circular of all materials (around 100 billion tonnes) used per year, down from $9.1 \%$ two years ago because of an increase of extraction, the build-up of material stocks, and low levels of end-of-use processing and cycling [18].

Here lies the territorial trap of the $\mathrm{CE}$, whereby a conceptual error occurs regarding region or cities as fixed units or containers, separated from outside political and socioeconomic spaces. If, then, the (non-) success of circular policies of these spaces is used, the results are predefined (cf. [19]). As such, the more or less amount of successful CE stories defines then how a government is performing, (implicitly), thus favouring individual (mostly subsidized) efforts instead of more overall adjustments regarding the $\mathrm{CE}$. This makes it also difficult to objectively compare administrative areas regarding their efforts to strive towards a CE. Moreover, as agenda-setting theories have pointed out [20], as such, the uncritical discourse of circular success stories can even be used by policy actors as a strategy to push particular agendas to the front at the expense of others [21,22].

In this paper, the research objective was to assess the (potential) success of circular policy ambitions without focusing on the (successful) projects themselves. Our hypothesis was that focussing on success stories blurs our understanding of the actual situation of the $\mathrm{CE}$ of a certain region or city. Therefore, in contrast, we assessed circular policy ambitions by analysing what their potential is to effectively let the $\mathrm{CE}$ emerge as a public value. Thus, to become more circular, in comparison with the current situation, this requires influencing all activities and not only creating a few success stories within or linked to the administrative responsible area or structure [23]. Our focus is on the lowest administrative level, namely, the municipal level. In particular, we focus on port cities, municipalities characterized by an economy centring on knowledge and industrial logistical economy [24]. We focus on these, because our proposition is that they have particular contexts that potentially lend themselves better to adapt (more) a CE. Next, to avoiding the use of primary materials, it is assumed that the CE also will strive towards a (re)production and (re)consumption system or paradigm [25] that remains as local as possible $[26,27]$. Therefore, if successful, the CE will most likely be characterized by a 'glocal' system [28], whereby global (re)production networks will keep on existing [29,30], but with a more (sustainable) balance departing from the local level. What is more, translating the CE of 2050 back to the policy choices today, urban regions having the space for and/or are already hosting industrial (re)production or logistical functions, have a higher potential to adapt to a CE in comparison with urban regions which, today, do not have the space and/or industrial (re)production or logistical functions. The assumption here is that existing residential, agricultural, or nature land use will not (all) be transformed into industrial land use. However, this is of course only the CE potential of matching (re)production and (re)consumption, understood in geographical economic terms. In a reciprocal way, this is also the opportunistic reason why many port cities' authorities, the local and the port authorities, put the $\mathrm{CE}$ as their central competitive ambition and are trying to let the $\mathrm{CE}$ emerge as a public value that defines all activities within, towards, and from their urban/maritime economies. However, in spatial terms, as described by Van den Berghe and Vos [22], the CE ambitions of the local authorities and the port authorities can conflict within the same port city. In Amsterdam, currently a land use conflict exists between port and city to transform an existing maritime area into a residential area, although both use the discourse of circularity to claim their 'right' on that particular area. The urban government links circularity to the built environment, stating that all new built buildings will be circular, consequently helping to achieve its $\mathrm{CE}$ ambitions. The port authorities link circularity to (re)production processes and the need of such functions to be located as close as possible to the city [22]. 
In other words, the higher potential of port cities to adapt to a $\mathrm{CE}$, understood in geographical economic terms, is not (always) the same perspective on CE from some policy-makers within port cities.

The remaining of this paper is as follows. First, we will introduce the concept of public value and how it is constituted by its legitimacy and operational capacity. Legitimacy is understood as the legal and policy context, while the operational capacity is understood in this paper as the industrial/physical production capacity. The public value concept lends itself ideally to assess how the circular policy ambitions (legitimacy) are aligned or not with the existing operational capacity. In other words, as such, we are able to link policy of the CE with the economic/technical side of the CE, two 'parts of the $\mathrm{CE}^{\prime}$ that are mostly not linked to each other [25]. The (non-) alignment between the two then informs us of the potential of the policy ambitions to let the $\mathrm{CE}$ emerge as a public value, eventually thus influencing all activities to become more circular. The third section explains our operational framework. In our results, we map the legitimacy and support, or the circular policies and their ambitions, and the operational capacity of the CE. As we will explain, we assess the latter by looking at the 'negative' CE operational capacity, or the operational capacity of incinerators in Flanders (Ghent) and The Netherlands (Amsterdam). In our discussion, we will show how in Flanders the local-to-regional CE ambitions are better aligned with the operational capacity of the $\mathrm{CE}$, while in The Netherlands a lock-in is created that hinders a $\mathrm{CE}$ that is able to go beyond the incineration or recover level. Based on our results, we conclude with policy recommendations towards the local and regional strategic CE management of the port cities of Ghent and Amsterdam.

\section{The Circular Economy as Public Value}

\subsection{The Public Value Concept}

The public value concept was coined by Moore [31] and is an organizing principle focusing originally on public sector organizations but has become more widely used. Public value describes the value that an organization contributes to the society. It can be the result from improving the government itself as an asset to society, or it can be the result from the delivery of specific benefits to the people. Moore saw public value as the equivalent of the shareholder value sought by the private sector, whereby public organizations seek public value, rewarded in an arguably similar way as pursuing shareholder value. Moore used public value as a 'counterweight' for the then widely applied New Public Management approach.

New Public Management (NPM) emerged in the United Kingdom during the Thatcher and Major governments in the 1980s and 1990s, subsequently adapted in many different ways around the world [32]. In general, it focuses on using approaches from the private sector in public management. The basic idea is that a government outsources a number of its tasks via competitive contracting, increasing the efficiency and the quality of the public service delivery and leading to an increased value for the taxpayers' money. It is considered that the private sector, motivated by market incentives, is better capable of efficiently delivering a number of public services, within the conditions set by government. The public administration itself should thus insist on accountability, supported by methods such as tools as performance-based budgeting. This then results in reducing governments in search of their most effective size and shape, accomplished through strategic reviews, consolidation, and reorganisation and leaving those tasks to the market to which the market is best equipped.

From a democratic point of view, NPM creates, in theory, more transparency and a better understanding of how the government spends public money. Central to NPM is, namely, the use of performance measurement systems that enhance the legitimacy and accountability of government operations. Consequently, based on these analyses, one should be able to detect if a government performance is 'good' or 'bad' based on predefined criteria. However, this is the case in theory. The challenge is to operationalize this. As explained by Moore [33], at first, the need for objective measures seems to be a technical one to measure the success—or not—of public organizations in altering social conditions in order to create public value. However, in turn, it becomes a managerial problem 
as to how to deploy such technical tools in combination with day-to-day activities in organizations; for example, how to hold someone accountable for their performance? At that point, it exposes a political problem: what is the value that is pursued?

\subsection{The Lack of Strategic Management can Constrain Sustainable Development}

The main limitation of NPM is the difficulty, or even impossibility, to attribute observed changes in social conditions. Causality is difficult to observe due to the many intervening variables. In addition, in many cases, changes need a long time before they visibly emerge. The feedback comes in late, which makes it little verifiable to relate change to the daily operations and adjust and improve them if needed. Consequently, the NPM focus on measuring results to improve the accountability led not to a predicted 'creative destruction' [34] of inefficient and ineffective public services, but to a defensive behaviour of public agencies and to an endless discussion on the definition of public value. With, amongst others, its ill-defined character and absence of agreed-upon evaluation criteria, the NPM concept qualifies as a 'wicked problem' [35]. The result of this all was that, rather than focusing on solving societal problems, public agencies started to focus on justifying past performance, leading to stronger institutional inertia instead of change. Such reinforcing feedback mechanisms leading to institutional lock-in and reduced or absence of organisational responsibility for collectively produced outcomes have also been observed by Ulrich Beck in his work on the 'risk society' [36].

Following this, one crucial element of private agencies' behaviour did not immediately find its way to public governance, namely, strategic management [33]. Strategic management has been developed in the business world to guide the often-by-scenarios driven decision-making of private-sector firms [37]. Nonetheless, strategic management was incorporated in public management, albeit in a slightly different way [38]. Strategic management in public governance does not focus on the uncertain risks. In contrary to private policy-making, it focuses on a desired future, giving attention to the aspects that are controllable and less the external complex and dynamic environment that influences development [33,39].

Especially for sustainable development, taking into account the external complex and dynamic environment, when aiming to achieve a desired future, is important. Sustainable development-thus also the CE as its 'newest' concept-requires strong strategic management, combining the private- and public-sector understanding of this instrument. Contributing to changes in the long term requires the alignment of different stakes in the short term and the long term. However, as explained by Boons and Spekkink [40], in many countries, the responsibility for sustainable development, in light of NPM, has since the 1980s been externalised for a large part to the private sector. Hereby, the role of the government has evolved to the facilitator of transformation, setting the long-term goals, while market mechanisms were expected to incentivize private parties in making the changes needed to achieve the goals. The private-sector and market-dominated process poses a challenge for the strategic management of sustainable development for public governments, as they are not (anymore) directly in control of the effective (re)production capacities.

\section{Operational Framework}

To guide public managers in a complex and dynamic environment, Moore [31] introduced his strategic triangle. The strategic triangle informs public managers as to how to create public value by successfully aligning the sources of legitimacy and support of the public value and the operational capacity. Within the triangle lies then the strategic management, or the area of control of the decision-makers (Figure 1). 


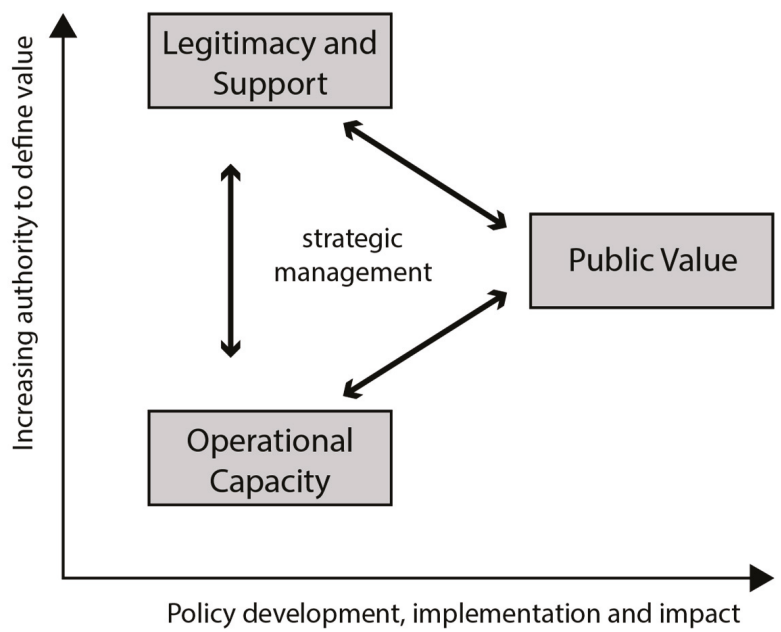

Figure 1. The Strategic Triangle (Moore [31])

In this paper, we regard the $\mathrm{CE}$ as a public value that, however, is 'still in the making.' While a lot of attention has already been given to describing the legitimacy and support of the $\mathrm{CE}$, especially during recent years (cf. [41]), arguably less attention has been given to the operational capacity to enhance a CE. Moore [31] defines the operational capacity as the developed capacity to achieve the desired result. Translated to the $\mathrm{CE}$, we understand the operational capacity thus as the capacity within a given location, in this case Ghent (Flanders) and Amsterdam (The Netherlands), that can enable activities to become (more) circular. While these activities can be also software or orgware, in this paper we focus on the hardware operational capacity, understood as the technical capacity to make existing production and consumption processes more circular. Moore's triangle thus enables us to link the political and public administrative side of the $\mathrm{CE}$ with the operational capacity, which is an economic and technical view on the CE. In other words, the triangle checks if the policy ambitions are in line with the existing economic operational capacity. If the legitimacy and operational capacity is aligned, according to Moore [31], a public value can emerge. However, methodologically, it is arguably impossible to assess the operational capacity of the CE. Every product has different parts, which have, again, different applications and require different (re)production processes. In addition, in geography and time, these differ significantly. Therefore, we take into account the non-, or negative-operational capacity of the CE, based on the ladder of Lansink (Figure 2).

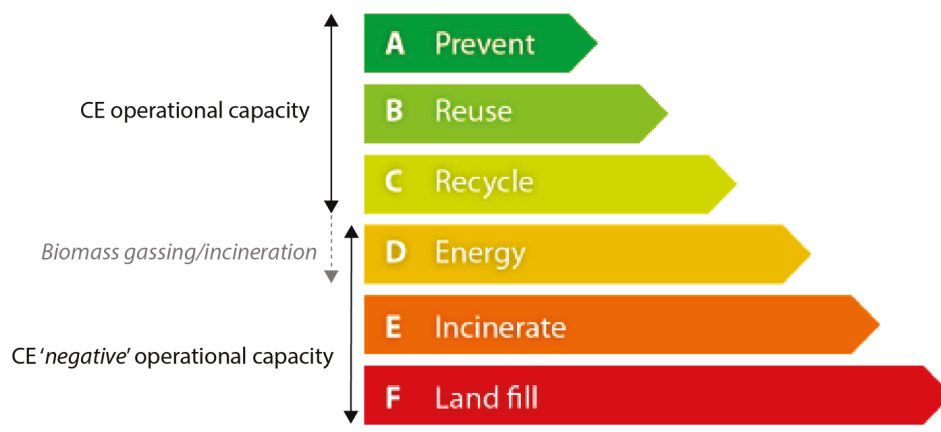

Figure 2. The ladder of Lansink and the (negative) operational capacity of the circular economy (CE) (source: authors). 
Different from the 'positive' CE operational capacity, the 'negative' operational capacity is the same for all products and materials: all materials or waste that are sent to a landfill or are being incinerated cannot be recycled or reused. Otherwise stated, landfills and incinerators can be seen as the CE's negative operational capacity, arguably thus producing a negative circular public value. Note that many incinerators also generate ('green') energy, given that waste-to-energy solutions have been considered to deliver 'green' energy according to the European directives on renewable energy and on biomass [42]. We, however, take incinerators into account that burn all kinds of waste, or residual waste, including biomass. Biomass that is collected separately, is being exclusively gassed and/or incinerated to generate energy, is here not included and can be regarded as a 'grey zone' for sustainable development (Figure 2). Nonetheless, we are aware of the contested status given the many perverse incentives that possibly annihilate the reduction of the environmental impact; for example, by growing forests for incineration or by importing bio-waste, thus generating transport-related emissions and impact [43].

To assess the current public value of CE, we will map the (un)alignment between the CE public management legitimacy and support, and the economic and technical CE negative operational capacity. We focus hereby on the port cities of Ghent and Amsterdam, respectively in Flanders (Belgium) and The Netherlands. We have chosen these two port cities because, first, both Flanders and The Netherlands are seen as forerunners in waste management within Europe [44,45]. Second, while both the cities of Ghent and Amsterdam have stated clear circular policy ambitions for their urban economies, also their ports-and thus their port authorities-have put the CE as a central policy ambition for their maritime economies. Third, arguably, port cities are administrative regions or municipalities wherein both (re)consumption and (re)production can (potentially) be organised. Internationally, in general, two main categories of waste are distinguished: household waste and company waste. Within port cities, these two categories are present in significant amounts. Fourth, in regard to a full CE, port cities can potentially become places were thus (re)consumption and (re)production is better aligned, an argument that is today already used within the discourse of the port of Amsterdam to safeguard its license to operate [22]. Summarized, port cities can offer a lens on the challenges between the alignment of CE policy ambitions and the CE operational capacity to facilitate this. We base our analysis on a historical analysis of the waste management in Flanders and The Netherlands, eventually assessing Moore's triangle today.

\section{Results}

\subsection{The EU Waste Reduction Policies}

The European Commission (EC) has a long tradition on regulating waste and supporting recycling activities. For municipal waste (MSW) the important directives are the Packaging and Packaging Waste Directive (94/62/EC) [46], the Landfill Directive (1999/31/EC) [47], the Directive on the incineration of waste (2000/76/EC) [48], and the Waste Framework Directive (WFD, 2008/98/EC) [49]. The latter sets the bar of minimum 50\% recycling, increased to $60 \%$ by 2025 and $65 \%$ by 2030, in its 2015 report [10]. Nonetheless, discrepancies in their implementation and the Union's aspiration to become more circular by the middle of this century, made an amendment of WFD needed. Perhaps, one of the main reasons for a Directive change was the Waste-to-Energy debate on its role in the CE. While the WFD resorts on Lansink's ladder, some authors and organizations (e.g., Zero Waste Europe, Global Alliance for Incinerator Alternatives) believed that much more attention was put on incineration than on waste prevention and recycling [50]. Proof of this is that the EC highlights the opportunities for energy recovery through incineration in its Science Hub, through an article by Scarlat et al. [51] setting the potential for almost 250 new incineration and co-firing plants in Europe. Directive 2018/851/EC [52] came to amend the WFD with the aim of transforming current European's waste management into sustainable material management, providing a definition of material recovery apart from energy recovery, and, among other measures, seeks to avoid support to landfilling and incineration among local and regional authorities. Likewise, the European Green Deal [53] privileges the opportunity to 
expand sustainable and job-intense economic activities, sustainable product policies with the potential of significant waste reduction, and the stimulation of a potential lead market by developing new technologies and sustainable innovative solutions to waste.

\subsection{Flanders-Ghent}

The institutional waste landscape in Belgium is regionalized (cf. Flanders, Brussels, and Wallonia). First, for household waste, every region is responsible for the waste plans, while—as in most European countries-municipalities are responsible for the collection and treatment. During the second half of the 20th century, municipalities increasingly experienced difficulties to cope with the growing amount of waste [54]. There were several reasons for this. First, the increased use of artificial fertilizers in the agriculture sector turned human, animal, and organic waste useless. Second, increasingly gas and gasoline were used to centrally heat buildings, making families let go of their 'individual' waste-to-energy: their fireplaces. Third, the increasing consumption society resulted in an increase of plastics and packaging materials that not only increased the amount of waste, but also became mixed with other (re)usable waste, thus making it all unusable. This resulted eventually on its top during the 1970s, in around $250 \mathrm{~kg}$ residual, or unusable, waste per capita per year-in total 1.5 million tonnes-that was generated in Flanders [54]. At that time, there was almost no treatment opportunity for this residual waste. The standard procedure was to dump the waste into large landfills or to (non-filtered) incinerate it, only sporadic with waste-to-energy. From the beginning of the 1970s, the Belgian state increasingly started to subsidise incinerators. An important reason was the oil crisis, which made waste-to-energy more lucrative [54]. Incinerators remained, however, more expensive than landfills. Within Flanders/Belgium, numerous landfills existed and, although there were protests [54], they remained an important destination for national and international waste. Illustrative is that, in 1979, the municipality of Amsterdam intended to dump 400,000 tonnes of household residual waste in the municipality of Rupel [54], which was eventually cancelled [54]. Eventually, in 1983, it was forbidden to use the Flemish landfills for non-Flemish waste. However, since waste is regionalized in Belgium, for years, Dutch residual waste was landfilled in Wallonia [54,55].

From the mid-1970s, the first separate waste collections were organised. Following the European directive on waste [56], also Belgium, and thus Flanders, had to come up with a waste plan. Because of the political restructuring of Belgium, the Flemish decree on Waste Products eventually came into force in 1985 [57] and became renewed every five years [54]. This first plan focused on regulating, closing, and cleaning the existing numerous landfills (in 1983 there were 455 landfills, of which only one-third had a permission, [54]) to optimize the use of incinerators and to increase the separate collection of waste. During the 1980s, the total of household waste, from which first $31 \%$ was combusted and $44 \%$ went to a landfill, changed to $55 \%$ and $20 \%$, respectively [54].

In 2018, on average $468.5 \mathrm{~kg}$ per person per year was collected in Flanders. Of this household waste, $68.9 \%$ (up from $10 \%$ in 1988 , [54]) was recycled $(44.2 \%$ ) or composted $(21.5 \%)$. This resulted in $145.6 \mathrm{~kg}$ per person per year as residual waste [58]. Of this residual waste, after, for example, sand is separated, $91.3 \%$ is incinerated with energy recuperation ( $30 \%$ of the total amount of waste). Among the residual waste, more than half $(56 \%)$ is still recyclable or compostable [58]. Hence, to further encourage the municipalities to increase the prevention and the separate collection of waste, the Flemish Public Department of Waste (OVAM) has set the bar on average in Flanders to $138 \mathrm{~kg}$ per person per year in 2022 [59].

Next to household waste, there is company waste. For a long time, company waste did not receive any attention as the economy prevailed over ecology. However, during the 1970s, especially the treatment of the enormous quantities of often-dangerous industrial waste became an important political debate in Flanders. Until then, in most cases, industrial waste was being dumped on land or in the sea or being incinerated on land or via large incinerator ships. If this was not possible, industrial waste was exported. However, the European Union started to forbid dangerous waste being 
transported across borders (finalized in [60]). Similarly to household waste, company waste treatment became a mandatory aspect, and to date, it is being separated into reusable and residual waste.

In Flanders, the total household waste in 2018 was 3,087,209 tonnes (Figure 3). Of this, 959,204 t were household residual waste (around $70 \%$ is thus at least recycled). After another legal specification of waste handling, for example, the exclusion of sand and other non-flammable elements, 91.3\%, or around 876,000 tonnes went to an incinerator [58]. Annually, around 8 million tonnes of company waste are generated (2016: 8.2 Mtonnes) [61]. Around 85\% is reused, thus higher than for household waste, while around $15 \%$ is incinerated or landfilled ( 881,036 tonnes). While the household residual waste had decreased from 1,016,604 tonnes in comparison with 2013, company residual waste saw an increase of $5.8 \%$. Even corrected with the increased employment, relatively, company residual waste increased, implementing that it has to decrease by $15 \%$ towards the 2022 goal. OVAM [58] did an analysis on the company residual waste and found that around $44 \%$ of the waste could be reused.

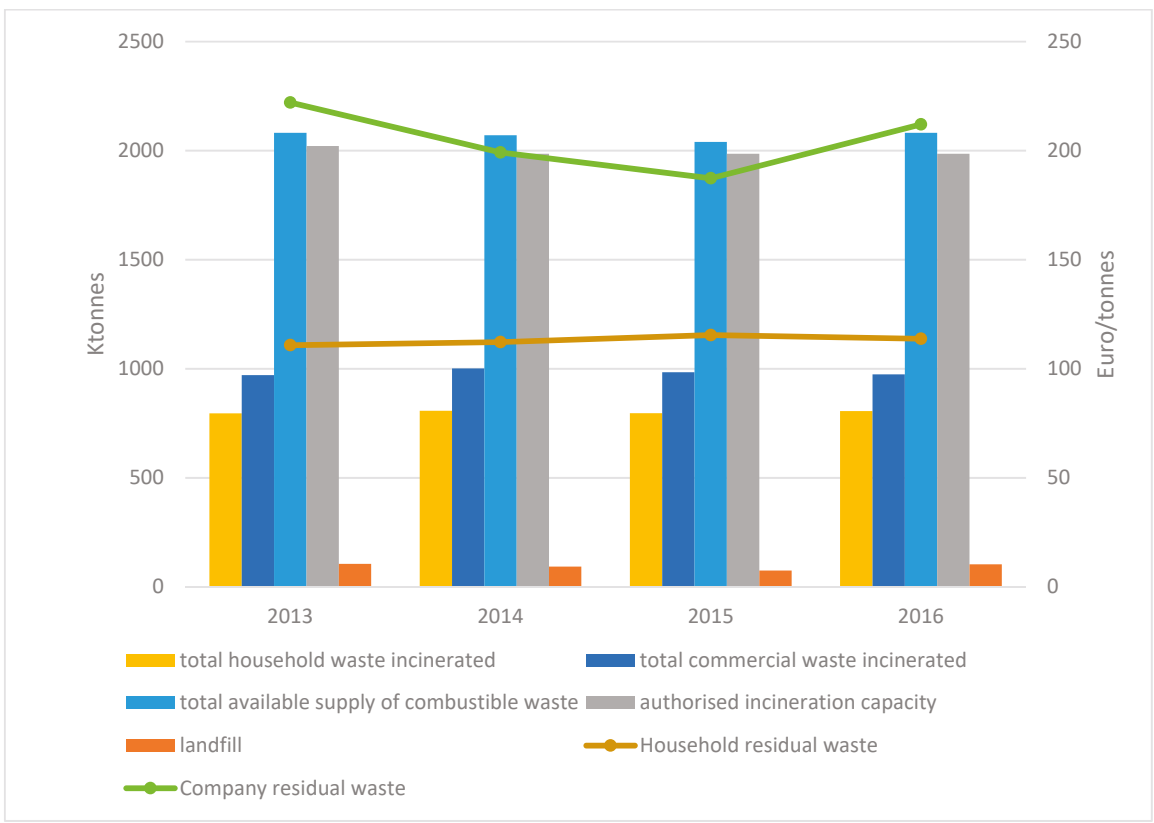

Figure 3. The total and deviation of amount of incinerated waste and landfill in Flanders, and the evolution of the prices for incineration in Flanders (figure: authors). Note that these prices are a combination of taxes (around 10\%) and operational costs. For company residual waste, the prices are a combination of the two prices for low and high calorific waste [62].

In total, taking also into account other smaller residues, there was a total supply of almost 2 million tonnes (1,978,224 tonnes) of waste that could be incinerated in 2018. This is higher than the available incinerator capacity in Flanders, which is $1,867,754$ tonnes. In other words, within Flanders, in 2018, there was a shortage of around 80,000 tonnes incinerator capacity [62]. This deficit is being exported or (temporally) sent to a landfill (Figure 3). In 2020, an extra 100,000 tonnes capacity will be opened, which, in other words, will imply that the total supply of household and company waste is approximately the same as the capacity of incinerators in Flanders. OVAM, via the Flemish Government, actively controls the total capacity of incinerators in Flanders [59]. The basic idea here is to encourage separating and reusing waste, and only in a last stepping to combust it [54]. By capping, and gradually lowering, the incinerator capacity in Flanders, the prices for incineration are deliberately kept relatively high (Figure 3), to thus encourage higher steps on the ladder of Lansink. 
Ghent is a port city located in the west of Flanders. The city hosts around 250,000 inhabitants. In 2018, the port of Ghent merged with the Dutch port of Zeeland, creating the European North Sea Port (NSP) port authority. Both the city as well as the port authority have stated their circular ambitions [63-65]. First, the city of Ghent has put the CE as an inclusive resilient future of its urban economy that is able to lead the transition of its employment structure. Under this umbrella, it has put six themes to the forefront: mobility/logistics, circular building, water, materials, food, and local production. In general, the city of Ghent plans to achieve a CE whereby materials are reused as much as possible, combining a network view (of actors and materials) with a geographical view (to keep it as local as possible) [65]. Moreover, Ghent explicitly states that it wants to become a 'glocal' production place, whereby as much as possible is produced locally, with global import and export where needed [64]. Ghent operates its own incinerator where it combusts the residual waste of its inhabitants. The incinerator has a capacity of 100,000 tonnes per year that generates heat and electricity for its own purposes as well as for a nearby hospital. The capacity is sufficient to process the residual waste of Ghent and several neighbouring municipalities [54].

Second, the North Sea Port has an overall sustainable strategy to strive for climate neutrality of 50\% in 2030 and $100 \%$ in 2050 [63]. To achieve this, it prioritizes four strategies: (i) sustainable energy production, (ii) the use of hydrogen, (iii) circular production, and (iv) the storage and use of $\mathrm{CO}_{2}$. In practice, on the one hand, the NSP is a partner, with the city of Ghent among others, of the Cleantech Cluster Ghent, wherein via subsidies and projects circular practices are subsidised. On the other hand, the NSP will further extend its Flemish/Dutch pipeline infrastructure within its port area and towards the hinterland, whereby both materials as energetic products (e.g., $\mathrm{CO}_{2}, \mathrm{H}_{2}$ ) can be exchanged [66].

\subsection{The Netherlands/Amsterdam}

During the 20th century, similar to Belgium and many other countries, waste treatment was the responsibility of local municipalities. The dominant processing of waste was via landfills. However, following the increased economic activity, the amount of waste grew and also the contamination of it by synthetic products [67]. During the 1970s, the ecological cost and the impact on our planet became higher on the agenda, notably by the Club of Rome [68]. Within the European Union, The Netherlands, arguably, took a leading role in the regulation of the waste sector. Illustrative is that parliament member Ad Lansink became linked to the then-introduced 'ladder of Lansink' (Figure 2), which is yet much referred to as a leading principle for sustainable development [55]. Therefore, this is different from Belgium. The Netherlands, some ten years earlier, in 1979, introduced laws regulating chemical and regular waste. Consequently, it became very difficult to keep on using landfills. As these laws did forbid the import of waste-the opposite of today-they did not forbid the export of waste. Thus, since the landfills in Flanders were not yet strictly regulated, soon a significant flow of residual waste was transported from The Netherlands to Flanders and, after 1983 until the 1990s, to Wallonia $[54,67]$.

During the 1980s and the beginning of the 1990s, a significant restructuring took place of the Dutch waste infrastructure. The main concern was to better organize the waste processing capacity of Dutch waste, instead of exporting it to other countries (e.g., Belgium). Therefore, a significant increase of public investments in incinerators took place, and the responsibility became centralised to the national level.

In 2018, 8.5 million tonnes of household waste were collected. This results in $494 \mathrm{~kg}$ per inhabitant per year, a decrease of around $60 \mathrm{~kg}$ since 2008; $206 \mathrm{~kg}$ consisted of residual waste (34.8\%), $288 \mathrm{~kg}$ were collected separately $(65.2 \%)$. Absolutely and relatively, these figures per capita are comparable with Flanders. In total, around 3 million tonnes of household waste annually were combusted [69]. Next, around 4.5 million tonnes of company residual waste were combusted in 2018 [70]. Different from Flanders, no combustible residual waste was sent to landfills (Figure 4). 


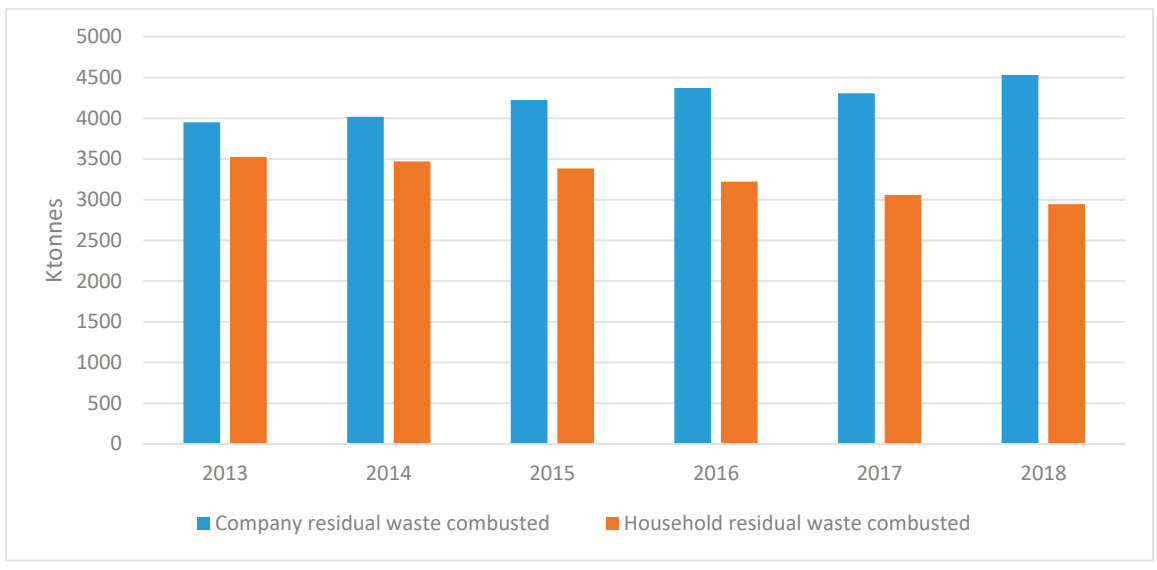

Figure 4. The amount of company and household residual waste combusted and the total landfill (figure: authors, data from [70]).

The reason for this is because the incinerator capacity in The Netherlands is significantly higher than the supply of combustible waste. While in 1980 the incinerator capacity was 2.2 million tonnes, this increased to almost 8 million tonnes today [55]. (Figure 5). The increase of incinerator capacity was needed to prevent the growing amount of waste from being landfilled. Especially by the end of the 1990s, new incinerator technologies were introduced to further reduce the emissions through placing filters and optimising the energy recovery of the plants. In addition, the Dutch Government encouraged the use of the residuals to make concrete, especially for road and infrastructure constructions. From the 1980s to the beginning of the 21st century, the incinerator capacity doubled [67].

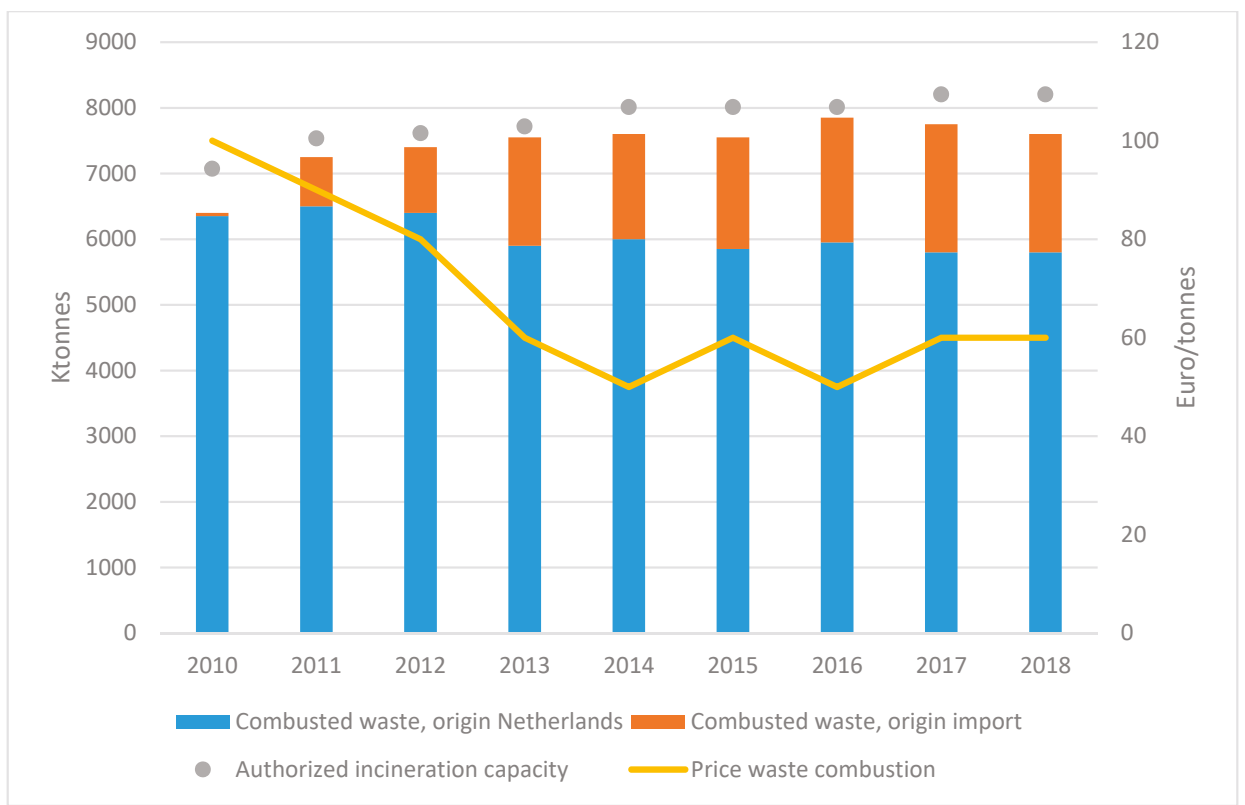

Figure 5. The amount and origin of combusted waste, the authorized incineration capacity in The Netherlands, and the evolution of the price of combustion (figure: authors, data from [70]). 
From the beginning of the 21st century, an important shift occurred in the Dutch waste policy [55]. Waste became regarded as a valuable economic good. While this was derived in the first place from an ecological point of view, a consequence was also that the waste became an economic market and, as all other economic markets, should have its own (inter)national regulations and privatized companies. This led to the fact that, in 2006, it was allowed that non-Dutch waste could be imported, while until now, exporting waste is still taxed highly. Thus, the waste management of The Netherlands became linked with the waste management of other countries. As explained by [67], the situation in the 2000s was that The Netherlands had chosen incinerators and re-use as the main options; Belgium focused on consumers and recycling, and the United Kingdom for landfilling.

During the last decade, a lot has changed. First, in The Netherlands, the amount of combustible waste kept on decreasing and is supposed to decrease towards 5 million tonnes in 2022. At the same time, the incinerator capacity kept on growing. This led to two intertwined effects. First, an overcapacity of incinerators illustrated that, since 2010, 1 million tonnes capacity has been added. Since incinerator plants need a minimal operational flow of waste, foremost waste from the United Kingdom is today imported to The Netherlands, around 1.5 million tonnes today. Remarkable is that, during the beginning of the 2010s, within policy reports this was perceived environmentally positively [71]. This was based on the difference of environmental effects of or sending waste to landfills in the United Kingdom or transporting this waste to The Netherlands towards its incinerators; the latter thus being more environmental positive than the former. Without going further into that in this paper, this changing point of view is a consequence of taking into account or not the effect of 'problem displacement' [25], or here, arguably, the opposite 'problem inclusion.' While with problem displacement there is a lack of responsibility to tackle the (environmental) problem, here one is dependent on the lack of responsibility of another actor. Second, the price of incineration decreased significantly, from around 100 euros per tonne in 2010 to around 65 euros per tonne today (Figure 5). This is significantly lower than in Flanders.

Arguably, within The Netherlands, the port and city of Amsterdam are leading in terms of CE ambitions. Already in 2015, the city of Amsterdam launched its circular plan, which has been renewed in 2020 [72,73]. The city has appointed three focus areas: food and organic flows, consumption goods, and the built environment. These are three of the five focus areas appointed by the Dutch Government [12]. Of these five, the industrial sector and plastics are not appointed as a priority for the city of Amsterdam [72]. The port authority of Amsterdam has put the CE as part of its central strategy since 2016 [74]. Since then, CE has only become more important for the port authority within its strategy, albeit this is part of its strategy to defend its license to operate following the particular situation with the city of Amsterdam regarding a land use conflict between maritime and urban land use $[75,76]$. Remarkably, this land use conflict is using on both sides the CE discourse, albeit different 'parts' of the CE are chosen [22]. The city authority, aiming to redevelop an existing maritime area close to the city into a new residential area, uses circularity within its plans linked to the built environment. Their reasoning is that the new built area will be constructed in a circular way (e.g., design, material use) that will help to achieve its CE ambitions. The port authority, though, uses circularity understood in (re)production processes. They claim that the area under discussion is needed to host circular functions (e.g., waste treatment) that are located as close as possible to the city; this to avoid thus the effect of 'problem displacement' $[25,26]$.

\section{Discussion}

Using this triangle as a framework, we can now bring our results together (Figure 6). Our results show that, arguably, Flanders and The Netherlands in terms of waste management have switched positions recently. The Netherlands, with their early national waste management plans, were during the 1970s and 1980s a forerunner in terms of sustainable development. Illustrative for this is that their national ladder of Lansink became also an internationally known strategic and policy tool for short- and long-term environmental policy [27]. While at that time the incinerator capacity 
in The Netherlands was not sufficient, significant flows of waste were sent to landfills in Flanders and later to Belgium. This shows that, in Flanders, ecology was not high on the policy agenda, and the (linear) economy prevailed.

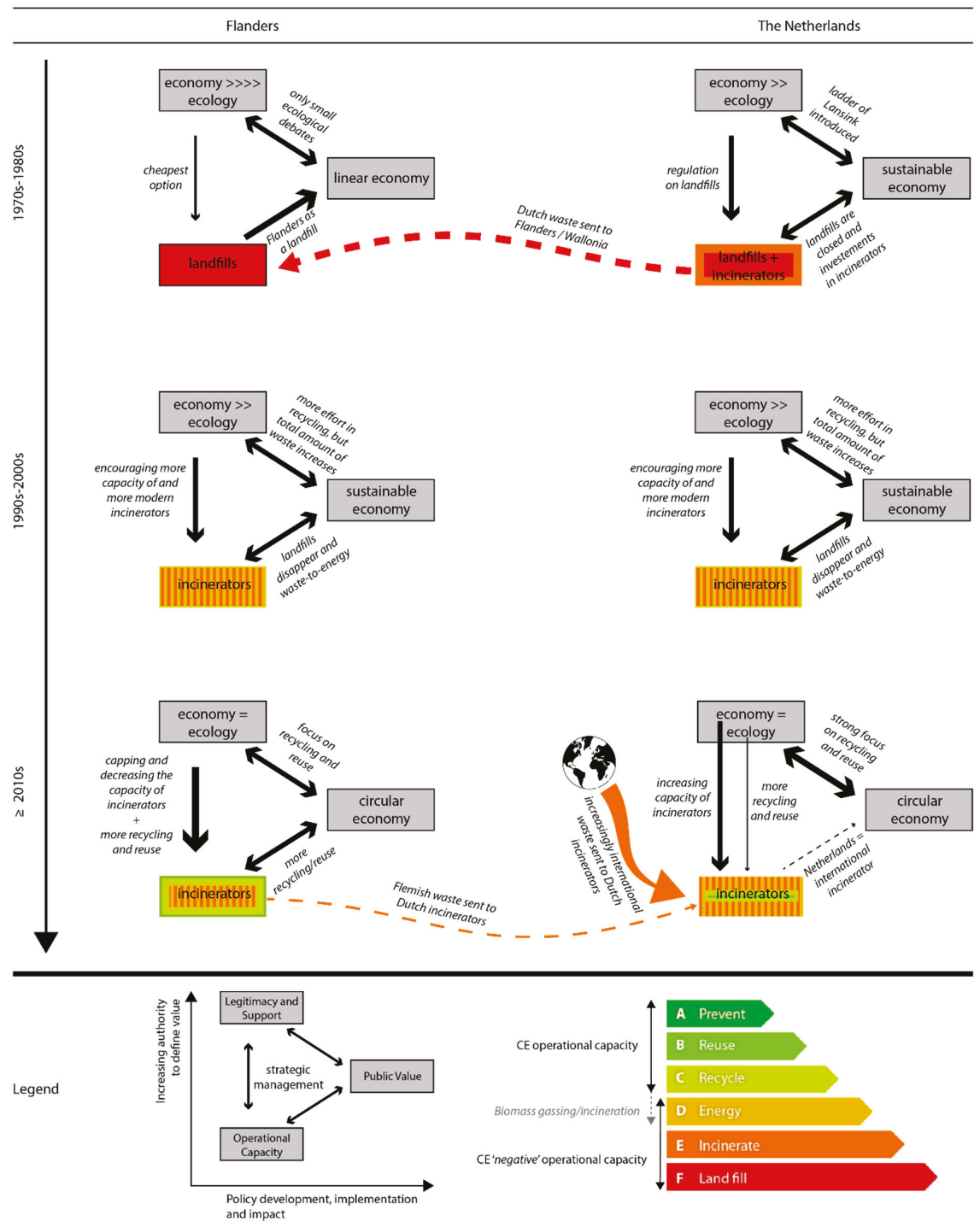

Figure 6. The result of the mapping of the evolution of waste management in Flanders and The Netherlands, using the triangle of Moore and the ladder of Lansink (1995) (source: authors).

During the 1990s, Flanders gradually caught up with The Netherlands. Incinerators were built and modernised, and, at the same time, attention was given to recycling and reuse. Nonetheless, the amount of waste kept on growing, both in Flanders and in The Netherlands, following the increased economic activity and the growth of population. However, landfills gradually were closed, 
and, in both Flanders and The Netherlands, relatively more waste was recycled, with incineration and, finally, landfill as last resorts.

\section{The Legacy of an Internationally Oriented New Public Management Hinders a Balanced Local-Oriented CE Triangle}

This brings us to the centre of the triangle of Moore [31]: strategic management. As explained, to successfully create a public value, one needs to align the legitimacy and support with the operational capacity-hence the strategic management. In light of creating the $C E$ as a public value, two essential aspects are needed: (i) the recycling, reuse, or refuse of materials, and (ii) striving to do these as local as possible. The first aspect is used to foster innovation and increased employment $[15,34]$ in the existing activities or to attract non-existing activities and employment in that particular region. The second is used to link this to the spatial planning of such innovative CE. Both aspects explain to some level—next to for example climate change goals—why many local administrative governments, like port cities, put the $\mathrm{CE}$ as a central policy ambition for their economies. This will demand, especially in The Netherlands, a difficult transition. With the dawn of the 21st century, The Netherlands had optimized their waste management. At this moment, an arguably lock-in emerged that focussed on waste incineration. We understand lock-in here as the situation whereby two systems, in this case waste management and waste treatment, are so much linked to each other that the situation in one of the systems hinders, or locks, the other one from evolving. This lock-in between the ladder of Lansink and the incinerator capacity explains why the strategic management towards a CE of the port city of Amsterdam is more limited than the one of the port city of Ghent. The lock-in of Amsterdam can be linked to two main reasons. First, increasingly the European environmental ambitions were heightened. In particular, the European Commission raised its ambitions on renewable energy sources (RES) for electricity (RES-E) and transport (RES-T). According to Hoppe and van Bueren [77], Dutch shares of RES were disappointing compared to the Union's ambitions, for the Dutch electricity system is "best described as a fossil-based thermal system, dominated by inexpensive natural gas and coal as main production sources" (p. 67). Likewise, the modest target of $9 \%$ by 2010 and $17 \%$ in 2020 of the Directive 2001/77/EC [78] on RES-E was not seen as a threat, since RES-E was produced from biomass and different types of waste were considered as such. The latter brings us to the second main reason. From the beginning of the 2000s, The Netherlands—in line with NPM-began to see waste as an economic good and incinerators as assets that could be financially break-even and rely on forms of self-regulation within the regulatory framework set by central and local governments. This created an internationally oriented incinerator market in The Netherlands. In other words, the NPM principles here got mixed with the sustainable goals of waste-to-energy as an ideal win-win solution: manage waste, while increasing the share of 'green' energy, as demanded by the EU.

This is in contrast to Flanders, where the capping of the maximum allowed amount of incinerator capacity was deliberately kept low, and from 2022 even will decrease. The prices to incinerate are therefore significantly higher in Flanders than in The Netherlands, especially during the last decade. The lock-in in The Netherlands has even increased, as more and more waste-to-energy incinerators have been connected to heat networks, also to decrease the use of natural gas. Consequently, there is an increasing demand of this type of generated heat, thus an increased need to combust waste. This makes the (local) energy system dependent on waste combustion. More recently, this became a greater challenge, because, as in the rest of Europe, increasingly the CE is embraced, and thus the prevention of waste is strived for. Already in the figures, it can be seen that the total amount of residual waste is decreasing. Therefore, not only because of the increased capacity of incinerators, but also of the increased link with local heating networks, The Netherlands has to import waste.

To summarize, if one wants to assist the (potential of) local CE strategic management, one should analyse how the triangle is (un)aligned (Figure 7). Only in this way, the potential of a CE within a port city, and thus the (re)connection of port and city, could be achieved. Essential for a CE is that materials 
are at least recycled, but also remain as local as possible. Such localization requires not only dedicated and consistent regulative frameworks across scales and sectors, but also an operational capacity that is not (only) aimed at optimizing economic drivers, but also takes into account the ecological aspects of these.

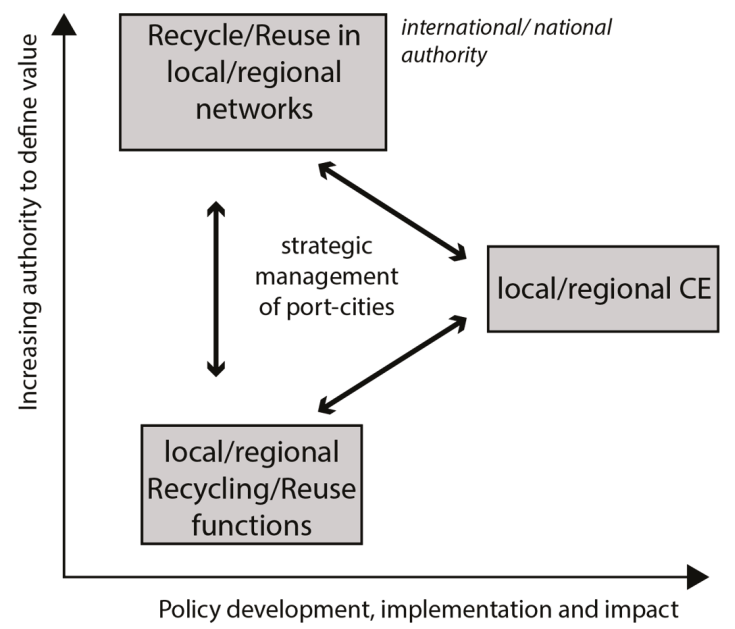

Figure 7. The strategic management of port cities to create a local/regional CE.

\section{Conclusions}

This paper focussed on the potential of the CE strategic management of local port cities, by not focusing on them in the first place. Local authorities, in cases such as the port cities of Ghent and Amsterdam, have increasingly put forward the $\mathrm{CE}$ as their core future socioeconomic business model. Similar to other concepts in the past, increasingly, policy documents and ambitions are formulated in this field. Arguably, Amsterdam is seen as an (international) forerunner, both the urban government as the port authority, following their clearly stated ambitions and regulations (cf. [79]). As explained by Moore [31], it is, however, also necessary that these policy ambitions are aligned with the operational capacity to enable the emergence of the CE as (local) public value. In other words, urban regions which have the space for and/or already host industrial (re)production or logistical functions, have a higher potential to adapt to a CE compared to urban regions which, to date, do not have the space and/or industrial (re)production or logistical functions.

Our results show that, in this respect, the CE policy ambitions of Ghent are more realistic than those of Amsterdam. In The Netherlands, in light of NPM, the waste management sector has developed towards an internationally oriented incinerator sector, competing on market prices. During the last decade, the capacity of incinerators has increased, while the price has decreased significantly. In addition, increasingly the incinerators have been linked to waste-to-energy heat networks, creating all together a lock-in between waste management and waste treatment, resulting in that the ladder of Lansink 'is stuck on' the incinerator step.

Bringing this back to Amsterdam, in reality, it is increasingly relatively more expensive to recycle, reuse, or refuse materials, than to incinerate waste. Thus, if at least circular programs are not subsidised or increasingly other factors (e.g., social and/or environmental externalities) are taken into account within the price, the circular business models of Amsterdam-based companies and organisations - and thus also the overall circular ambition of the port city of Amsterdam-, are less realistic compared to Ghent's. In Flanders, the incinerator capacity is capped and decreasing, keeping the incinerator price high to make recycling, reusing, or refusing more interesting over incineration. 
This will only become more if social and/or environmental externalities (e.g., $\mathrm{CO}_{2}$ ) are taken into account. If the legal framework and support are further improved (e.g., making it fiscally more interesting to reuse materials, create 'circular labels'), the operational capacity to enhance the CE (e.g., clusters) is more likely to happen.

Such context holds important policy recommendations for port cities and other governmental organisations. Creating a CE is not only about posing ambitious circular goals or to put all efforts in a successful story that lends itself ideally for marketing. The real challenge is to align the existing circular operational framework with these ambitions, fostering changes in the systems of production and consumption at operational levels rather than changes over the whole system, or transitions usually urged for. Especially for ports and their port authorities, that host international companies thriving on global production and supply chains, it is a challenge to help transit their business case towards locally recycling, reusing, or refusing of materials as much as possible. While much attention now goes to the 'positive' circular operational capacity such as establishing pipelines or altered (re)production processes, another way is to decrease the 'negative' circular operational capacity such as landfills and incinerators and thus decrease the 'negative' circular public value. If this is done, the incentive to, first, move up on the ladder of Lansink and, second, to remain as local as possible, will become bigger, therefore the potential of the policy ambition to let the CE emerge as a local public value.

Author Contributions: K.V.d.B. is the main author of the article. He has set up the idea and structure of the paper and has done the empirical research and writing. F.B.A. helped with the European legislation, E.v.B. helped with the theoretical part. All authors have read and agreed to the published version of the manuscript.

Funding: This research was partly funded by the expertise centre Accelerating the Circular Economy in Zuid-Holland (ACCEZ) of the Dutch province of South-Holland (grant number PZH-2018-658193468).

Acknowledgments: Although this paper was written during Covid-19 isolation time, we want to thank colleagues and the online discussions that helped to improve this paper. We also want to thank four anonymous reviewers for their valuable comments.

Conflicts of Interest: The authors declare no conflict of interest and the funders had no role in the design of the study; in the collection, analyses, or interpretation of data; in the writing of the manuscript, or in the decision to publish the results.

\section{References}

1. Harrison, J. Seeing like a business: Rethinking the role of business in regional development, planning and governance. Territ. Politics Gov. 2020, 1-21. [CrossRef]

2. Agnew, J. The territorial trap: The geographical assumptions of international relations theory. Rev. Int. Politics Econ. 1994, 1, 53-80. [CrossRef]

3. Bauwens, T.; Hekkert, M.; Kirchherr, J. Circular futures: What will they look like? Ecol. Econ. 2020, 175, 106703. [CrossRef]

4. Geissdoerfer, M.; Savaget, P.; Bocken, N.M.; Hultink, E.J. The circular economy-A new sustainability paradigm? J. Clean. Prod. 2017, 143, 757-768. [CrossRef]

5. Ghisellini, P.; Cialani, C.; Ulgiati, S. A review on circular economy: The expected transition to a balanced interplay of environmental and economic systems. J. Clean. Prod. 2016, 114, 11-32. [CrossRef]

6. Su, B.; Heshmati, A.; Geng, Y.; Yu, X. A review of the circular economy in China: Moving from rhetoric to implementation. J. Clean. Prod. 2013, 42, 215-227. [CrossRef]

7. UN. Circular Economy: The New Normal? United Nations: New York, NY, USA, 2018.

8. OECD. Business Models for the Circular Economy. Opportunities and Challenges from a Policy Perspective; Organisation for Economic Co-operation and Development: Paris, France, 2019.

9. COM. A New Circular Economy Action Plan. For a Cleaner and More Competitive Europe; European Commission: Brussels, Belgium, 2020.

10. COM. Closing the Loop-An EU Action Plan for the Circular Economy; European Commission: Brussels, Belgium, 2015.

11. Vlaamse Overheid. Vlaanderen Circulair. Een Stuwende Kracht Naar een Circulaire Economie in Vlaanderen; Vlaamse Overheid: Brussels, Belgium, 2017. 
12. Dutch Government. Nederland Circulair in 2050; Dutch Government: The Hague, The Netherlands, 2016.

13. Hobson, K. Closing the loop or squaring the circle? Locating generative spaces for the circular economy. Prog. Hum. Geogr. 2015, 40, 88-104. [CrossRef]

14. Carlson, A.; Burtraw, D. Lessons from the Clean Air Act: Building Durability and Adaptability into US Climate and Energy Policy; Cambridge University Press: Cambridge, UK, 2019.

15. PBL. Outline of the Circular Economy; PBL Netherlands Environmental Assessment Agency: The Hague, The Netherlands, 2019.

16. Reike, D.; Vermeulen, W.J.; Witjes, S. The circular economy: New or Refurbished as CE 3.0?-Exploring controversies in the conceptualization of the circular economy through a focus on history and resource value retention options. Resour. Conserv. Recycl. 2018, 135, 246-264. [CrossRef]

17. Zink, T.; Geyer, R. Circular economy rebound. J. Ind. Ecol. 2017, 21, 593-602. [CrossRef]

18. De Wit, M.; Hoogzaad, J.; Von Daniels, C. The Circularity Gap Report 2020; Ruparo: Amsterdam, The Netherlands, 2020.

19. Sunley, P. Relational economic geography: A partial understanding or a new paradigm? Econ. Geogr. 2009, 84, 1-26. [CrossRef]

20. McCombs, M.E.; Shaw, D.L.; Weaver, D.H. New directions in agenda-setting theory and research. Mass Commun. Soc. 2014, 17, 781-802. [CrossRef]

21. Valenzuela, F.; Bohm, S. Against wasted politics: A critique of the circular economy. Ephemer. Theory Politics Organ. 2017, 17, 37.

22. Van den Berghe, K.; Vos, M. Circular area design or circular area functioning? A discourse-institutional analysis of circular area developments in Amsterdam and Utrecht, The Netherlands. Sustainability 2019, 11, 4875. [CrossRef]

23. Sayer, A. Method in Social Science: A Realist Approach; Routledge: London, UK, 2010.

24. Van den Berghe, K.; Jacobs, W.; Boelens, L. The relational geometry of the port-city interface: Case studies of Amsterdam, the Netherlands, and Ghent, Belgium. J. Transp. Geogr. 2018, 70, 55-63. [CrossRef]

25. Korhonen, J.; Nuur, C.; Feldmann, A.; Birkie, S.E. Circular economy as an essentially contested concept. J. Clean. Prod. 2018, 175, 544-552. [CrossRef]

26. North, P. Eco-localisation as a progressive response to peak oil and climate change-A sympathetic critique. Geoforum 2010, 41, 585-594. [CrossRef]

27. Van den Berghe, K.; Dabrowski, M.; Ersoy, A.; Wandl, A.; van Bueren, E. The circular economy as re-emerging industry and the importance of the role of space [working paper]. Delft Univ. Technol. 2020. [CrossRef]

28. Swyngedouw, E. Globalisation or 'glocalisation'? Networks, territories and rescaling. Hist. Econ. Soc. Bull. 2004, 17, 25-48. [CrossRef]

29. Burger, M.J.; Stavropoulos, S.; Ramkumar, S.; Dufourmont, J.; Van Oort, F. The heterogeneous skill-base of circular economy employment. Res. Policy 2019, 48, 248-261. [CrossRef]

30. Storper, M. The Regional World: Territorial Development in a Global Economy; Guilford Press: New York, NY, USA, 1997.

31. Moore, M. Creating Public Value: Strategic Management in Government; Harvard University Press: Cambridge, MA, USA, 1995.

32. Hendriks, F.; Tops, P. Local public management reforms in the Netherlands: Fads, fashions and winds of change. Public Adm. 2003, 81, 301-323. [CrossRef]

33. Moore, M.H. Recognizing Public Value; Harvard University Press: Cambridge, MA, USA, 2013.

34. Schumpeter, J.A. Capitalism, Socialism and Democracy; Routledge: New York, NY, USA, 2003.

35. Rittel, H.W.J.; Webber, M.M. Dilemmas in a general theory of planning. Policy Sci. 1973, 4, 155-169. [CrossRef]

36. Beck, U. Risk Society: Towards a New Modernity; SAGE Publications: London, UK, 1992.

37. Wade, W. Scenario Planning: A Field Guide to the Future; Wiley: Hoboken, NJ, USA, 2012.

38. Hoetjes, P.J. Mapping the Market: A Portfolio Approach for Informed Deliberation of Urban Development Strategies. Ph.D. Thesis, University of Amsterdam, Amsterdam, The Netherlands, 2010.

39. Amer, M.; Daim, T.U.; Jetter, A. A review of scenario planning. Futures 2013, 46, 23-40. [CrossRef]

40. Boons, F.; Spekkink, W. Verinnerlijking van milieuverantwoordelijkheid in de Nederlandse chemische industrie. Over de complexiteit van meervoudige processen; Wetenschappelijke Raad voor het Regeringsbeleid: The Hague, The Netherlands, 2015. 
41. Salomone, R.; Cecchin, A.; Deutz, P.; Raggi, A.; Cutaia, L. Industrial Symbiosis for the Circular Economy. Operational Experiences, Best Practices and Obstacles to a Collaborative Business Approach; Springer: Berlin/Heidelberg, Germany, 2020.

42. Hoppe, T.; Van Bueren, E.; Solorio, I.; Jörgens, H. From frontrunner to laggard: The Netherlands and Europeanization in the cases of RES-E and biofuel stimulation. In A Guide to EU Renewable Energy Policy. Comparing Europeanization and Domestic Policy Change in EU Member States; Solorio, I., Jörgens, H., Eds.; Edward Elgar Publishing: Cheltenham, UK, 2017.

43. Bentsen, N. Carbon debt and payback time-Lost in the forest? Renew. Sustain. Energy Rev. 2017, 73, 1211-1217. [CrossRef]

44. EEA. Resource Efficiency and Circular Economy in Europe-Even More from Less. An Overview of Policies, Approaches and Targets of Belgium in 2018; European Environment Agency: København, Denmark, 2019.

45. EEA. Resource Efficiency and Circular Economy in Europe-Even More from Less. An Overview of Policies, Approaches and Targets of The Netherlands in 2018; European Environment Agency: København, Denmark, 2019.

46. European Union. Directive 94/62/EC on packaging and packaging waste. In 94/62/EC; European Union: Brussels, Belgium, 1994.

47. European Union. Directive 1999/31/EC on the landfill of waste. In 1999/31/EC; European Union: Brussels, Belgium, 1999.

48. European Union. Directive 2000/76/EC on the incineration of waste. In 2000/76/EC; European Union: Brussels, Belgium, 2000.

49. European Union. Directive 2008/98/EC on waste and repealing certain Directives. In 2008/98/EC; European Union: Brussels, Belgium, 2008.

50. Malinauskaite, J.; Jouhara, H.; Czajczynska, D.; Stanchev, P.; Katsou, E.; Rostkowski, P.; Thorne, R.; Colón, J.; Ponsá, S.; Al-Mansour, F.; et al. Municipal solid waste management and waste-to-energy in the context of a circular economy and energy recycling in Europe. Energy 2017, 141, 2013-2044. [CrossRef]

51. Scarlat, N.; Fahl, F.; Dallemand, J.-F. Status and opportunities for energy recovery from municipal solid waste in Europe. Waste Biomass-Valorization 2018, 10, 2425-2444. [CrossRef]

52. European Union. Directive 2018/851 amending Directive 2008/98/EC on waste. In 2018/851; European Union: Brussels, Belgium, 2018.

53. COM. Communication on the European Green Deal; COM: Brussels, Belgium, 2019.

54. OVAM. 30 jaar OVAM-De Openbare Vlaamse Afvalstoffenmaatschappij in Historisch Perspectief; Academia Press: Gent, Belgium, 2011.

55. Drift. Staat van Transitie: Dynamiek in Mobiliteit, Klimaatadaptatie en Circulaire Economie; Drift: Rotterdam, The Netherlands, 2019.

56. European Union. Directive 75/442/EEC on waste. In 75/442/EEC; European Union: Brussels, Belgium, 1975.

57. Vlaamse Overheid. Afvalstoffendecreet; Vlaamse Overheid: Brussels, Belgium, 1981.

58. OVAM. Huishoudelijk afval en Gelijkaardig Bedrijfsafval 2018; OVAM: Mechelen, Belgium, 2019.

59. OVAM. Uitvoeringsplan Huishoudelijk Afval en Gelijkaardig Bedrijfsafval; OVAM: Mechelen, Belgium, 2019.

60. COM. Basel Convention on the control of transboundary movements of hazardous wastes and their disposal. In 93/98/EEC; Council, E., Ed.; European Commission: Brussels, Belgium, 1993.

61. OVAM. Bedrijfsafvalstoffen Productiejaar 2004-2016; OVAM: Mechelen, Belgium, 2018.

62. OVAM. Tarieven en Capaciteiten Voor Storten en Verbranden. Actualisatie tot 2017; OVAM: Mechelen, Belgium, 2018.

63. NSP. Duurzaamheidsambitie 2030_Duurzaamheid werkt verder; North Sea Port: Ghent, Belgium, 2016.

64. Stad Gent. Lokaal en sociaal. Naar een Gentse Circulaire Economie; Stad Gent: Ghent, Belgium, 2018.

65. Stad Gent. Samen Circulair. Potentieel voor economie en werkgelegenheid in Gent; Stad Gent: Ghent, Belgium, 2018.

66. NSP. Onderzoek Clean Undergroudn Sustainable Transport (CUST); North Sea Port: Ghent, Belgium, 2019.

67. Loorbach, D. Transition Management. New Mode of Governance for Sustainable Development; Erasmus University Rotterdam: Rotterdam, The Netherlands, 2007.

68. Meadows, D.H.; Meadows, D.L.; Randers, J.; Behrens, W.W. The Limits to Growth. A Report for the Club of Rome's Project on the Predicament of Mankind; Universe Books: New York, NY, USA, 1972.

69. CBS. Nauwelijks meer afval, beter gescheiden; Centraal bureau voor de statistiek: CBS: The Hague, The Netherlands, 2019.

70. RWS. Afvalmonitor; Rijkswaterstaat: Utrecht, The Netherlands, 2020. 
71. CE Delft. Verbranden in Nederland of stroten in Groot-Brittannie? Milieukundige analyse van de verwerking van brits huishoudelijk afval in Nederland; CE Delft: Delft, The Netherlands, 2012.

72. Gemeente Amsterdam. Amsterdam Circulair 2020-2025 Strategie; Gemeente Amsterdam: Amsterdam, The Netherlands, 2020.

73. Gemeente Amsterdam. Amsterdam Circulair. Een visie en routekaart voor de stad en regio; Gemeente Amsterdam: Amsterdam, The Netherlands, 2015.

74. Amsterdam Port Authority. Jaarverslag 2015; Amsterdam Port Authority: Amsterdam, The Netherlands, 2016.

75. Van den Berghe, K. Planning the Port City. A Contribution to and Application of the Relational Approach, Based on Five Case Studies in Amsterdam (The Netherlands) and Ghent (Belgium); Ghent University: Ghent, Belgium, 2018.

76. Wiegmans, B.; Louw, E. Changing port-city relations at Amsterdam: A new phase at the interface? J. Transp. Geogr. 2011, 19, 575-583. [CrossRef]

77. Hoppe, T.; Van Bueren, E. Guest editorial: Governing the challenges of climate change and energy transition in cities. Energy Sustain. Soc. 2015, 5. [CrossRef]

78. European Union. Directive 2001/77/EC on the promotion of electricity produced from renewable energy sources in the internal electricity market. In 2001/77/EC; European Union: Brussels, Belgium, 2001.

79. Boffey, D. Amsterdam to embrace 'doughnut' model to mend post-coronavirus economy. The Guardian, 8 April 2020.

(C) 2020 by the authors. Licensee MDPI, Basel, Switzerland. This article is an open access article distributed under the terms and conditions of the Creative Commons Attribution (CC BY) license (http://creativecommons.org/licenses/by/4.0/). 


\title{
Article \\ Seaports as Nodal Points of Circular Supply Chains: Opportunities and Challenges for Secondary Ports
}

\author{
Marta Mańkowska ${ }^{1, *}$, Izabela Kotowska ${ }^{2}$ and Michał Pluciński ${ }^{1}$ \\ 1 Institute of Management, University of Szczecin, Cukrowa 8, 71-004 Szczecin, Poland; \\ michal.plucinski@usz.edu.pl \\ 2 Faculty of Engineering and Economics of Transport, Maritime University of Szczecin, H. Pobożnego 11, \\ 70-500 Szczecin, Poland; i.kotowska@am.szczecin.pl \\ * Correspondence: marta.mankowska@usz.edu.pl
}

Received: 23 March 2020; Accepted: 9 May 2020; Published: 11 May 2020

\begin{abstract}
This paper focuses on the development of secondary ports in the circular economy model (as a node of circular supply chains) to implement sustainable seaports in the context of the structural changes taking place in the global economy, trade, and maritime transport. The purpose of this article is to identify the opportunities, challenges, and key actions to be taken by secondary ports in circular supply chains. The research method applied was a single case study. The object of the study was the seaport of Szczecin (Poland). Our study showed that the secondary ports lacking technical conditions to serve large vessels, but with available space to develop their transshipment, storage, industrial, distribution, and logistics activities, may become major participants in circular supply chains. Taking advantage of the opportunities associated with participating secondary ports in the circular supply chain requires facing a number of challenges identified in the current literature, such as return-flow uncertainty, transport and infrastructure, the availability of suitable supply chain partners, coordination and information sharing, product traceability, and cultural issues. Our study partially confirms the significance of these challenges for secondary ports. The significance of these challenges depends on the kind of circular supply chain, i.e., whether the supply chain is a producer or a consumer chain. Our study shows that a very important challenge for both types of chains is the problem of internal resistance to change. This still-unsolved issue involves the persistent linear mindset of the port authority, which is manifested mainly as investor evaluation policy based exclusively on the declared annual transshipment volume, which fails to take actions to provide the available land plots with the infrastructure necessary for the terminals and industrial plants that participate in circular supply chains. Simultaneously, for secondary ports, we proved that it is stevedores (who are flexible and fast in adapting to new market conditions, strongly determined to search for new cargo types to replace those that have vanished, and who adapt the scope of their services) who play a key role in stimulating the development of circular supply chains. As a main managerial implication for the authorities of secondary ports, such authorities should create appropriate policies for investor assessments and the utilisation of available areas within the port premises to encourage the enterprises engaged in circular supply chains to invest in and develop their businesses within the port's premises. It is also necessary to develop appropriate communication between port authorities and their external stakeholders. As a managerial implication for the stevedores in secondary ports, these entities should first develop their service offers to address cargo as part of the circular supply chains (with more comprehensive service offers and added-value services, such as freight forwarding services, stuffing, packing, and mixing of cargo) and develop cooperation with other stakeholders of circular supply chains.
\end{abstract}

Keywords: circular economy; circular supply chain management; secondary seaports; port authority; stevedores 


\section{Introduction}

While the concept of sustainable and green ports has become the subject of numerous in-depth studies [1-6], the transformation of seaport business models towards a circular economy is a relatively new area of research. The concept of the circular economy is also perceived as a prerequisite for the sustainable growth of a seaport [7]. This approach is observable in the European Union (EU) policy [8-10], in which seaports that function within a circular economy model may constitute a driving force toward sustainable growth.

At the same time, the studies completed so far indicate that, due to the diversity of seaports and port cities, there cannot be a single, universal plan of action for a seaport to undergo a transition towards a circular economy model [11]. Taking into account the classification of seaports that distinguishes between primary, secondary, and tertiary ports [12], current studies on the transformation of ports towards a circular economy focus mainly on the analyses of case studies describing the primary ports in Europe and Asia that hold high competitive positions in the maritime transport market and have significant technological and innovative advantages, i.e., [4,13-16]. Pursuing a circular economy through these ports is mainly done via symbiosis with industry or research and innovation centres focused on a circular economy, while the purpose of those measures is to decrease dependence on fossil fuels, improve energy efficiency, optimise waste management, and increase the engagement of stakeholders in the planning of port development.

To date, no studies address issues related to secondary ports that aspire to implement a circular economy but have lesser technical parameters and operate on a smaller scale (often in a highly competitive environment of primary ports, for whom they fulfill complementary functions) [17]. For any ports of this category, striving for sustainable growth and implementing a circular economy may be a challenge. Secondary ports, to a large extent, are affected by any structural changes in the global economy, trade, and maritime transport, which are stimulated by the increasingly stricter climate policies [4,18-21]. The impacts of those changes on the operations of seaports are manifested by the gradual decrease in traditional bulk cargo groups (e.g., coal and ores) in port transshipment operations. Competitiveness among this category of ports is also limited by the technical parameters that prevent such ports from handling the increasingly larger vessels being put into operation. Consequently, secondary ports are under strong pressure to attract new cargo groups to replace the vanishing ones. A great opportunity for the sustainable development of these ports may be circular supply chains. However, to develop a competitive position with a secondary port as a node in circular supply chains, that port must first face several challenges.

The purpose of this article is to identify the opportunities and challenges, as well as the key actions, for secondary ports approaching circular supply chains. This study applied a single-case-study method for the secondary port in Szczecin (Poland). The results may be used by port enterprises and management bodies of other secondary ports that have similar potential and face similar challenges to help them elaborate their strategies for development as links in circular supply chains.

\section{The Literature Review}

The underlying assumption of a circular economy model is that waste is used as a resource in other parts of the value chain by shifting the focus to closing material loops through reduction, reuse, and recycling at the system level [22-25]. Therefore, the general purpose of the circular economy model is 'closing the loops' [8]. At the same time, the circular economy model does not focus exclusively on limiting the use of environmental resources as a sink for residuals but instead strives to create self-sufficient production systems in which materials are recycled [26-28].

The circular economy concept stimulates the creation of circular supply chains that make it possible for all products to re-enter the cycle as input materials at the end of their life cycles [29,30]. Nasir et al. [28], by comparing the linear and circular supply chain systems, proved that the circular supply chain makes it possible to reduce greenhouse gas emissions and that transport processes are responsible for more total emissions than the linear chain. At the same time, the enterprises in the study 
were not convinced that circular supply chains are cost-effective and did not think that obtaining social benefits was a sufficient argument to implement them, especially because the higher levels of circularity attained by the enterprises could be related to higher economic costs due to the increasing prices of resources [31]. The studies completed so far have also shown that the most successful enterprises in implementing reverse supply chains are those able to strictly coordinate their reverse and forward supply chains, thereby creating a closed-loop system and maximising value creation throughout the product life cycle. Nevertheless, reverse supply chains may also be open-loop chains when the materials are recovered by entities other than the original producers and used in the production of other products [32,33].

The related studies underline the key role of seaports in developing a circular economy [16,34-36]. Seaports, as industrial complexes and intermodal nodes with strong interconnections to the hinterland and urban areas, play the role of global centres that handle the flow of resources for which they create added value [37]. Moreover, their impacts reach far beyond the administrative borders of the port. Girard [25] emphasises that the circular economy model in seaports is a manifestation of a synergistic approach that combines economic, logistic, and industrial activities with the cultural heritage of the port and the port city, as well as the creativity of its public, which yields a dynamic, complex, and balanced system. Striving to implement a circular economy model through a port is a circularisation process of the port, which consists of industrial, urban, city-territorial, or regional symbiosis. The transition of the linear structure of major ports like Amsterdam and Antwerp towards circular models is facilitated by the presence of industrial parks, cluster interconnections, and urban centres in the vicinity [35]. In previous studies that consider the experiences of various countries and major ports (especially European, Asian, and North American ports), the circular economy activities comprise three levels: micro, i.e., reusing the waste flows within one company; mezzo, i.e., the industrial symbiosis between two or more companies within the port (the development of eco-industrial parks); and macro, i.e., establishing inter-regional port industry networks focused on exchanging recycled resources [13,23,24,38-40]. Notteboom et al. [16], based on the best practices of leading European ports such as Rotterdam, Antwerp, North Sea Port, and Zeebrugge, emphasize that, under the circular economy business model, the main port activities are the promotion of industrial ecology, the use of renewable energy sources, and the development of seaports as hubs for recycle flows. In this last case, seaports are core nodes (recycling hubs) in the circular supply chains whose recycling flows are delivered, transformed into new products, and re-exported around the world. The experience of primary ports, according to past studies, shows that the port authorities play the key role in stimulating the development of sea-land circular supply chains $[4,13,16,41]$.

At the same time, these studies $[4,18,20,21]$ demonstrate that seaports have to cope with many challenges determined primarily by structural and climatic changes. The circular economy concept may help seaports to increase their competitiveness in an economy with scarce natural resources, thereby facilitating the growth of their innovativeness and decreasing the negative impacts of port operations on the environment and the neighbourhood [42-44]. This particularly concerns the secondary ports threatened with obsolescence and dereliction resulting from, inter alia, the ongoing transformation of the port premises to fulfil urban and tourist functions while abandoning traditional port operations. Secondary ports are also known as minor, assisting, peripheral, feeder, regional, or small and medium-sized ports. In the most general terms, they are classified by their size, capacity, and throughput, which are smaller than those of national major ports [12,45-47], and more broadly by assessing their location, international connectivity, industries, logistics and distribution activities, relative cluster position, hinterland capture area, gross domestic product (of the port city and of the hinterland), and market share [12,48]. In terms of annual handling volumes, secondary ports are considered small and medium seaports - those with an annual handling volume of less than or equal to 10 million tonnes (small ports) and more than 10 million tonnes but up to and including 50 million tonnes (medium ports) [41]. 
The development of secondary ports is hindered mainly by factors such as the insufficient technical parameters preventing the ports from serving large vessels, deficient systems of hinterland transport, a lack of space for development, or an unfavourable regulatory framework. The transformation of secondary ports towards a circular economy thus constitutes an opportunity but also a challenge. Carpenter et al. [13] rightly point out that, for all ports, a key requirement for commercial and economic viability is to retain the business of the ships served by them and to remain accessible to those ships. Simultaneously, De Langen and Sorn-Friese [4] (based on the commodity composition of the United States' foreign trade and in-depth case studies of Dutch ports) indicate that even though the development of the circular economy model stimulates the emergence of circular industries within seaports, it may also contribute to a decrease in transshipment volumes in traditional bulk cargo groups (the outcome of the 'shortening' of supply chains). In our opinion, these effects of the transformation will be experienced most strongly by secondary ports. A greater engagement in the circular supply chains may be an effective solution to secure the future of secondary ports in this competitive and ever-changing environment, thus promoting the sustainable growth of the port and the port city and helping them maintain and develop their basic functions (i.e., ship serving).

However, previous studies rightly highlight the numerous challenges faced by seaports developing their activities in circular supply chains [49,50]. Linder and Williander [49] emphasize that the transition towards circular supply chains may raise challenges related to the uncertainty of the quantity, quality, and timing of product returns that arise, especially in closed-loop supply chains. The importance of return-flow uncertainty in circular supply chain management was also indicated by Bressanelli et al. [50]. The authors, using an in-depth literature review (63 papers) and their own research (the multiple-case-study method), identified 24 challenges to transition towards a circular economy, grouped into the seven categories of economic and financial viability, market and competition, product characteristics, standards and regulation, supply chain management, technology, and users' behaviour. For supply chain management challenges, in addition to return-flow uncertainty, the authors also point to such major challenges as the availability of suitable supply chain partners, higher transportation costs, and problems of coordination and information sharing.

To summarize, the studies completed so far on the transition towards a circular economy in seaports are mainly based on the experiences of major ports that have at their disposal high-quality infra- and superstructures, as well as appropriate regulatory frameworks and know-how. Such ports play the role of major hubs for large general and bulk cargo flows and are less affected by the structural changes taking place in the global economy. In general, these studies show that, in major ports, the process of circularisation pertains mainly to developing industrial symbiosis and implementing solutions that apply renewable energy sources. The studies completed so far have hardly addressed the opportunities and challenges faced by ports as recycling hubs in circular supply chains, particularly secondary ports, which this article focuses on.

\section{Materials and Methods}

The main steps of the overall research process are presented in Figure 1.

In the first stage, the literature review process was carried out, which highlighted an existing research gap. Then, the research method and main object of the research (a secondary port in Szczecin) were selected. This study applied the single-case-study method [51]. As pointed out in [52], single-case-based research enables direct observations and interactions that provide insights that are not possible from a distance. Following the principles of this method, the following research questions were formulated:

1. What are the main opportunities for secondary ports as nodes in circular supply chains?

2. What kinds of challenges are faced by secondary ports when approaching circular supply chains?

3. How do secondary ports respond to these opportunities and challenges? 
The object of the study was the seaport in Szczecin, as a link in sea-land circular supply chains. The seaport in Szczecin is one of the main universal seaports in Poland; it is located on the Baltic Sea and meets the criteria of a secondary port.

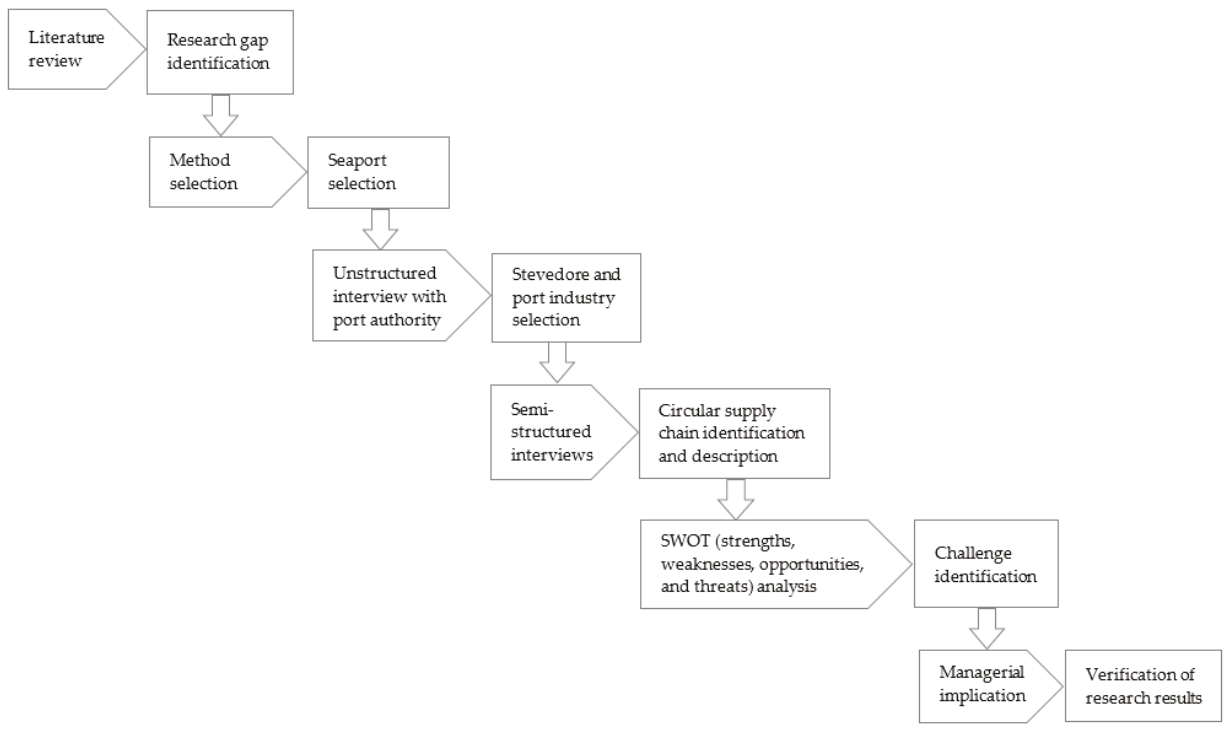

Figure 1. The main steps of the research process.

In recent years, this port has faced a number of challenges connected predominantly with the structural changes in the global economy, in trade and maritime transport, and in the Polish economy (political changes and the development of a free-market economy initiated in the 1990s), which have led to gradual decreases in the transshipment volumes of major bulk cargo, such as coal and ore, accompanied by an increased share of general cargo or cargo classified as 'other bulk cargo' (Figure 2).

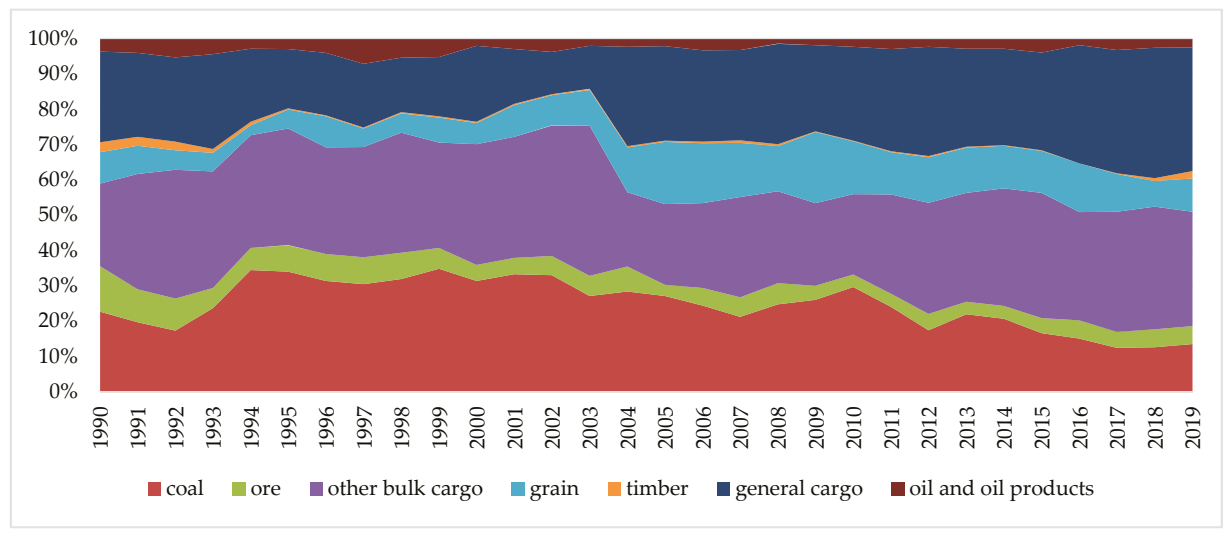

Figure 2. The breakdown of transshipment volumes in the port of Szczecin (1990-2019). Source: Compiled by the authors based on the Szczecin and Świnoujście Seaports Authority.

Handling the cargo flows moved within circular supply chains is a great opportunity for the port in Szczecin due to the lack of a possibility to handle large ships and the lack of interest of the operators 
of large specialised terminals, the availability of vast areas for investment, the possibility of being served by various hinterland transport modes (including inland shipping), the stevedores' experience in serving various cargo groups (which includes distribution and logistics services), and the location of port industry facilities and waste recycling plants [53].

To apply the single-case-study method to the period of January-February 2020, direct in-depth interviews were conducted among the companies operating in the port of Szczecin, such as stevedores and various port industries. An in-depth interview was also conducted with a representative of the Szczecin and Świnoujście Seaports Authority.

The first step of the study was to identify the entities engaged in the operating activities (stevedores) and industrial activities (port industries) in the port of Szczecin, connected (in whole or in part) with circular supply chains (the cargo flows involved waste or by-products in at least one direction). The entities were selected on the basis of our own observations and knowledge obtained by the literature review, studying the enterprises' websites, and information obtained via unstructured in-depth interviews held with a representative of the Szczecin and Swinoujście Seaports Authority. This information, along with statistical data on the volume and breakdown of port transshipments (in terms of cargo type and destination), helped to identify the target stevedore group, while the data on industrial activities (line of business) made it possible to identify the target port industry group.

Finally, out of the total group of 12 stevedoring companies running their operations in the port of Szczecin, 4 entities were selected for further study. Out of the 8 port industry entities, 4 were also selected for further study ( 3 of which dealt with pyrolysis and 1 with limestone grinding). Due to the temporary suspension of business activity, it was not possible to hold an interview with one of the pyrolysis plants. Consequently, interviews were only conducted with the representatives of 3 entities. The necessary data on the fourth entity's operations were obtained from the Szczecin and Świnoujście Seaports Authority, which made it possible to consider that entity in the research results. (See Table 1).

Table 1. Number and breakdown of the examined entities.

\begin{tabular}{ccc}
\hline Type of Entity & Stevedores & Port Industries \\
\hline Total number of entities active in the port in Szczecin & 12 & 8 \\
\hline Number of entities selected to be studied via the in-depth interview method & 4 & 4 \\
\hline Number of entities fully examined via the in-depth interview method & 4 & 3 \\
\hline
\end{tabular}

The second step of the study involved a semi-structured in-depth interview (held by phone and in person) of the 7 entities ( 4 stevedores and 3 port industries). The interviews were aimed at identifying the circular supply chains that involve the examined entities and operate via the port in Szczecin. The interviews were based on open-ended questions.

In the first part of the interviews with the stevedore representatives, the respondents were asked about their type of handled cargo. The obtained information made it possible to specify the kinds of cargo handled by the entities and to select the cargo types that are part of the flows of the circular supply chains. At this stage, it was necessary to explain to the representatives of said entities the idea of a circular supply chain. The respondents did not know the concept and were not aware that they participated in supply chains defined as circular supply chains. The second part of the interview was aimed at a detailed analysis of the flow and handling of the selected groups of cargo by the examined entities. The surveyed respondents were asked the following questions:

1. What are the directions of the analysed cargo flows (identification of cargo flow routes in the supply chain: place/country of departure)?

2. How is the cargo handled in the sea-land transport chains (identification of subsequent transport modes)?

3. What scope of cargo-related services is provided on the port premises (transshipment, storage, and additional services)? 
4. What are the main conditions for serving the analysed cargo groups and developing the relevant services (legal, market, organisational, social, and especially environmental factors)?

In the first part of the interviews with the port industry representatives (analogous to the stevedores), we focused on identifying the resources and products applied in the production operations and their intended use. Further into the interview, the subjects were asked questions analogous to those used for the stevedores (items 1-3) on the directions of the cargo flows, transport services, and the operating conditions for the examined groups of resources / semi-products / finished goods. Additionally, this group of respondents was also asked the following questions:

1. Does the applied production/processing technology have any adverse environmental impacts?

2. How is your cooperation with other entities on the port premises?

3. What are the perspectives for your business operations?

Apart from selecting the entities to be included in the study, the unstructured in-depth interview held with the Szczecin and Świnoujście Seaports Authority was also used to obtain information on the following:

1. Interests of the enterprises engaged in the international trading of waste/by-products, whose business activities are located in Szczecin port, including transshipment and storage services, additional services, and industrial operations.

2. The prerequisites for developing this kind of activity in the port of Szczecin with regard to the available land reserves (port premises management policies) and the cooperation between the port authority, stevedores, and port industries operating on the premises.

The main difficulties encountered during the interviews with all the respondent groups were the groups' lack of knowledge about the circular economy and circular supply chains. Moreover, for some industrial plants, it was not possible to obtain full information due to their business secrets.

The obtained data made it possible to identify and analyse in detail the sea-land circular supply chains running through Szczecin. Flows of the following cargo were analysed: steel products-scrap metal, copper concentrate-sulphuric acid, limestone-gypsum, car tyres-oil, soot, scrap metal, and wood waste-ground wood waste.

In the next stage of research, a qualitative strengths, weaknesses, opportunities, and threats (SWOT) analysis for the secondary port in Szczecin was performed. The main opportunities and challenges of the secondary port as a node in the circular supply chains were identified. Then, the main directions of the necessary remedial actions were determined. The challenges identified in the single case study of the seaport in Szczecin, in connection with the existing opportunities and directions of the postulated actions, were confronted with theoretical knowledge. In the last stage, we verified the obtained results by matching current theory with our empirical observations [52].

\section{Results}

\subsection{In-Depth Analysis of the Circular Sea-Land Supply Chain via the Port in Szczecin}

To illustrate the opportunities and challenges related to the transformation of seaport business models towards the circular economy as a prerequisite for sustainable seaport development (and considering the gradual decrease in the transshipment volumes of traditional bulk cargo), in-depth analyses of the circular supply chains served via the seaport in Szczecin were performed. This analysis included all supply chains currently passing through the port of Szczecin whose cargo flows involve waste or by-products (in at least one direction). The circular supply chains identified in this way were analysed in terms of their cargo flow routes, subsequent transport modes, cargo-related services, and the main conditions for their presence in the seaport (for legal, market, organizational, social, and especially environmental reasons).

Chain 1. Steel Products-Scrap Metal. 
One of the most frequently noted circular supply chains is the transport of steel products (product) and scrap metal (waste/resource). In the port of Szczecin, there are two variations of this chain, which differ by the degree to which the transshipment and industrial enterprises operating in the port engage in processing the cargo being moved within the chain.

In the first variant (1a), the port's role in the chain focuses exclusively on the operations of transshipment and the temporary storage of products (steel products, i.e., wire rods and reinforcement steel) and waste (scrap metal). Scrap metal is transported to the port from the foreland (mainly from Russia) using handy-sized vessels. The port handling operations are performed in the bulk area of the port in Szczecin. The scrap metal is carried on barges to the steelworks located in the port's transit hinterland where steel products are manufactured. On the reverse route, steel products, such as wire rods and reinforcement steel, are shipped to metal engineering and automotive plants in the distant and proximate foreland (ports located mainly in North America, Africa, and Europe). See Figure 3 for detailed cargo flow diagram and cargo flow model.

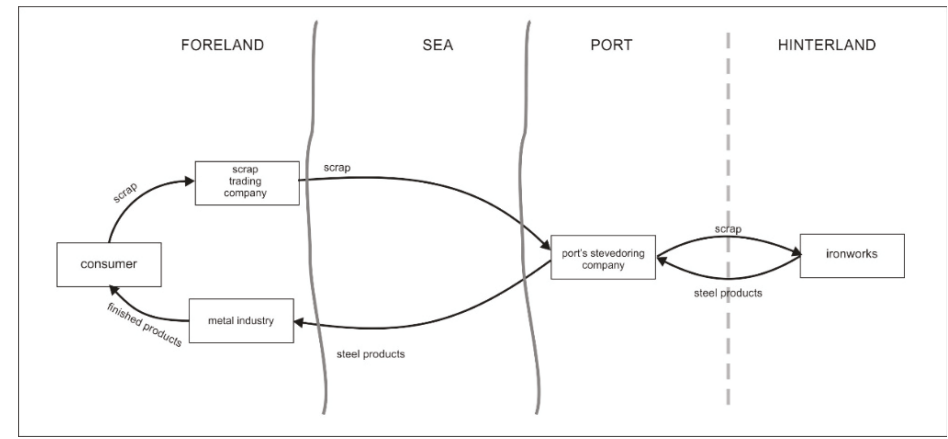

(a)

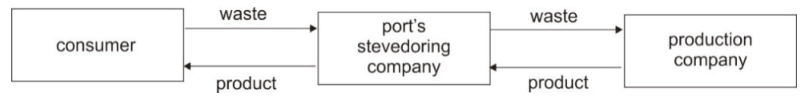

(b)

Figure 3. Example 1a: The supply chain loop for steel products-scrap metal. (a): detailed cargo flow diagram; (b): cargo flow model. Source: Compiled by the authors.

In the second variant $(1 \mathrm{~b})$, the flow of products and waste occurs in the opposite direction. Additionally, the variant includes the partial processing of waste, as well as additional operations related to cargo distribution and logistics. (See Figure 4)

Steel products are brought from the ports located in the foreland of the port in Szczecin (i.e., ports in Russia and Finland) to the general cargo and bulk areas in the port of Szczecin, where they are unloaded and stored. The cargo are delivered to consignees in the Szczecin port's hinterland by rail and road transport. On the reverse route, the waste (scrap metal) is brought from customers (mainly from Poland and Germany) by rail and road. In that case, however, port handling is not limited only to transshipment and short-term storage. Scrap metal goes to a dedicated, specialised terminal for processing and transshipment, where scrap metal mixes are prepared to meet the specific needs of specific metalwork. At the terminal, scrap metals are crushed and mixed with some components imported by maritime transport. The sea portion of the reverse chain comprises the transport of scrap metals to various consignees (metalworks) in the foreland of the Szczecin port (i.e., to Finland). 


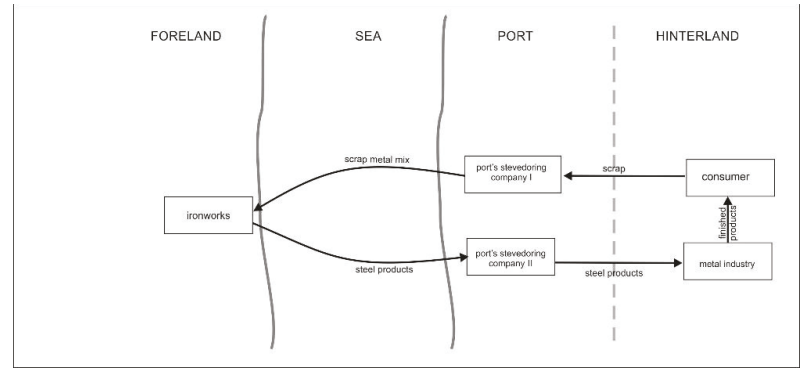

(a)

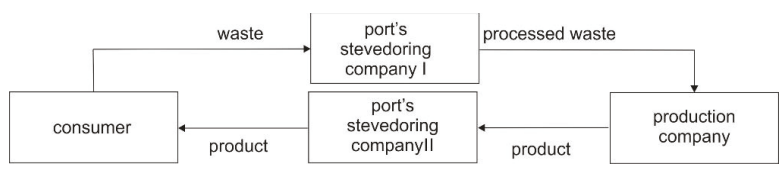

(b)

Figure 4. Example 1b: The supply chain loop for steel products-scrap metal. (a): detailed cargo flow diagram; (b): cargo flow model. Source: Compiled by the authors.

\section{Chain 2. Copper Concentrate-Sulphuric Acid.}

The second analysed supply chain encompasses the flow of resources (copper concentrate) and by-products of copper production (sulphuric acid). See Figure 5.

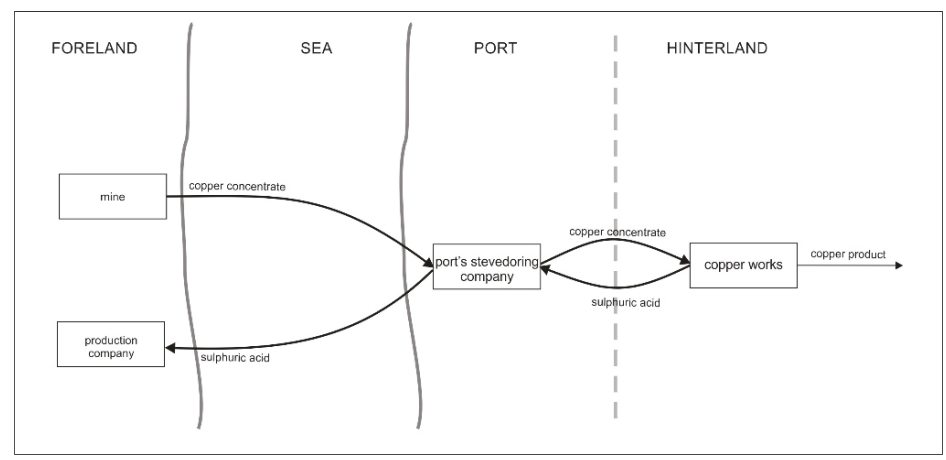

(a)

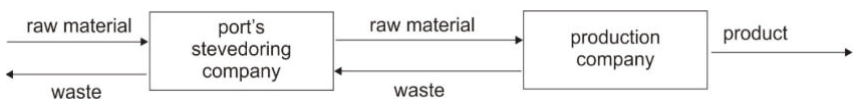

(b)

Figure 5. Example 2: The supply chain loop for copper concentrate-sulphuric acid. (a): detailed cargo flow diagram; (b): cargo flow model. Source: Compiled by the authors. 
The resource (copper concentrate) is brought from the distant foreland of the seaport in Szczecin (the ports of South America) and is transshipped in the bulk area of the seaport in Szczecin by a stevedoring company. The recipient is a large copper company in the distant hinterland, and the cargo is delivered by rail (using Talbot self-unloading wagons). On the reverse route, $98 \%$ sulphuric acid (post-industrial waste in copper production) is brought by tank wagons to the port in Szczecin. The port handling operations are performed by the same stevedoring company in a specialised terminal for sulphuric acid transshipment. The consignees of the acid located in the foreland are chemical plants (mainly manufacturers of fertilisers) located in Africa, Europe, and South America.

\section{Chain 3. Limestone-Gypsum.}

The third analysed supply chain comprises the flow of the resource (limestone) and post-industrial waste (gypsum). See Figure 6.

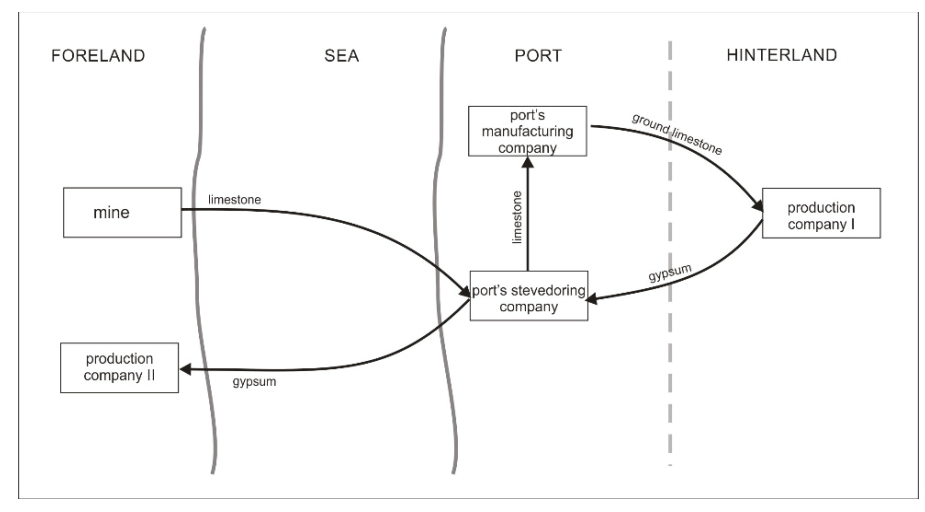

(a)

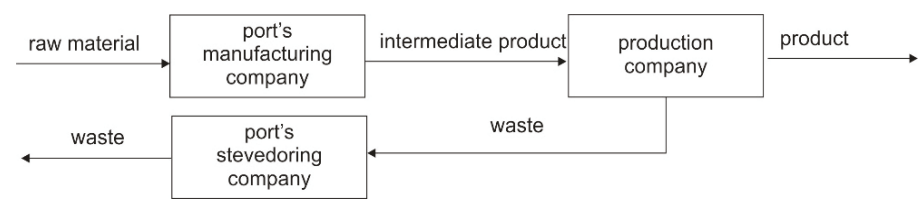

(b)

Figure 6. Example 3: The supply chain loop for limestone-gypsum. (a): detailed cargo flow diagram; (b): cargo flow model. Source: Compiled by the authors.

The resource (limestone) is supplied from Gotland with small coaster vessels to the port in Szczecin, where it is unloaded in the bulk cargo terminal. Next, the cargo goes to the limestone grinding plant located on the port premises. Following processing, a portion of the cargo is shipped by road transport to the (conventional coal-fuelled) power plant located in the proximate hinterland of the port, where the ground limestone is used to remove sulphur dioxide from flue gases. Synthetic gypsum is the return load. It is brought to the port in Szczecin by road transport, transshipped onto sea vessels, and carried to the ports in Sweden and then to building material manufacturers.

Chain 4. Tyres-Oil, Soot, Scrap Metal.

The fourth analysed supply chain encompasses the haulage of waste, including used vehicle tyres and products resulting from the processing of tyres (pyrolysis). See Figure 7. 


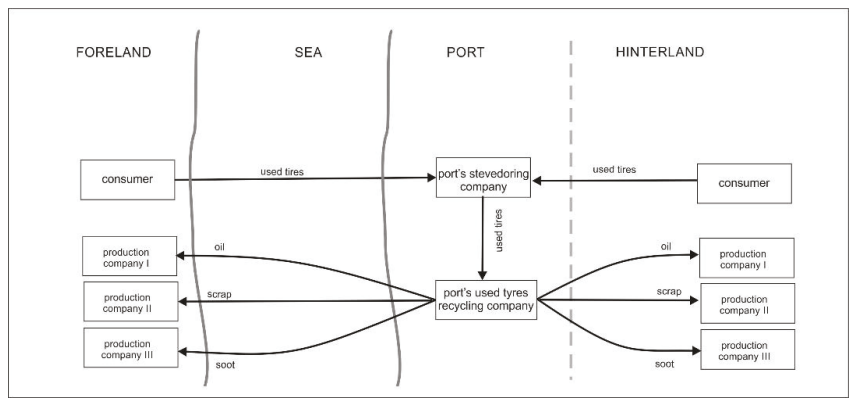

(a)

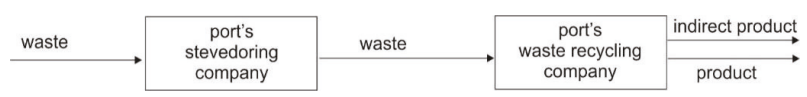

(b)

Figure 7. Example 4: The supply chain loop for tyres-oil, soot, and scrap metal. (a): detailed cargo flow diagram; (b): cargo flow model. Source: Compiled by the authors.

Used tyres are brought to the port in Szczecin both from the hinterland (by road transport from Poland and Germany) and from the port's foreland (both as bulk and containerised cargo). On the port premises, the used tyres are processed in two processing plants, located, respectively, in the general cargo area and in the industrial part of the port. The resulting products are scrap metal, soot, and oil. Currently, these products are shipped mainly to consignees located in the hinterland. Oil is the most popular among customers, as it is predominantly used as fuel and is one-third cheaper than conventional fuel oil. A potential target group for this oil could also be sea vessel operators. Based on an agreement with one of the companies, a tank for the storage and distribution of this oil by sea was constructed on the port premises.

The other product, soot, is also transported by road (with silo trucks) to customers in the domestic market. In the future, soot could also be shipped in a containerised form to overseas consignees. Soot is a resource used in the automotive industry for the production of rubber products such as car mats and new tyres (if sufficient quality can be assured). The third type of product resulting from the pyrolysis of tyres, scrap metal, is used in the metal industry.

Chain 5. Wood waste-ground wood waste.

The fifth analysed supply chain covers the flow and processing of wood waste as a resource for the power engineering sector. See Figure 8.

Polluted wood waste is delivered to the seaport in Szczecin from Swedish ports. The port handling services are performed in the bulk cargo terminal of the port in Szczecin by a stevedoring company. Then, the cargo is carried by inland shipping to a wood-waste processing plant in the proximate hinterland (cross-border transport to Germany). On the reverse route, ground wood waste is carried to the bulk cargo terminal in the port of Szczecin This cargo, which is lightweight and takes up significant space, is difficult to transship. Therefore, it requires a wider range of services apart from transshipment (e.g., compacting it on the ship). Next, the cargo is carried by sea to Swedish ports, from where it is delivered to power stations as biomass.

There are many factors important for creating the abovementioned circular supply chains via the seaport in Szczecin. For example, for the 'steel products-scrap metal' chains (1a, 1b), the most significant factor was waiving the obligation for companies to have permits for the cross-border transport of scrap metal in 2013. Obtaining these permits took much time and effort. Issuing a permit 
was dependent on indicating a concrete entity with which the company was to cooperate in serving the supply chain, as well as the cooperation time and estimated cargo (scrap metal) volume to be brought into the country. Apart from the proximate location in relation to the German market, an important factor was also the navigable inland waterway connecting Szczecin with the German inland waterway system (chain 1 and chain 5), the vast unoccupied areas within the port premises (suitable for the location of distribution terminals and industrial plants) (chain 1b, chain 2, chain 3), and the stevedore's guarantee of high-quality transshipment, distribution, and logistics services for the cargo in question (all the chains covered by the study). The study also showed that the durability of the identified sea-land circular supply chains via the secondary port of Szczecin is affected mainly by the rising domestic demand and changes in the destinations of waste deliveries and products as the objects of the transport flows. These factors cause a periodic and partial shifting of cargo flows from sea-land supply chains to land supply chains (chain 2, chain 3).

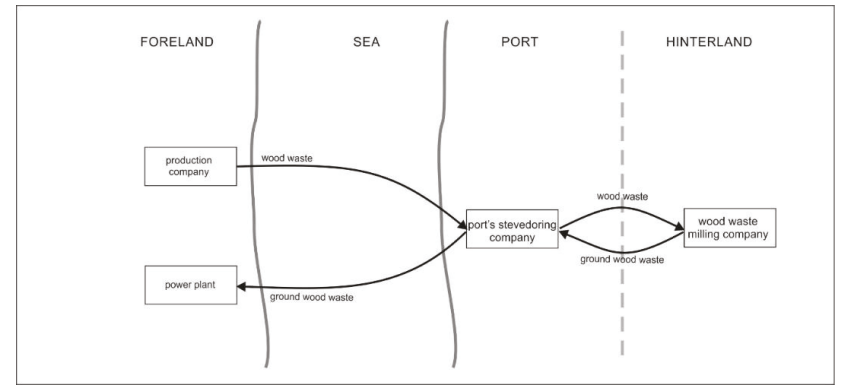

(a)

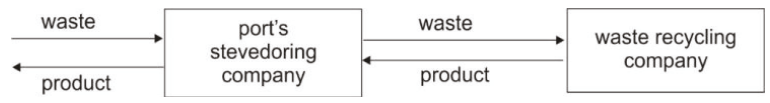

(b)

Figure 8. Example 5: The supply chain loop for wood waste. (a): detailed cargo flow diagram; (b): cargo flow model. Source: Compiled by the authors.

Moreover, the analysed examples indicated that the developing local cooperation between the entities participating in the circular supply chain (i.e., between stevedores and industrial plants and between stevedores and specialised distribution terminals) did not rule out further cooperation between the entities operating in the port with the circular supply chain links in the distant hinterland or more remote foreland. The decisive factor is the value of the cargo (waste) itself. For cargo of a low unit value (e.g., saw dust, gypsum, and scrap metal), the shippers strive to minimise the transport costs (proximate locations in the hinterland and in the foreland). In turn, for cargo with higher unit values (e.g., acid), the costs of transport are less important and are not a constraint when searching for partners, even in the more distant foreland of the port.

The analysed sea-land circular supply chains contribute to the diversification of the transshipment volume breakdown of the seaport in Szczecin (Figure 9).

An increasingly more significant share in the breakdown is held by cargo from the 'Other bulk cargo' group, which contains the above described by-products or waste. The share of this cargo category, excluding periodic decreases, has presented a rising trend since 2004, while the volumes of traditional cargo groups, such as the coal and ore transported in linear supply chains, have been falling. 


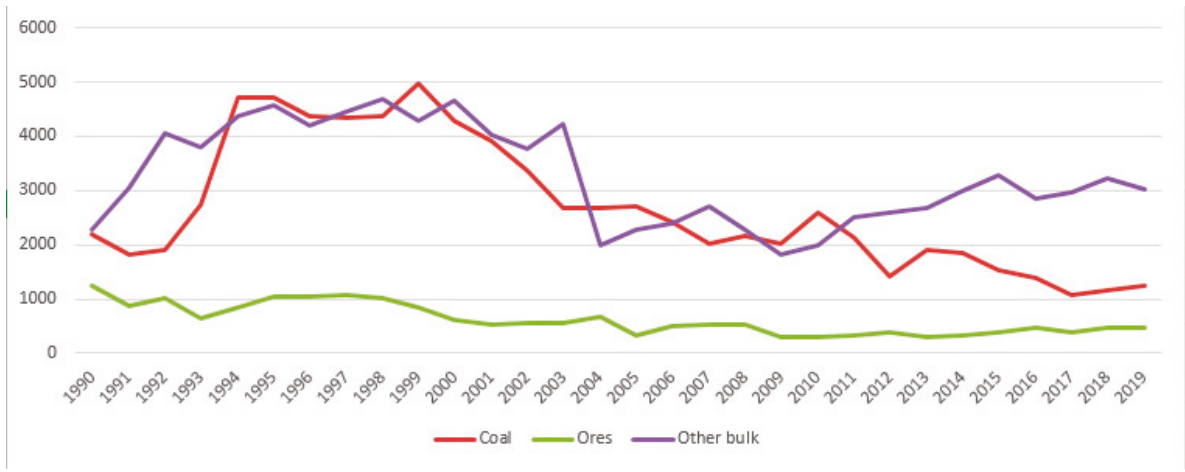

Figure 9. Changes in the port transshipment volumes in the analysed sea-land circular chains ('Other bulk cargo') compared to the transshipment of coal and ore in the seaport in Szczecin for 1990-2019 in k tonnes. Source: Compiled by the authors based on the Szczecin and Świnoujście Seaports Authority.

\subsection{SWOT Analysis for the Port in Szczecin Approaching Circular Supply Chains}

Taking advantage of the opportunities associated with the greater participation of the seaport in circular supply chains, as one of the ways to achieve sustainable development, requires tackling a number of challenges. To identify these challenges, a qualitative SWOT analysis for the port in Szczecin as a node in the circular supply chain was performed (Table 2).

Table 2. SWOT analysis for the secondary port in Szczecin as a nodal point in a circular supply chain.

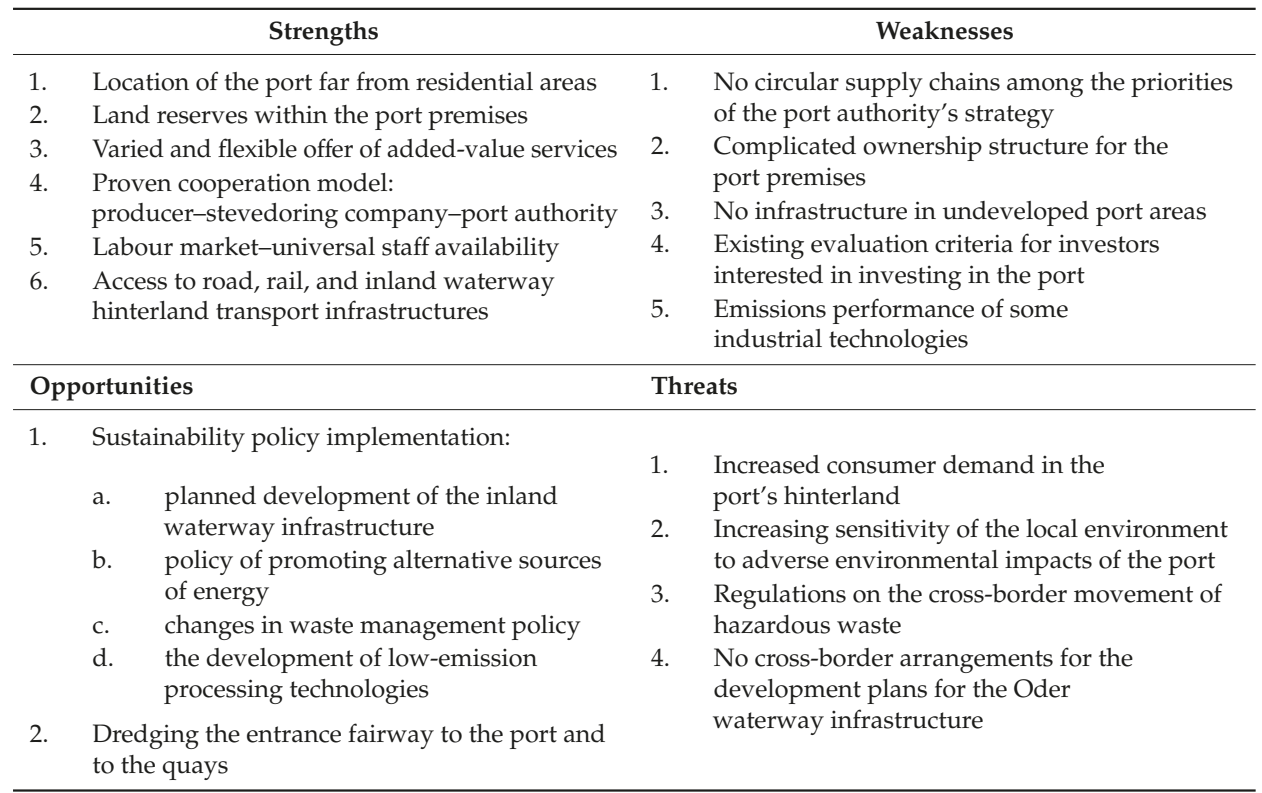

Source: Compiled by the authors.

Although circular supply chains do not generate large transshipment volumes, they generate considerable quantities of added-value services like the stuffing, packing, or mixing of cargo. A significant opportunity for developing these chains in the port of Szczecin, as well as in other seaports, lies in the activities connected to sustainability policy implementation, including the promotion of 
alternative sources of energy or changes in waste management that make it possible for industrial plants to obtain profits because they collected the waste.

Unfortunately, even though waste utilisation provides clear benefits in terms of environmental protection, some waste processing technologies generate considerable pollutant emissions. A clear advantage of the port in Szczecin is its location in an area excluded from residential functions. However, this does not limit the social pressure to mitigate the negative impacts of business activity on the local environment. A challenge and opportunity for the future growth of circular supply chains involving environmentally harmful processing is to apply new processing technologies. This is exemplified by the emission-free tyre pyrolysis technology developed in cooperation with academics and applied in practice (chain 4).

From the perspectives of various stakeholders of circular supply chains (e.g., industrial plants and distribution terminals), an important advantage of the examined port is the availability of land reserves on its premises. However, for the port in Szczecin, this land is undeveloped and lacks any hydrotechnical or land infrastructure (e.g., quays, electric power networks, a water supply, or sewage pipework). The priorities listed in the current strategy of the Szczecin and Świnoujście Seaports Authority do not include any provisions related to supporting circular supply chains through this port. Moreover, it seems that the measures generally applied by ports to evaluate investors (total turnover) disqualify any investors who are unable to declare large transshipment volumes (i.e., several hundred thousand tonnes per year). The transshipment of the cargo served in circular supply chains is much smaller (most often tens of thousands of tonnes per year), which, as per the current investor evaluation criteria, makes such ports unattractive to the port authority. A possible challenge and guideline to be followed by port authorities would be an enlargement of the investor evaluation criteria, e.g., including the environmental benefits of the planned activities (disposal / waste processing).

Another barrier to the development of circular supply chains in the analysed port is that some land plots to be used for business purposes belong to entities other than the port authority. This Authority has a pre-emptive right to purchase land plots. However, in recent years, the Authority has rarely availed itself of this right. Having all the land plots located on the port premises would provide a better possibility for the port authority to administer the land resources and would make it possible to establish new entities operating within circular supply chains.

An undoubted advantage of the examined port becoming a participant of circular supply chains is the varied and flexible services provided by stevedores, such as flexible transshipment and storage services, as well as additional services (e.g., freight forwarding) and added-value services provided in relation to the cargo in circular supply chains (e.g., chain 5, where stevedores provide typical handling operations, such as compacting the wood waste on the ship), as well as a wide range of services offered to industrial plants and specialised distribution terminals participating in such chains. This flexibility would not be possible without highly qualified staff, which is an advantage held not only by the analysed port. In secondary ports equipped with multitask terminals, qualified staff perform various works (e.g., on-site transport, stacking, stowage, and other handling operations). The said service offers are related to the trilateral cooperation model developed in the port: producer-stevedoring company-port authority. The process by which stevedores adapt to serving cargo as part of a circular supply chain is a permanent process that results from both the diversity of cargo and the added-value services accompanying the cargo flows, as well as the legal requirements connected with handling hazardous cargo in cross-border transport.

The strength of the studied port is its access to three modes of transport, including inland shipping, which is suitable for carrying low-value waste. An opportunity for the further growth of circular supply chains via this port is the national programme for developing the inland waterway infrastructure, which has been adopted and commenced, through which the Oder Waterway is set to be upgraded to achieve international waterway parameters. A threat for this programme implementation is the lack of coordination of activities in the cross-border area. 
Opportunities for the development of circular supply chains should be identified with the development project implemented within the current EU programming period, which consists of dredging the entrance fairway and the quay area up to $12.5 \mathrm{~m}$ (to serve fully loaded 40,000 DWT vessels instead of the present 20,000 DWT). The new parameters of the port infrastructure will contribute to improved competitiveness of the land-sea chains via Szczecin relative to the land chains (resulting from the growing demand for some types of cargo to be part of circular chains in the port's hinterland). Vessels with a two-times higher carrying capacity will make it possible to reduce the transport costs, which will enable the fulfilment of contracts with partners located in the port's more remote foreland. Some threats for circular supply chains may be connected to the following interdependence: serving larger ships requires the storage of larger consignments in the port, which requires more storage space. Consequently, there may be more pressure on using the last available areas provided with the infrastructure for purposes other than handling the cargo that is part of the circular supply chain. Therefore, it is important to coordinate any development projects aimed at improving the parameters of the existing port infrastructure with any development projects aimed at providing infrastructures in undeveloped parts of the port premises. Many secondary ports implement measures to serve larger vessels. Given that the port authorities' strategies do not aid circular supply chains, many new investors operating in circular supply chains may go unnoticed.

To generalize the obtained research results based on the SWOT analysis for the port in Szczecin, the identified challenges for secondary seaports connected with the development of circular supply chains were confronted with the current literature.

\section{Discussion}

The current literature has thoroughly investigated the challenges of circular supply chains. Great cognitive value can be found, for example, in the research results of Bressanelli et al. (2019) [50], which include a broad overview of the academic literature supplemented by empirical studies, thereby offering a source of current knowledge about the major challenges connected to the development of circular supply chains. However, these studies do not refer directly to land-sea chains. The challenges to circular supply chain development identified in the literature, compared to the research results for the secondary port in Szczecin, are presented in Table 3. Our study primarily showed that the relevance of particular challenges depends on the kind of circular supply chain. Based on the completed analyses of the circular supply chains running via the port in Szczecin, we identified the following two kinds of chains:

1. Consumer chains, which include the individual consumers from whom the waste originates (chains $1 \mathrm{a}, 1 \mathrm{~b}$, and 4 )

2. Producer chains, which include post-industrial waste or the by-products of industrial plants (chains 2, 3, and 5)

Table 3. Challenges of secondary ports when approaching circular supply: Current theory versus empirical observation.

\begin{tabular}{|c|c|c|c|c|c|c|}
\hline \multirow{2}{*}{$\begin{array}{c}\text { No./type of circular supply chain } \\
\text { Challenges: }\end{array}$} & 1a & $1 b$ & 2 & 3 & 4 & 5 \\
\hline & Consumer & Consumer & Producer & Producer & Consumer & Producer \\
\hline Return-flow uncertainty & $\checkmark$ & $\checkmark$ & o & o & $\checkmark$ & - \\
\hline Availability of suitable supply chain partners & - & - & - & - & - & o \\
\hline Coordination and information sharing & $\checkmark$ & $\checkmark$ & o & o & $\checkmark$ & o \\
\hline Cultural issues & & & $\begin{array}{l}\checkmark \text { for po } \\
\quad-\text { for } s\end{array}$ & $\begin{array}{l}\text { athorities } \\
\text { edores }\end{array}$ & & \\
\hline
\end{tabular}

Legend: $\checkmark \quad$ - applied; o $\quad$ - partly applied; - $\quad$ - not applied. Source: Compiled by the authors based on [50]. 
In the literature, the most frequently indicated challenge to circular supply chain development is return-flow uncertainty. However, the study conducted in the port of Szczecin only partially confirmed the importance of this challenge to secondary ports. This challenge is relevant predominantly to the circular supply chains whose waste comes from individual consumers. This is exemplified by the analysed chains 1a, 1b (scrap metal), and 4 (tyres), even though, for these chains, the implemented waste management policy (mandatory waste collection by municipality services) ensures the possibility of recycling more waste, so the stabilisation of such chains may be expected.

For the chains whose waste is derived directly from the production process (chains 2, 3, and 5), the risk resulting from flow uncertainty is generally no different than that of linear chains. Both the nature of the contracts (the contracting parties are often large industrial plants) and the minimum volumes agreed upon with the port terminals guarantee the continuity of flows in the circular supply chains. Some degree of uncertainty results only from the fluctuations in the regional and national demand for cargo to be a part of the circular supply chains (chain 2 and chain 3 ).

According to the literature, circular supply chains generate a greater demand for transport compared to linear chains. Our study only partially confirmed the legitimacy of this claim. For chains based on production waste (chains $2,3,5$ ), the engagement of transport processes in circular supply chains is similar to that for two separate linear chains (resources for production and products), whereas an increase in transport takes place for chains engaging individual customers who generate waste. This situation is observed for chains $1 \mathrm{a}, 1 \mathrm{~b}$ (closed-loop chains), and 4 (partially closed-loop).

Another significant factor indicated in the literature is the availability of suitable supply chain partners. However, this study conducted in the port in Szczecin did not confirm the problems connected with sourcing partners to serve circular supply chains. Considering the problems faced by secondary ports (a decrease in transshipment volumes, e.g., coal and ores), stevedoring companies having at their disposal multitask terminals and qualified staff who are eager to serve circular supply chains. However, the challenges may be significant when serving chains that involve hazardous cargo (e.g., chain 5) that requires appropriate administrative permits, or when the production plant in the seaport applies a pollution-intensive technology (one of the plants in chain 4), but even these obstacles are overcome by the ports (through the development of alternative technologies).

Another significant challenge is the problem of coordination and information sharing. The significance of this challenge was confirmed by the majority of cases we analysed. This problem is distinctly visible for consumer chains (1a, 1b, and 4), as waste dispersion among small suppliers generates problems with the information flow. However, for producer chains $(2,3$, and 5), in which all the links within the chain are unambiguously identified and between which cooperation takes place on a long-term contract basis, this factor has limited impact. It is manifested if there was no prior and precise information on the planned transshipments in a given year from a producer participating in the circular supply chain.

Our study also confirmed the significance of yet another challenge identified in the literature: product traceability. This is a significant challenge for consumer chains, whose waste is not standardised (e.g., the scrap metal in chains $1 \mathrm{a}$ and $1 \mathrm{~b}$ ). For chains whose waste is precisely specified (which is a requirement for any waste generated in production plants) or when waste comes from individual consumers but with standardised parameters (chain 4), product traceability does not seem to be a considerable challenge.

However, our study confirmed the considerable challenge of internal resistance to change (cultural issues). This challenge impacts all the circular supply chains in a similar manner. In the operational areas (stevedores) of secondary ports, there is already a strong conviction that it is necessary to adapt to handling the cargo involved in circular supply chains. However, this is not the case for port authorities, who show a more linear mindset. As a consequence, their fundamental instruments (i.e., the port's development strategy) do not provide any offers for circular supply chains. The investor evaluation policy is thus based on the transshipment volume only, and no actions are taken to provide available 
land plots with the infrastructure necessary for the terminals and industrial plants that participate in circular supply chains.

\section{Conclusions}

This paper focused on issues connected with the development of secondary ports as nodes in the circular supply chains of the circular economy model, which is the basis for implementing the sustainable seaports in the context of the structural changes taking place in the global economy, trade, and maritime transport.

Firstly, our study confirmed that the most important threat to the development of secondary ports is a decrease in the transshipment volume in the traditional bulk cargo group. This is shown by the changes in the breakdown of transshipments in the port of Szczecin (Figure 9). Secondary ports that do not have technical conditions to serve large vessels, but have available space to develop their transshipment, storage, industrial, distribution, and logistics activities (and are trimodal (i.e., have access to road, rail, and inland waterway hinterland transport infrastructures)), may become major participants in circular supply chains. Focusing port development on serving circular supply chains can help secondary ports retain the business of ships. The completed analysis of the case studies additionally indicates that, regardless of the significance of geographical proximity (highlighted in the literature) for the development of industrial symbiosis and eco-industrial parks in seaports, circular supply chains may also operate on a global level. This concerns cargo with higher unit values (e.g., chain 2), where transport costs are not a constraint in searching for partners, even in the port's remote foreland.

Secondly, taking advantage of the opportunities associated with the secondary ports in the circular supply chain requires facing several challenges. Our study partially confirmed the significance of the challenges to circular supply chain management identified in the literature, such as return-flow uncertainty, transport and infrastructure, the availability of suitable supply chain partners, coordination and information sharing, product traceability, and cultural issues. The significance of these challenges depends on the type of circular supply chain, i.e., whether it is a producer or a consumer chain. The in-depth analysis of the sea-land circular supply chains presented in this article proves that most of the challenges indicated in the literature pertain to consumer chains, particularly return-flow uncertainty, higher transport costs, and product traceability, as well as the problem of coordination and information sharing. Producer chains, in turn, tend to be more durable because they are contract-based. The issues related to the availability of suitable supply chain partners were not a substantial problem for the stevedores and port industries, apart from the handling of hazardous goods.

However, our study showed that a very important challenge for both types of chains is internal resistance to change (a cultural issue). This was relevant for all the analysed examples of circular supply chains. The example of the port in Szczecin indicates that stevedores systematically adapt to the changing market conditions and understand the potential of circular supply chains. They are urged to search for new cargo flows to replace their vanishing traditional bulk cargo. This stimulates them to cooperate with the port industry and expand their range of services. Some of the sea-land circular supply chains analysed in this article require a broader range of time-consuming additional logistics services provided by port enterprises in addition to the basic transshipment services. The cargo types flowing in the circular supply chains are characterised by considerable diversity, while their annual volumes are relatively low (50-300 thousand tonnes). Consequently, they are not attractive to stevedores operating in large primary ports, who are interested in serving larger cargo flows under long-term contracts. However, an unresolved issue is the persisting linear mindset of the secondary port authority, which is manifested mainly in the investor evaluation policy based exclusively on the declared annual transshipment volume and fails to provide the available land plots with the infrastructure necessary for terminals and industrial plants that participate in the circular supply chains. At the same time, the analysed examples of the secondary port in Szczecin indicate that sea-land 
circular supply chains may contribute to developing-within the port premises—specialised terminals that serve several port functions through one entity (the terminal operator).

The studies completed so far indicate the overarching role of port authorities in the development of circular supply chains. However, according to our study, for secondary ports, stevedores (who are flexible and fast in adapting to new market conditions, strongly determined to search for new cargo types to replace those that have vanished, and adapt the scope of their services) play the key role in stimulating the development of circular supply chains. Nevertheless, from a long-term perspective, the conditioning factor for the further growth of the circular supply chains in secondary ports will be appropriate policy developed by port authorities (a circular mindset).

As the main managerial implication for the authorities of secondary ports, such authorities should support the development of sea-land circular supply chains and thus the port's pursuit of increased sustainability, especially via an appropriate policy for investor assessment (taking into account, besides quantitative criteria like total turnover, qualitative criteria, such as the value of cargo services or the amount of waste used in the process) and the utilisation of any available areas within the port premises (synchronising the process of port infrastructure development and the process of providing utilities to undeveloped port areas) to encourage enterprises engaged in circular supply chains to invest in and develop their business within the port's premises. It is also necessary to develop appropriate communication between port authorities and their external stakeholders, including the local environment (seaport city residents), to transfer information on replacing pollution-intensive production technologies with low-emission or zero-emission ones, the cross-border environment for providing information on cross-border transport infrastructure for the development of circular supply chains, and the competitiveness of secondary ports (also including major participants of the sea-land circular supply chains located in the seaport hinterland with regard to information on the impact of the upgraded port infrastructure to ensure the competitiveness of sea-land circular supply chains relative to land chains).

As a managerial implication for stevedores operating in secondary ports, these entities should first develop their service offers to address cargo as part of the circular supply chains (i.e., more comprehensive service offers and added-value services, such as freight forwarding services and the stuffing, packing, and mixing of cargo) and to meet the requirements of hazardous waste handling, which is one of the main types of cargo moved in circular supply chains; they should also develop cooperation with the other stakeholders of circular supply chains (dedicated distribution terminals and industrial plants).

As a suggestion for future research, it is necessary to further study the transformation of secondary ports towards a circular economy, including both in-depth studies of single cases and multiple case studies on other secondary ports that cope with similar problems as the port in Szczecin. In particular, we recommend developing studies on the impact of circularising secondary ports on the revitalisation of port areas to handle the circular supply chain. It is also worth developing studies that address the issues related to sea-land circular supply chain development, taking into account the specific nature of producer and consumer chains.

Author Contributions: Conceptualization, M.M.; data curation, M.P.; formal analysis, M.M.; investigation, I.K., M.M., and M.P.; methodology, I.K. and M.M.; resources, M.M.; writing—original draft, M.M., M.P., and I.K.; review and editing, M.M., M.P., and I.K. All authors have read and agreed to the published version of the manuscript.

Funding: The project is financed within the framework of the program of the Minister of Science and Higher Education under the name "Regional Excellence Initiative" in the years 2019-2022; project number 001/RID/2018/19. The amount of financing: PLN 10,684,000.00.

Acknowledgments: We would like to thank all the reviewers and the journal editors for their insightful comments and suggestions towards improving our manuscript.

Conflicts of Interest: The authors declare no conflict of interest. 


\section{References}

1. Lam, J.S.L.; Notteboom, T. The Greening of Ports: A Comparison of Port Management Tools Used by Leading Ports in Asia and Europe. Transp. Rev. 2014, 34, 169-189. [CrossRef]

2. Davarzani, H.; Fahimnia, B.; Bell, M.; Sarkis, J. Greening ports and maritime logistics: A review. Transp. Res. Part D Transp. Environ. 2016, 48, 473-487. [CrossRef]

3. Di Vaio, A.; Varriale, L. Management Innovation for Environmental Sustainability in Seaports: Managerial Accounting Instruments and Training for Competitive Green Ports beyond the Regulations. Sustainability 2018, 10, 783. [CrossRef]

4. de Langen, P.; Sornn-Friese, H. Ports and the Circular Economy. In Green Ports; Bergqvist, R., Monios, J., Eds.; Elsevier: Amsterdam, The Netherlands, 2019; pp. 85-108.

5. Dooms, M. Stakeholder Management for Port Sustainability. In Green Ports; Bergqvist, R., Monios, J., Eds.; Elsevier: Amsterdam, The Netherlands, 2019; pp. 63-84.

6. Oniszczuk-Jastrząbek, A.; Czermański, E.; Cirella, G.T. Sustainable Supply Chain of Enterprises: Value Analysis. Sustainability 2020, 12, 419. [CrossRef]

7. Geissdoerfer, M.; Savaget, P.; Bocken, N.M.P.; Hultink, E.J. The Circular Economy-A new sustainability paradigm? J. Clean. Prod. 2017, 143, 757-768. [CrossRef]

8. COM(2014) 398 Towards a Circular Economy: A Zero Waste Programme for Europe; European Commission: Brussels, Belgium, 2014.

9. Closing the Loop - An EU Action Plan for the Circular Economy COM/2015/0614 Final; European Environment Agency: København, Denmark, 2015.

10. $\operatorname{COM(2019)} 190$ Report from the Commission to the European Parliament, The Council, The European Economic and Social Committee and the Committee of the Regions on the implementation of the Circular Economy Action Plan; European Commission: Brussels, Belgium, 2019.

11. Ezzat, A.M. Sustainable development of seaport cities through circular economy: A comparative study with implications to Suez Canal corridor project. Eur. J. Sustain. Dev. 2016, 5, 509. [CrossRef]

12. Rahman, N.S.F.A.; Ismail, A.; Othman, M.K.; Roslin, R.A.M.; Lun, Y.V. Decision making technique for analysing performance of Malaysian secondary ports. Int. J. Shipp. Transp. Logist. 2018, 10, 468-496. [CrossRef]

13. Carpenter, A.; Lozano, R.; Sammalisto, K.; Astner, L. Securing a port's future through Circular Economy: Experiences from the Port of Gävle in contributing to sustainability. Mar. Pollut. Bull. 2018, 128, 539-547. [CrossRef]

14. Karimpour, R.; Ballini, F.; Ölcer, A.I. Circular economy approach to facilitate the transition of the port cities into self-sustainable energy ports-A case study in Copenhagen-Malmö Port (CMP). WMU J. Marit. Aff. 2019, 18, 225-247. [CrossRef]

15. Karimpour, R.; Ballini, F.; Ölcer, A.I. Port-City Redevelopment and the Circular Economy Agenda in Europe. In European Port Cities in Transition; Carpenter, A., Lozano, R., Eds.; Springer: Cham, Switzerland, 2020; pp. 53-71.

16. Notteboom, T.; van der Lugt, L.; van Saase, N.; Sel, S.; Neyens, K. The Role of Seaports in Green Supply Chain Management: Initiatives, Attitudes, and Perspectives in Rotterdam, Antwerp, North Sea Port, and Zeebrugge. Sustainability 2020, 12, 1688. [CrossRef]

17. Monios, J. Cascading feeder vessels and the rationalisation of small container ports. J. Transp. Geogr. 2017, 59, 88-99. [CrossRef]

18. Notteboom, T.E.; Winkelmans, W. Structural changes in logistics: How will port authorities face the challenge? Marit. Policy Manag. 2001, 28, 71-89. [CrossRef]

19. Pallis, A.A.; de Langen, P.W. Seaports and the structural implications of the economic crisis. Res. Transp. Econ. 2010, 27, 10-18. [CrossRef]

20. Oniszczuk-Jastrząbek, A.; Czermański, E.; Dẹbicka, O.; Czuba, T. Globalization process in the maritime transport-causes, symptoms and effects. Annales Universitatis Apulensis Series Oeconomica. 2019, 21, 65-74. [CrossRef]

21. Lees, R.M. The impacts of a world in transformation on the prospects for maritime transport. In Maritime Transport and the Climate Change Challenge; Routledge: Abingdon, UK, 2012; pp. 60-69. [CrossRef]

22. Feng, L. An Introduction to the Circular Economy; People's Press: Beijing, China, 2004. 
23. Yuan, Z.; Bi, J.; Moriguichi, Y. The Circular Economy: A New Development Strategy in China. J. Ind. Ecol. 2008, 10, 4-8. [CrossRef]

24. Yong, R. The circular economy in China. J. Mater. Cycles Waste Manag. 2007, 9, 121-129. [CrossRef]

25. Fusco Girard, L. Toward a Smart Sustainable Development of Port Cities/Areas: The Role of the "Historic Urban Landscape" Approach. Sustainability 2013, 5, 4329-4348. [CrossRef]

26. McDonough, W.; Braungart, M. Cradle to Cradle: Remaking the Way We Make Things; North Point Press: New York, NY, USA, 2010.

27. Francas, D.; Minner, S. Manufacturing network configuration in supply chains with product recovery. Omega 2009, 37, 757-769. [CrossRef]

28. Nasir, M.H.A.; Genovese, A.; Acquaye, A.A.; Koh, S.C.L.; Yamoah, F. Comparing linear and circular supply chains: A case study from the construction industry. Int. J. Prod. Econ. 2017, 183, 443-457. [CrossRef]

29. Guide, V.D.R.; Van Wassenhove, L.N. The evolution of closed-loop supply chain research. Oper. Res. 2009, 57, 10-18. [CrossRef]

30. Jayant, A.; Gupta, P.; Garg, S.K. Perspectives in Reverse Supply Chain Management(R-SCM): A State of the Art Literature Review. Jordan J. Mech. Ind. Eng. 2012, 6.

31. Ellen MacArthur Foundation, McKinsey Center for Business and Environment. Growth within: A Corcular Economy Vision for a Competitive Europe; Ellen MacArthur Foundation: Isle of Wight, UK, 2015.

32. Guide, J.V.; Van Wassenhove, L.N. The reverse supply chain. Harv. Bus. Rev. 2002, 80, 25-26.

33. Genovese, A.; Acquaye, A.A.; Figueroa, A.; Koh, S.C.L. Sustainable supply chain management and the transition towards a circular economy: Evidence and some applications. Omega 2017, 66, 344-357. [CrossRef]

34. Cerceau, J.; Mat, N.; Junqua, G.; Liming, L.; Laforest, V.; Gonzalez, C.; Lin, L. Implementing industrial ecology in port cities: International overview of case studies and cross-case analysis. J. Clean. Prod. 2014, 74, 1-16. [CrossRef]

35. Kuipers, B. Ports as catalysts for change towards a circular economy Illustrations from the ports of Amsterdam and Antwerp. In Proceedings of the ESPO Conference, Athens, Greece, 21-22 May 2015.

36. Kyllönen, M. Can the EU's circular economy apply to ports. Parliament Magazine Politics Policy People. Available online: https://www.theparliamentmagazine.eu/articles/opinion/can-eus-circular-economy-applyports (accessed on 7 February 2020).

37. Haezendonck, E.; Coeck, C.; Verbeke, A. The Competitive Position of Seaports: Introduction of the Value Added Concept. Int. J. Marit. Econ. 2000, 2, 107-118. [CrossRef]

38. Zhang, L.; Yuan, Z.; Bi, J.; Zhang, B.; Liu, B. Eco-industrial parks: National pilot practices in China. J. Clean. Prod. 2010, 18, 504-509. [CrossRef]

39. Liu, C.; Côté, R. A Framework for Integrating Ecosystem Services into China's Circular Economy: The Case of Eco-Industrial Parks. Sustainability 2017, 9, 1510. [CrossRef]

40. Masi, D.; Day, S.; Godsell, J. Supply Chain Configurations in the Circular Economy: A Systematic Literature Review. Sustainability 2017, 9, 1602. [CrossRef]

41. Verhoeven, P. European Port Governance Report of an Enquiry into the Current Governance of European Seaports; European Sea Ports Organisation: Brussels, Belgium, 2010.

42. Hollen, R.M.A.; Van Den Bosch, F.A.J.; Volberda, H.W. Strategic levers of port authorities for industrial ecosystem development. Marit. Econ. Logist. 2015, 17, 79-96. [CrossRef]

43. Merk, O. OECD Regional Development Working Papers 2013/13 The Competitiveness of Global Port-Cities: Synthesis Report; OECD: Paris, France, 2013.

44. Van Dooren, N.; Braam, G. The Netherlands as a Circular Hotspot. 2015. Available online: http://greenalliance.org.uk/resources/6 (accessed on 7 February 2020).

45. Khalid, N.; Ang, M.; Cory, E.; Hasan, A. Assessing the Issues, Challenges and Prospects of Selected Secondary Ports in Peninsular Malaysia; Centre for Maritime Economics and Industries: Kuala Lumpur, Malaysia, 2011.

46. Margarino, S. A Cluster Initiative: Secondary Ports as Hubs for Smart Growth and Sustainable Connectivity; European Regional Development Fund (ERDF): Lille, France, 2014.

47. Ding, Z.Y.; Jo, G.S.; Wang, Y.; Yeo, G.T. The Relative Efficiency of Container Terminals in Small and Medium-Sized Ports in China. Asian J. Shipp. Logist. 2015, 31, 231-251. [CrossRef]

48. Feng, L.; Notteboom, T. Peripheral challenge by Small and Medium Sized Ports (SMPs) in Multi-Port Gateway Regions: The case study of northeast of China. Pol. Marit. Res. 2013, 20, 55-66. [CrossRef] 
49. Linder, M.; Williander, M. Circular Business Model Innovation: Inherent Uncertainties. Bus. Strategy Environ. 2017, 26, 182-196. [CrossRef]

50. Bressanelli, G.; Perona, M.; Saccani, N. Challenges in supply chain redesign for the Circular Economy: A literature review and a multiple case study. Int. J. Prod. Res. 2019, 57, 7395-7422. [CrossRef]

51. Yin, R.K. Case Study Research. Design and Methods, 3rd ed.; SAGE Publications, Inc.: Thousand Oaks, CA, USA, 2003; ISBN 01796437.

52. Andersen, P.H.; Dubois, A.; Lind, F. Process validation: Coping with three dilemmas in process-based single-case research. J. Bus. Ind. Mark. 2018, 33, 539-549. [CrossRef]

53. Mańkowska, M.; Pluciński, M. A Strategy Towards Diversification of Operations. The Case Study of the Stevedoring Enterprise. Eur. J. Serv. Manag. 2018, 257-268. [CrossRef]

(C) 2020 by the authors. Licensee MDPI, Basel, Switzerland. This article is an open access article distributed under the terms and conditions of the Creative Commons Attribution (CC BY) license (http://creativecommons.org/licenses/by/4.0/). 

Article

\title{
Driving Mechanism of Port-City Spatial Relation Evolution from an Ecological Perspective: Case Study of Xiamen Port of China
}

\author{
Ling Yu ${ }^{1,2}$, Pengfei Xu ${ }^{2}$, Jia Shi ${ }^{1}$, Jihong Chen ${ }^{1, *}$ and Hong Zhen ${ }^{1, *}$ \\ 1 College of Transport and Communications, Shanghai Maritime University, Shanghai 201306, China; \\ yul@theidi.com (L.Y.); jiashi0625@163.com (J.S.) \\ 2 CCCC Third Harbor Consultants Co., Ltd, Shanghai 200032, China; xupf@theidi.com \\ * Correspondence: jhchen@shmtu.edu.cn (J.C.); hongzhen@shmtu.edu.cn (H.Z.); Tel.: +86-21-38282334 (J.C.); \\ +86-21-65853792 (H.Z.)
}

Received: 29 February 2020; Accepted: 31 March 2020; Published: 3 April 2020

\begin{abstract}
With the economic globalization continuing to advance, coastal port cities have enjoyed increasingly prominent status and roles as the link between the sea and the land and an important window of foreign trade and exchanges. However, port cities, while embracing rapid development, have also produced a significant impact on natural resources and the ecological environment. Ecological environment protection has become a must-consider factor for sustainable development of port cities. To secure coordinated and sustainable development of ports and cities, this paper utilizes the system dynamics theory and approaches the subject from driver analysis. In the traditional port-city collaboration system model, indicators of ecological perspectives such as land resources and environmental protection are introduced to build a dynamic model for the spatial evolution system of port-city coupling system based on ecological protection, and the dynamic mechanism of port-city spatial relation evolution is analyzed in depth with a case study of Dongdu Port Area of Xiamen Port. The model's simulation results show that from an ecological perspective, the spatial distance between the port and the city is critical to their sustainable and coordinated development. Only after the port-city spatial distance increases moderately can the development efficiency of the port-city system welcomes a relatively significant increase. Managing the port-city distance well has a significant driving effect on capacity enhancement of the port and economic development of the city. This provides a theoretical reference for further studies on port-city coordinated and sustainable development and provides constructive suggestions for the government to make relevant decisions.
\end{abstract}

Keywords: ecological perspective; port-city system; coordinated development; system dynamics

\section{Introduction}

With international trade transactions growing, ports, as key hubs for land-water transportation, play an important role in a city's economic development. However, the rapid development of ports has also put port cities under a series of ecological challenges such as disordered resources and environmental pollution caused by excessive development [1-3]. A port city is a highly populated area, while the ecological environment is what human beings rely on to live by. As people's awareness of the hazards to the ecological environment keeps rising, protecting port city ecology for sustainable development of ports has become a focus of attention of social development. According to previous research findings [4], the port-cityspatial relation has also changed accordingly as port and city step into different stages of development and plays an important role in port-city coordinated development. For example, China has been promoting its port management system reform in recent years. Taking this opportunity, port cities have enjoyed vigorous development and port-city relations have become 
increasingly close. Specifically, the spatial changes between port and city are particularly significant: Port and city are gradually moving farther away from each other, stretching the distance between port and city, and the original industrial shoreline of ports is gradually transformed into a waterfront shoreline of cities. This can be attributed to many reasons.

From the perspective of ports, as larger ships feature lower costs of transportation, ships have been following an upsizing trend in recent years. To meet the requirements of ship upsizing, port structure has changed, highlighting the upsizing trend of ports, with specialized ports gradually moving to deep-water areas with better shoreline resources [3]. This gradually pulls port and city apart in their spatial relation. For example, Shanghai Port developed from Huangpu River to Yangtze River, and then to the open seas. The water depth of $-16 \mathrm{~m}$ has been a very critical factor during the process [5]. Fuzhou Port gradually shifted from the inner port area of Minjiang River estuary to Jiangyin Port Area and Luoyuan Bay Port Area, out of similar considerations [3,6].

From the perspective of city, in addition to developing port transportation, shoreline resources also serve to develop a waterfront shoreline for the city and its residents. This is particularly important for developing the city's tertiary industry and improving residents' quality of life [7]. As the scale of the port continues to rise, a large amount of cargo has to be transported across urban areas, which imposes greater pressure on urban commuting traffic, leaving the traffic in port cities more congested and the contradiction between port expansion and urban development increasingly intensified.

From the perspective of ecological benefits, greenness and environment protection have become inevitable trends and urgent requirements for port development under the constraints of resources and environment. Port-front areas are usually home to the industries with serious pollution of dust or noise. The impacts of these industries on the urban environment can be significantly reduced if they move farther away from urban areas [8]. Meanwhile, as cities continue to expand, the shorelines and land resources occupied by port areas will see their values rising, making them more suitable for developing high-end and non-polluting service industries that have higher production values. From the efficient use of resources point of view, the government has the incentive to relocate these original industrial factories and areas as well as the ports to out of the cities.

With the emergence and development of the third- and fourth-generation ports, port services that are dominated by cargo warehousing and handling have failed to meet the increasingly diversified needs of economic activities, while related modern service sectors such as trade, ship financing, maritime insurance, maritime law, shipping transactions, and shipping brokerage have enjoyed rapid development. Ports have gradually changed from transportation centers to comprehensive shipping service centers. However, the development of the shipping service sector depends not only on the city's logistics, finance, insurance, information, and other soft functions, but also on port infrastructure. Meanwhile, as important hubs, ports can lead industries to agglomerate and then develop new port-front cities, and further enable leap-forward expansion of cities' economy. If the port-city distance is too large, the longer time for commuting as well as cargo collection, distribution, and transportation, and the too-high economic costs will all adversely impact industrial development and new city development. Therefore, properly managing the port-city distance can maximize the ports' role in driving cities' economy while minimizing the adverse impact on cities.

Therefore, despite that port-city separation has become an important development trend of the port-city relation, ports still need to be within a certain distance to their cities to maximize the coupling role between the port and the city. This paper adopts the system dynamics method and starts from the port, city, and ecology perspectives, with Xiamen as an example for study, to introduce indicators such as shoreline resource occupation, land resource occupation, and pollution emissions to build a system dynamics (SD) model of a port-city coupling system based on ecological benefit concepts. Through multi-scenario simulation, the paper makes comparative analysis on the impact of port-cityspatial distance changes on the sustainable development of Xiamen to maximize the economic, environmental, and social benefits and provide theoretical references and policy-making advice for coordinated development of the port city. 
The article is structured as follows. Section 2 reviews relevant literature on port-cityrelations, and Section 3 builds a system dynamics model. In Section 4, an empirical analysis is made using Xiamen Port as an example. Finally, in Section 5, main conclusions of the paper and corresponding opinions are presented.

\section{Literature Review}

The research on port-city relation derives from the port location theory in the 1930s [9]. With the changes of the social economy, the research scope has been expanding to form five major research fields today. This section starts from the five major research fields and focuses on the quantitative research results of the port-city relation, supplemented by a summary of related literature in the past.

\subsection{Existing Mechanisms of Port-cityRelations}

The first part focuses on port-city spatial structures and connections. Scholars at home and abroad have proposed a range of port system and port space evolution models based on empirical cases of port cities in various countries or regions, such as the Anyport model and the Taaffee six-stage and four-stage models [10-14]. Debrie and Raimbault [4] assumed that economic sectors (stakeholders in transportation, water, housing, energy, industry, etc.) have a significant impact on the development mechanism of the city, and applied an analysis framework based on regional negotiation to two inland port cities to understand how stakeholder interactions change urban geography. Ducruet [15] pointed out that the container revolution and the spatial distribution of new industrial activities were the main factors in port-city relations. The maritime network had produced a significant impact on the port-city interface in the past three decades. He used simple features including geographic coordinates, urban population, logistical activities, port infrastructure, and maritime traffic to highlight regional differences and analyzed port cities on the worldwide scale. The second part focuses on the industrial development of the port area and the port's impact on the area. Many scholars studied the impacts of the industrial development of ports and port-front areas on the functions, environment, leisure space, and redevelopment of the area from the perspectives of port industry, port logistics, and waterfront living space [16-20]. The third part is the related research on port-city traffic network connections [7,21]. Monios et al. [22], with Port of Gothenburg as an example, studied the location selection of ports' logistics distribution facilities, and pointed out that city planners should coordinate logistics transportation from a regional perspective and identify the logistics activities that should be located near the port, rather than blindly competing with inland areas for better facility locations. The fourth part discusses the sustainable development of ports and cities and construction of green ecological ports. From the perspective of port and port city development, taking into account the ecological environment protection while developing the port can enhance the sustainability capacity of the city $[23,24]$. We will discuss the fifth major area of research in the next section, namely the study on quantitative analysis of port-city relations.

\subsection{Quantitative Research on Port-cityRelations}

Many scholars have carried out quantitative analysis on port-city relations and explored the differences, connections, and interrelations between different cities from a regional angle. Such research is represented by Vallega who selected relevant indicators of port cities; the proportion between them can be obtained through certain data standardization to reflect the type of port city relationship [25]. Vallega found that there existed wide gaps in the port-city relations between different areas of the world. For example, most European port cities emphasized the role of ports for the entire European continent, and the port-city interdependence was relatively weak yet stable. Meanwhile, most Asian port cities relied more on the rapid development of port-related industries in coastal areas and drove constant expansion of the cities' economic scales through port development [26]. Apart from this, the quantitative research on port-city relations can be roughly divided into three parts. The first part proposes, revises, and applies the relative concentration index (RCI) model. Many scholars utilized 
the RCI model to classify port cities [27-29]. Wu further analyzed the features of changes in port-city relations [30]. The second part reveals the multifaceted nature of port-city relations by constructing a comprehensive index system and applying a diverse quantitative model. The main purpose is to use the grey correlation, the system dynamics model, and the system entropy to study the intensity change of the relations between ports and cities [31,32]. The third part proposes the development theory of port cities and explains the development stages of port cities based on the quantitative intensity features or changes of port-cityconnections. Examples in this regard include Guo and Han who proposed a port-cityspatial evolution model [33], and Karel et al. who proposed a method for analyzing port-cityconnection mechanisms [34].

\subsection{Under-Researched Aspects}

To sum up, most studies focused on exploring the relations between ports and cities in terms of spatial structure, economic development, transportation networks, etc., but few looked at the ecological benefits of ports. "Ecotypic" ports refer to resource-saving and environment-friendly ports. Construction of ecotypic ports requires the evaluation of the impacts on the urban environment as well as the consumption of land, shorelines, and other important resources while looking at the size and costs of port transportation [23]. Since the state urged the construction of ecotypic ports, changing the spatial distance between ports and cities has become an important measure for many coastal cities to develop ecotypic ports for sustainable development. For example, the Huangpu River Port of Shanghai Port has been largely relocated to Waigaoqiao Port Area and Yangshan Deep-water Port Area; the up-scaling transportation in the north main port area of Tianjin Port has seriously disrupted the green and livable urban construction of Binhai New Area, which leads to the current planning of adjustment and relocation of the port area; Xiamen Dongdu Port Area has transformed some multi-purpose terminals to cruise berths and is planning to move the freight function to out of the island; Ningbo Beilun Port also intends to gradually transfer bulks transshipment operations to Chuanshan Port Area and Majishan Port Area, which are farther away from the city $[1,3,6]$. Some scholars have tried to evaluate the impact of port-city separation in recent years, but most of them ended up with qualitative descriptions, lacking quantitative research on the changes of factors such as resource consumption, environmental protection, and integrated transport costs that arise from port-city separation. There is no mature systematic theoretical method on how to keep the port-city spatial distance within a moderate range. Therefore, this paper, based on existing research results, focuses on addressing the following problems: 1) How to build a port-city development model based on an ecological perspective; 2 ) how to quantitatively analyze the impact of port-city spatial distance on urban resources use, environmental protection, and integrated transport costs of ports during port-city interactions; 3 ) targeted suggestions on how to maintain an appropriate spatial distance for port-city development.

\section{Modeling}

System dynamics (SD) is a science that combines the theory of system science with computer simulation technology. It is a method to study the system structure and feedback changes. The coupling system of port and city is dynamic in nature, including several subsystems, and the self-correcting and self-reinforcing effects of these subsystems affect the sustainable development of port cities. Port is not only related to social and economic environments, but also closely connected to the ecological environment and resources; therefore, this article applies the method of system dynamics, where the city system, port system, and environment resources system are the three subsystems constituting a harbor city comprehensive system coupling, and incorporates environmental constraints into the model, so as to comprehensively and objectively analyze a harbor city regarding the feasibility of the coupling system of sustainable development measures. The development trend of the port city in the future is simulated by adjusting the parameter changes in the model to maximize the economic benefits, social benefits, and environmental benefits. 


\subsection{System Structure Relations}

The first step in the study of system dynamics is to determine the system boundary; that is, to determine the structure of the system. The port and city coupling system includes three parts: Urban subsystem, port subsystem, and environmental resources subsystem. The urban subsystem refers to the urban economy as the main body (including GDP, fixed-asset investment, volume of trade, etc.). Port subsystem refers to the factors related to port development (including port throughput, freight pressure, port investment, port passing capacity, length of available shoreline, etc.). The environmental resources subsystem mainly consists of two parts: The additional pollution treatment cost caused by port operation activities and the impact of infrastructure construction on the consumption of natural resources. System dynamics is quite suitable for studying the interrelations between main factors in the system. It converts purely static methods into dynamic simulation, featuring flexible equations and non-fixed model structures. This enables effective simulation and research of system dynamics and facilitates comparative analysis of hypothesis to provide a basis and support for decision-making. According to the system analysis and coordination principle, the port-city spatial system can be divided into three subsystems: Urban subsystem, port subsystem, and ecological subsystem. The system framework of the model is shown in Figure 1.

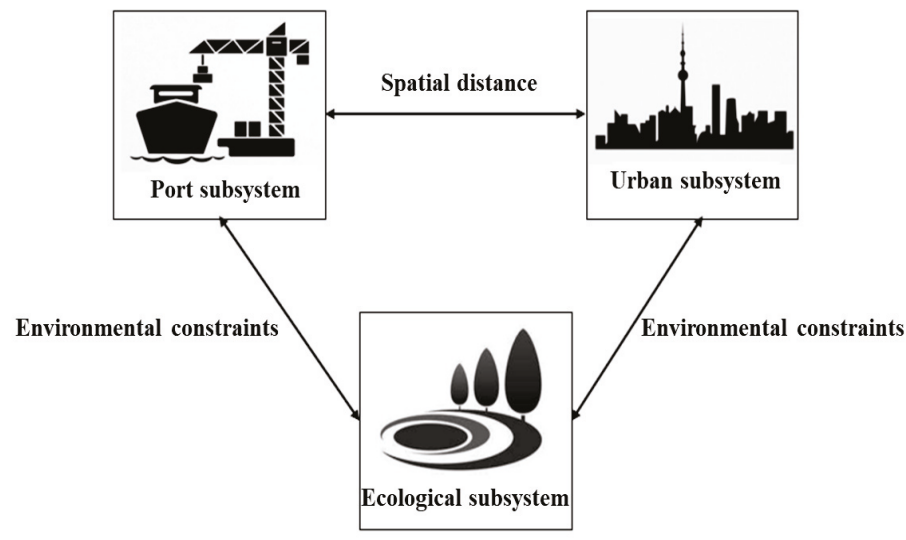

Figure 1. System Framework.

Each subsystem is built up by the state variables from cumulative effects, the speed variables from control effects, auxiliary variables, parameters, coefficients, and constants. Each subsystem not only depends on its internal structure for operation but is also subject to the correlations of other subsystems. The development of city economy is an important guarantee for port construction and operation. With the development of city economy, the city has more funds to invest in the construction of port and its collection and distribution system, providing the port with space for comprehensive logistics activities and inland connection channels, so as to make the port continuously adapt to the needs of higher level development of city economy. The port, as a transportation hub, is the center of the transformation of various means of transportation. A large number of goods are gathered in the port to promote economic development. At the same time, the area around the port also developed the processing industry, which promoted the development of industry and international trade and attracted foreign investment. However, port infrastructure construction may have a negative impact on the ecosystem, thus causing adverse social and environmental impacts and restricting the development of cities and ports.

In the coupled port and city system, the urban subsystem is the driving force to promote economic development and progress. The material wealth created by urban economic activities can improve people's living quality and living standard, and further attract more people to develop in port cities. The 
economic value created by economic activities can also drive the development of the port subsystem, and the development of the port will react on the city and drive the economic growth of the city. The environmental resources subsystem is the foundation of the port city's economic activities, and the carrying capacity of natural resources directly affects the economic development level of the port city. The subsystems and factors of the port and city coupling system are interrelated and influence each other, which have the characteristics of obvious dynamics, complexity, and multiple feedback.

\subsection{System Analysis and Indicators}

According to the system framework, we can select the indicators that can comprehensively reflect the situations of the three subsystems [23]. In fact, each indicator in the system dynamics model has direct or indirect connections. The indicators form a whole, but we have divided them into three subsystems to analyze the structure and context of the system more clearly, as described below. Finally, according to the correlation of each index in the three subsystems, the Port-cityspatial system causality diagram is obtained as shown in Figure 2.

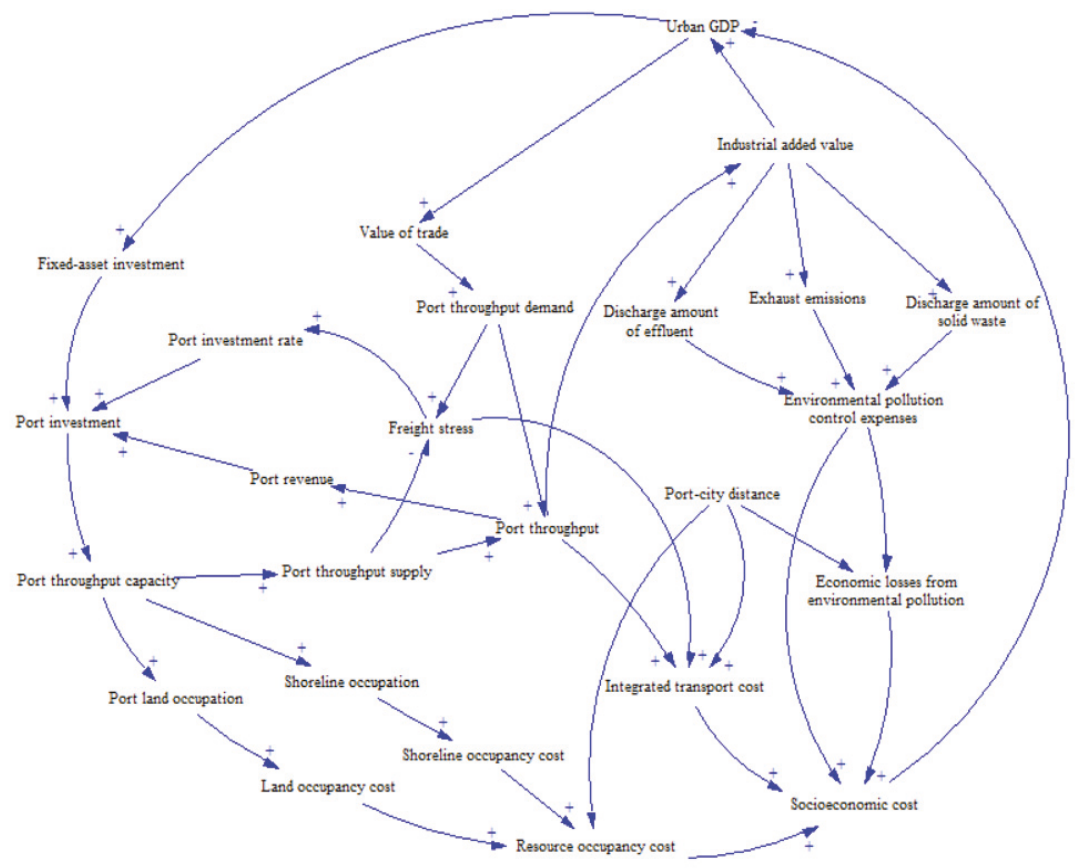

Figure 2. Port-cityspatial system causality diagram from ecological perspective.

\subsubsection{Urban Subsystem}

The urban subsystem reflects the city's economy and is the primary objective of developing the port. At the same time, as the carrier of port, the development of export-oriented economy and comprehensive transportation system also promoted the development of port. Main indicators include urban GDP, fixed-asset investment, fixed-asset investment of port, and value of trade. Urban GDP reflects the level of economic development in the hinterland; fixed-asset investment includes fixed-asset investment of the port and others to reflect the construction status of infrastructure such as the port; value of trade reflects the potential demand for the port. The urban subsystem includes two feedback loops (Figures 3 and 4). Feedback loop 1 is a negative feedback loop, feedback loop 2 is a positive feedback loop. 


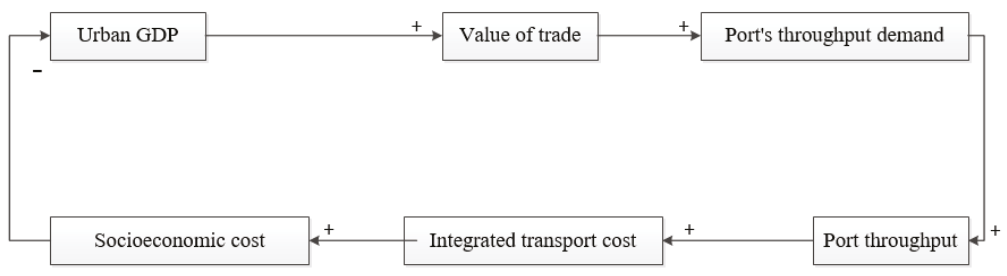

Figure 3. Feedback loop 1 in the urban subsystem

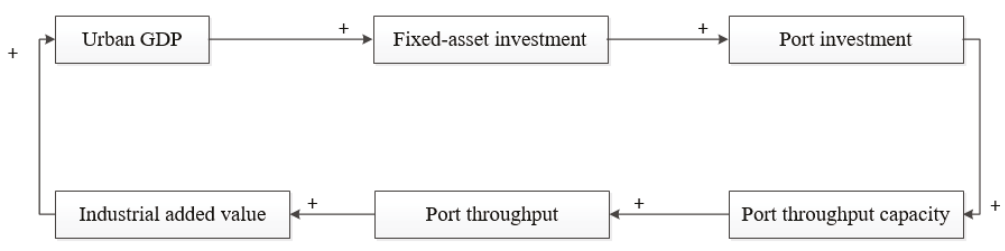

Figure 4. Feedback loop 2 in the urban subsystem.

On the one hand, the increase of city's GDP can improve the trade volume and port throughput, so as to accelerate the industrial development, and finally drive the GDP growth. So, the second one is the positive feedback chain. On the other hand, the increase of GDP will lead to the increase of transportation volume, bring more pollution, and thus generate more socioeconomic cost. Therefore, the first one is the negative feedback chain.

\subsubsection{Port Subsystem}

As an important infrastructure and window of foreign trade, the port plays a great role in promoting the economic development of surrounding areas. Thus, the port subsystem is the key of discussion in this paper. Its relations with the city have always attracted the attention of academia and is a hotspot of research. Main indicators include port throughput, water-borne freight demand, throughput supply of port, freight pressure, port investment, port throughput capacity, port trafficability, and length of available shoreline. The urban subsystem and the port subsystem are linked up by the total production value of traffic and transportation, warehousing as well as post and telecommunications industries, and the total import and export values, to achieve interaction and constraints between the two. The port subsystem consists of three feedback chains (see Figures 5-7). Feedback loop 3 and 5 are positive feedback loops, while feedback loop 4 is a negative one.

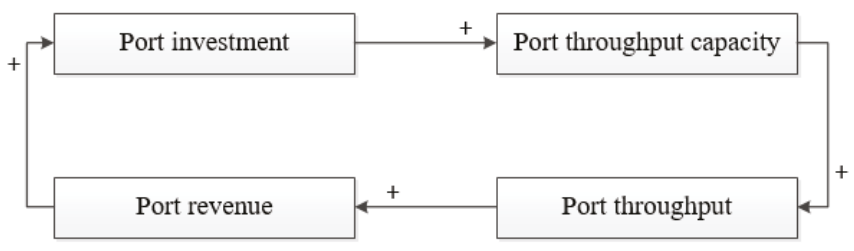

Figure 5. Feedback loop 3 in the port subsystem.

The increase of port investment can speed up port construction, improve port throughput, promote industrial development, and bring more investment to the port. Therefore, the third one is the positive feedback chain. The increase of shoreline load not only increases port throughput and city GDP, but also brings environmental pollution and increases socioeconomic cost. So, the fourth is the positive feedback chain, and the fifth is the negative feedback chain. 


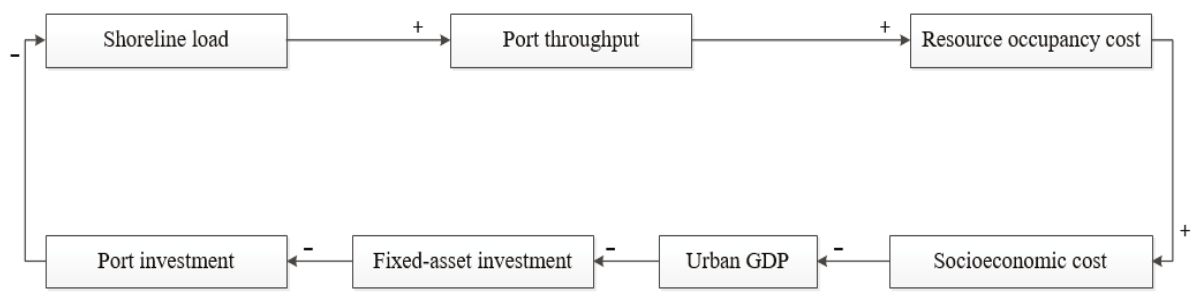

Figure 6. Feedback loop 4 in the port subsystem.

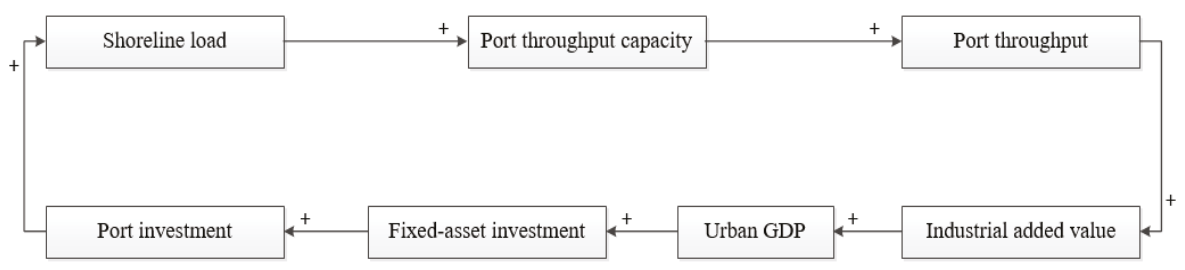

Figure 7. Feedback loop 5 in the port subsystem.

\subsubsection{Environmental Resources Subsystem}

The environmental resources subsystem plays a restrictive and economy-regulating role in the entire system. Economy and port development cannot go without resources. How to rationally utilize resources and reduce the cost of environmental governance are key to the current economic transformation and development. If no governance measures are taken, the environmental impact is usually negative. Therefore, this subsystem includes a negative feedback chain (feedback loop 6, see Figure 8). This is a negative feedback loop. Indicators of the subsystem include effluent discharge, exhaust emissions, solid waste discharge, environmental governance cost, environmental pollution loss, shoreline occupancy cost, and land occupancy cost. Specifically, effluent and solid waste discharge amounts will drive up the environmental pollution control expenses. Increased port throughput will increase the overall transportation cost of the cargo collection, distribution, and distribution system. Costs of the land and shoreline occupied by port construction will be reflected in the cost of resource occupation. Ultimately, the three factors will collectively constitute the socioeconomic cost in port-city relations.

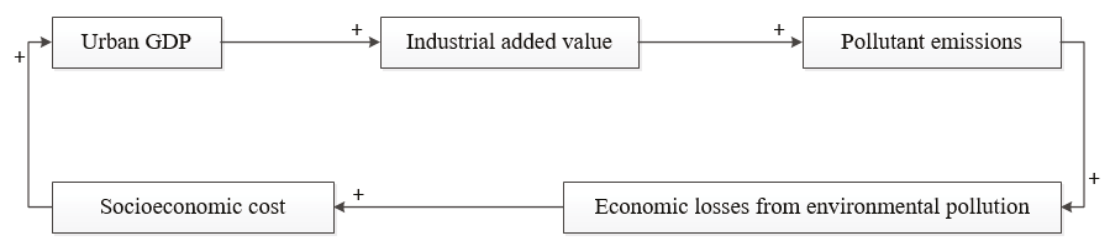

Figure 8. Feedback loop 6 in the environmental resources subsystem.

\subsection{Flow Chart Analysis and Equation Establishment of Port-citySpatial Relation System}

Based on the causality feedback chart and mechanism analysis of various subsystems, a system dynamics model of port-city spatial relations can be constructed (Figure 9). The evolution process of the three port-city spatial subsystems is presented by a dynamic mechanism, an interactive mechanism, and a stress mechanism. The dynamic mechanism is embodied in that, between the urban, port, and ecological subsystems, the rapid economic development and the rapid growth of throughput play a more prominent driving role in the early stage of port-city coordinated development; the interactive mechanism is primarily embodied in the growth and maturing stages of port-city coordination 
when the port-city system achieves orderly and gradual evolution of the system through functional transformation and coordination and cooperation of various subsystems; the stress mechanism exists in various stages of port-city coordination. Each development stage of the port-city system has a threshold which, once crossed, will lead to a variation of the system. Tables 1-3 present the important equations related to socio-economy, ecological environment, and spatial resources in the model. At the end of the paper, the specific meaning of each abbreviation in the table is listed. In the tables, "IF THEN ELSE" means making a conditional judgment on the contents of the following parentheses and selecting the number that matches the condition. Integrate means to integrate the values in brackets.

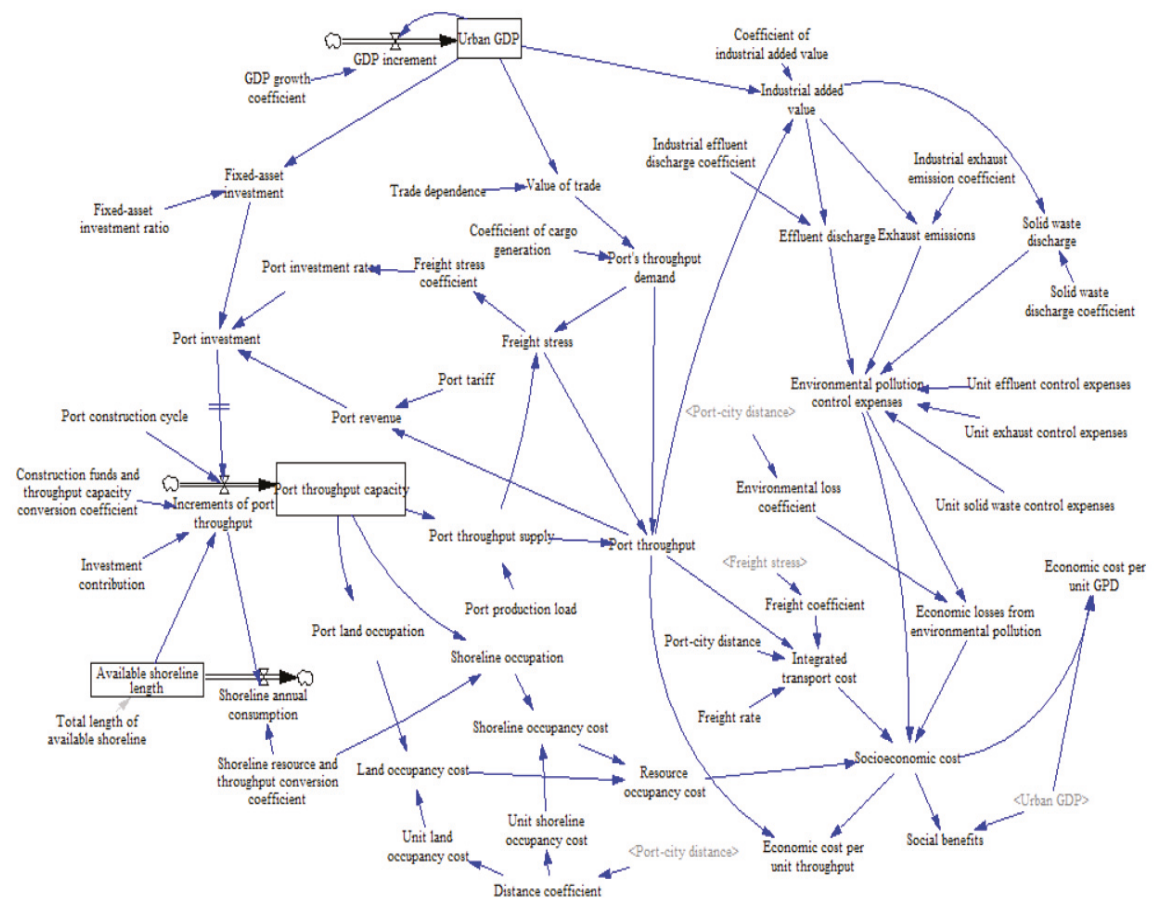

Figure 9. System dynamics flow chart of port-city spatial relations from ecological perspective.

Table 1. Socio-economic equations for urban and port subsystems.

\begin{tabular}{c}
\hline IGDP $=$ GDP $\times$ GGC \\
SB $=$ GDP - SEC \\
FAI $=$ GDP $\times$ FAIR \\
PI $=$ FAI $\times$ PIR + PR $\times$ coefficient \\
PIR $=$ CPC $\times$ coefficient \\
IPT = IF THEN ELSE $($ ASL $>2000$, DELAY $3($ C and TCCC $\times$ PI $\times$ IC, PCC $)$, DELAY3 $($ CF and TCCC $\times$ PI $\times$ IC, \\
PCC $\times 0.01)$ \\
PT $=$ INTEG $($ IPT $)$ \\
PTS $=$ PT $\times$ PPL \\
SAC $=$ IPT $\times$ CS and TCC \\
ASL $=$ TLAS + INTEG $(-S A C)$ \\
VT $=$ GDP $\times$ TD \\
PTD $=$ VT $\times$ CCG \\
ROC $=$ LOC + SOC \\
FP $=$ PTD $/$ PTS \\
ITC $=$ PT $\times$ ATD $\times$ FR $\times(1+$ coefficient $\times$ FP^ 4$)$ \\
SEC $=$ ELEP + ITC + ROC + EPCE
\end{tabular}


Table 2. Relation equations for environmental resources subsystem.

$\begin{array}{r}\mathrm{IAV}=\mathrm{GDP} \times \mathrm{CIAV}+\mathrm{PT} \times \mathrm{PCC} \\ \mathrm{ED}=\mathrm{CED} \times \mathrm{IAV} \\ \mathrm{EE}=\mathrm{CEE} \times \mathrm{IAV} \\ \mathrm{SWD}=\mathrm{CSWD} \times \mathrm{IAV} \\ \mathrm{EPCE}=\mathrm{SWD} \times \mathrm{USWCE}+\mathrm{UECE} \times \mathrm{EE}+\mathrm{UECE} \times \mathrm{ED} \\ \hline\end{array}$

Table 3. Related important equations for port-cityspatial resources.

\begin{tabular}{c}
\hline PT $=$ IF THEN ELSE $($ FP $>1$, PTS, PTD $)$ \\
PLO $=$ PT $\times$ coefficient \\
SO $=$ PT $\times$ coefficient \\
SOC $=\mathrm{SO} \times$ USOC \\
LOC $=$ PLO $\times$ ULOC \\
\hline
\end{tabular}

\section{Empirical Case}

Container transportation of Xiamen Port is distributed in four port areas of Dongdu, Songyu, Haicang, and Zhaoyin. Dongdu Port Area, as a deep-water port area constructed after the reform and opening up, has made indelible contributions in guiding and serving the industrial layout and development of Huli Industrial Zone and promoting the construction of Xiamen Special Economic Zone. However, with the elevation of socio-economic and urban development levels in Xiamen Island in recent years, the cargo handling operations in Dongdu Port Area have brought many negative effects to the island's ecological environment and traffic and transportation, aggravating the conflict with the city. In particular, the handling and warehousing of more than 4 million TEU containers on the island each year has greatly impaired the urban environment and occupied valuable land resources on the island; the high number of large container trucks have also imposed great stress on the island's traffic and increased risks of traffic safety. To address this issue, Xiamen Port urged, in its overall planning, the gradual relocation of the freight function of Dongdu Port Area to Haicang and Xiang'an port areas. The overall layout of Xiamen port is shown in Figure 10.

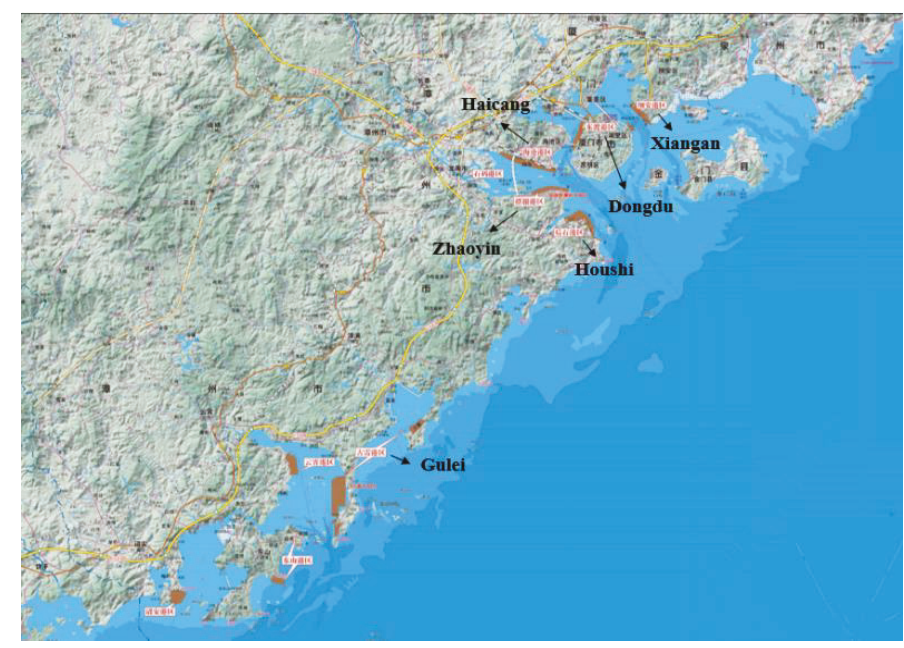

Figure 10. The overall layout of Xiamen port. 


\subsection{Data Sources and Model Validity Check}

Main data of this paper came from Xiamen Statistical Yearbooks and Xiamen Port Statistical Yearbooks. The structure and dimension consistency of the model was validated with the help of the Vensim software. A total of 10 years of historical data from 2007 to 2016 were selected, with their historical significance validated. The errors between the system's indicators and actual values were within the range of $5 \%$. The model sports a sound behavior re-production capability and can truly reflect the actuality of the Xiamen port-city system (see Tables 4 and 5).

Table 4. List of basic data of main indicators.

\begin{tabular}{|c|c|c|c|c|c|c|c|}
\hline Year & $\begin{array}{l}\text { GDP } \\
\text { (Billion } \\
\text { Yuan) }\end{array}$ & $\begin{array}{l}\text { Total Import and } \\
\text { Export Values } \\
\text { (Million USD) }\end{array}$ & $\begin{array}{l}\text { Throughput } \\
\text { (10,000 Tons) }\end{array}$ & $\begin{array}{l}\text { Trafficability } \\
(10,000 \text { Tons) }\end{array}$ & $\begin{array}{l}\text { Length of } \\
\text { Occupied } \\
\text { Shoreline } \\
\text { (m) }\end{array}$ & $\begin{array}{l}\text { Industrial Added } \\
\text { Value above a } \\
\text { Designated Scale } \\
\text { (100 Million Yuan) }\end{array}$ & $\begin{array}{c}\text { Port } \\
\text { Investment } \\
\text { (100 Million } \\
\text { Yuan) }\end{array}$ \\
\hline 2007 & 1388 & 39,778 & 8117 & 8266 & 17,763 & 625 & 31 \\
\hline 2008 & 1560 & 45,389 & 9702 & 9261 & 16,773 & 680 & 26 \\
\hline 2009 & 1737 & 43,314 & 11,096 & 9559 & 17,598 & 670 & 30 \\
\hline 2010 & 2060 & 57,036 & 12,728 & 10,041 & 18,522 & 869 & 27 \\
\hline 2011 & 2539 & 70,167 & 15,654 & 13,439 & 22,597 & 1117 & 35 \\
\hline 2012 & 2817 & 74,491 & 17,227 & 14,104 & 23,923 & 1164 & 26 \\
\hline 2013 & 3018 & 84,094 & 19,088 & 14,174 & 24,431 & 1212 & 18 \\
\hline 2014 & 3274 & 83,553 & 20,504 & 16,188 & 27,934 & 1240 & 19 \\
\hline 2015 & 3466 & 83,291 & 21,023 & 16,550 & 28,827 & 1254 & 21 \\
\hline 2016 & 3784 & 77,177 & 20,904 & 17,300 & 29,749 & 1265 & 23 \\
\hline
\end{tabular}

Table 5. Comparison of simulated values and actual values of main indicators.

\begin{tabular}{|c|c|c|c|c|c|c|}
\hline Year & $\begin{array}{c}\text { Actual GDP } \\
\text { (100 Million } \\
\text { Yuan) }\end{array}$ & $\begin{array}{c}\text { Simulated GDP } \\
\text { (100 Million } \\
\text { Yuan) }\end{array}$ & $\begin{array}{c}\text { Deviation } \\
(\%)\end{array}$ & $\begin{array}{c}\text { Actual } \\
\text { Throughput } \\
\text { (10,000 Tons) }\end{array}$ & $\begin{array}{c}\text { Simulated } \\
\text { Throughput } \\
\text { (10,000 Tons) }\end{array}$ & $\begin{array}{c}\text { Deviation } \\
(\%)\end{array}$ \\
\hline 2007 & 1388 & 1388 & $0.00 \%$ & 8117 & 8338 & $2.72 \%$ \\
\hline 2008 & 1560 & 1563 & $0.17 \%$ & 9702 & 9388 & $-3.24 \%$ \\
\hline 2009 & 1737 & 1785 & $2.74 \%$ & 11,096 & 10,722 & $-3.38 \%$ \\
\hline 2010 & 2060 & 2101 & $1.97 \%$ & 12,728 & 12,975 & $1.94 \%$ \\
\hline 2011 & 2539 & 2570 & $1.20 \%$ & 15,654 & 15,690 & $0.23 \%$ \\
\hline 2012 & 2817 & 2816 & $-0.05 \%$ & 17,227 & 16,523 & $-4.09 \%$ \\
\hline 2013 & 3018 & 3042 & $0.79 \%$ & 19,088 & 18,587 & $-2.63 \%$ \\
\hline 2014 & 3274 & 3270 & $-0.10 \%$ & 20,504 & 19,658 & $-4.13 \%$ \\
\hline 2015 & 3466 & 3522 & $1.61 \%$ & 21,023 & 20,164 & $-4.08 \%$ \\
\hline 2016 & 3784 & 3848 & $1.69 \%$ & 20,904 & 20,217 & $-3.29 \%$ \\
\hline
\end{tabular}

\subsection{Simulation Test}

\subsubsection{Setting of Simulation Parameters}

After the system dynamics model is established, simulation test is key to the research. This paper provides quantitative technical support for decision-making of the government and companies by simulating various policy solutions. In fact, when various simulation parameters are taken into account, first the validity of existing data of Xiamen Port is checked. Then, the solutions are compared and selected through parameter hypotheses of several feasible and reasonable solutions. Considering the period length of the data used for history simulation and the uncertainty in the long term to come, the starting year of simulation of the model is set to 2017 and the ending year is set to 2030, with the interval DT $=1$ year, and the model step is 0.625 .

\subsubsection{Scenarios and Solutions}

The paper aims to explore port-city coordinated development based on ecological benefits. In fact, port-city development comes from government and company planning. What we need to do is to analyze the consequences from different port-city system planning with the ecological benefits taken 
into account, to unveil the underlying driving mechanism. Alternatively, we can, without changing the port-city distance, change other factors and compare the extent of impacts from different solutions to see whether there exist differences in the influences of the two cases. The ultimate metrics of the evaluation are the port throughput and GDP at unit socio-economic cost.

Based on this idea, the paper devises the following 15 scenarios. Scenarios 1-5 are based on the current port-city distance. By changing port infrastructure investment (that is, increasing port construction at the original site), use of shoreline resources (that is, improving the port itself and shoreline utilization efficiency), and improvement of environmental governance means (that is, enhancing environmental protection measures and reducing environmental governance cost), we can observe the efficiency change of port-city development. Scenarios 6-10 look at the benefits and impacts from modest increases in the port-city distance (such as relocation of Xiamen Dongdu Port Area to Xiang'an, Houshi, and other port areas). Scenarios 11-15 look at the benefits and impacts from significant changes in the port-city distance (such as relocation of Xiamen Dongdu Port Area to Gulei and other port areas) (see Table 6).

Table 6. Simulation scenarios in the paper.

\begin{tabular}{ccccc}
\hline Scenario & $\begin{array}{c}\text { Contribution } \\
\text { of Investment }\end{array}$ & $\begin{array}{c}\text { Conversion Factor of Shoreline } \\
\text { Resources and Throughput } \\
(\mathbf{m} / \mathbf{1 0 , 0 0 0} \text { Tons) }\end{array}$ & $\begin{array}{c}\text { Unit Cost for Pollutant } \\
\text { Treatment } \\
(\mathbf{1 0 , 0 0 0} \text { Yuan/10,000 Tons) }\end{array}$ & $\begin{array}{c}\text { Port-cityDistance } \\
\text { (km) }\end{array}$ \\
\hline 1 & 0.62 & 1.95 & 0.5 & 5 \\
2 & 0.64 & 1.95 & 0.5 & 5 \\
3 & 0.62 & 1.90 & 0.5 & 5 \\
4 & 0.62 & 1.95 & 0.48 & 5 \\
5 & 0.64 & 1.90 & 0.48 & 5 \\
6 & 0.62 & 1.95 & 0.5 & 20 \\
7 & 0.64 & 1.95 & 0.5 & 20 \\
8 & 0.62 & 1.90 & 0.5 & 20 \\
9 & 0.62 & 1.95 & 0.48 & 20 \\
10 & 0.64 & 1.90 & 0.48 & 100 \\
11 & 0.62 & 1.95 & 0.5 & 100 \\
12 & 0.64 & 1.95 & 0.5 & 100 \\
13 & 0.62 & 1.90 & 0.5 & 100 \\
14 & 0.62 & 1.95 & 0.48 & 100 \\
\hline
\end{tabular}

\subsubsection{Discussion of Results}

Scenario 1 is a basic scenario that has passed the data validity test. This scenario shows that the urban GDP and throughput increase over time, while the port shoreline resources keep declining. This is a natural development, that is, without changing the existing layout, especially without changing the port-city spatial distance, the city and the port can meet the target planned values of urban GDP and throughput, but their development is based on the premise of resource consumption, which is not conducive to ecological protection. Figure 11 shows the simulation results of scenarios 1-5.

Scenarios 2-5 are based on Scenario 1, with only one or two parameters changed, without changing the port-city distance, to evaluate various major parameters and indicators of port-city development. A comparison with Scenario 1 shows that Scenario 2, which increases port investment and port scale, has a significant impact on GDP and throughput growth, but this also leads to rising unit social cost accordingly. Such growth is at the cost of shoreline and land resources; Scenario 3, instead of building new ports, seeks benefits from technology and management, which can indeed lower the unit social cost, but the room for change and improvement is limited and the hidden safety risks may rise if long-term high benefits are sought after; Scenario 4 neither builds new ports nor mines the potential of ports internally. Instead, it enhances its technical expertise to reduce the environmental pollution control expenses. Overall, this approach can lower the unit social cost while driving up the urban GDP, but like Scenario 3, this approach limits the room for growth; Scenario 5 changes two variables at the 
same time, yet is similar to the scenarios that have only one variable changed. Overall, the space for growth is limited.

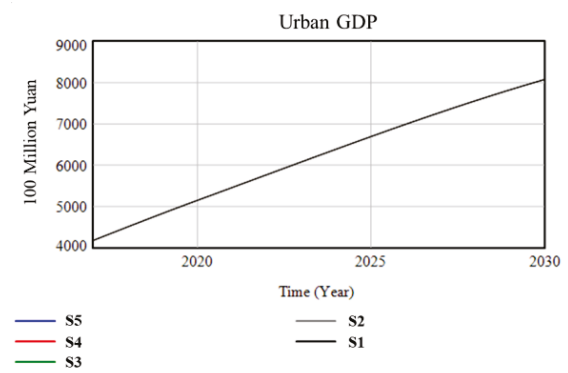

(a)

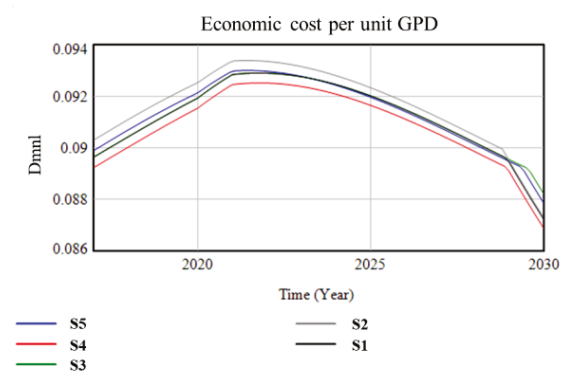

(c)

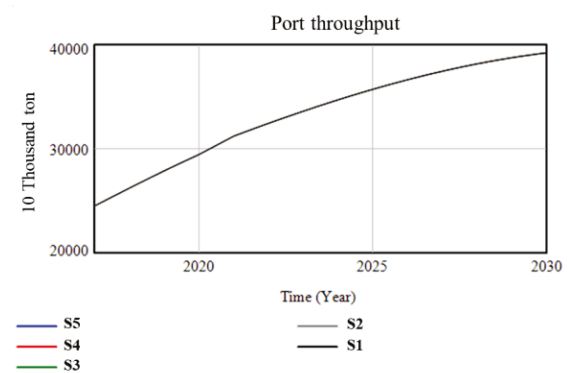

(b)

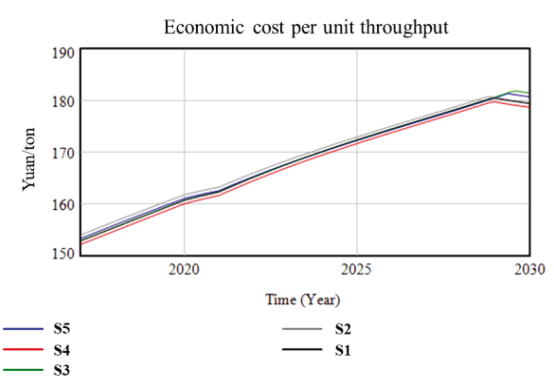

(d)

Figure 11. Simulation results of Scenarios 1-5: (a) Urban GDP, (b) Port throughput, (c) Economic cost per unit GDP and (d) Economic cost per unit throughput. Note: Since the objective of the scenarios is to meet the requirements of urban development for GDP and port throughput to observe the operating efficiency of the port and the city, the GDP and throughput are consistent across scenarios.

Scenarios 6-10 observe the changes of the above indicators to evaluate the entire system by changing the port-city spatial distance. Figure 12 shows the simulation results of scenarios 6-10. A comparison with the basic Scenario 1 shows that Scenario 6 significantly reduces the socio-economic cost on the premise of meeting GDP, throughput, and other indicators. This marks a huge change compared to Scenarios 2-5 and has broad space for development as well; Scenarios 7-10 are similar to Scenarios 2-5; that is, increasing port investment, improving port management, and environmental protection on the basis of Scenario 6. These scenarios also mark improvement over Scenario 6, but the change is not as significant as that between Scenario 1 and Scenario 6 .

Scenarios 11-15 observe the changes of the above indicators to evaluate the entire system by further increasing the port-cityspatial distance. Figure 13 shows the simulation results of scenarios 11-15. A comparison with the basic Scenario 1 and Scenario 6 shows that Scenario 11 posts significant improvement over Scenario 1, but underperforms Scenario 6; that is, the unit socio-economic cost is reduced. This is because in the scenario, the port is too far away from the city and industries, leading to increased cost of the port for cargo collection, distribution, and transportation, which has reduced the efficiency. Scenarios 12-15 are similar to Scenarios 7-10 and 2-5; that is, increasing port investment, improving port management, and environmental protection on the basis of Scenario 11. These scenarios also post improvement over Scenario 11, but they are not as good as Scenarios 7-10. 

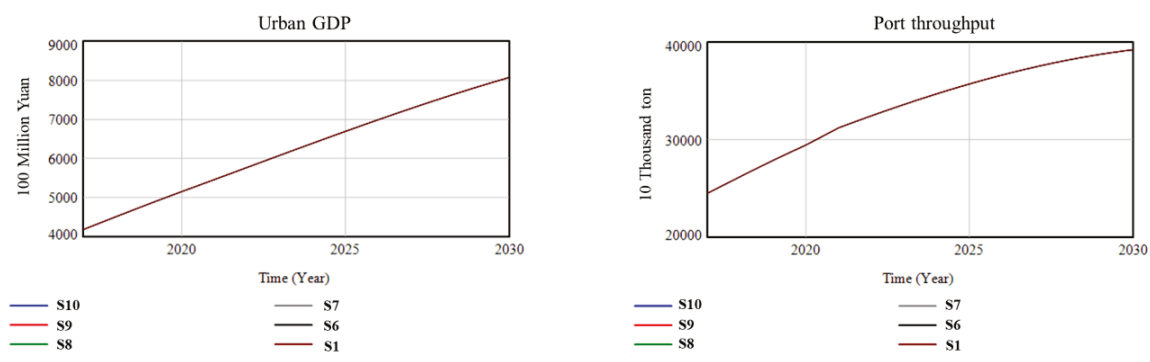

(a)

(b)
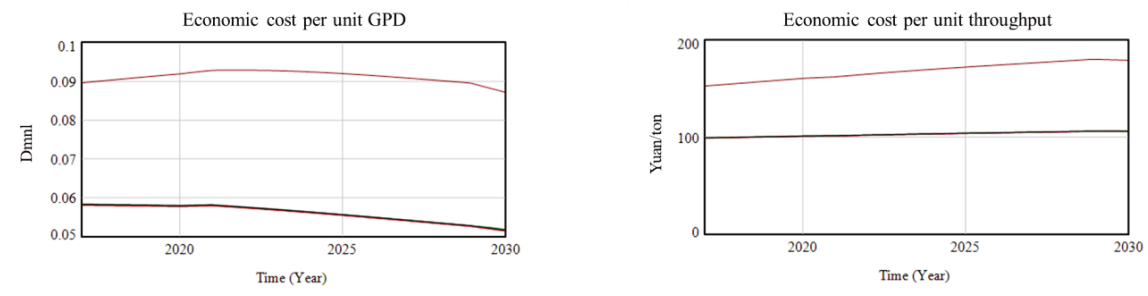

二 $\begin{gathered}\mathrm{s} 10 \\ \mathbf{s} 9 \\ \mathrm{ss}\end{gathered}$

二 $\begin{gathered}\mathrm{s} 7 \\ \mathrm{~s} 6 \\ \mathrm{~s} 1\end{gathered}$

(c)

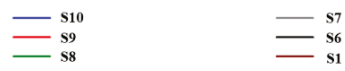

(d)

Figure 12. Simulation results of Scenarios 6-10: (a) Urban GDP, (b) Port throughput, (c) Economic cost per unit GDP and (d) Economic cost per unit throughput.

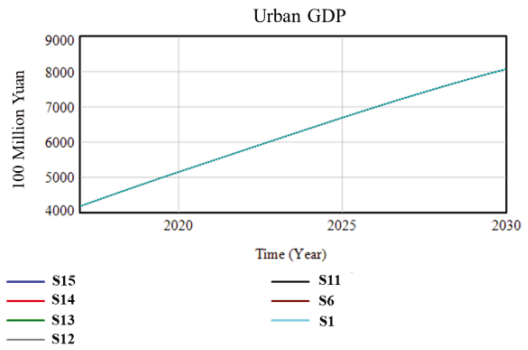

(a)

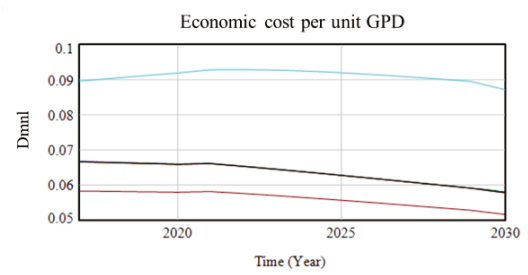

$-\mathrm{S} 15$
$\square$
$\mathrm{S} 14$
$\mathrm{~S} 13$
$\mathrm{~S} 12$

s11
s6
s1

(c)

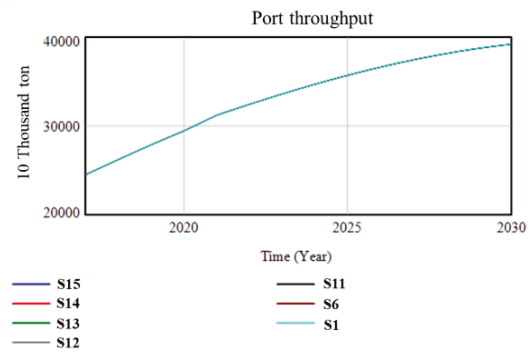

(b)
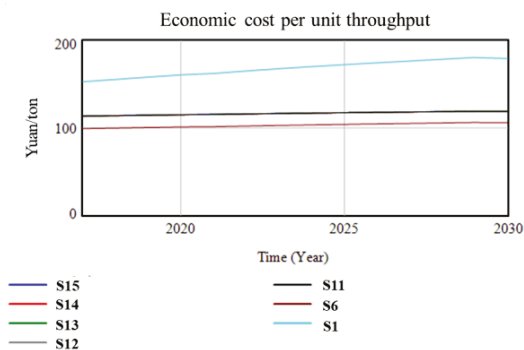

(d)

Figure 13. Simulation results of Scenarios 11-15: (a) Urban GDP, (b) Port throughput, (c) Economic cost per unit GDP and (d) Economic cost per unit throughput. 
To sum up, to boost the ecological benefits of the entire system, Xiamen Port (including the ports in the Xiamen Port region and the Zhangzhou Port region) needs to step out of the island for development and transform from an island-type port to a bay-type one. From the simulation results of the model, only after the port-city spatial distance becomes larger can the efficiency of GDP and port throughput growth be improved; and can the port-city development be coordinated, greener, and more efficient. Therefore, the government should actively plan and construct new port areas and accelerate the relocation and transformation of Dongdu Port Area. However, it is worth noting that the port-city spatial distance cannot be increased indefinitely and should be put within a reasonable range. A layout that scatters over a wide area can increase the cost of cargo collection, distribution and transportation and thereby reduce the system efficiency [35]. Therefore, Xiang'an Port Area and Houshi Port Area among others are suitable for development. Comparatively speaking, Xiang'an Port Area, which is closer to Quanzhou, the hinterland of cargo sources, is an optimal option on the premise of good political relations with Taiwan.

\section{Conclusions and Prospects}

This paper utilizes system dynamics methods to introduce ecological indicators such as land resources and environmental protection to the traditional port-city coordination system model and constructs a new SD model to explore port-city coordinated development based on ecological benefits. The paper makes up for the lack of attention to ecological benefits in port-city coupling systems in existing studies. Through different planning of the port-city system and analysis of the simulation results under different circumstances, the paper tries to find the driving mechanism of port-city spatial changes. Alternatively, without changing the port-city distance, the paper changes other factors to see whether there exist differences in the influences of the two cases. Finally, the planning performance is evaluated based on the port throughput and GDP at unit socio-economic cost and we get the following conclusions. Spatial distance is vital for coordinated port-city development. When the port-city spatial distance moderately increases, the value of the land resources occupied by the port moves down, the impact on the city's environment becomes smaller, and the growth rates of GDP and port throughput increase accordingly. The system also becomes more "ecotypic". However, the port-city spatial distance cannot be too large, as too large a distance will drive up the cost of cargo collection, distribution, and transportation, thereby reducing the efficiency of the port and industry. To address this issue, the paper proposes suggestions to promote coordinated development of Xiamen Port and Xiamen city. First, Xiamen Port (including the ports of the Xiamen Port region and the Zhangzhou Port region) needs to step out of the island and transform from an island-type port to a bay-type one, with the port-city spatial distance put under rational control. Second, under the premise of good political relations with Taiwan, Xiang'an Port Area and Houshi Port Area are more suitable for development, and Xiang'an Port Area, in comparison, is a better option because of being closer to Quanzhou, the hinterland of cargo sources. On the other hand, the port areas that are farther away, such as Gulei, generate lower ecological benefits than Xiang'an or Houshi does because of increased cost of cargo collection, distribution, and transportation. They are more suitable for developing ports that are less correlated with the hinterland, such as the ports supporting rear petrochemical bases.

This paper combines the port-city coupling system and the system dynamics theory to study the port-city spatial relation evolution mechanism under ecological constraints, which makes up for the gap in the existing port-city coupling system research and provides a theoretical direction for further study on the port-city coupling system theories. However, the model in this paper operates under normal development of the society, without considering the impacts of factors such as the international trade environment and situation and natural environment changes on the development of the port-city coupling system. It is a future trend to introduce uncertain factors into the port-city coupling system research. 
Author Contributions: L.Y. and P.X. conceived the research idea, established the mathematical models, and co-wrote the paper. J.S. carried out the result analysis and revised the paper. J.C. and H.Z. designed and supervised this study. All authors have read and agreed to the published version of the manuscript.

Funding: The authors gratefully acknowledge support from the National Natural Science Foundation of China (Grant No. 51879156 and 51409157), Shanghai Pujiang Program(17PJC053), and High-level talent project funding plan of transportation industry supported by the Ministry of Transport of the People's Republic of China (Grant No. 2019-012). However, the authors are solely responsible for all the views and analyses in this paper.

Conflicts of Interest: The authors declare no conflict of interest.

\begin{tabular}{ll} 
Abbreviations & \\
\hline GDP: gross domestic product & TP: freight pressure \\
GGC: GDP growth coefficient & PLO: port land occupation \\
SB: social benefits & SO: shoreline occupation \\
SEC: social economy cost & SOC: shoreline occupancy cost \\
FAI: fixed-asset investment & USOC: unit shoreline occupancy cost \\
FAIR: fixed-asset investment ratio & OLC: land occupancy cost \\
PI: port investment & ULOC: unit land occupancy cost \\
PIR: port investment rate & ROC: resource occupancy cost \\
PR: port revenue & ITC: integrated transport cost \\
CPC: cargo pressure coefficient & ATD: average transport distance \\
IPT: increments of port throughput & FR: freight rate \\
ASL: available shoreline length & IAV: industrial added value \\
CF: construction funds & CIAV: coefficient of industrial added value \\
TCCC: throughput capacity conversion coefficient & PCC: port contribution coefficient \\
IC: investment contribution & ED: effluent discharge \\
PCC: port construction cycle & CED: coefficient of effluent discharge \\
PTS: port throughput supply & EE: exhaust emission \\
PPL: port production load & CEE: coefficient of exhaust emission \\
SAC: shoreline annual consumption & SWD: solid waste discharge \\
CS: coastal resources & EPCE: environmental pollution control expenses \\
TLAS: total length of available shoreline & UECE: unit exhaust control expenses \\
VT: value of trade & USWCE: unit solid waste control expenses \\
TD: trade dependence & UECE: unit effluent control expenses \\
PTD: port throughput demand & ELEP: economic losses from environmental pollution \\
CGC: coefficient of cargo generation & ELC: environmental loss coefficient \\
\hline
\end{tabular}

\section{References}

1. Chen, J.; Huang, T.; Xie, X.; Lee, P.T.W.; Hua, C. Constructing Governance Framework of a Green and Smart Port. J. Mar. Sci. Eng. 2019, 7, 83. [CrossRef]

2. Chen, J.; Xue, K.; Ye, J.; Huang, T.; Tian, Y.; Hua, C.; Zhu, Y. Simplified neutrosophic exponential similarity measures for evaluation of smart port development. Symmetry 2019, 11, 485. [CrossRef]

3. Chen, J.; Zheng, T.; Garg, A.; Xu, L.; Li, S.; Fei, Y. Alternative maritime power application as a green port strategy: Barriers in China. J. Clean. Prod. 2019, 213, 825-837. [CrossRef]

4. Debrie, J.; Raimbault, N. The port-cityrelationships in two European inland ports: A geographical perspective on urban governance. Cities 2016, 50, 180-187. [CrossRef]

5. Hou, L.J.; Geerlings, H. Dynamics in sustainable port and hinterland operations: A conceptual framework and simulation of sustainability measures and their effectiveness, based on an application to the Port of Shanghai. J. Clean. Prod. 2016, 135, 449-456. [CrossRef]

6. Hua, C.; Chen, J.; Wan, Z.; Xu, L.; Bai, Y.; Zheng, T.; Fei, Y. Evaluation and governance of green development practice of port: A sea port case of China. J. Clean. Prod. 2019, 249. [CrossRef]

7. Wang, L.H.; Hong, Y. Spatial structure of container port systems across the Taiwan straits under the direct shipping policy: A complex network system approach. Acta Geogr. Sin. 2016, 71, 605-620. 
8. Boulos, J. Sustainable Development of Coastal Cities-Proposal of a Modelling Framework to Achieve Sustainable City-Port Connectivity. Procedia Soc. Behav. Sci. 2016, 216, 974-985. [CrossRef]

9. Yang, W.Y.; Zhang, G.W. Transportation Geography; Commercial Press: Beijing, China, 1986; pp. 1-305.

10. Wu, C.J.; Gao, X.Z. A model of port-citydevelopment. Geogr. Res. 1989, 4, 9-15.

11. Notteboom, T.; Rodrigue, J. Port regionalization: Towards a new phase in port development. Marit. Policy Manag. 2005, 32, 297-313. [CrossRef]

12. Liang, S.B.; Cao, Y.H.; Wu, W. Evaluation of the comprehensive effect of the interactive development between port backup area and city-The example of Shanghai WaiGaoQiao. Res. Environ. Yangtze Basin 2011, 20, 1411-1417.

13. Guo, J.K.; Du, X.F.; Han, Z.L. Dynamic analysis of influencing factors on the growth of coastal ports in Liaoning province. Geogr. Geo Inf. Sci. 2015, 31, 87-100.

14. Rizzo, A. Rapid urban development and national master planning in Arab Gulf countries. Qatar as a case study. Cities 2014, 39, 50-57. [CrossRef]

15. Ducruet, C.; Wang, J.; Olivier, D.; Notteboom, T.; Slack, B. A metageography of port-cityrelationships Ports, Cities, and Global Supply Chains. Eng. Ashgate Publ. Ltd. 2007, 11, 157-172.

16. Dutt, F.J.; Surinder, C.A. (Eds.) The Asian City: Processes of Development, Characteristics and Planning; Kluwer Academic Publishers: Dordecht, The Netherlands, 1994; pp. 52-61.

17. Akhavan, M. Development dynamics of port-cities interface in the Arab Middle Eastern world: The case of Dubai global hub port-city. Cities 2017, 60, 343-352. [CrossRef]

18. Ye, S.L.; Cao, Y.H.; Wang, J.W. Spatio-temporal evolution characteristics and mechanism of the port logistics system along the Yangtze River. Geogr. Res. 2018, 37, 925-936.

19. Shen, Y.F.; Liu, S.H.; Zhang, J. The correspondence among industrial cluster, city group and port group on the Yangtze River area. Econ. Geogr. 2010, 30, 778-783.

20. Tang, Y.T.; Chan, F.K.S.; Griffiths, J. City profile: Ningbo. Cities 2015, 42, 97-108. [CrossRef]

21. Guo, J.; Wang, S.; Wang, D.; Liu, T. Spatial structural pattern and vulnerability of China-Japan-Korea shipping network. Chin. Geogr. Sci. 2017, 27, 697-708. [CrossRef]

22. Monios, J.; Bergqvist, R.; Woxenius, J. Port-centric cities: The role of freight distribution in defining the port-city relationship. J. Transp. Geogr. 2018, 66, 53-64. [CrossRef]

23. Schipper, C.A.; Vreugdenhil, H.; Jong, D. A sustainability assessment of ports and port-city plans: Comparing ambitions with achievements. Transp. Res. Part D 2017, 57, 84-111. [CrossRef]

24. Gao, Z.Q.; Chang, D.H.; Ye, W.H. On evolvement orientations of port cities: Sustainable development strategies. China Popul. Res. Environ. 2010, 20, 102-109.

25. Vallega, A. Fonctions portuaires et polarizations littorals dans lanouvelle régionalisation de la Méditerranée, quelques réflexions. French-Japanese Geogr. Colloq. 1979, 2, 44-48.

26. Wang, C.; Ducruet, C. New port development and global city making: Emergence of the Shanghai-Yangshan multilayered gateway hub. J. Transp. Geogr. 2012, 25, 58-69. [CrossRef]

27. European Port-Cityinterface and Its Asian Application. Available online: www.researchgate.net/publication/ 41540248 (accessed on 2 April 2020).

28. Chen, H.; Luan, W.X.; Wang, Y.W. Quantitative study on relationship between port function and urban function in China. Geogr. Res. 2009, 28, 475-483.

29. Jiang, L.L.; Wang, S.J.; Liu, Z.H. Evaluation and comparison of size relationship between port and port-city: Taking the port-cities of Liaoning Province as example. Sci. Geogr. Sin. 2011, 31, 1468-1473.

30. Wu, Q. The revolution of port-cityrelationship in modern China (1961-1936): The analysis to the relation concentration index as the example. J. Chin. Hist. Geogr. 2012, 27, 70-81.

31. Liang, S.B.; Cao, Y.H.; Wu, W. The effect analysis of Nanjing city-port interactive development under the background of globalization. Geogr. Res. 2007, 3, 599-608.

32. Yang, S.; Pan, J. Dynamic simulation and regulation of port-citycoupling development: Taking Lianyungang as a case. Geogr. Res. 2011, 30, 1021-1031.

33. Guo, J.K.; Han, Z.L. The port-cityspatial system evolution theory and empirical study of Chinese seaport city. Sci. Geogr. Sin. 2013, 33, 1285-1292. 
34. Berjghe, K.V.D.; Jacobs, W.; Boelens, L. The relational geometry of the port-city interface: Case studies of Amsterdam, the Netherlands, and Ghent, Belgium. J. Transp. Geogr. 2018, 70, 55-63. [CrossRef]

35. Zhao, Q.Y.; Xu, H.; Wall, R.S.; Stavropoulos, S. Building a bridge between port and city: Improving the urban competitiveness of port cities. J. Transp. Geogr. 2017, 59, 120-133. [CrossRef]

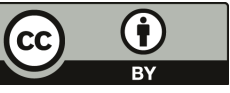

(C) 2020 by the authors. Licensee MDPI, Basel, Switzerland. This article is an open access article distributed under the terms and conditions of the Creative Commons Attribution (CC BY) license (http://creativecommons.org/licenses/by/4.0/). 


\title{
Value Creation through Corporate Sustainability in the Port Sector: A Structured Literature Analysis
}

\author{
Michael Stein * and Michele Acciaro \\ Hapag-Lloyd Center for Shipping and Global Logistics (CSGL), Kühne Logistics University, \\ Großer Grasbrook 17, 20457 Hamburg, Germany; michele.acciaro@the-klu.org \\ * Correspondence: michael.stein@the-klu.org; Tel.: +49-040-328707-0
}

Received: 31 May 2020; Accepted: 27 June 2020; Published: 8 July 2020

\begin{abstract}
Corporate Sustainability (CS) in the port sector has emerged as an important driver behind strategy definition for port authorities globally. It has been argued that CS practices have the potential of delivering value for port users and, as such, grant port operators and port managing entities competitive advantages. There is, however, limited evidence behind this claim. The difficulty with collecting such evidence is that we lack measures of port value creation, and CS metrics have rarely been developed and applied in ports. This paper provides a framework for collecting empirical evidence aimed at assessing in what way CS can benefit port competitiveness. The framework is built on a systematic literature analysis of the past years. The literature analysis exceeds previous comparable contributions by its analytical detail and provides valuable new insights on sustainability in the maritime domain. The research indicates that the accurate measurement of CS initiatives in the port sector is urgent and meaningful. When appropriately measured, the value that CS can deliver to port users becomes apparent. This is, however, often created indirectly via branding, risk mitigation, etc. The paper contributes to academic knowledge as it is the first to develop a rigorous CS measurement framework usable for ports in terms of value.
\end{abstract}

Keywords: corporate sustainability; green ports; scale development; stakeholders; corporate social responsibility

\section{Introduction}

Ports have been working on improving their sustainability profiles in the last decades, and few ports globally can afford today to ignore the negative impacts associated with the economic activities taking place within or in the proximity of the port. As awareness for environmental and social issues increases globally, port sustainability is not a matter for developed countries only, although there are still the major ports in Europe, Asia, and North America that lead the way on environmental and social issues. Climate change has also played an important role in creating awareness of sustainability practices in the maritime sectors [1]. The increasing presence of green marketing and promotion among major ports, for example, is a sign of the perceived need of port administrators to profile the port in the eye of an increasingly critical public opinion. Although there is a great variety in the degree of commitment towards sustainability among ports [2], there is a general tendency towards making sure that everything good the port does in terms of reducing its negative impacts is publicized.

In addition to the materials made available on the Internet, port authorities and other port managing entities have developed strategic documents and sustainability reports that show how port managers intend to develop the port further and what has been achieved in the last years. Some of these documents are probably more exercises in public relations than hard commitments towards sustainability, but their publication has contributed to facilitating and informing the broader debate on sustainable ports. While this debate is far from coming to a close, the increasing attention to enhancing sustainability in ports is certainly a positive development. 
This tendency has generated a renewed interest among both academics and port specialists in the processes and drivers behind the formulation of such sustainability strategies, their effectiveness, and their impacts on port management. Although environmental and social issues among ports are not a new topic, it has been suggested elsewhere [3] that the overall deregulation that has characterized the port industry in the last decades has certainly increased the value associated with developing corporate social responsibility (CSR) among port authorities and, consequently, the need for port-specific CSR strategies.

Over the last decade, growing interest in corporate social responsibility as well as environmental impacts of and within the maritime sector increased due to pressing global concerns related to climate change and citizen mobilization on port- and shipping-related issues [4]. The media coverage of environmental issues, such as oil spills, and protest action, such as in the case of port workers' strikes, continue to maintain the visibility of port sustainability issues to the general public and have initiated questions of accountability [5]. Port managing corporations have been forced to start shifting their main objectives beyond profit maximization to include sustainable performance [6]. It is regarded as necessary to extend stakeholder involvement in maritime governance and to embrace a larger sustainable co-operation between stakeholders in the shipping industry $[7,8]$. In addition, buyer-driven environmental upgrading is being increasingly recognized as important, although it is not likely to result in change in management practices and operation unless it is supported by clear, predictable, and enforceable global regulations [9].

Port economic activities generate a wide range of external environmental and societal effects [10]. Port authorities are demanded to take action to minimize the negative impacts on their communities as well as society in general, and strive to maximize the value generated by port activities. In many ports around the world, port authorities are also responsible for the development and implementation of port expansion plans, and the assessment of the benefits and costs associated with such expansions is critical. Port authorities generally also act as landlords, and they exert a great influence on the definition of the terms of concession agreements and in the provision of incentives for terminal operators and port users. It is, therefore, understandable that they are often obliged to take responsibility for social and environmental effects deriving from port activities and that they should closely regard such impacts.

Ports are the locations of a variety of environmental effects, some of which derive from the nature of port business itself; others stem from the proximity of ports to urban and industrial sites, and others are the results of the specific topographies of port areas at the intersection between water and land. A distinction can be made between natural and anthropogenic pressures for ports [11]. These pressures often result in conflicts on port resource utilization, primarily land and water, which include commercial cargo loading and unloading operations, industrial activities, tourism, fisheries, and nature preservation. Given the scarcity in many regions of the world of port areas and the high costs of developing new ports, these conflicts are likely to increase in relevance over time.

Pressure to improve sustainability among production and distribution of goods has raised new challenges in all stages of the supply chain and in most industries. Nowadays, ports find themselves in the position to balance commercial and economic growth on the one side and the reduction of negative environmental and social effects on the other side. Ports, as part of a supply chain network, are required to deal with short-term views, private and public interests, and commercial and social objectives, as they are considered responsible for a wider set of environmental impacts [12,13].

Port authorities have, then, an important part to play in the moderation and resolution of such conflicts. They need to safeguard the commercial and economic interests of the port, but, given the public-private character of many port authorities around the world, are also entrusted with protecting the interest of the public and of the local port communities, on which, in the end, their agency depends. The management of stakeholders can be considered as one of the main tasks of port authorities [12].

However, little is known when it comes to measurement and quantification sustainability in port operations. It is the intention of this paper to shed light on port sustainability measurements by developing a framework to collect and benchmark empirical indicators for sustainability in ports. 
Existing environmental rating schemes in the shipping sector are often unclear and inconsistent in their data collection, thus creating difficulty in providing uniform measures across a very heterogenous industry [9].

This paper builds on the necessity of structuring data collection processes in port sustainability. After a brief introduction on the definition and main aspects regarding CSR in the maritime industry in Section 2, the research methodology is presented in Section 3. The methodology is split into a literature review as well as a framework analysis. Section 4 presents a conceptual framework for sustainability data collection in ports based on the literature. Section 5 concludes and discusses the limitations of the research.

\section{Sustainability and Corporate Social Responsibility}

\subsection{Definition of Sustainability}

Various contributions on the topic of sustainability in the industry vary with their specific definitions of the topic. The most widely accepted basic definition follows the so-called Brundtland Commission or World Commission on Environment and Development (WCED) of the United Nations in 1987. Sustainable development was defined as "development that meets the needs of the present without compromising the ability of future generations to meet their own needs". In other words, it was later adopted as "increasing the welfare of the present generation while simultaneously not decreasing the welfare of the next generation" [14]. Following Elkington [15], the context of sustainability was understood as a holistic concept comprising the three unique aspects of economic, environmental, and social sustainability, which is often referred to as the triple bottom line (TBL). He connected sustainability to the process of simultaneously achieving three inter-linked goals-economic prosperity, environmental protection, and social equity. This combination of three inter-linked aspects (economic, environmental, and social) was adopted by the United Nations Commission on Sustainable Development (UNCSD) in 2011, and is widely accepted in the literature of the past decade (see, for example, $[1,6,16,17]$ ). It is pointed out by Lu et al. [16] that the difference between the terms "sustainability" and "green" is significant. Although the terms are often used interchangeably, "sustainability" needs to include the consideration on economic, environmental, and societal issues, while "green" is focused only the environment. It should be stressed that when addressing any economic, environmental, or societal issue, one is rapidly confronted with their interrelations. From a maritime viewpoint, the concept of the green port was initially proposed in 2009 during the United Nations Climate Change conference, according to Wang et al. [18], and primarily focused on low-carbon emission ports. The concept of the sustainable port appeared in the literature later (e.g., [3]).

\subsection{Perception of Sustainability}

As already pointed out, port infrastructure, operations, and port-related industrial and economic activities have adverse consequences on the environment and are held responsible for negative external effects $[10,19]$. Ports facilitate commercial and economic growth on the one hand, but also reduce the quality of air and marine water in their vicinities on the other hand [13].

It has been highlighted that sustainability is increasingly seen as one "key driver in port development for the next decades" [1]. It is stated that ports must "plan and manage their operations and future expansion (growth) in a sustainable way in order to cope with the limited or decreased environmental space and intensified interactions with their hinterlands" [1]. On the port management side, CSR management strategies are, therefore, moving from a cost-saving orientation towards resilience and a value-adding sustainability-focused regime [1].

Environmental impacts of the shipping industry are perceived as more and more severe, including air pollutant emissions, oil and chemical water pollution, litter, sewage, and invasive species in ballast water [20]. Furthermore, the abuse of maritime policies with the use of flags of 
convenience to avoid national or regional regulation and tax evasion is characteristic for this industry [8]. Yliskylä-Peuralahti et al. [21] characterize two types of companies competing with each other in the shipping market: "Those companies that are responsible and focus on high-quality shipping and those that focus on providing low-cost services at the expense of safety and the environment". However, with increasing customer awareness, NGO campaigns, and emerging regulations, both national and international, aiming at enhancing the environmental impact of production and transportation of goods, the whole shipping sector (as well as other corporate actors) is driven to address the footprint linked to their transport service.

First, shipping companies and ports do realize the competitive advantages of sustainability as an instrument to enhance service quality as part of the company's differentiation strategy [22]. Unfortunately, globalization, the competitive maritime environment, and its weak regulatory frameworks led to a situation where responsible shipping companies often stand in a lower competitive position relative to companies focusing on short-term gains. This aspect is enhanced especially when non-sustainable companies diffuse CSR practices within the industry by co-operating with each other in alliances [8]. In addition, the lack of enforcement mechanisms and missing stakeholder pressure led to a relatively low number of shipping companies and ports participating in CSR practices so far.

On the regulatory side, regulations take a long time until coming into force, which often reduces the necessity for port operators to act, thus slowing down changes. Frankel [23] already included the impact of ballast water on port design in the 1980s. It is also stated that "the impacts on surface water quality are caused by generated sewage, bilge wastes, sludge, waste, oil discharges, and leakages of harmful materials both from shore and ships" [13]. After two decades of complex negotiations between IMO (International Maritime Organization) Member States, the International Convention for the Control and Management of Ships' Ballast Water and Sediments (BWM Convention) was finally adopted in 2004. Within this scope, the "Guidelines for approval of ballast water management systems (G8) have been revised in 2016 and converted into a mandatory Code for approval of ballast water management systems (BWMS Code), which was adopted by MEPC 72 (April 2018) and enters into force in October 2019" (IMO, 2019).

With slow and heterogeneous regulations on the one side and high competition on the other side, a growing number of contributions consider a pressure from the industry and non-financial stakeholders as well as customers and other institutions, such as banks, as relevant $[8,9]$.

\subsection{Gains from Implementing Corporate Social Responsibility}

CSR is nowadays connected to a variety of advantageous factors in the maritime domain, with a growing number of indicators in the literature. On the social/ecological side, it was indicated that port-authority-driven environmental efforts raised the positive image of the local community, thus building trust in the port [24]. Without doubt, the economic aspect of CSR will have the most weight in a company's decision to change or adopt responsible measures. Studies also indicate a positive correlation between CSR efforts and economic advantages. CSR in shipping is claimed to provide an added advantage for firms by differentiating their services, avoiding port state interventions, receiving permissions to operate in environmentally sensitive areas, and improving the image for recruiting new personnel [25,26]. It is furthermore shown by Drobetz et al. [27] that "responsible firms, which contribute both economically and ethically to the society and local communities they serve, are better positioned to grow in terms of reputation and revenues". According to the Porter hypothesis [28] that was transferred to maritime sustainability by Cheon et al. [29], "stringent environmental policies and regulations can facilitate firms' efficiency and innovation, thus contributing to their ability to accomplish various sustainable development objectives". In addition to this rather general statement, more narrow aspects supporting this theory in the shipping industry were found. One example for financial CSR gains is shown by Drobetz et al. [27], stating that an increased CSR transparency lowers information costs on the investor's side, leading to potential positive financial effects. In addition, decreased environmental incidents within a port reduce damage rates, benefitting the port's service 
reputation and attracting more customers [29]. Ref. [6] reveals that socially responsible activities among shipping firms will positively affect customer satisfaction, which appears to be related to public recognition of the firm. Their results imply that a shipping company facing tight competition can have a competitive edge if it satisfies its customers, since this will result in customers' long-term commitment and loyalty [6]. The case study of Wilhelm Wilhelmsen indicates how CSR rationales are already adopted by firms, including a variety of economically advantageous aspects, such as "managing risk, improving resource efficiency and access to capital, responding to or pre-empting regulations, encouraging innovation, and building future market opportunities" [30].

\subsection{Challenges of Introducing Corporate Social Responsibility in the Maritime Sector}

Despite being the most important cargo transport mode in terms of cargo numbers, the maritime transport sector is still "perceived as one of the laggards in processes of environmental upgrading" [31]. A number of reasons have been identified in the literature, indicating a certain challenge in introducing sustainability into this domain. When describing the maritime domain, one must differentiate between the shipping and the port side; however, understanding each individual challenge is necessary for a holistic understanding.

The ship owner side is affected by the challenge of highly cyclical markets with small margins [9], where the demand on transport services is derived from a variety of micro- and macro-factors in different producing industries. While many maritime studies seem to disregard this aspect by only focusing on one shipping niche, Ref. [9] found evidence suggesting a more differentiated evaluation on shipping sectors with regard to sustainability. According to them, the large shipping segments of dry bulk, tankers, and containers vary in their characteristics of relationships between cargo owners and transport service providers (shipping companies). They name "differences in type of cargo, trade distribution patterns, market concentration and ownership, contract length, and bargaining power dynamics" as reasons for their assumption. According to their research, the container market ships branded goods (container), where cargo owners start placing demands on shipping companies about their environmental performance. In tanker shipping, where oil-producing corporations represent the transport-service-requiring firms, environmental concerns about oil spills are present, as those generate high costs and damage the customer's brand due to wide media coverage.

In contrast, the dry bulk shipping market has minimal to no interest in environmental performance, as raw materials are further processed and not linked to any end customer. Consumer pressure in the bulk shipping segment is perceived as secondary given the business-to-business nature of this transport industry, with low media visibility on its environmental impact [7,9]. According to Poulsen et al. [9], "without the explicit governance traits of either strong buyer or supplier power, environmental upgrading is fundamentally absent in dry-bulk shipping". Compared to other shipping industry sectors, the cruising industry provides a different example of consumer pressure with increasing demand on CSR practices [8]. It is shown that, among these major shipping markets, buyer-driven pressure on environmental upgrading, as a result of the cargo being directly linked to the final brand customer, is key for environmental developments in the shipping sector.

A basic challenge for shipping firms remains in offering their shipping operations, being profitable and coping with competition, and increasing their environmental footprint at the same time [32]. The shipping sector has a need to remain attractive to investors and freight customers, as well as to regulators and present and future employees, were each fraction has different demands on sustainability. Furthermore, the challenge of excess shipping tonnage in the market over the past decade further drives shipping firms to lower costs [5]. On the employer side, the "size of the shipboard crew has been dramatically reduced and the profession tends to be characterized by relatively inferior working conditions and high insecurity due to short-term contracts and a high crew turnover" [8].

On the port side, it is indicated that "while ports are certainly aware of environmental initiatives, they are only realized when they are deemed economically feasible in the short term, and have no negative implications for operational efficiency," according to Veyvar et al. [17]. They base this 
assumption on "immense cost pressures and customers' unwillingness to pay for environmental protection in port operations." A fundamental challenge lies in a port's inability to move due to high investment barriers in setting up its infrastructure. The "presence of ports that cannot exit the market, despite low performance, also triggers greater performance variation among ports that face strong competitive pressure," according to Cheon et al. [33]. The relatively high entry barriers of environmental investments were also highlighted by Poulsen et al. [9]. Veyvar et al. [17] summarize that "while win-win situations between multiple dimensions of sustainability are possible, it is necessary to balance the different dimensions due to trade-off situations." Industries characterized by financial pressure on service costs and strong competition are particularly faced with difficulties in justifying investments without tangible effects or immediate payoff and operability [17]. It is stated that the location of a port also affects its sustainable ability, as rural ports are faced with a requirement for investments in training and education on sustainability to deal with the scarcity of skilled personnel in rural areas.

\section{Methodology}

\subsection{Comparison with Past Literature Reviews}

Table 1 shows a comparison of literature reviews of maritime and other comparable supply chain sustainability contributions. Each review follows a systematic approach, as presented in Tranfield et al. [34] or similar contributions. Although the authors of [34] state that systematic reviews shall "minimize bias through exhaustive literature searches", a closer look into the methodology of these reviews reveals potential improvement in the criteria used for literature selection. The authors of [35] limited their sampling to contributions with a minimum of 25 citations. From a qualitative viewpoint, this method is likely to exclude potentially important contributions, especially those of the last years of the timeframe, as citations grow over time. Other contributions, such as [36-39], only conducted an abstract analysis by screening for relevant (and the most important) subjectively chosen topics.

The authors argue that both title and abstract consist of a brief description of a research, but are not enough to provide a clear and full comprehension of a contribution. Clustering contributions through a literature analysis is an important step in science, requiring going "beyond mere descriptions of the paper" [40]. The gaps revealed among the past contributed literature reviews in the area of sustainability, however, indicate that the analyses were not comprehensive or that the basics tenets of systematic literature reviews, as proposed by [34,40], were not adhered to.

Table 1. Comparisons among various literature review contributions.

\begin{tabular}{cccccc}
\hline Publisher & Year & Scope & Timeframe & Sample & Ratio \\
\hline \multicolumn{7}{c}{ Maritime sustainability literature reviews } \\
\hline [35] Sislian et al. & 2016 & 198 & $1987-2013$ & 49 & 0.247 \\
\hline [39] Lim et al. & 2019 & 704 & $1990-2017$ & 21 & 0.030 \\
\hline [41] Davarzani et al. & 2016 & 2180 & $1975-2014$ & 338 & 0.155 \\
\hline [42] Bjerkan and Seter & 2019 & 148 & $2010-2018$ & 70 & 0.473 \\
\hline [43] Hakam and Solvang & 2013 & 334 & $1985-2012$ & N.A. & N.A. \\
\hline This study & 2020 & 104 & $2016-2020$ & 72 & 0.692 \\
\hline \multicolumn{6}{c}{ Other supply-chain sustainability literature reviews } \\
\hline [36] Tachizawa and Wong & 2014 & 681 & $1976-2014$ & 39 & 0.057 \\
\hline [37] Centobelli et al. & 2017 & 415 & $1960-2014$ & 46 & 0.111 \\
\hline [38] Evangelista et al. & 2018 & 582 & $2000-2016$ & 88 & 0.151 \\
\hline [44] Rajeev et al. & 2017 & 1068 & $2000-2015$ & 59 & 0.055 \\
\hline [45] Aguinis and Glavas & 2012 & 588 & $1970-2011$ & 181 & 0.308 \\
\hline
\end{tabular}

Another crucial factor in past literature reviews is the ratio of the actual sample compared to the scope of articles reviewed. Past contributions mainly considered a ratio of only $5-16 \%$ (see [36-41]), 
while few contributions considered more than $20 \%$ [35,45], and only Ref. [42] considered almost half of their scope with $47 \%$. The authors argue that disregarding the majority of contributions in a literature analysis is most likely to create bias in the results, as many disregarded contributions might have contained valuable information about the research topic. This argument is further underlined by the intangible nature of sustainability itself, creating difficulties in weighing, measuring, and comparing using statistical techniques. This aspect makes it even more crucial to maintain a qualitative view on the topic and to gather bits of information from various contributions in order to create knowledge as a whole.

\subsection{Literature Analysis Description}

The literature analysis followed the methodology of a systematic literature review based on $[34,40]$. The analysis aimed to identify articles published in peer-reviewed and open-access journals in the English language from no earlier than January 2016 to provide contemporary insights into the broad aspect of maritime sustainability. The authors included open-access journals, such as "Sustainability", because relevant insights into a research topic are not exclusively reserved for peer-reviewed journals, especially when research is innovative, thus lacking a certain basis of knowledge. There were several reasons for considering the short timeframe of only 4.5 years, ranging from January 2016 until June 2020.

Firstly, the analysis follows up on the work of Acciaro (2015) [3], who already provided a detailed discussion on CSR value creation in the port sector based on an extensive literature analysis. Secondly, the concept of CSR-based literature analysis in the maritime domain is not new, and has been evaluated by various contributions (see $[35,36,39,41,43-45]$ ). However, a detailed look at these contributions reveals a gap in recent contributions after 2015, as displayed in Table 2 below. Thirdly, the authors aimed to reflect the contemporary aspect of maritime sustainability. As regulations and orientations (both political and economic) change due to geopolitical events, so changes the focus on sustainability, requiring evidence based on recent contributions of the most recent years. This aspect is not chosen randomly, but follows the approach of [42] that already addressed this aspect.

Table 2. Comparisons among various literature review contributions.

\begin{tabular}{cc}
\hline Year of Publication & Number of Contributions \\
\hline 2016 & 20 \\
2017 & 17 \\
2018 & 22 \\
2019 & 10 \\
2020 (till June) & 3 \\
\hline Sum & 72 \\
\hline
\end{tabular}

The literature review was conducted using online databases by applying the following keyword structure, as shown in Table 3. All contributions were read completely before being regarded/disregarded for the final review. The contributions were checked for cross-references to studies made in the area of interest. Those cross-references were taken into account to enhance the reliability of this study's literature review. In total, 104 contributions were identified, of which 32 were excluded for not meeting the requirements. Among the excluded contributions, 20 did not contribute to the research topic in terms of content (12 "port pricing", 6 "CSR in Shipping", 1 "port sustainable pricing", 1 port incentives), 4 contributions were university-owned publications outside any journal, and 8 contributions were book chapters or conference proceedings. Only Bjerkan and Seter [42] provided a comparable level of detail by choosing their sample and including cross-references. In total, the literature research revealed 72 out of 104 contributions, resulting in a ratio of $69.2 \%$, or a sample reduction of only $30.8 \%$. 
Table 3. Keyword search matrix.

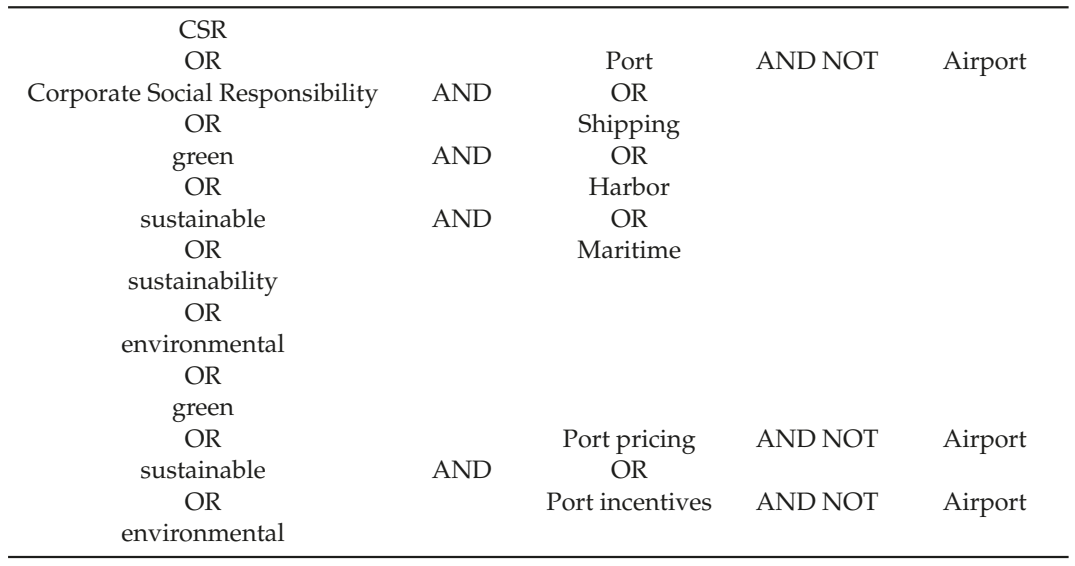

The 72 considered contributions were distributed among the years 2016-2020 and are shown in Table 2. The research was conducted until June 2020, so that the annual number of related contributions could be estimated to reach a comparable number. The sample contributions are distributed among 23 journals, with the top five journals accounting for $54.1 \%$ of the sample, and are distributed among Transportation Research Part D (16), Maritime Policy \& Management (10), Sustainability (6), The Asian Journal of Shipping and Logistics (5), and Marine Policy (4), as shown in Table 4.

Table 4. Comparisons among various literature review contributions.

\begin{tabular}{cc}
\hline Journal & Contributions \\
\hline Transportation Research Part D & 16 \\
Maritime Policy \& Management & 10 \\
Sustainability & 7 \\
The Asian Journal of Shipping and Logistics & 5 \\
Marine Policy & 4 \\
Journal of Cleaner Production & 3 \\
Energy Policy & 3 \\
Maritime Economics \& Logistics & 2 \\
Journal of Business Ethics & 2 \\
Environmental Science and Policy & 2 \\
WMU Journal on Maritime Affairs & 2 \\
Transport Policy & 2 \\
Geoforum & 2 \\
International Journal on Shipping and Transport Logistics & 2 \\
Research in transportation business \& management & 2 \\
Marine Pollution Bulletin & 1 \\
Sustainable Development & 1 \\
Journal of Marine Science and Engineering & 1 \\
Safety Science & 1 \\
Ocean and Coastal Management & 1 \\
Transportation Research Record & 1 \\
Journal of Transport Geography & 1 \\
International Journal of Logistics Management & 1 \\
\hline Total & 72 \\
\hline
\end{tabular}

Out of the 72 contributions of the sample, 19 were of a theoretical nature, 42 of a practical nature, and 11 used a mixed-method approach. Out of the non-theoretical studies, 15 contributions were 
conducted in Asia, 18 in Europe, 11 globally, 8 in North America, and 1 in Africa. The distribution of the contributions is displayed in Figure 1.

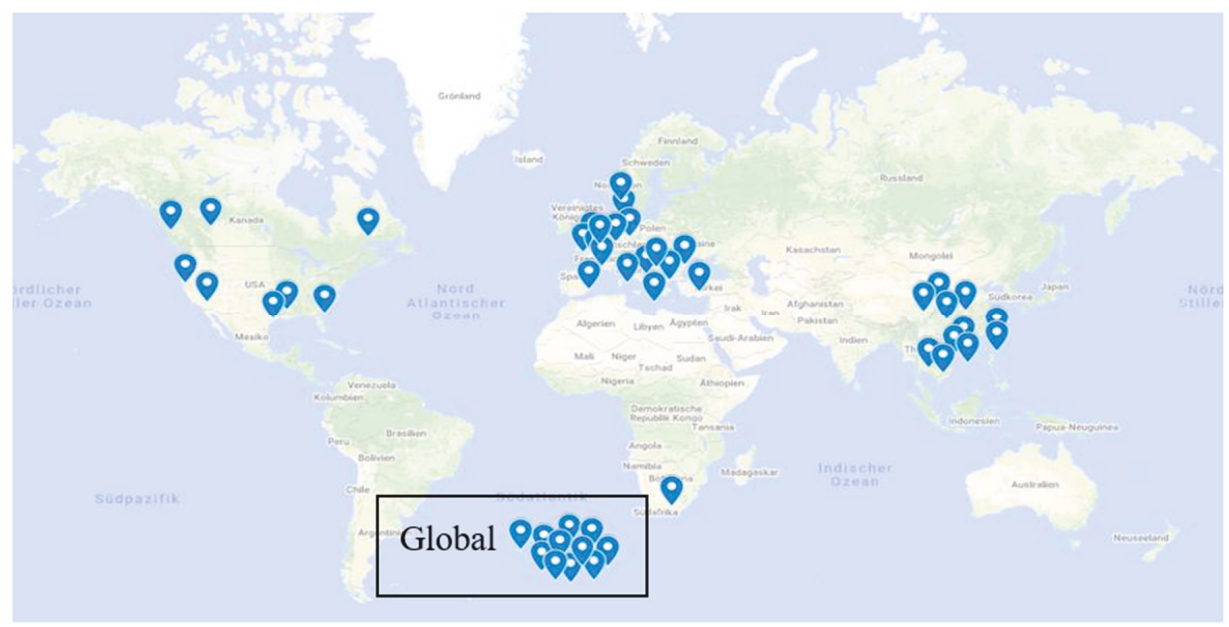

Figure 1. Global distribution of the sample's research. Source: Authors (2020) using Google Maps.

On the basis of the literature review, a conceptual framework was created (see Table 5). A conceptual framework is defined as an either visual or written product explaining the key factors, concepts, or variables to be studied and the presumed relationships among them [46]. Studies furthermore pointed out the importance of structured frameworks as a basic contribution for future research (see $[46,47])$. This paper focuses on providing a structured basis to empirically understand and measure sustainable action in the maritime domain. The combination of a conceptual framework analysis based on a structured in-depth literature analysis of contemporary contributions was, therefore, chosen to be a relevant and well-suited research tool.

Table 5. Framework clustering.

\begin{tabular}{|c|c|c|}
\hline Cluster & Usable Framework & Contributions \\
\hline \multirow{3}{*}{ Underlying theories } & Corporate social responsibility (CSR)-affecting theories & [33] \\
\hline & CSR customer satisfaction theories & [22] \\
\hline & CSR theories & {$[29,38]$} \\
\hline \multirow{9}{*}{ CSR policy and decisions } & Policy initiatives and practices & {$[9,19,48]$} \\
\hline & Port examples on environmental strategies & [17] \\
\hline & Power/fuel topics & [42] \\
\hline & Top 10 environmental priorities in EU ports mentioned & [49] \\
\hline & Policy initiatives and practices & [50] \\
\hline & Owner alliances & [8] \\
\hline & Ship rating schemes & [8] \\
\hline & Green hinterland strategy matrix & [51] \\
\hline & Instruments available to port authorities & [52] \\
\hline \multirow{4}{*}{ Affecting factors } & Port competition & [53] \\
\hline & Management's perception/concerns about CSR & {$[5,6]$} \\
\hline & Implementation complexity & [54] \\
\hline & Stakeholders & [55] \\
\hline
\end{tabular}


Table 5. Cont.

\begin{tabular}{ccc}
\hline Cluster & Usable Framework & Contributions \\
\hline \multirow{3}{*}{ Measurements } & Sustainability performance measurements & {$[1,16,56-59]$} \\
\cline { 2 - 3 } & Environmental Performance Indicators & {$[60]$} \\
\cline { 2 - 3 } & & {$[61]$} \\
\cline { 2 - 3 } & & {$[62]$} \\
\cline { 2 - 3 } & Particular Matter 10 comparison of ship/shore energy sources & {$[63]$} \\
\cline { 2 - 3 } & Generic energy mapping and consumption & {$[64]$} \\
\hline
\end{tabular}

Among the 72 evaluated contributions from 2016-2020, several contributions provided individual frameworks with regard to various topics of sustainability in the maritime sector. In sum, 32 frameworks were identified and clustered into the four topics of CSR measurements (12), CSR policy and decisions (11), CSR-affecting factors (5), and underlying theories regarding CSR in the maritime sector (4). Four contributions provided a qualitative evaluation of the basic theories that affect or cause CSR actions in the maritime domain. These studies range from general CSR-affecting theory [33] over customer satisfaction theory [22] to general CSR theories [29,55] CSR policy initiatives and practices were evaluated in eleven studies from 2016-2019. Both theories and policy practices reflect a rather qualitative view of CSR in shipping, but only provide a limited capability of actually building empirical evidence regarding this topic. For the sake of this paper's research, focus will be shifted towards extracting information on how to measure CSR operations. In sum, 18 contributions provided frameworks that indicated how to measure CSR or CSR-related values in the maritime domain. Factors affecting CSR were differentiated in port competition factors [53].

The managements' perceptions of CSR [5,6], CSR implementation complexity [54], and stakeholders [55], as well as measurements regarding CSR-related factors, were evaluated among 12 studies. These studies range from sustainability performance measurements (6) over environmental performance indicators (3) to other indicators (3). A detailed survey of the identified frameworks is provided in Table 6.

Table 6. Economic factors.

\begin{tabular}{|c|c|c|c|}
\hline Cluster & Aspect & Measurement & Source \\
\hline \multirow{6}{*}{ Income and profitability } & Amount of cargo handled & annual cargo volume & {$[56]$} \\
\hline & Productivity/throughput/growth & cargo volume per vessel & {$[56,57,61]$} \\
\hline & Corporate and property taxes & tax income & {$[56]$} \\
\hline & Input cost & costs & {$[56]$} \\
\hline & Investment and market share & investment amount, market share & {$[6,61]$} \\
\hline & Management efficiency & & {$[56]$} \\
\hline \multirow{5}{*}{ Service quality } & Hinterland connection & $\begin{array}{l}\text { meters of transport ways, } \\
\text { amounts of connections }\end{array}$ & {$[61,66]$} \\
\hline & Quality of handling & $\begin{array}{l}\text { numbers of accidents, } \\
\text { environmental impact per } \\
\text { handling }\end{array}$ & {$[6,53,61]$} \\
\hline & Port operations & qualitative questionnaires & {$[53,56]$} \\
\hline & Port charges & costs & {$[56]$} \\
\hline & Input cost & costs & {$[56]$} \\
\hline \multirow{5}{*}{ Macro-value } & GDP generation & GDP income & {$[56,57,66]$} \\
\hline & Tax generation & tax income & {$[56]$} \\
\hline & Trade facilitation & trade amounts & [56] \\
\hline & Cruise tourism & passenger numbers & {$[61]$} \\
\hline & Traffic & transhipments, cargo handling & {$[53,61]$} \\
\hline
\end{tabular}


Given the limitations of this paper's research, the framework analysis focused on contributions regarding affecting factors and measurements of studies that already contributed. The TBL approach was applied to differentiate measurements into categories of economic (Table 6), social (Table 7), and environmental (Table 8) factors.

Table 7. Social factors.

\begin{tabular}{|c|c|c|c|}
\hline Cluster & Aspect & Measurement & Source \\
\hline \multirow{5}{*}{ Community impact } & Employment & number of jobs created & {$[6,56,61,66]$} \\
\hline & Safety & number of safety incidents & {$[56,62]$} \\
\hline & Security & number of security incidents & {$[62]$} \\
\hline & Resilience & recovery time & {$[57,61]$} \\
\hline & Heritage and cultural impact & existing Yes/No & {$[56,61]$} \\
\hline \multirow{3}{*}{ Employment quality } & CSR communication/education & quality of training & {$[1,5,16,58,60]$} \\
\hline & CSR decision involvement & existing Yes/No & {$[16]$} \\
\hline & Corporate culture & existing Yes/No & {$[16,58,67]$} \\
\hline \multirow{5}{*}{$\begin{array}{l}\text { Legal and political } \\
\text { benefits }\end{array}$} & CSR policy & existing Yes/No & {$[1,5,6,16,58,60]$} \\
\hline & CSR information publication & number of reports & {$[5,16,58,68]$} \\
\hline & CSR efforts beyond compliance & existing Yes/No & {$[1,58]$} \\
\hline & $\begin{array}{l}\text { Establishment of evaluation } \\
\text { indicators }\end{array}$ & existing Yes/No & {$[1,58]$} \\
\hline & Green port development plan & plan existing & {$[1,5,54,60]$} \\
\hline
\end{tabular}

Table 8. Environmental factors.

\begin{tabular}{|c|c|c|c|}
\hline Cluster & Aspect & Measurement & Source \\
\hline \multirow{4}{*}{$\begin{array}{l}\text { Water pollution } \\
\text { management }\end{array}$} & Fuel spill contingency plan & existing Yes/No & {$[58]$} \\
\hline & Ballast water pollutant control & existing Yes/No & {$[6,58,61]$} \\
\hline & Cargo spill control prevention & existing Yes/No & {$[58]$} \\
\hline & Sewage/wastewater treatment & existing Yes/No & {$[56-58,60,66]$} \\
\hline \multirow{8}{*}{ Eco-efficiency } & Hazard waste management & existing Yes/No & {$[56,58,62,69,70]$} \\
\hline & $\begin{array}{l}\text { Solid waste dumping } \\
\text { management }\end{array}$ & existing Yes/No & {$[56-58,60]$} \\
\hline & Energy consumption & in $\mathrm{KW} / \mathrm{h}$ & {$[16,58,60-62,66,70-72]$} \\
\hline & Water consumption & in liters & {$[60,62,69,70]$} \\
\hline & Waste generation & in tons & {$[60,66,70,71]$} \\
\hline & $\begin{array}{l}\text { Green materials/designs for } \\
\text { construction }\end{array}$ & existing Yes/No & {$[1,16,58]$} \\
\hline & Heat generation & & {$[58]$} \\
\hline & Energy quality & renewable source Yes/No & {$[16,54,58,63,64,68,72]$} \\
\hline \multirow{8}{*}{$\begin{array}{l}\text { Air pollution } \\
\text { management }\end{array}$} & Speed/combustion reduction & existing Yes/No & {$[1,58,60]$} \\
\hline & $\begin{array}{l}\text { Regulations on the emissions } \\
\text { of toxic gas }\end{array}$ & existing Yes/No & {$[16,54,57,58,62,69-71]$} \\
\hline & Cold ironing & existing Yes/No & {$[1,58,72]$} \\
\hline & $\begin{array}{c}\text { Encouraging the use of } \\
\text { low-sulphur fuel }\end{array}$ & existing Yes/No & {$[1,54,58,72]$} \\
\hline & $\begin{array}{l}\text { Encouraging public transport } \\
\text { mode development }\end{array}$ & existing Yes/No & {$[58]$} \\
\hline & Light emissions & sustainable source Yes/No & {$[58,60]$} \\
\hline & Dust control & existing Yes/No & {$[16,58]$} \\
\hline & $\begin{array}{l}\text { Emission reduction due to } \\
\text { berth allocation }\end{array}$ & in tons & {$[73-77]$} \\
\hline
\end{tabular}


Table 8. Cont.

\begin{tabular}{cccc}
\hline Cluster & \multicolumn{1}{c}{ Aspect } & Measurement & Source \\
\hline \multirow{4}{*}{ Noise control } & Noise reduction & in decibels & {$[58]$} \\
\cline { 2 - 4 } & Regulations on noise control & existing Yes/No & {$[57,58,66,70]$} \\
\cline { 2 - 4 } & $\begin{array}{c}\text { Avoiding disturbance to the } \\
\text { community during } \\
\text { infrastructure construction } \\
\text { and expansion }\end{array}$ & & {$[58]$} \\
\hline \multirow{4}{*}{$\begin{array}{c}\text { Marine ecological } \\
\text { protection and biology } \\
\text { system preservation }\end{array}$} & $\begin{array}{c}\text { Wetland and marine habitat } \\
\text { preservation }\end{array}$ & existing Yes/No & {$[56,58,61]$} \\
\cline { 2 - 4 } & $\begin{array}{c}\text { Reducing infrastructure } \\
\text { disturbance to marine biology } \\
\text { density }\end{array}$ & & {$[56,58,61,70]$} \\
\cline { 2 - 4 } & $\begin{array}{c}\text { Port entrance sediment and } \\
\text { coastal erosion control }\end{array}$ & existing Yes/No & {$[58,61]$} \\
\cline { 2 - 4 } & Soil and sediment quality & existing Yes/No & {$[62,69,70]$} \\
\cline { 2 - 4 } & Biotope creation & existing Yes/No & {$[61,66]$} \\
\cline { 2 - 4 } & Tree planting in port area & {$[16,58]$} \\
\cline { 2 - 4 } & Dredging sediment disposal & {$[58,61,66]$} \\
\cline { 2 - 4 } & Ballast water pollutant control & existing Yes/No & {$[58,61]$} \\
\hline
\end{tabular}

Economic factors can be differentiated into clusters of income and profitability, service quality, and macro-values. While the clusters of income and profitability and service quality reflect internal economic CSR factors, the aspect of macro-values draws a broader picture. It is once more shown that ports, although being a major source of pollution and ecological disturbance, do create a benefit for their surrounding society in terms of welfare, job generation, and tourism. A holistic CSR discussion should always keep both advantages and disadvantages in mind.

\section{Framework Analysis}

Although social and environmental factors are widely covered in the evaluated literature, the individual measurements often refer to a simple existing/non-existing question in the beginning. Further research should focus on the cost structure of a port operation and its connection to port operating costs.

On the basis of the literature, the conceptual framework presented in Figure 2 is proposed. External factors include regulation, macroeconomic conditions, port governance, and societal perceptions. They influence port business activities as well as constraint port strategy. Port business generates economic, social, and environmental impacts. How port business activities generate these impacts is the result of CSR activities. The impacts also shape the CSR, which is seen as an integral part of corporate strategy. Assuming that the main objective of a port business strategy is value creation, future research should find reliable metrics of value and impacts and empirically assess how CSR actions impact value creation in the port sector. 


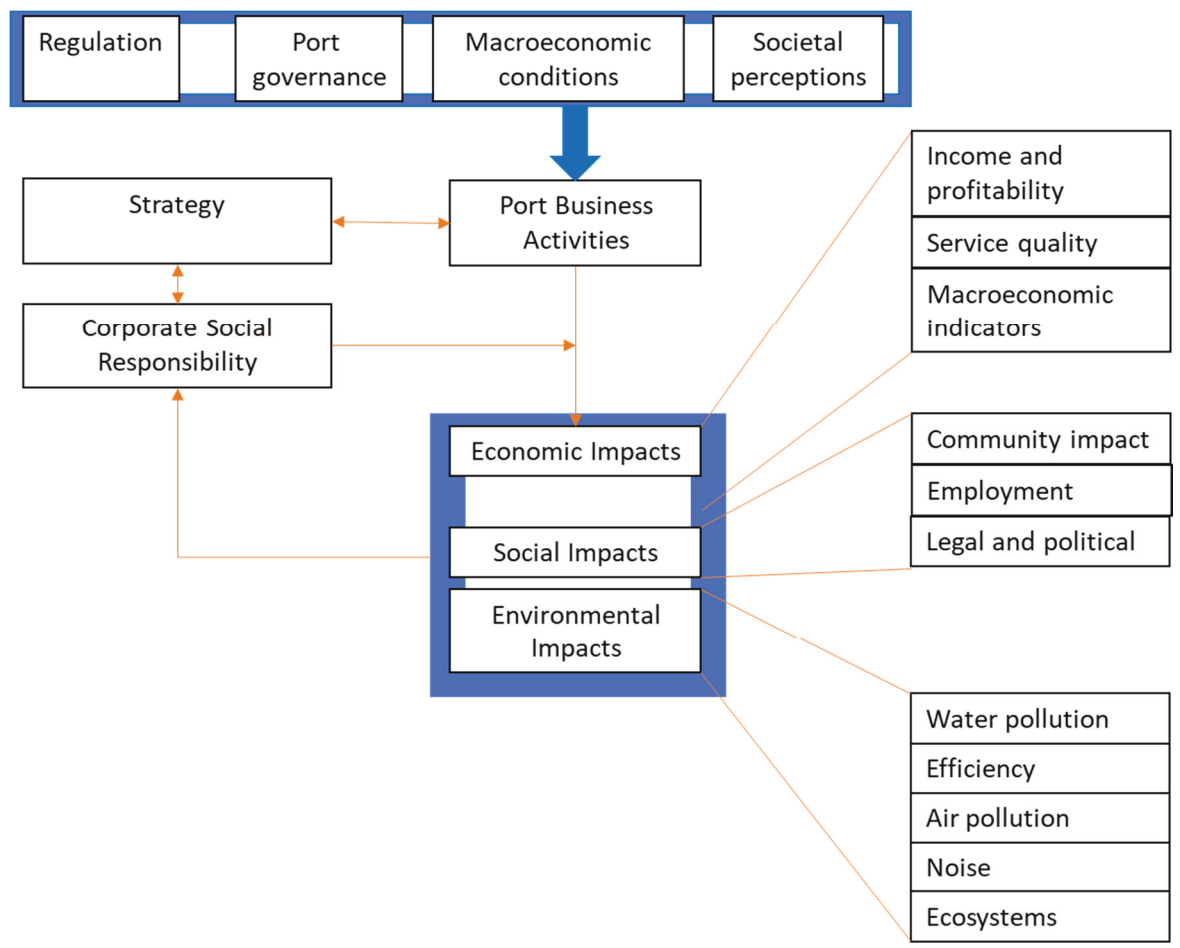

Figure 2. Proposed conceptual framework.

\section{Conclusions}

Building empirical evidence on an intangible asset such as sustainability is a challenging yet important task for maritime academics and for port managers. Sustainability will remain a top priority for the maritime industry, and increasing pressure will be placed on global value chains to reduce their social and environmental impacts. It is therefore important to develop structured approaches to measure the benefits of sustainability and to increase sustainability visibility in the maritime chains. This paper conducted a detailed analysis on maritime sustainability literature. A total of 104 contributions were analyzed in detail, and 16 existing frameworks developed in previous sustainability studies were connected. The framework links applicable measurements of sustainable action to port operations based on academic contributions of the past decade.

In comparison to prior literature analyses on CSR in the maritime industry as well as other transport logistics areas, the analysis conducted here exceeds previous studies through its in-depth analysis and sample size. It is the first study that sheds light on the very contemporary aspect of CSR literature after 2016, and provides new and valuable insights for academia, stakeholders, and policyand decision-makers. The proposed conceptual framework uses the triple bottom line approach of known CSR discussions.

This paper contributes to academic knowledge, as it is the first to develop a Corporate Sustainability (CS) measurement framework that is usable for ports in terms of value creation. The paper is beneficial to society and business, since it offers a framework that can be applied in practice to measure the effectiveness of CS initiatives in terms of value for ports.

Based on the limitations of this paper as a literature analysis, future research should:

- $\quad$ Test and refine the proposed framework; 
- Enhance the framework on the basis of similar studies in other domains;

- Determine adequate metrics to measure value and impacts;

- Develop an economic model to evaluate the relationship between port business activities and CSR;

- Test the framework by quantifying the value of CSR activities to specific port cases and then across ports.

Since CSR in the maritime domain remains an ongoing discussion in the academic context, the need for contributions that close the gap between theory and practice is of benefit for future environmental awareness within the maritime transport sector. This contribution provides a solid basis for future research on value creation and value measurement on CSR operations in ports on a contemporary basis of the most recent years.

Author Contributions: M.S.: Design of the study, conducting the literature analysis, interpretation of the data, conception of the paper, implementation of reviewer suggestions; M.A.: quality control, assistance in writing the paper, framework creation. All authors have read and agreed to the published version of the manuscript.

Funding: This research has been supported by the Social Sciences and Humanities Research Council of Canada (SSHRC) project (No 895-2017-1003): "Green Shipping: Governance and Innovation for a Sustainable Maritime Supply Chain". The APC are paid by the Hapag-Lloyd Center for Shipping and Global Logistics (CSGL).

Conflicts of Interest: The authors declare no conflict of interest.

\section{References}

1. Lu, C.S.; Lai, P.L.; Chiang, Y.P. Container Terminal Employees' Perceptions of the Effects of Sustainable Supply Chain Management on Sustainability Performance. Marit. Policy Manag. 2016, 43, 597-613. [CrossRef]

2. Lam, J.S.L.; Notteboom, T. The Greening of Ports: A Comparison of Port Management Tools Used by Leading Ports in Asia and Europe. Transp. Rev. 2014, 34, 169-189. [CrossRef]

3. Acciaro, M. Corporate Responsibility and Value Creation in the Port Sector. Int. J. Logist. Res. Appl. 2015, 18, 291-311. [CrossRef]

4. Lai, K.H.; Lun, Y.H.V.; Wong, C.W.Y.; Cheng, T.C.E. Measures for Evaluating Green Shipping Practices Implementation. Int. J. Shipp. Transp. Logist. 2013, 5, 217-235. [CrossRef]

5. Lam, J.S.L.; Lim, J.M. Incorporating Corporate Social Responsibility in Strategic Planning: Case of ShipOperating Companies. Int. J. Shipp. Transp. Logist. 2016, 8, 273-293. [CrossRef]

6. Shin, Y.; Thai, V.V. A Study of the Influence of Sustainable Management Activities on Customer Satisfaction and Long-Term Orientation in the Shipping Industry: Evidence from Users of Korean Flagged Shipping Service. Int. J. Shipp. Transp. Logist. 2016, 8, 1-20. [CrossRef]

7. Yliskylä-Peuralahti, J.; Gritsenko, D. Binding Rules or Voluntary Actions? A Conceptual Framework for CSR in Shipping. WMU J. Marit. Aff. 2014, 13, 251-268. [CrossRef]

8. Parviainen, T.; Lehikoinen, A.; Kuikka, S.; Haapasaari, P. How Can Stakeholders Promote Environmental and Social Responsibility in the Shipping Industry? WMU J. Marit. Aff. 2018, 17, 49-70. [CrossRef]

9. Poulsen, R.T.; Ponte, S.; Lister, J. Buyer-Driven Greening? Cargo-Owners and Environmental Upgrading In Maritime Shipping. Geoforum 2016, 68, 57-68. [CrossRef]

10. Dinwoodie, J.; Truck, S.; Knowles, H.; Benhin, J.; Sansom, M. Sustainable Development of Maritime Operations in Port. Bus. Strategy Environ. 2012, 21, 111-126. [CrossRef]

11. Vandermeulen, J.H. Environmental Trends of Ports and Harbors: Implications for Planning and Management. Marit. Policy Manag. 1996, 23, 55-66. [CrossRef]

12. Dooms, M.; Verbeke, A.; Haezendonck, E. Stakeholder Management and Path Dependence in Large-Scale Transport Infrastructure Development: The Port of Antwerp Case (1960-2010). J. Transp. Geogr. 2013, 27, 14-25. [CrossRef]

13. Roh, S.; Thai, V.V.; Wong, Y.D. Towards Sustainable Asean Port Development: Challenges and Opportunities for Vietnamese Ports. Asian J. Shipp. Logist. 2016, 32, 107-118. [CrossRef]

14. Pearce, D.W.; Warford, J.J. The Concepts of Sustainable Development: World without End: Economics, Environment, and Sustainable Development; Oxford University Press: Oxford, UK, 1993.

15. Elkington, J. Towards the Sustainable Corporation: Win-Win-Win Business Strategies for Sustainable Development. Calif. Manag. Rev. 1994, 36, 90-100. [CrossRef] 
16. Lu, C.S.; Shang, K.C.; Lin, C.C. Examining Sustainability Performance at Ports: Port Managers' Perspectives on Developing Sustainable Supply Chains. Marit. Policy Manag. 2016, 43, 909-927. [CrossRef]

17. Vejvar, M.; Lai, K.H.; Lo, C.K.; Fürst, E.W. Strategic Responses to Institutional Forces Pressuring Sustainability Practice Adoption: Case-Based Evidence from Inland Port Operations. Transp. Res. Part D Transp. Environ. 2018, 61, 274-288. [CrossRef]

18. Wang, G.; Li, K.X.; Xiao, Y. Measuring Marine Environmental Efficiency of a Cruise Shipping Company Considering Corporate Social Responsibility. Mar. Policy 2019, 99, 140-147. [CrossRef]

19. Acciaro, M.; Vanelslander, T.; Sys, C.; Ferrari, C.; Roumboutsos, A.; Giulliano, G.; Lam, J.S.L.; Kapros, S. Environmental Sustainability In Seaports: A Framework for Successful Innovation. Marit. Policy Manag. 2014, 41, 480-500. [CrossRef]

20. Lindgren, J.F.; Brynolf, S.; Wilewska-Bien, M.; Andersson, K. (Eds.) Shipping and the Environment: Improving Environmental Performance in Marine Transportation; Springer: Berlin/Heidelberg, Germany, 2016.

21. Yliskylä-Peuralahti, J.; Gritsenko, D.; Viertola, J. Corporate Social Responsibility and Quality Governance in Shipping. Ocean Yearb. 2015, 29, 417-440. [CrossRef]

22. Yuen, K.F.; Thai, V.V. Corporate Social Responsibility and Service Quality Provision in Shipping Firms: Financial Synergies or Trade-Offs? Marit. Policy Manag. 2017, 44, 131-146. [CrossRef]

23. Frankel, E.G. Port Planning and Development; John Wiley \& Sons Inc.: Hoboken, NJ, USA, 1987.

24. Puig, M.; Wooldridge, C.; Michail, A.; Darbra, R.M. Current Status and Trends of the Environmental Performance in European Ports. Environ. Sci. Policy 2015, 48, 57-66. [CrossRef]

25. Thai, V.V.; Balasubramanyam, L.; Yeoh, K.K.L.; Norsofiana, S. Revisiting the Seafarer Shortage Problem: The Case of Singapore. Marit. Policy Manag. 2013, 40, 80-94. [CrossRef]

26. Österman, C.; Rose, L. Assessing Financial Impact of Maritime Ergonomics on Company Level: A Case Study. Marit. Policy Manag. 2015, 42, 555-570. [CrossRef]

27. Drobetz, W.; Merikas, A.; Mrika, A.; Tsionas, M.G. Corporate Social Responsibility Disclosure: The Case of International Shipping. Transp. Res. Part E 2014, 71, 18-44. [CrossRef]

28. Porter, M.; Van Der Linde, C. Toward A New Conception of the Environment-Competitiveness Relationship. J. Econ. Perspect. 1995, 9, 97-118. [CrossRef]

29. Cheon, S.; Maltz, A.; Dooley, K. The Link Between Economic and Environmental Performance of The Top 10 Us Ports. Marit. Policy Manag. 2017, 44, 227-247. [CrossRef]

30. Hargett, T.R.; Williams, M.F. Wilh. Wilhelmsen Shipping Company: Moving from CSR Tradition to CSR Leadership. Corp. Gov. 2009, 9, 73-82. [CrossRef]

31. Lister, J.; Poulsen, R.T.; Ponte, S. Orchestrating Environmental Governance in Maritime Shipping. Glob. Environ. Chang. 2015, 34, 185-195. [CrossRef]

32. Cheng, Y.H.; Tsai, Y.L. Factors Influencing Shippers to Use Multiple Country Consolidation Services in International Distribution Centers. Int. J. Prod. Econ. 2009, 122, 78-88. [CrossRef]

33. Cheon, S.; Song, D.W.; Park, S. Does more competition result in better port performance? Marit. Econ. Logist. 2018, 20, 433-455. [CrossRef]

34. Tranfield, D.; Denyer, D.; Smart, P. Towards A Methodology for Developing Evidence-Informed Management Knowledge by Means of Systematic Review. Br. J. Manag. 2003, 14, 207-222. [CrossRef]

35. Sislian, L.; Jaegler, A.; Cariou, P. A Literature Review on Port Sustainability and Ocean's Carrier Network Problem. Res. Transp. Bus. Manag. 2016, 19, 19-26. [CrossRef]

36. Tachizawa, M.E.; Yew Wong, C. Towards A Theory of Multi-Tier Sustainable Supply Chains: A Systematic Literature Review. Supply Chain Manag. Int. J. 2014, 19, 643-663. [CrossRef]

37. Centobelli, P.; Cerchione, R.; Esposito, E. Environmental Sustainability in the Service Industry of Transportation and Logistics Service Providers: Systematic Literature Review and Research Directions. Transp. Res. Part D Transp. Environ. 2017, 53, 454-470. [CrossRef]

38. Evangelista, P.; Santoro, L.; Thomas, A. Environmental Sustainability in Third-Party Logistics Service Providers: A Systematic Literature Review From 2000-2016. Sustainability 2018, 10, 1627. [CrossRef]

39. Lim, S.; Pettit, S.; Abouarghoub, W.; Beresford, A. Port Sustainability and Performance: A Systematic Literature Review. Transp. Res. Part D Transp. Environ. 2019, 72, 47-64. [CrossRef]

40. Denyer, D.; Tranfield, D. Producing a Systematic Review. In The Sage Handbook of Organizational Research Methods; Sage Publications Ltd.: Thousand Oaks, CA, USA, 2009; pp. 671-689. 
41. Davarzani, H.; Fahimnia, B.; Bell, M.; Sarkis, J. Greening Ports and Maritime Logistics: A Review. Transp. Res. Part D Transp. Environ. 2016, 48, 473-487. [CrossRef]

42. Rajeev, A.; Pati, R.K.; Padhi, S.S.; Govindan, K. Evolution of Sustainability in Supply Chain Management: A Literature Review. J. Clean. Prod. 2017, 162, 299-314. [CrossRef]

43. Aguinis, H.; Glavas, A. What We Know and Don't Know About Corporate Social Responsibility: A Review and Research Agenda. J. Manag. 2012, 38, 932-968. [CrossRef]

44. Bjerkan, K.Y.; Seter, H. Reviewing Tools and Technologies for Sustainable Ports: Does Research Enable Decision Making In Ports? Transp. Res. Part D Transp. Environ. 2019, 72, 243-260. [CrossRef]

45. Hakam, M.H.; Solvang, W.D. Container Ports Sustainability-A Literature Review. In IEEE 4th International Conference on Cognitive Infocommunications (Coginfocom); IEEE: Piscataway, NJ, USA, 2013; pp. 803-810.

46. Shields, P.; Rangarajan, N. A Playbook for Research Methods: Integrating Conceptual Frameworks and Project Management; New Forums Press: Stillwater, OK, USA, 2013.

47. Miles, M.B.; Hubermann, A.M. Qualitative Data Analysis: A Sourcebook of New Methods; Sage: Beverly Hills, CA, USA, 1994.

48. Ashrafi, M.; Acciaro, M.; Walker, T.R.; Magnan, G.M.; Adams, M. Corporate sustainability in Canadian and US maritime ports. J. Clean. Prod. 2019, 220, 386-397. [CrossRef]

49. Hossain, T.; Adams, M.; Walker, T.R. Sustainability initiatives in Canadian ports. Mar. Policy 2019, 6, 103519. [CrossRef]

50. Chen, C.; Lam, J.S.L. Sustainability and interactivity between cities and ports: A two-stage data envelopment analysis (DEA) approach. Marit. Policy Manag. 2018, 45, 944-961. [CrossRef]

51. Aregall, M.G.; Bergqvist, R.; Monios, J. A global review of the hinterland dimension of green port strategies. Transp. Res. Part D Transp. Environ. 2018, 59, 23-34. [CrossRef]

52. Notteboom, T.; Lam, J. The greening of terminal concessions in seaports. Sustainability 2018, $10,3318$. [CrossRef]

53. Esmer, S.; Nguyen, H.O.; Bandara, Y.M.; Yeni, K. Non-price competition in the port sector: A case study of ports in Turkey. Asian J. Shipp. Logist. 2016, 32, 3-11. [CrossRef]

54. Poulsen, R.T.; Ponte, S.; Sornn-Friese, H. Environmental upgrading in global value chains: The potential and limitations of ports in the greening of maritime transport. Geoforum 2018, 89, 83-95. [CrossRef]

55. Lam, J.S.L.; Yap, W.Y. A stakeholder perspective of port city sustainable development. Sustainability 2019, 11, 447. [CrossRef]

56. Xiao, Z.; Lam, J.S.L. A systems framework for the sustainable development of a Port City: A case study of Singapore's policies. Res. Transp. Bus. Manag. 2017, 22, 255-262. [CrossRef]

57. Wan, C.; Zhang, D.; Yan, X.; Yang, Z. A novel model for the quantitative evaluation of green port development-A case study of major ports in China. Transp. Res. Part D Transp. Environ. 2018, 61, 431-443. [CrossRef]

58. Chen, Z.; Pak, M. A Delphi analysis on green performance evaluation indices for ports in China. Marit. Policy Manag. 2017, 44, 537-550. [CrossRef]

59. Teerawattana, R.; Yang, Y.C. Environmental performance indicators for green port policy evaluation: Case study of Laem Chabang port. Asian J. Shipp. Logist. 2019, 35, 63-69. [CrossRef]

60. Di Vaio, A.; Varriale, L.; Alvino, F. Key performance indicators for developing environmentally sustainable and energy efficient ports: Evidence from Italy. Energy Policy 2018, 122, 229-240. [CrossRef]

61. Schipper, C.A.; Vreugdenhil, H.; De Jong, M.P.C. A sustainability assessment of ports and port-city plans: Comparing ambitions with achievements. Transp. Res. Part D Transp. Environ. 2017, 57, 84-111. [CrossRef]

62. Antão, P.; Calderón, M.; Puig, M.; Michail, A.; Wooldridge, C.; Darbra, R.M. Identification of occupational health, safety, security (OHSS) and environmental performance indicators in port areas. Saf. Sci. 2016, 85, 266-275. [CrossRef]

63. Kotrikla, A.M.; Lilas, T.; Nikitakos, N. Abatement of air pollution at an Aegean island port utilizing shore side electricity and renewable energy. Mar. Policy 2017, 75, 238-248. [CrossRef]

64. Boile, M.; Theofanis, S.; Sdoukopoulos, E.; Plytas, N. Developing a Port Energy Management Plan: Issues, Challenges, and Prospects. Transp. Res. Rec. 2016, 2549, 19-28. [CrossRef]

65. Shiau, T.A.; Chuen-Yu, J.K. Developing an indicator system for measuring the social sustainability of offshore wind power farms. Sustainability 2016, 8, 470. [CrossRef]

66. Geerts, M.; Dooms, M. Sustainability Reporting for Inland Port Managing Bodies: A Stakeholder-Based View on Materiality. Sustainability 2020, 12, 1726. [CrossRef] 
67. Notteboom, T.; Lugt, L.V.D.; Saase, N.V.; Sel, S.; Neyens, K. The Role of Seaports in Green Supply Chain Management: Initiatives, Attitudes, and Perspectives in Rotterdam, Antwerp, North Sea Port, and Zeebrugge. Sustainability 2020, 12, 1688. [CrossRef]

68. Lam, J.S.L.; Li, K.X. Green port marketing for sustainable growth and development. Transp. Policy 2019, 84, 73-81. [CrossRef]

69. Seguí, X.; Puig, M.; Quintieri, E.; Wooldridge, C.; Darbra, R.M. New environmental performance baseline for inland ports: A benchmark for the European inland port sector. Environ. Sci. Policy 2016, 58, 29-40. [CrossRef]

70. Puig, M.; Pla, A.; Seguí, X.; Darbra, R.M. Tool for the identification and implementation of Environmental Indicators in Ports (TEIP). Ocean Coast. Manag. 2017, 140, 34-45. [CrossRef]

71. Roos, E.C.; Neto, F.J.K. Tools for evaluating environmental performance at Brazilian public ports: Analysis and proposal. Mar. Pollut. Bull. 2017, 115, 211-216. [CrossRef] [PubMed]

72. Iris, C.; Lam, J.S.L. A review of energy efficiency in ports: Operational strategies, technologies and energy management systems. Renew. Sustain. Energy Rev. 2019, 112, 170-182. [CrossRef]

73. Venturini, G.; Iris, Ç.; Kontovas, C.A.; Larsen, A. The multi-port berth allocation problem with speed optimization and emission considerations. Transp. Res. Part D Transp. Environ. 2017, 54, 142-159. [CrossRef]

74. Du, Y.; Chen, Q.; Quan, X.; Long, L.; Fung, R.Y. Berth allocation considering fuel consumption and vessel emissions. Transp. Res. Part E Logist. Transp. Rev. 2011, 47, 1021-1037. [CrossRef]

75. Wang, T.; Li, M.; Hu, H. Berth allocation and quay crane-yard truck assignment considering carbon emissions in port area. Int. J. Shipp. Transp. Logist. 2019, 11, 216-242. [CrossRef]

76. Peng, Y.; Wang, W.; Liu, K.; Li, X.; Tian, Q. The Impact of the allocation of facilities on reducing carbon emissions from a green container terminal perspective. Sustainability 2018, 10, 1813. [CrossRef]

77. Liu, D.; Ge, Y.E. Modeling assignment of quay cranes using queueing theory for minimizing $\mathrm{CO}_{2}$ emission at a container terminal. Transp. Res. Part D Transp. Environ. 2018, 61, 140-151. [CrossRef]

(C) 2020 by the authors. Licensee MDPI, Basel, Switzerland. This article is an open access article distributed under the terms and conditions of the Creative Commons Attribution (CC BY) license (http://creativecommons.org/licenses/by/4.0/). 

Article

\title{
Sustainability Reporting for Inland Port Managing Bodies: A Stakeholder-Based View on Materiality
}

\author{
Magali Geerts * and Michaël Dooms \\ Department of Business, Vrije Universiteit Brussel, B-1050 Brussels, Belgium; michael.dooms@vub.be \\ * Correspondence: magali.geerts@vub.be
}

Received: 31 January 2020; Accepted: 21 February 2020; Published: 25 February 2020

\begin{abstract}
Sustainability reporting has been marked by a rise in importance in recent years as it has proved to be an important management tool in the understanding of where an organization is situated along the sustainability pathway. However, industries have shown different behaviors towards embracing this practice. In this paper, we turn our attention to the port industry, using the metropolitan inland Port of Brussels (Belgium) as a case study. Given the contested nature of port activities within urban regions, metropolitan inland ports are expected to benefit from the development of a sustainability report as it allows a more transparent account of the contribution of port activities to the objectives of different stakeholder groups in the urban environment. The case study is based on a survey yielding 74 valid responses from different stakeholder groups (employees, clients, and broader society). Our results show that the expected content of a sustainability report is viewed differently by these various stakeholder groups in terms of the relative importance of the dimensions of the Triple Bottom Line (TBL), as well as in terms of the specific indicators representing material issues. Furthermore, the concept of boundary setting with respect to the different dimensions of the TBL and the desired level of inclusion by stakeholders during the development of a sustainability report are differently assessed. The paper is of interest to academics as well as policy makers, as the research results complement the existing insights on sustainability reporting in general and can be used as basis to stimulate the adoption of sustainability reporting by inland ports.
\end{abstract}

Keywords: sustainability reporting; inland ports; Triple Bottom Line; materiality analysis; stakeholder management; boundary setting

\section{Introduction}

In the present business environment, organizations are under pressure by diverse groups of stakeholders to pay attention to 'sustainability' when they report about their performance. Existing literature and recent research show that the term 'sustainability' and associated management and reporting practices are mostly centered around three large domains, namely economic, social, and environmental-in other terms the Triple Bottom Line or TBL dimensions (people, planet, and profit). From a historical perspective, the end of the 19th century was characterized by the emergence of the practice of financial reporting. About a century later, the importance of social and environmental aspects linked to business activities had increased and hence stimulated organizations to publish additional nonfinancial information [1]. Since then, a remarkable increase in the availability of information related to the (positive/negative) effects of an organization's operations in terms of both social and environmental aspects can be observed [2,3]. Most of the largest global companies, i.e., $93 \%$ of the top 250 companies listed in the Fortune Global 500 ranking (also called the G250) [4], are investing time and resources to report and communicate on what can be defined as sustainable performance [3], which is reflected in an increase in the practice of sustainability reporting of almost $60 \%$ since KPMG's first survey on the topic in 1999. The TBL concept is often used as a framework to operationalize the 
content of a sustainability report [5], as it is based on the same three dimensions (economic, social, and environmental) that are required in a sustainability report, as stated by the Global Reporting Initiative (GRI) definition [6].

While initially multinational corporations have been central in the sustainability debate, as well as in scientific research around the topic, the scope has recently been broadened to organizations in general. However, international reporting guidelines and standards (such as the GRI), as well as codes of conduct, are still largely built upon the features of larger organizations. Due to this development, there exists a reporting gap between large multinationals and small-medium enterprises (SMEs) [7], as the latter category is constrained by human and financial resources [8]. In general, SMEs continue to struggle with finding the balance between the value that arises from sustainability initiatives, of which sustainability reporting is one, and the organizational costs linked to it [9]. Furthermore, research on sustainability reporting is largely centered around the private (for profit) sector. On the other hand, public sector organizations, fully or partially owned by the government, may face stronger accountability expectations and obligations, as they are charged with tasks covering holistic thinking on social welfare and justice of the public $[10,11]$. As a result, public sector organizations and state-owned enterprises (SOEs) are more and more stimulated, and even legally required in some countries (e.g., Sweden) to disclose sustainability performance information.

For the research presented in this paper, we turn our attention to the port industry, which is characterized by the presence of public sector organizations. More specifically, we focus on inland ports (as defined by Rodrigue and Notteboom [12]), and the often (partially) government owned port managing bodies (PMBs) — the use of 'port authority' diminishes because of the increase of many new governance models, covering more responsibilities than only those of an authority [13]. Those PMBs are responsible for coordinating, regulating, and developing the economic activities by, inter alia, allocating land to port users (mostly private companies) to carry out logistics and industrial activities using inland waterways, while at the same time monitoring both public and private values [14]. Inland ports operate under different, sometimes more extreme circumstances than seaports, specifically when it comes to their relatively small organizational size (in terms of human and financial resources) and their location in densely populated areas. Given the widespread positive and negative externalities associated with port activities, inland PMBs are confronted with stakeholder pressure to improve the 'sustainability' footprint of the logistics and industrial areas they manage. This creates specific challenges in the context of sustainability reporting implementation, as the growing complexity of the practice has not yet been equated with a similar degree of methodological sophistication [15]. In the specific context of inland ports, there exists a need to better understand the perspectives of different stakeholder groups, both on the general concept of sustainability (reporting) and the related methodological aspects such as materiality, boundary setting, and the need for stakeholder inclusion. Furthermore, existing research is often focused on the insights of the postimplementation phase of the practice of sustainability reporting. This paper provides an alternative approach by putting the focus on a case study that is yet to start with the development of a sustainability report. Hence, this research aims to provide knowledge on expectations and needs of inland PMBs' stakeholders, stimulating the wider industry to start reporting by partially bridging the often mentioned barrier of the lack of resources and knowledge.

The paper is organized as follows. Section 2 starts by providing an overview of the current situation of sustainability reporting in the port industry, followed by a discussion on important methodological topics related to sustainability reporting and for which no equivocal answer exists at present: TBL concept, boundary setting, materiality, and stakeholder inclusion. Section 3 contains the methodology. Section 4 provides an overview and interpretation of the survey results and Section 5 provides a synthesis of the literature insights and survey results, respectively the theoretical and practical perspective on the discussed topics. A general conclusion and limitations of the research as well as suggestions for future research are presented in Section 6. 


\section{Literature Review}

\subsection{Sustainability Reporting in the Port Industry}

According to Lynch et al. [3], sectors that have the largest (negative) influence on the environment and society (e.g., oil and gas, mining, etc.) tend to show larger efforts concerning sustainability initiatives, with sustainability reporting being part of it. For example, the airport sector has developed sector-specific guidelines under the auspices of the GRI, providing a practical framework to work with. However, due to the nonexistence of sectoral guidelines for ports and their managing bodies, the port industry has not yet reached the same level as other subsectors in the transportation industry. Nevertheless, in recent years, PMBs have become aware of their role and responsibility in the global transportation supply chain with respect to their environmental and social performance. In the context of seaports, PMBs are increasingly including sustainability reporting into their long-term development strategy [16], as they are not only aware of the benefits linked to it, but also because they mostly possess the necessary financial and human resources to do so. However, in general, the industry still shows a large variety in approaches. This is due to significant differences in terms of the type and profile of port activities (e.g., industrial and logistics oriented seaports, cruise ports, inland ports, and fishing ports), which leads to different (or even no) approaches concerning sustainability reporting $[17,18]$. Since 2015, as a trade association initiative, some larger seaports have installed a specific working group-International Association of Ports and Harbors-Permanent International Commission for Navigation Congresses (IAPH-PIANC) WG174 Sustainability Reporting for Ports-with participation of seaport representatives, consultants, and academics. This working group aims to establish port-specific sustainability reporting standards to create a more harmonized reporting framework given the multiple approaches used by the PMBs [18].

In contrast to seaports, sustainability reporting is still largely undiscovered territory for inland ports. Furthermore, as stated by Vejvar, Lai, Lo, and Fürst [19] “even though inland port operators strive for economic viability, there are growing pressures from various stakeholders for continuous enhancement of their environmental and social sustainability practices". However, no inland port or dry port, to our knowledge, has already published a sustainability report. Inland ports, given their relative smaller size in terms of operations, are considered the smaller players within the port sector [19]. They are also subject to more stringent internal financial and human constraints, and operate in an environment of high external stakeholder pressure. At the same time, their importance increases as they are a key element for sustainable port system development, given their role in new patterns of freight distribution caused by structural changes in logistics, such as port regionalization and the associated hinterland services development $[20,21]$. Mostly located within urban surroundings, inland PMBs need to deal with many different stakeholder groups pursuing different economic, social, and environmental interests in the port [21]. Unfortunately, not all of those stakeholder groups are equally aware of the positive contributions of an inland port, such as regional employment creation, value-added generation and more sustainable freight transport. Hence, embedding sustainability practices into the strategic plans and reporting about it should support societal stakeholders in perceiving the positive effects of the presence of an inland port in the urban region [22].

\subsection{TBL Principle and Boundary Setting}

At present, organizations face large pressures from different stakeholders to monitor and disclose information beyond mere financial performance. As a result, organizations are forced to rethink their idea of performance measurement in relation to their stakeholders, highlighting the need to include the social and environmental dimensions. However, including those extra dimensions into the business strategy and reporting practices requires new frameworks and standards to work with. The TBL concept is one of the most commonly used frameworks to assess economic, social, and environmental performance, and is considered as one of the best markers for defining the level of sustainability of an organization [23,24]. According to Gray and Milne [24], a strong TBL-based report covers and 
elaborates on all dimensions equally, and provides linkages and trade-offs between them. However, more than $50 \%$ of the topic-specific GRI Standards belong to the social dimension [25], suggesting a rather unbalanced implementation.

Furthermore, a topic that has not yet received a lot of attention in literature is that of boundary setting in sustainability reports. Sustainability is foremost regarded as a global concept, which implies a certain degree of complexity when applied at the organizational level [24]. More specifically, sustainability issues related to social or environmental performance transcend the boundaries of the organization [26]. Unlike financial reporting boundaries, which rely on the principle of financial control, boundaries concerning sustainability performance explicitly need to consider impacts beyond full organizational control [15]. Setting the boundaries between the organization and its context is a multisided question, as it is not always a case of willingness but also of complexity. Broadening the reporting boundary to include, for example, the full port supply chain calls for data that are often not available in general or not available for the PMB specifically. Vice versa, for some indicators, broadening the scope does not necessarily mean gaining extra insightful information, for example, measuring gender equality on the level of the actors within the whole supply chain is less relevant. This research investigates how inland port stakeholders perceive (1) the idea of an equal contribution of the three TBL dimensions in a sustainability report, and (2) how boundaries should be defined for several categories of indicators.

\subsection{Materiality and Stakeholder Inclusion}

In the context of traditional financial reporting, the concept of materiality is shaped by both quantitative and qualitative aspects, all of them defined and written down in standards set by international organizations, imposed by governments, and used as a basic element of market-based investment decision-making $[27,28]$. For nonfinancial information, the narrative is very different, as this information cannot be directly and clearly valued in a market setting [29]. Materiality in the context of nonfinancial information therefore focuses on the external accounting of economic, environmental, social, and governance impacts towards stakeholders and not just investors as the principal 'market' (or 'audience') interested [27,30]. Stakeholders, as broadly defined by Clarkson [31], are "persons or groups that have or claim ownership, rights, or interests in a corporation and its activities, past, present, or future".

In practical terms, in order to provide a sustainability report in which all stakeholders are provided with relevant and comprehensive information, it is crucial to include those elements that reflect the interests and requests of each stakeholder group [27]. Reporting frameworks, such as GRI Standards, provide guidelines in order to handle the challenge of information asymmetry between organizations and their stakeholders, and to reduce the risk of not covering all material aspects. Therefore, a materiality analysis should be based on a participatory process, proactively engaging all stakeholders in an interactive dialogue to determine those aspects of information that are the most material [28]. This dialogue can entail different degrees of inclusion, reflecting gradual paths of stakeholder engagement. In our research, we have used and adapted the model of Friedman and Miles [32] to define the desired level of stakeholder inclusion in the process of sustainability reporting as perceived by stakeholders (Table 1). The seven different levels of involvement go from one extreme 'no or limited inclusion' to the other 'full inclusion'. It is often considered that the higher the level of inclusion, the greater the societal acceptance of strategic choices, and thus, the less unanticipated issues that can occur as committees have been ex ante included in the processes [33]. 
Table 1. Seven different levels of stakeholder inclusion.

\begin{tabular}{|c|c|c|c|c|c|c|}
\hline \multicolumn{3}{|c|}{ No or limited inclusion } & & & \multicolumn{2}{|c|}{ Full inclusion } \\
\hline 1. & 2 & 3 & 4 & 5 & 6 & 7 \\
\hline $\begin{array}{l}\text {-Knowledge } \\
\text { about the } \\
\text { decisions. } \\
\text {-One-way } \\
\text { dialogue } \\
\text { (e.g., briefing } \\
\text { sessions, } \\
\text { leaflets, } \\
\text { corporate } \\
\text { reports. }\end{array}$ & $\begin{array}{c}\text {-Educating, } \\
\text { explaining, and } \\
\text { informing } \\
\text { stakeholders. } \\
\text {-One-way and/or } \\
\text { two-way } \\
\text { dialogue (e.g., } \\
\text { verified } \\
\text { corporate social } \\
\text { reports, } \\
\text { workshops). }\end{array}$ & $\begin{array}{l}\text {-Stakeholders } \\
\text { may advise. } \\
\text {-Being heard } \\
\text { before a } \\
\text { decision. } \\
\text {-Two-way } \\
\text { dialogue (e.g., } \\
\text { surveys, focus } \\
\text { groups, } \\
\text { interviews, } \\
\text { etc.). }\end{array}$ & $\begin{array}{c}\text {-Stakeholders } \\
\text { provide conditional } \\
\text { support. } \\
\text {-Having an } \\
\text { influence on } \\
\text { decisions. } \\
\text {-Multiway dialogue } \\
\text { (e.g., bargaining, } \\
\text { constructive } \\
\text { dialogue). }\end{array}$ & $\begin{array}{c}\text {-Collaboration/ } \\
\text { partnership. } \\
\text {-Some or joint } \\
\text { decision-making } \\
\text { power. } \\
\text {-Multiway } \\
\text { dialogue (e.g., } \\
\text { strategic } \\
\text { alliances, joint } \\
\text { ventures). }\end{array}$ & $\begin{array}{c}\text {-Minority } \\
\text { representation } \\
\text { of stakeholders } \\
\text { in the } \\
\text { decision-making } \\
\text { process. } \\
\text {-Multiway } \\
\text { dialogue (e.g., } \\
\text { board } \\
\text { representation). }\end{array}$ & $\begin{array}{c}\text {-Majority } \\
\text { representation } \\
\text { of stakeholders } \\
\text { in the } \\
\text { decision-making } \\
\text { process. } \\
\text {-Multiway } \\
\text { dialogue (e.g., } \\
\text { community } \\
\text { projects). }\end{array}$ \\
\hline
\end{tabular}

Table adapted by the authors from Friedman and Miles [32].

In the specific context of PMBs, especially those managing inland ports, the different types of ownership structures and the variety of involved stakeholder groups complicate the approach towards proper stakeholder engagement and the associated materiality analysis. For example, in most cases, the government does not only operate from a regulating role but also as a full or partial shareholder of the PMB, which creates a multitude of divergent objectives that need to be reached simultaneously. In parallel, all other stakeholder requests, such as those of port users, local communities, etc., need to be considered as well, as these parties heavily influence long-term port development plans [34-36]. The solution to this challenge does not limit itself to mere information dissemination strategies, but requires a high level of inclusion and a strong collaborative stakeholder approach in order to continuously increase the added value of the port and maintain its license to operate [36]. However, even though acceptance of strategic choices is mostly linked to a high level of stakeholder inclusion, it is important to investigate if the highest level of inclusion is desired by all stakeholders, as this also requires some investment in resources from their side. As a result, next to materiality, our research gathers complementary insights on the preferred degree of inclusion of the different stakeholder groups in the context of the development of a sustainability report.

In addition, by including stakeholders at the very beginning of the process and simultaneously taking account of the preferred level of inclusion, PMBs avoid that their potential efforts for developing a sustainability report are considered as a reactive solution with "greenwashing" reasons. As many papers highlight [37-39], the practice of developing a sustainability report should have the intention to inform and educate stakeholders, to create an environment of multiway dialogue and solution-thinking about pressing problems, to be able to measure and monitor past actions and future plans, etc. In other words, it is utterly important that the initiatives taken in light of improving the sustainability performance are seen as building blocks of the overall strategy of the organization.

\section{Methodology}

\subsection{Case Study Selection: The Inland Port of Brussels}

The definition of an inland port is polymorphic, meaning that it differs depending on certain features, such as its location, activities, connectivity, and role [12]. However, following the reasoning of Rodrigue and Notteboom [12], the Port of Brussels can be described as a comprehensive inland port as it encompasses inland waterway systems and handles a variety of traffic structures (inter alia construction materials, oil products, and containers). The Port of Brussels is a key node within the Trans-European Transport Network (TEN-T) and is located approximately $50 \mathrm{~km}$ from Antwerp, Europe's second largest seaport. Around 5 million metric tons are transshipped each year at the Port of Brussels. It makes part of the Seine-Scheldt basin connecting French, Belgian, Dutch, and German ports and waterway networks. As the port areas are located in the middle of the Brussels Capital Region (a so-called port "intra muros"), it is an interesting example of a metropolitan supporting 
type inland port. The metropolitan supporting type shows a dominant urban and regional logistics functionality (e.g., construction industry logistics and distribution of consumer goods). Furthermore, port activities take place within or nearby residential areas, and are subject to continuous, outright contestation, hence reflecting the need for intensive and high-quality stakeholder interaction [40].

\subsection{Survey Design: Stakeholders and Topics}

For the purpose of this research, a survey was designed and disseminated to the major stakeholder groups of the Port of Brussels. The identification of the critical stakeholder groups was conducted making use of the general stakeholder theory $[31,33]$ and complemented by the port-specific insights of Notteboom and Winkelmans [41], who identified four generic categories of stakeholders in the broader port environment. Initially, the following stakeholder groups were considered: personnel of the PMB, clients of the port (in this case tenants), broader society, and government agencies. The personnel of the PMB were considered as a salient stakeholder as they are entrusted with the daily managerial and operational tasks having a direct impact on the ongoing concerns of the port area. We decided to restrict the 'clients' category to tenants of the port as there is no direct nor intense commercial relationship of the PMB with inland shipping providers, as the tenants directly contract them and/or own or lease their own vessels for waterway transport. Furthermore, the broader society does not have a direct impact on the daily activities of the port, but at the same time experiences the positive/negative effects of the port activities on their own objectives, and actively influences political decision-makers. Finally, the 'government' stakeholder group is particular as these stakeholders are at the same time the principal shareholders/owners of the port but also need to act in accordance with the interests of the larger Brussels urban community, sometimes even being part of it. This breakdown into stakeholder categories was validated by several representatives of the Port of Brussels.

The survey started with a number of profile questions, followed by two general questions that probed for the uniform understanding and interpretation of the concepts of sustainability and sustainability reporting. The further content of the questionnaire was built upon comprehensive desk research and exploratory interviews with experts in the port environment, focusing on four large topics: (1) TBL concept, (2) materiality issues, (3) boundary setting, (4) stakeholder inclusion. Questions were expressed as close-ended affirmations, as this line of questioning helps in attaining a higher response rate [42], and is easier to code and analyze, while also avoiding mis-responses and misunderstandings with regard to the scales used $[43,44]$. To encode the questionnaire into an online version, we made use of the software program Qualtrics. Two pilot test runs took place by three representatives of the Port of Brussels, with modifications added after each pilot test before the final validation.

\subsection{Data Collection}

For the selection of the relevant respondents we made use of, and were dependent on, the stakeholder database of the Port of Brussels. Due to the EU data protection law (GDPR), the identification of relevant stakeholders, as well as the distribution of the survey accompanied by a cover letter, were handled by the Port of Brussels itself. The survey was sent out at the beginning of March 2019 and data were collected in the subsequent months, March and April 2019.

\subsection{Data Processing and Analysis}

SPSS was used to conduct statistical tests on the full amount of data. Furthermore, in order to analyze the question-specific data related to the TBL concept (see infra, Section 4.2), we based ourselves on the same method as applied in Calabrese et al. [7], namely the analytic hierarchy process (AHP) method. We opted for AHP because the questions probed for, in a way, subjective, qualitative information. The approach was deliberately chosen as it is a structured technique used to analyze complex multiple-criteria problems involving qualitative judgements. It splits the decision-making process into separate parts, each part assessing the importance of objects shown as a 
paired comparison $[45,46]$. Every partial analysis consists of detailed in-depth results per stakeholder group, as well as broader overall conclusions.

\section{Results}

First, the most fundamental sample statistics are described before discussing the results of the analysis, which are divided into the different research areas of the case study.

\subsection{Sample Statistics}

Four stakeholder groups were initially defined (clients, personnel, broader society, and government). Unfortunately, no answers were received from the 'government' stakeholder group, which led to the removal of the entire group from the analysis. After personal contacts with several governmental representatives, who answered the survey, it became clear that they filled out the survey from their role as moderator of broader societal objectives. Most of them are also part of the local community as they reside in the Brussels Capital Region (i.e., the 'broader society' stakeholder group). In total, 105 responses were received, of which 31 needed to be deleted because of respondents that dropped out at the beginning of the survey. The division is as follows: clients (12), personnel (26), and broader society (36).

Even though the response rate of the 'clients' stakeholder group is not considerably high, the received responses are provided by the most relevant members of this group. The important objective was to reach those clients with the largest share in the total usage of the waterways of the Port of Brussels (a group of around 30 members) as they possess the largest control over the port. Furthermore, they also strengthen and confirm the strict terminology of an inland port as applied in this paper. In $75 \%$ of the received questionnaires, the client indeed makes frequent use of the waterways. Furthermore, the survey was sent out to all personnel members in order to not discriminate among the staff. However, being confronted on a regular basis with, and having an opinion/idea about, the concept of sustainability was a precondition to fill out the survey. In order to minimize the bias of self-selection, questions probing for the function of the respondent and his/her years of interest in sustainability were posed. Out of the 26 answers, only 2 come from personnel working for the department 'environment, health, and safety services'. All other received questionnaires come from respondents of various departments, showing an accurate representation of the organization. Also in terms of years of interest, a proper sample of respondents with a variety of experience and knowledge about the subject can be noted. The 'broader society' stakeholder group shows a good representation of several different stakeholder profiles.

According to Gay and Diehl [47], the type of research involved (descriptive, correlational, or experimental), defines the number of respondents needed to reach an acceptable response rate for analysis. They state that in the case of descriptive research, which is applied in this paper, a sample size covering $10 \%$ of the population is sufficient and $20 \%$ when the population is small. Given the number of received responses for each stakeholder group, in particular the clients, we can state that the sample size reflects a plausible proportion of the targeted population. Unfortunately, some questions were not fully completed by the respondents. For this reason, ' $n$ ' reflecting the absolute amount of answers will always be shown with each question being discussed. However, this has never led to the response rate being compromised. In all cases, the condition mentioned above remained fulfilled.

\subsection{TBL Balance}

The first part of the survey intended to investigate the perception of the stakeholders towards the content of a sustainability report. In other words, should each TBL dimension be equally elaborated on in a sustainability report? As mentioned in the methodology (Section 3.4), the AHP method was applied to analyze this data. Results are shown in Table 2. All stakeholder groups do not equally value the three dimensions of the TBL. In general, the findings suggest that the dimension 'environment' should encompass almost $50 \%$ of a sustainability report compared to the weak results of the social 
dimension. Looking at the clients, the difference becomes even larger. For them the focus lay on the economic and environmental, less on the social dimension, in comparison with the other two stakeholder groups.

Table 2. Proportion of TBL concepts in a sustainability report.

\begin{tabular}{cccc}
\hline & Economic & Social & Environmental \\
\hline Personnel $(n=26)$ & $23 \%$ & $34 \%$ & $43 \%$ \\
\hline Clients of the port $(n=12)$ & $31 \%$ & $20 \%$ & $49 \%$ \\
\hline Broader society (including government) $(n=36)$ & $21 \%$ & $33 \%$ & $46 \%$ \\
\hline
\end{tabular}

In light of current environmental discussion, the importance of the environmental dimension is not surprising. During the past decades, organizations have indeed put a larger focus on environmental issues, leading to a gap in the level of accuracy when comparing the conceptual and practical development of social and environmental performance [23]. Furthermore, looking at the clients' results we can further notice a dominance of the economic over the social dimension. A plausible explanation could be that financial reporting does not entirely satisfy the needs and demands of its relevant stakeholders, which are not shareholders, but are interested in and influenced by the actions of the organization. As mentioned by Deegan and Rankin [48], the users of an annual report are not exclusively limited to shareholders, but represent a varied cross-section of society. This supports the growing need for either extending the existing content of an annual report, focusing on more than just the financial side of an organization, or to create a separate sustainability report.

\subsection{Materiality Issues}

In order to explore those issues that are perceived as material by the different stakeholder groups, we made use of a Likert scale to grade each issue according to its level of importance, which is reflected by an indicator (ranging from 1 'not important' to 7 'very important'). The shortlist of possible material indicators was compiled based on literature research, the materiality analysis of the Port of Antwerp [49], and on own exploratory research in the context of the support for an industry working group (IAPH-PIANC Working Group 174), as well as recently completed applied research projects such as the PORTOPIA project [50]. In total, 38 indicators, adapted to the context of an inland port and divided into seven large domains, could be identified: economic (4), social (7), environmental (12), logistic and operational performance (5), mobility (3), port-city relationship (4), and satisfaction/perception (3). These seven domains were identified to cover the specific context of the Port of Brussels as not all indicators could immediately be categorized under the existing TBL dimensions.

The approach for the analysis was similar to the one applied in Font et al. [30], i.e., indicators were considered as Likert scale items on an interval level, to which parametric tests were applied. As stated in Font et al. [30] by Norman [51], regardless of the original data, for sample sizes greater than five, the central limit theorem underpins the condition that the means of those samples are generally normally distributed. For this analysis we compared the mean of each individual issue/indicator with a materiality baseline, which we set at a score of 5 (out of 7, i.e., 4 as neutral score), thus implying that the indicator is of importance. An extra t-test was applied to those indicators with a mean slightly lower than 5 to investigate if the difference was significant. The overview of means and related results of the list of indicators can be found in Table 3. Results show that for the stakeholder group 'personnel', 37 out of 38 indicators comply with the materiality baseline, meaning that they can be considered as material issues. Only the indicator 'staff turnover' is regarded not important enough to include into a sustainability report. The clients show the same results as the personnel and add the indicator 'gender equality' as unimportant issue. In conjunction with the other results, the broader society group also perceives two indicators as not worthy to pay attention to: 'staff turnover' and 'level of difficulty hiring staff'. Remarkably, all nonsignificant indicators are part of the social dimension. 
Table 3. List of indicators.

\begin{tabular}{|c|c|c|c|c|}
\hline & Personnel & Clients & Broader Society & Average \\
\hline \multicolumn{5}{|l|}{ Economic } \\
\hline Investment volume & 5.2 & $\underline{4.6}$ & 5.0 & 4.9 \\
\hline Procurement practices & 5.6 & $\underline{4.4}$ & 5.4 & 5.1 \\
\hline Indirect economic impact (added value) & 5.0 & 5.2 & 5.3 & 5.2 \\
\hline Direct economic impact (added value) & 5.8 & 5.3 & 5.4 & 5.5 \\
\hline \multicolumn{5}{|l|}{$\begin{array}{ll} & \text { Social } \\
\end{array}$} \\
\hline Staff turnover & 4.3 & 4.1 & 4.3 & 4.2 \\
\hline Level of difficulty hiring staff & $\underline{4.5}$ & $\underline{4.4}$ & 4.3 & 4.4 \\
\hline Gender equality & $\underline{4.9}$ & 3.3 & 5.2 & 4.5 \\
\hline Indirect employment & 5.5 & $\underline{4.8}$ & 5.4 & 5.2 \\
\hline Direct employment & 5.7 & 4.9 & 5.6 & 5.4 \\
\hline Health and safety at work & 5.4 & 5.5 & 5.2 & 5.4 \\
\hline Education and training & 5.4 & 5.4 & 5.4 & 5.4 \\
\hline \multicolumn{5}{|l|}{ Environmental } \\
\hline Odors & 5.3 & 5 & 5 & 5.1 \\
\hline Dredging & 5.9 & $\underline{4.8}$ & 5.3 & 5.3 \\
\hline Port expansion & 5.5 & $\underline{4.9}$ & 5.8 & 5.4 \\
\hline Biodiversity/nature & 6 & 5.1 & 5.4 & 5.5 \\
\hline Noise & 5.9 & 5.3 & 5.5 & 5.6 \\
\hline Ship waste & 6.2 & 5.8 & 6.1 & 6.0 \\
\hline Water consumption & 6.5 & 5.6 & 5.9 & 6.0 \\
\hline Green policy and actions & 6.5 & 5.6 & 6 & 6.0 \\
\hline Port waste & 6.3 & 5.8 & 6.1 & 6.1 \\
\hline Ship discharges to water & 6 & 6.2 & 6.1 & 6.1 \\
\hline Energy consumption & 6.7 & 5.8 & 6.1 & 6.2 \\
\hline Quality/emissions (air, water, soil) & 6.7 & 6.1 & 6.1 & 6.3 \\
\hline \multicolumn{5}{|l|}{ Logistic and Operational Performance } \\
\hline Spatial productivity per quay meter & 5.5 & 5 & 5.3 & 5.3 \\
\hline Area usage of the different sectors & 5.5 & 5.1 & 5.2 & 5.3 \\
\hline Throughput per quay meter & 5.6 & 5.2 & 5.5 & 5.4 \\
\hline Seaport connectivity & 5.6 & 5.4 & 5.9 & 5.6 \\
\hline Intermodal connectivity & 5.9 & 5.7 & 6.2 & 5.9 \\
\hline \multicolumn{5}{|l|}{ Mobility } \\
\hline Modal split commuter traffic & 5.7 & 5.1 & 5.1 & 5.3 \\
\hline Road congestion around the port area & 5.8 & 5.6 & 6 & 5.8 \\
\hline Future actions & 6.1 & 5.8 & 6.1 & 6.0 \\
\hline \multicolumn{5}{|l|}{ Port-City } \\
\hline Integration of the port into the Trans-European waterways' framework & 6 & $\underline{4.8}$ & 5.7 & 5.5 \\
\hline $\begin{array}{l}\text { Integration of the territorial management of the Canal area in present and } \\
\text { future plans of the port }\end{array}$ & 5.8 & 5.6 & 6.1 & 5.8 \\
\hline $\begin{array}{l}\text { Integration of the port into plans of new developments on Federal and } \\
\text { Regional level (Flanders/Wallonia) }\end{array}$ & 6.2 & 5.6 & 5.7 & 5.8 \\
\hline $\begin{array}{l}\text { Integration of present and future port activities into the } \\
\text { metropolitan environment }\end{array}$ & 6.3 & 5.5 & 6 & 5.9 \\
\hline \multicolumn{5}{|l|}{$\begin{array}{l}\text { Satisfaction/Perception } \\
\end{array}$} \\
\hline User/client satisfaction & 5.7 & $\underline{4.9}$ & 5.4 & 5.3 \\
\hline Employee satisfaction & 5.8 & $\underline{4.8}$ & 5.3 & 5.3 \\
\hline Local communities' perception & 5.8 & 5.1 & 5.4 & 5.4 \\
\hline$N=$ & 22 & 12 & 30 & 64 \\
\hline
\end{tabular}

Underlined numbers = indicators with a mean lower than 5; Numbers in red = indicators with a mean significantly different from $5(p<0.05)$. 
In order to have a more general overview and to shed light on some of the higher-level tendencies, additional descriptive statistics were applied to the data. More specifically, the technique of quartiles was used to have a more in-depth look at the distribution of the responses of all stakeholder groups per indicator. A tendency to assign higher importance to the economic indicators can be observed. However, clients seem to be more interested in general high-level economic indicators, like (in)direct economic impact, than those linked to the daily businesses of the port. Overall, the social indicators are valued less important. The distribution of answers from personnel for the indicators 'staff turnover' and 'level of difficulty hiring staff' is very spread out, showing few persons for whom this issue is not even important enough to be mentioned in a sustainability report. The same phenomenon holds true for the indicators 'health and safety at work' and 'education and training'. Among the answers of the personnel there are some unexpected tendencies, with people showing no interest in the inclusion of these indicators in a sustainability report. Taking a closer look, it seems to be employees with the most recent interest in the topic 'sustainability' (compared to the other respondents) that gave the lower scores. Nevertheless, these indicators are given high overall scores by the clients and broader society. Additionally, more than $50 \%$ of the clients are not interested in gender equality in the organization, in contrast with the results of the broader society, where $70 \%$ of the answers are equal or above the score of 5 .

Furthermore, as expected, the environmental indicators are given a high level of importance by all stakeholders. Issues such as energy consumption and quality/emissions almost even reach the maximum score of 7 . The same level of importance is also acknowledged by academics with papers looking into these specific research areas [52,53]. Results of the 'broader society' stakeholder group make us believe that the survey has been answered by many stakeholders with a professional 'urban development' background. The indicators 'spatial productivity per meter of quay' and 'seaport connectivity', as well as issues related to the port-city relationship and the integration of the port into regional, national, and international transport and infrastructure development plans are given very high scores. In contrast, the answers of the clients regarding the integration of the port into the Trans-European waterways' framework are very divided, with one of the lowest means of the exercise (see Table 3). A possible explanation is that most waterway users in Brussels use fixed, specific connections that already function very well and are not hampered by infrastructural bottlenecks on the wider EU waterway network. Finally, developing an indicator that reflects the perception and satisfaction of the different stakeholders is regarded as very important by the personnel of the PMB. It shows awareness of the increasing influence that external stakeholders have on port activities and development, making it a necessity to invest in superior stakeholder management.

\subsection{Boundary Setting}

Besides defining the materiality of several indicators, setting the boundaries is another complex dilemma that needs to be determined when preparing a sustainability report. The respondents were asked to select for each dimension (economic-social-environmental) the boundary that they deemed of high relevance for the PMB to report on (based on what is feasible in the PMB's present situation). The boundaries were defined by the authors based on the organizational and geographical/operational features of the port, following the approach and philosophy in Archel, Fernandez, and Larrinaga [54]. If the PMB should report an indicator on both the level of the PMB itself as well as on the level of the port cluster separately, the respondent needed to tick both boundaries A and B. If the respondent was of the opinion that the PMB should measure an indicator only on the level of the port cluster (thus not for the PMB separately), only boundary B should be ticked. Table 4 shows the results of this exercise.

Although there is accordance on the contribution of environmental indicators in a sustainability report, a small difference between the stakeholder groups can be noticed when it comes to defining the relevant boundaries. For the clients and community stakeholders, it seems to be very important that environmental indicators are calculated comprising all activities of the supply chain, in contrast with the view of the personnel who considers boundaries A and/or B as sufficient. A similar reasoning 
applies in large part to the social dimension, with clients and broader society stakeholders focusing on boundary C. In general, we can state that the personnel prefers to first put the focus on the own organization with attempts to broaden the scope, in comparison to the two other stakeholder groups, for whom the boundary of the organization is a minimum condition and who prefer to see indicators calculated on broader boundaries. For all stakeholder groups, the economic dimension should be analyzed with a focus on the first two boundaries, thus focusing on those actors that can have a direct impact on the going concern of the organization.

Table 4. Boundaries per domain perceived by the different stakeholder groups.

\begin{tabular}{|c|c|c|c|c|c|}
\hline \multicolumn{6}{|c|}{ Economic } \\
\hline & $\mathrm{A}$ & B & $\mathrm{C}$ & $\mathrm{D}$ & No opinion \\
\hline Personnel $(n=22)$ & $55 \%$ & $59 \%$ & $32 \%$ & $23 \%$ & $5 \%$ \\
\hline Clients/users $(n=12)$ & $42 \%$ & $58 \%$ & $17 \%$ & $8 \%$ & $8 \%$ \\
\hline Broader Society $(n=30)$ & $43 \%$ & $53 \%$ & $30 \%$ & $23 \%$ & $20 \%$ \\
\hline \multicolumn{6}{|c|}{ Social } \\
\hline & A & $\mathrm{B}$ & C & $\mathrm{D}$ & No opinion \\
\hline Personnel $(n=22)$ & $55 \%$ & $41 \%$ & $45 \%$ & $23 \%$ & $5 \%$ \\
\hline Clients/users $(n=12)$ & $33 \%$ & $25 \%$ & $58 \%$ & $17 \%$ & $8 \%$ \\
\hline Broader Society $(n=30)$ & $37 \%$ & $43 \%$ & $57 \%$ & $10 \%$ & $20 \%$ \\
\hline \multicolumn{6}{|c|}{ Environmental } \\
\hline & $\mathrm{A}$ & $\mathrm{B}$ & $\mathrm{C}$ & $\mathrm{D}$ & No opinion \\
\hline Personnel $(n=22)$ & $64 \%$ & $55 \%$ & $36 \%$ & $27 \%$ & $5 \%$ \\
\hline Clients/users $(n=12)$ & $42 \%$ & $42 \%$ & $33 \%$ & $50 \%$ & $8 \%$ \\
\hline Broader Society $(n=30)$ & $40 \%$ & $50 \%$ & $43 \%$ & $43 \%$ & $20 \%$ \\
\hline
\end{tabular}

$\mathrm{A}=$ Port Managing Body organization; $\mathrm{B}=$ port area/cluster (including industry/logistics and including the hinterland interface); $\mathrm{C}=$ local/regional community; $\mathrm{D}=$ impact of upstream and downstream supply chain activities taking place outside the port borders and beyond the local/regional community.

\subsection{Stakeholder's Willingness for Inclusion}

The creation of mutual responsibility between the organization and its stakeholders is necessary to maintain the license to operate as expectations can be managed and aligned with each other [55]. However, such inclusion also requires time and efforts from the stakeholders. Eventually, stakeholders would prefer a level of inclusion for which the cost-benefit balance will be neutral or positive.

Based on the adapted version of the model of Friedman and Miles [32] (see Section 2.3, Table 1), each respondent was asked to indicate the desired level of inclusion during the process of sustainability reporting. Each level is linked to a number, ranging from 1 (no inclusion) to 7 (full inclusion). Table 5 presents the mean and related standard deviation. All stakeholder groups have a mean of almost 5, which corresponds with a level of collaboration, joint decision-making, and multiway dialogue. However, looking at the standard deviations, this result should be interpreted with caution. A more in-depth analysis of the results shows that the majority of the clients gave a score of 5 or 6 , but two outliers could be identified with a score of 1 and 2 . In all probability, this can be explained by the type, size, portfolio of activities, etc. of the organizations in question. The distributions of the personnel and broader society are quite comparable, with answers equally divided between 3 and 7 . This shows that the personnel of the port is aware of the importance of strong stakeholder inclusion, not only to anticipate demands and expectations, but also to create a learning environment stimulated through mutual interaction. Although being important for the urban region, the PMB is not a dominant player and does not have the ultimate bargaining position, which causes long lead times to realize projects (5 to 10 years). For this reason, the PMB should always keep its stakeholder strategy on point. 
Table 5. Preference of stakeholder inclusion by the different stakeholder groups.

\begin{tabular}{ccc}
\hline & Mean & SD \\
\hline Personnel $(n=21)$ & 4.95 & 1.564 \\
\hline Clients/users of the port $(n=11)$ & 4.64 & 1.690 \\
\hline Broader society $(n=30)$ & 4.90 & 1.213 \\
\hline
\end{tabular}

Furthermore, a question concerning preferred communication tools was also posed to the external stakeholder groups (clients and broader society). Figure 1 shows that a survey and a workshop are the desired tools by both stakeholder groups. In a second phase, more face-to-face meetings are favored, with a preference for a one-on-one conversation by the clients and a focus group by the community stakeholders. Being consulted every six months is the frequency chosen by the majority of both groups.

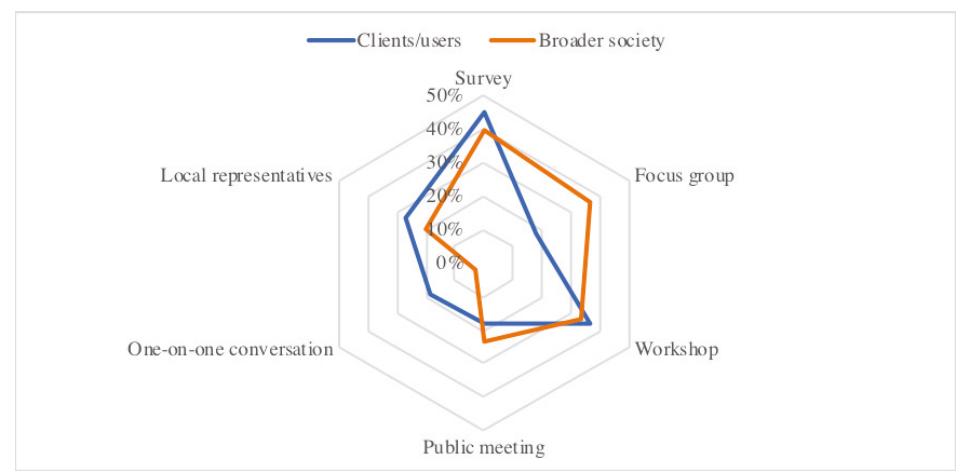

Figure 1. Communication means preferred by clients/users and broader society.

\section{Discussion}

Table 6 gives an overview of the different discussed topics by linking the literature and the survey results and adding concluding reflections. These reflections form the synthesis of the theoretical and practical perspective on some important topics at present with regard to sustainability reporting. Some additional explanation is provided in the sections below.

\subsection{TBL Balance and Materiality Issues}

More purpose-driven employees, risk education, monitoring long-term risks, etc. as internal, sometimes organization-specific advantages, cover just one part of the full set of advantages of sustainability reporting. Societal aspects, more externally driven, such as an increase in transparency, enhanced reputation, improved market position, improved stakeholder relations, etc. complete the list and characterize the growing importance of the practice $[1,3,56]$. Although sustainability reporting has already proven to be of value for organizations, developing such a report is not straightforward as social and environmental performances are very difficult to quantify and are unique to each organization. Issues that are considered material by stakeholders will differ between organizations, for example those situated in developing or developed countries, as local environmental and social requirements differ and as most likely another interpretation of the ideal ongoing concern strategy exists. These different conditions and playing fields for organizations will also be translated into different 'optimum' TBL balances per organization. However, it is important that each TBL dimension contains a minimum level of content determined by the highest common denominator in terms of objectives of the different stakeholder groups. Even though every situation is unique and needs proper judgement, the need for sector-specific guidelines is high as they could help in defining that necessary minimum level of compliance. 


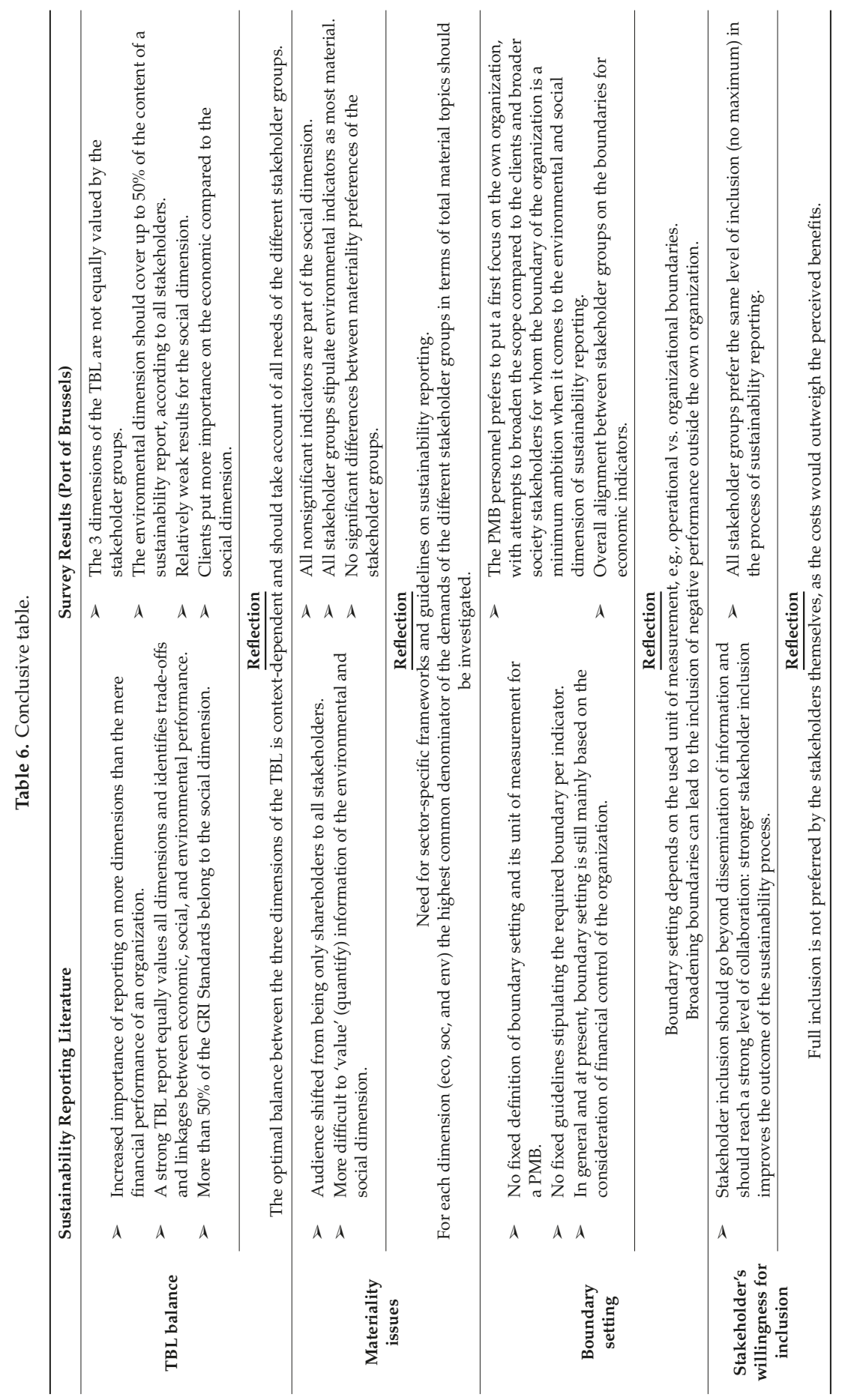




\subsection{Boundary Setting}

Boundary setting in the context of financial reporting is known and well-defined, i.e., based on the concept of financial control. Sustainability reporting on the other hand involves more than the economic aspects of an organization, meaning that the principle of boundary setting should consider more than only those aspects under financial control. Based on the unit of measurement, several approaches to sustainability boundary setting can be articulated. Two commonly used units of measurement are based on organizational and operational features, respectively horizontal and vertical boundary setting. In the context of ports, operational boundaries are often applied. Furthermore, based on the results, we observe that the PMB is more willing to broaden an indicator's boundary when this results in potentially showcasing more positive news, cfr. social dimension. In contrast, when broadening the boundary is associated with the potential publication of negative news, the PMB will be reluctant, cfr. environmental dimension.

Boundary setting is an important element of sustainability reporting as, when well-defined, it can form the link between the micro organizational level and the macro level contribution of the port cluster managed by the PMB to sustainable development. These insights will allow identifying and monitoring high level integration opportunities [57], as well as possible negative effects caused by seaports but 'absorbed' by inland ports. Inland ports with a strong license to operate might provide tangible benefits to seaports, as the latter rely on inland ports to achieve more sustainable hinterland logistics, and thus improving their own sustainability impacts. This in contrast with the inland ports in question, as they are responsible for the last mile of the transport chain and thereby confronted with the less attractive transport mode: road. In light of the research presented in this paper we also identified the availability of resources as a major barrier for inland ports to engage in sustainability reporting; deeper collaboration between inland and seaports within the same network/supply chains seems warranted. The main challenge of such collaboration is most likely the definition of sustainability reporting outputs, which still appeal to local stakeholders (e.g., local communities).

\subsection{Stakeholder's Willingness for Inclusion}

Although the level of stakeholder inclusion is mostly positively correlated with societal acceptance of strategic choices made on the level of the organization [33], a specific element related to cognitive or information overload should be considered [58]. When more stakeholders get involved in organizational and decision-making processes, this also means a larger exposure to new information and a potential increase in complexity of institutional partnerships. However, every organization, and by extension institutional system, is limited by its size, inter alia defined by its human and financial resources, which corresponds with a certain level of cognitive saturation. More specifically, above a certain level the benefits of additional information will exceed the costs of processing it. When stakeholders within the system ignore this limitation, chances increase that they will be confronted with a cognitive overload at some point, leading to an overall loss of value in terms of the information presented. In general, it is an exercise of balancing with a saturation level defined by the stakeholders' and organizations' particular characteristics. Therefore, the level of cognitive saturation of the Port of Brussels's stakeholder system will probably be lower as compared to a large seaport, such as the Port of Antwerp, and thus matching another optimal number of stakeholders to be included.

\section{Conclusions}

Inland ports operate under different, sometimes more extreme, circumstances than seaports, specifically when it comes to resource availability (human and financial), and the multitude of stakeholders influenced by the presence of the port in an urban context. This research contributes to existing literature as it approaches the concept of sustainability reporting in the context of inland port managing bodies from the perspective of three of their important stakeholder groups (personnel, clients, and broader society). The research results of the paper are of interest to academics and practitioners, 
as well as policy makers. The Port of Brussels has been used as a case study to discover potential gaps in expectations between different stakeholder groups with regard to sustainability (reporting) and its subdimensions: materiality, boundary setting, and stakeholder inclusion. The research shows how a materiality analysis and adequate boundary setting can play crucial roles in addressing the demands and needs of the different stakeholder groups, hence creating a better understanding and future progress in managing expectations. A sustainability report as a result of various exercises on all TBL dimensions can be regarded as the epitome of the 'sustainability DNA' of the port managing body, and will be of importance in strengthening its license to operate.

Limitations of the research concern the focus on one case study and the relatively small sample size. Due to the adoption of a holistic approach, based on the Port of Brussels as a case study, generalization should be made with caution. Insights of this paper provide only a first step in the development of a framework around sustainability reporting for inland port managing bodies and potentially also smaller seaports close to urban environments. Nevertheless, based on the findings of this exploratory research, several applications and possibilities for future research can be defined. First, this research can serve as a basis and information source for inland port managing bodies when analyzing the potential of sustainability disclosure, given the lack of examples in this domain. The analysis combines ideas found in literature with evidence in practice, which demonstrates the mutual benefits of collaborative research between academics and real-life practitioners. Second, as the focus of this research lies on the Port of Brussels as a metropolitan inland port, it would be interesting to also replicate the analysis to other types of inland ports, such as industry supporting types, or to other types of economies, such as emerging economies. For emerging economies in particular, the role of the port managing body when it comes to sustainability reporting (given different port governance frameworks), as well as the applied boundaries in terms of issues and stakeholders to be included, might differ substantially. Third, the survey instrument for this research has been developed in a way that it can easily be applied and adapted to the specific terms of other inland port cases or even smaller seaports next to or within urban environments, without losing the robustness of the survey. Additionally, the current insights could be complemented with in-depth interviews or focus groups with stakeholders to analyze more in-depth the underlying reasons behind some of the specific results of the survey.

Author Contributions: M.G.: conception and design of the study, methodology, acquisition of data, analysis and interpretation of the data, drafting the manuscript and data presentation, revising it critically for important intellectual content, final approval of the version to be published; M.D.: survey design and quality control, writing in parts related to discussions, quality control. All authors have read and agreed to the published version of the manuscript.

Funding: This research did not receive external funding.

Conflicts of Interest: The authors declare no conflict of interest.

\section{References}

1. Herzig, C.; Schaltegger, S. Corporate Sustainability Reporting: An overview. In Sustainability Accounting and Reporting; Schaltegger, S., Bennett, M., Burritt, R., Eds.; Springer: Berlin, Germany, 2006; chapter 13.

2. Kolk, A. A decade of sustainability reporting: Developments and significance. Int. J. Environ. Sustain. Dev. 2004, 3, 51-64. [CrossRef]

3. Lynch, N.C.; Lynch, M.F.; Casten, D.B. The Expanding Use of Sustainability Reporting: Standards Setting and Assurance Opportunities for CPAs. The CPA J. 2014, 84, 18-24.

4. KPMG. The road ahead: The KPMG Survey of Corporate Responsibility Reporting 2017. Available online: https://assets.kpmg/content/dam/kpmg/xx/pdf/2017/10/kpmg-survey-of-corporate-responsibilityreporting-2017.pdf (accessed on 13 September 2018).

5. Kuznetsov, A.; Dinwoodie, J.; Gibbs, D.; Sansom, M.; Knowles, H. Towards a sustainability management system for smaller ports. Mar. Policy. 2015, 54, 59-68. [CrossRef]

6. GRI. What is sustainability reporting? 2019. Available online: https://www.globalreporting.org/information/ sustainability-reporting/Pages/default.aspx (accessed on 25 October 2019). 
7. Calabrese, A.; Costa, R.; Levialdi, N.; Menichini, T. A fuzzy analytic hierarchy process method to support materiality assessment in sustainability reporting. J. Clean. Prod. 2016, 121, 248-264. [CrossRef]

8. Baumann-Pauly, D.; Wickert, C.; Spence, L.J.; Scherer, A.G. Organizing Corporate Social Responsibility in Small and Large Firms: Size Matters. J. Bus. Eth. 2013, 115, 693-705. [CrossRef]

9. Akan, M.M.; Fung, A.S.; Kumar, R. Process energy analysis and saving opportunities in small and medium size enterprises for cleaner industrial production. J. Clean. Prod. 2019, 233, 43-55. [CrossRef]

10. Greiling, D.; Grüb, B. Sustainability reporting in Austrian and German local public enterprises. J. Econ. Policy Reform 2014, 17, 209-223. [CrossRef]

11. Guthrie, J.; Farneti, F. GRI sustainability Reporting by Australian Public Sector Organizations. Public Money Manag. 2008, 28, 361-366. [CrossRef]

12. Rodrigue, J.-P.; Notteboom, T. Applications and Case Studies: Inland Ports/Dry Ports. In The Geography of Transport Systems, 1st ed.; Rodrigue, J.-P., Ed.; Routledge: New York, NY, USA, 2017.

13. Verhoeven, P.; Vanoutrive, T. A quantitative analysis of European port governance. Mar. Econ. Logist. 2012, 14, 178-203. [CrossRef]

14. Van der Lugt, L.; Dooms, M.; Parola, F. Strategy making by hybrid organizations: The case of the port authority. Res. Transp. Bus. Manag. 2013, 8, 103-113. [CrossRef]

15. Antonini, C.; Larrinaga, C. Planetary Boundaries and Sustainability Indicators. A Survey of Corporate Reporting Boundaries. Sust. Dev. 2017, 25, 123-137. [CrossRef]

16. Ashrafi, M.; Acciaro, M.; Walker, T.R.; Magnan, G.M.; Adams, M. Corporate sustainability in Canadian and US maritime ports. J. Clean. Prod. 2019, 220, 386-397. [CrossRef]

17. Bergqvist, R.; Monios, J. Green Ports: Inland and Seaside Sustainable Transportation Strategies, 1st ed.; Elsevier: Amsterdam, The Netherlands, 2018.

18. Maigret, A. Sustainability Reporting in the Port Sector: Is GRI the Way Forward? Master's Thesis, The International Institute for Industrial Environmental Economics, Lund, Sweden, 2014.

19. Vejvar, M.; Lai, K.-H.; Lo, C.K.Y.; Fürst, E.W.M. Strategic responses to institutional forces pressuring sustainability practice adoption: Case-based evidence from inland port operations. Transp. Res. Part D. 2018, 61, 274-288. [CrossRef]

20. Notteboom, T.; Rodrigue, J.-P. Port Regionalization: Towards a New Phase in Port Development. Marit. Policy Manag. 2005, 32, 297-313. [CrossRef]

21. Witte, P.; Wiegmans, B.; van Oort, F.; Spit, T. Governing inland ports: A multi-dimensional approach to addressing inland port-city challenges in European transport corridors. J. Transp. Geogr. 2014, 36, 42-52. [CrossRef]

22. Segui, X.; Puig, M.; Quintieri, E.; Wooldridge, C.; Darbra, R.M. New environmental performance baseline for inland ports: A benchmark for the European inland port sector. Environ. Sci. Policy. 2016, 58, $29-40$. [CrossRef]

23. Hubbard, G. Measuring Organizational Performance: Beyond the Triple Bottom Line. Bus. Strat. Env. 2009, 18, 177-191. [CrossRef]

24. Gray, R.; Milne, M. Towards Reporting on the Triple Bottom Line: Mirages, Methods and Myths. In The Triple Bottom Line: Does it add up? Henriques, A., Richardson, J., Eds.; Earthscan: London, UK, 2004; pp. 70-80.

25. GRI. GRI Standards Download Center. 2016. Available online: https://www.globalreporting.org/standards/ gri-standards-download-center/ (accessed on 5 November 2019).

26. Khan, S.A.R.; Jian, C.; Zhang, Y.; Golpîra, H.; Kumar, A.; Sharif, A. Environmental, social and economic growth indicators spur logistics performance: From the perspective of South Asian Association for Regional Cooperation countries. J. Clean. Prod. 2019, 214, 1011-1023. [CrossRef]

27. Belluci, M.; Manetti, G. Finance, Governance and Sustainability: Stakeholder Engagement and Sustainability Reporting, 1st ed.; Routledge: London, UK, 2019.

28. Calabrese, A.; Costa, R.; Levialdi, N.; Menichini, T. Materiality Analysis in Sustainability Reporting: A Method for Making it Work in Practice. Eur. J. Sustain. Dev. 2017, 6, 439-447. [CrossRef]

29. Mio, C. Materiality and assurance: Building the link. In Integrated Reporting, C.; Frigo, M.L., Riccaboni, A., Quattrone, P., Eds.; Springer Busso: Dordrecht, The Netherlands, 2013; pp. 79-94.

30. Font, X.; Guix, M.; Bonilla-Priego, M.J. Corporate social responsibility in cruising: Using materiality analysis to create shared value. Tour. Manag. 2016, 53, 175-186. [CrossRef] 
31. Clarkson, M.B.E. A stakeholder framework for analyzing and evaluating corporate social performance. Acad. Manag. Rev. 1995, 20, 92-117. [CrossRef]

32. Friedman, A.L.; Miles, S. Stakeholders: Theory and Practice, 1st ed.; Oxford University Press on Demand: Oxford, UK, 2006.

33. Freeman, E.R. Strategic Management: A Stakeholder Approach, e-book; Pitmann/Ballinger: Boston, USA, 1984.

34. De Langen, P.W. Stakeholders, conflicting interests and governance in port clusters. Res. Transp. Econ. 2007, 17, 457-477. [CrossRef]

35. Dooms, M.; Verbeke, A.; Haezendonck, E. Stakeholder management and path dependence in large-scale transport infrastructure development: The port of Antwerp case (1960-2010). J. Transp. Geogr. 2013, 27, 14-25. [CrossRef]

36. Dooms, M. Stakeholder Management for Port Sustainability: Moving from Ad-Hoc to Structural Approaches. In Green Ports: Inland and Seaside Sustainable Transportation Strategies; Bergqvist, R., Monios, J., Eds.; Elsevier: Amsterdam, The Netherlands, 2019; pp. 63-84.

37. Cahoon, S. Marketing communications for seaports: A matter of survival and growth. Marit. Policy Manag. Flagship J. Internat. Shipping Port Res. 2007, 34, 151-168. [CrossRef]

38. Lam, J.S.L.; Li, K.X. Green port marketing for sustainable growth and development. Transp. Policy. 2019, 84, 73-81. [CrossRef]

39. Parola, F.; Pallis, A.A.; Risitano, M.; Ferretti, M. Marketing strategies of Port Authorities: A multi-dimensional theorization. Transp. Res. Part A. 2018, 111, 199-212. [CrossRef]

40. Dooms, M.; Haezendonck, E.; Valaert, T. Dynamic green portfolio analysis for inland ports: An empirical analysis on Western Europe. Res. in Transp. Bus. Manag. 2013, 8, 171-185. [CrossRef]

41. Notteboom, T.; Winkelmans, W. Stakeholder Relations Management in Ports: Dealing with the Interplay of Forces among Stakeholders in a Changing Competitive Environment. In Proceedings of the Society of International Association of Maritime Economists (IAME), Panama City, Panama, 13-15 November 2002.

42. Kelley, K.; Clark, B.; Brown, V.; Sitzia, J. Good practice in the conduct and reporting of survey research. Int. J. Qual. Health Care 2003, 15, 261-266. [CrossRef]

43. Coombes, H. Research Using IT, 1st ed.; Palgrave: London, UK, 2001.

44. Swain, S.; Weathers, D.; Niedrich, R. Assessing three sources of mis-response to reversed Likert items. J. Mark. Res. 2008, 45, 116-131. [CrossRef]

45. Azapagic, A. Systems approach to corporate sustainability: A general management framework. Process Saf. Environ. Prot. 2003, 81, 303-316. [CrossRef]

46. Saaty, T.L. The Analytical Hierarchy Process, e-book; McGraw-Hill: New York, NY, USA, 1980.

47. Gay, L.R.; Diehl, P.L. Research Methods for Business and Management, e-book; Macmilan: New York, NY, USA, 1992.

48. Deegan, C.; Rankin, M. The materiality of environmental information to users of annual reports. Account. Audit. Account. J. 1997, 10, 562-583. [CrossRef]

49. Port of Antwerp. Materialiteitsoefening Met Stakeholders; Port of Antwerp: Anwerp, Belgium, 2016.

50. Portopia. European Port Industry Sustainability Report 2017. 2017. Available online: http://www. portopia.eu/wp-content/uploads/2017/11/D8.3-Annex4-EuropeanPortIndustrySustRep2017.pdf (accessed on 11 March 2019).

51. Norman, G. Likert scales, levels of measurement and the "Laws" of statistics. Adv. Health Sci. Educ. 2010, 15, 625-632. [CrossRef] [PubMed]

52. Iris, C.; Lam, J.S.L. A review of energy efficiency in ports: Operational strategies, technologies and energy management systems. Renew. Sustain. Energy Rev. 2019, 112, 170-182. [CrossRef]

53. Li, W.; Hilmola, O.-P.; Panova, Y. Container Sea Ports and Dry Ports: Future CO2 Emission Reduction Potential in China. Sustainability 2019, 11, 1515. [CrossRef]

54. Archel, P.; Fernandez, M.; Larrinaga, C. The Organizational and Operational Boundaries of Triple Bottom Line Reporting: A Survey. Environ. Manag. 2008, 41, 106-117. [CrossRef] [PubMed]

55. Manetti, G. The quality of stakeholder engagement in sustainability reporting: Empirical evidence and critical points. Corp. Soc. Responsib. Environ. Manag. 2011, 18, 110-122. [CrossRef]

56. Boston College Center for Corporate Citizenship and Ernst \& Young LLP. Value of Sustainability Reporting. 2013. Available online: http://www.confluencellc.com/uploads/3/7/9/6/37965831/ valueofsustainabilitysummary.pdf (accessed on 23 June 2019). 
57. Venturini, G.; Iris, C.; Kontovas, C.A.; Larsen, A. The multi-port berth allocation problem with speed optimization and emission considerations. Transp. Res. Part D: Transp. Environ. 2017, 54, 142-159. [CrossRef]

58. Neumann, B.R.; Roberts, M.L.; Cauvin, E. Stakeholder value disclosures: Anchoring on primacy and importance of financial and nonfinancial performance measures. Rev. Manag. Sci. 2011, 5, 195-212. [CrossRef]

(c) (1) BY

(C) 2020 by the authors. Licensee MDPI, Basel, Switzerland. This article is an open access article distributed under the terms and conditions of the Creative Commons Attribution (CC BY) license (http://creativecommons.org/licenses/by/4.0/). 
Article

\title{
Port-Related Emissions, Environmental Impacts and Their Implication on Green Traffic Policy in Shanghai
}

\author{
Yuyan Zhou ${ }^{1}$, Yan Zhang ${ }^{1,2,3, *}$, Dong Ma ${ }^{4}$, Jun Lu ${ }^{5}$, Wenbin Luo ${ }^{6}$, Yu Fu ${ }^{6}$, Shanshan $\mathrm{Li}^{1}$, \\ Junlan Feng ${ }^{1}$, Cheng Huang ${ }^{5, *}$, Wangqi Ge ${ }^{7}$ and Hong Zhu ${ }^{7}$ \\ 1 Shanghai Key Laboratory of Atmospheric Particle Pollution and Prevention (LAP3), \\ Department of Environmental Science and Engineering, Fudan University, Shanghai 200438, China; \\ yuyanzhou18@fudan.edu.cn (Y.Z.); shanshan_li1130@163.com (S.L.); 16210740003@fudan.edu.cn (J.F.) \\ 2 Shanghai Institute of Eco-Chongming (SIEC), Shanghai 200062, China \\ 3 Big Data Institute for Carbon Emission and Environmental Pollution, Fudan University, \\ Shanghai 200433, China \\ 4 State Environmental Protection Key Laboratory of Vehicle Emission Control and Simulation, \\ Chinese Research Academy of Environmental Sciences, Beijing 100012, China; madong@vecc-mep.org.cn \\ 5 Shanghai Academy of Environmental Science, Shanghai 200233, China; sunshinelujun@126.com \\ 6 Shanghai International Port Group Co. Ltd., Shanghai 200080, China; luowb@portshanghai.com.cn (W.L.); \\ fuyu@portshanghai.com.cn (Y.F.) \\ 7 Shanghai Urban-Rural Construction and Transportation Development Research Institute, Shanghai 200032, \\ China; gewangqi@163.com (W.G.); simonwx@126.com (H.Z.) \\ * Correspondence: yan_zhang@fudan.edu.cn (Y.Z.); huangc@saes.sh.cn (C.H.)
}

Received: 9 April 2020; Accepted: 12 May 2020; Published: 20 May 2020

\begin{abstract}
The port of Shanghai, as the world's largest container port, has been experiencing rapid development in recent years, with increasing cargo throughput capacity. The combustion of diesel fuels used by internal and external port-related container trucks and in-port machineries can release various pollutants, causing air pollution. The terminals are close to the residential area, and the emissions are concentrated, which is worth paying attention to. This study aims to synthetically assess the port-related emissions and their environmental impacts. We firstly constructed an emission inventory of air pollutants in the port of Shanghai and then used the WRF-CMAQ model to estimate the influence of port-related source emissions on air quality. The results show that the annual emissions of $\mathrm{SO}_{2}, \mathrm{NO}_{\mathrm{X}}, \mathrm{CO}, \mathrm{VOC}_{\mathrm{S}}, \mathrm{PM}, \mathrm{PM}_{10}, \mathrm{PM}_{2.5}, \mathrm{CO}_{2}, \mathrm{BC}$ and $\mathrm{OC}$ caused by cargo-handling equipment were $21.88 \mathrm{t}, 1811.22 \mathrm{t}, 1741.72 \mathrm{t}, 222.76 \mathrm{t}, 61.52 \mathrm{t}, 61.42 \mathrm{t}, 58.41 \mathrm{t}, 141,805.40 \mathrm{t}, 26.80 \mathrm{t}$ and $10.07 \mathrm{t}$ in 2015. The emissions of $\mathrm{NO}_{\mathrm{X}}, \mathrm{CO}, \mathrm{VOC}_{\mathrm{S}}, \mathrm{PM}_{10}$ and $\mathrm{PM}_{2.5}$ caused by external port-related container trucks were 18,002.92 t, $5308.0 \mathrm{t}, 1134.57 \mathrm{t}, 711.12 \mathrm{t}$ and $640.58 \mathrm{t}$. The exhaust of external port-related container trucks was much larger than that of cargo-handling equipment, so the impact on air quality was also higher than that of the machinery. The peak annual average concentrations of $\mathrm{PM}_{2.5}$ and $\mathrm{NO}_{\mathrm{X}}$ contributed by the port-related sources were $1.75 \mu \mathrm{g} / \mathrm{m}^{3}$ and $49.21 \mu \mathrm{g} / \mathrm{m}^{3}$, respectively, which accounted for $3.08 \%$ and $36.7 \%$, respectively, of the simulated ambient concentrations by all the anthropogenic emissions in Shanghai. Our results imply that the emission control policy to reduce the combined port-related emissions, especially for the cargo-delivery transportation phase from port to city, is key for large coastal port cities such as Shanghai.
\end{abstract}

Keywords: port-related emission; cargo-handling equipment; emission inventory; external container trucks; air quality

\section{Introduction}

The port of Shanghai is the world's largest container port, located in the middle of the Chinese mainland coastline, at the Yangtze River estuary. The port of Shanghai has a pivotal position in the 
world port industry [1,2] as an intersection for transportation along the east and west sides of the Yangtze River and along the coast [1]. As a hub of cargo transit, its establishment and operation have become a vital part of the transportation industry $[3,4]$. To cope with the unavoidable air pollution problems in this process, the construction of a green port must be put on the agenda as soon as possible [5-8]. Green port development focuses on the sustainable balance between environmental protection and economic interests. Green ports are guided by the green concept, in that new ports are constructed while promoting environmental health, ecological protection, the rational use of resources, low energy consumption and low pollution [9]. Green port practices have already been explored for many international ports (e.g., the ports of Long Beach and Los Angeles, the port of Sydney) $[5-8,10,11]$. Since 2015, when the Environmental Protection Law of the People's Republic of China was revised [12], the Chinese government has been paying increased attention to port environmental protection and the concept of green port development. Currently, relevant research has been started on green ports both in China and abroad $[1,13,14]$.

The machinery and handling equipment at ports are a great concern of green port projects [15]. They are mainly driven by diesel fuel with relatively low fuel quality, which may generate air pollutants [16]. Moreover, the port terminals are much closer to residential areas. Therefore, the air pollution caused by the machinery at the ports has a great impact on residents $[17,18]$. Three general methods are usually used for building port emission inventories. The United States Environmental Protection Agency (USEPA) has been working on tests for off-road mobile machinery and consequently developed the OFF-ROAD model. On the basis of the OFF-ROAD model, the USEPA has developed a more accurate estimation method of emissions from port-related sources [19]. However, this type of work started much later in China [20]. In China, we must refer to foreign basic parameters with respect to model application, which can cause unnecessary uncertainty.

Researchers in many countries use the second method, determining the exact production activity information, and build their methodology on the basis of machine power [21]. Agrawal et al. [22] estimated the rated power, emission factors and characteristic parameters. They then adjusted the results with fuel correction factors and control factors, thus building an emission inventory of Los Angeles in 2013. Fu et al. [23], Zhang et al. [24] and Shon et al. [25] used a similar methodology and constructed an emission inventory.

However, this method required a large amount of statistical data. Thus, the third method, based on fuel consumption [26], is much more widely used in China. This computing method ignores the discrepancies of power, length of service and other working condition parameters among different machines. Although accuracy is sacrificed to some extent, the parameters based on this method are easy to obtain. [27] estimated the fuel consumption of each piece of cargo-handling machinery and calculated the emissions according to the emission factors. Moreover, [28] used the top-down method based on the fuel consumption of unit containers and constructed an emission inventory of the Pearl River Delta in 2014.

Besides, some green port projects were more concerned about shipping-caused air pollution [29-32] and human health [33]. Previous related studies seldom combined the port land sources, cargo delivering trucks and ship emissions. In addition, they usually aimed at the establishment of emission inventories, but did not further evaluate the impact of port-related emissions on air quality and the environment. Thus, port-related air pollutant emissions and their environmental impacts are not systematically reported.

To make up for these two gaps, this study takes the largest container port as an example to estimate the port-related emissions and assesses their contributions to urban air pollution. This study focuses on the port of Shanghai and the Yangshan deep-water port, in the administrative division. Among the different terminals in the port of Shanghai, Waigaoqiao is the most important, followed by Yangshan, Wusong and Luojing. In this research, the basic data were obtained from the Shanghai Traffic Management Office. We firstly calculated the emissions of cargo-handling equipment based on fuel consumption and established a port-related emissions inventory with the combination of the 
emission inventory of external container trucks. We then used the WRF-CMAQ model to assess the impact of port-related emissions on air quality and made policy suggestions. The purpose of this study is to assess port-related emissions and their environmental impacts by investigating the emissions of port-related sources and providing corresponding academic support for green port construction in port cities like Shanghai.

\section{Materials and Methods}

\subsection{Study Area and Period}

As shown in Figure 1, the study area of this research is the port of Shanghai, which includes the Shanghai inland area, Chongming Island, Changxing Island and the Yangshan deep-water port. The latitude and longitude range from $120.5^{\circ} \mathrm{E}$ to $122.3^{\circ} \mathrm{E}$ and from $30.5^{\circ} \mathrm{N}$ to $32^{\circ} \mathrm{N}$ [34]. Located at the Yangtze River estuary, the port of Shanghai is a transportation hub port on the eastern coast of China. It is a world-famous port with well-developed shipping, transportation and service industries. The largest port area of the port of Shanghai is the Waigaoqiao port area, on the southern bank of the south port channel of the Yangtze River estuary. The Waigaoqiao port area has held the first position in the global ranking of annual cargo throughput. Other large port areas in Shanghai include the Wusong Ferry Terminal, the Luojing Ore Terminal, the Yangshan deep-water port and other piers along the Yangtze River.

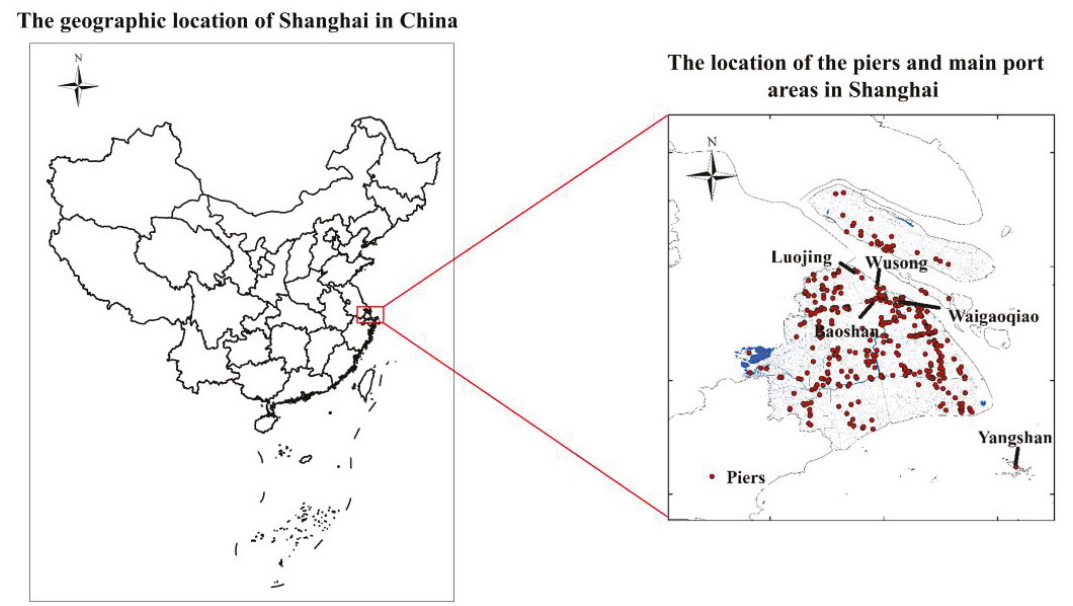

Figure 1. The study area, including Shanghai Inland Area, Chongming Island, Changxing Island and Yangshan Deep Water Port. The latitude and longitude range from $120.5^{\circ} \mathrm{E}$ to $122.3^{\circ} \mathrm{E}$ and $30.5^{\circ} \mathrm{N}$ to $32^{\circ} \mathrm{N}$.

We used 2015 as the base year for this study. The total emissions of different air pollutants from port-related sources throughout the entire year were estimated. The annual emissions were then scaled to monthly averages and used to simulate the impact on air quality.

\subsection{Source of Basic Machinery Data}

To investigate the basic situation of the statistics of the enterprises within the port of Shanghai in 2015, we cooperated with the Shanghai Traffic Management Office and obtained the port enterprise information, the basic data on cargo-handling equipment, the data on external container trucks and the emission factors of the different air pollutants of the port machinery. With respect to the mechanical data of the port, this study focuses mainly on the type of machinery, rated power, emission standards, energy types, annual operating hours and fuel consumption. For the data on external container trucks, 
this study includes mainly truck identities, traffic and routine activity. For the emission factor data, we classify the machinery and select the corresponding data according to the classification standards.

\subsection{Estimation Method of Emissions from Cargo-Handling Equipment}

We contacted the Shanghai Traffic Management Office and obtained a database of machinery with the exact holding volume, power, emission standards, annual working duration, fuel type and hourly-fuel consumption at every port enterprise. We then calculated the fuel consumption for the whole year with the following formula.

$$
\mathrm{C}_{\mathrm{i}}=\mathrm{H}_{\mathrm{i}}^{*} \mathrm{HC}_{\mathrm{i}}
$$

where:

$\mathrm{I}=$ machine $\mathrm{i}$,

$\mathrm{C}=$ annual fuel consumption (t/a),

$\mathrm{H}=$ annual working duration (h/a) and

$\mathrm{HC}=$ hourly fuel consumption $(\mathrm{t} / \mathrm{h})$.

The proper emission factors of every air pollutant for each individual machine were selected according to the four-class principle in the Emission Factors Library of Air Pollutant Sources, shown in Table A1 in the Appendix A. The principles include machine type, fuel type, rated power and emission standard. The emission factors of $\mathrm{SO}_{2}, \mathrm{NO}_{X}, \mathrm{CO}, \mathrm{VOC}_{\mathrm{S}}, \mathrm{PM}, \mathrm{PM}_{10}, \mathrm{PM}_{2.5}, \mathrm{CO}_{2}$, $\mathrm{BC}$ and OC were obtained, after which the following formula was used to compute the emissions of each air pollutant from each machine.

$$
E_{i, j}=C_{i}^{*} E F_{i, j} / 1000
$$

where:

$\mathrm{I}=$ machine $\mathrm{i}$,

$\mathrm{J}=$ air pollutant $\mathrm{j}$,

$\mathrm{E}=$ emission $(\mathrm{t} / \mathrm{a})$ and

$\mathrm{EF}=$ emission factor $(\mathrm{g} / \mathrm{kg})$.

Following an investigation at the Shanghai Traffic Management Office, the exact location of every port enterprise was also obtained. The computations are presented in terms of their spatial distribution.

\subsection{Estimation Method of Emissions from External Container Trucks}

The estimation of external container truck emissions was conducted using a road vehicle emission model. According to different time periods, different driving status indicators, such as model segment traffic and speed, are distributed to road traffic. Based on the road traffic calculation results with different driving status indicators, the IVE model was then applied and the total emissions were calculated. The emission factors of the different air pollutants are listed in Table A2 in the Appendix A.

\subsection{Air Quality Modeling}

We used the weather research and forecasting (WRF) model (version 3.3) and the community multiscale air quality (CMAQ) model (version 4.6) to estimate the concentration distribution of the different air pollutants [34]. For the model establishment, we inputted the inventory of the average monthly values of the year to the simulation, with $72 \mathrm{~h}$ of spin-up time per run. The initial and boundary conditions for the meteorological factors in this research were provided by the Chinese National Centers for Environmental Prediction (NCEP) Final Analysis (FNL) at a resolution of $1^{\circ} \times 1^{\circ}$ and time intervals of six hours. The CMAQ model used the carbon bond mechanism (CB05) for gas-phase chemistry and the AERO4 aerosol module. The grid resolution of the results is $1 \mathrm{~km} \times 1 \mathrm{~km}$ [34].

Due to the severity of $\mathrm{NO}_{\mathrm{X}}$ and the great impact of $\mathrm{PM}_{2.5}$ from port sources on human health, we chose $\mathrm{NO}_{\mathrm{X}}$ and $\mathrm{PM}_{2.5}$ as typical pollutants and simulated the concentration fields of $\mathrm{NO}_{\mathrm{X}}$ and $\mathrm{PM}_{2.5}$ in the case of winter and summer and the yearly average. The impact of the emissions from port-related sources on air quality was then discussed, as were the environmental effects of seasonal 
changes. Since the port-related sources were mainly composed of the point-sources of the dock areas and the line-sources along the transportation routes of external container trucks, the proportion of port-related sources in all industries could be dense in areas where these emissions are concentrated. Therefore, we also simulated and analyzed the distribution of these proportions in all industries to refine the environmental impact of port-related source emissions.

\section{Results}

\subsection{Engine Power and Emission Status of Port-Related Equipment and Fuel Consumption}

These statistics were based on 442 terminal enterprises in Shanghai, with a total of 3910 pieces of cargo-handling equipment within the survey. The basic parameters of the machines are shown in Figure 2. The machines investigated included forklifts, vehicles, hoisting machinery, towing tractors and other industrial machinery. Among the numbers of all the machines (Figure 2a), the number of towing tractors was the largest, with a total of 1444 pieces, accounting for $36.93 \%$, followed by forklifts, with a total of 1274 pieces, accounting for $32.58 \%$. The third largest was the number of other industrial machines, at 882 pieces, accounting for more than $22.56 \%$.

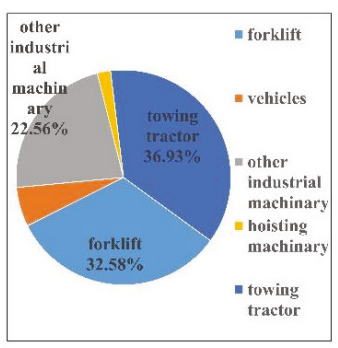

(a)

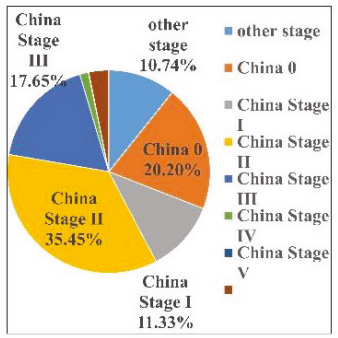

(d)

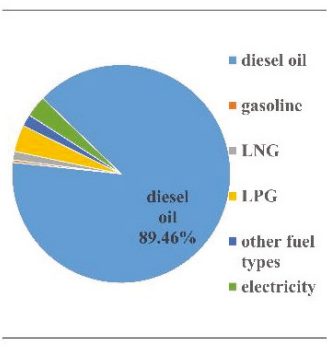

(b)

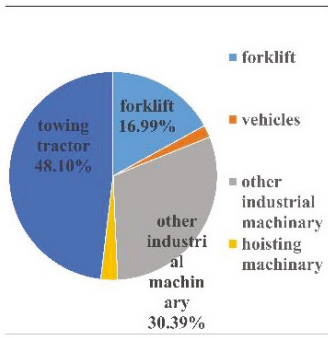

(e)

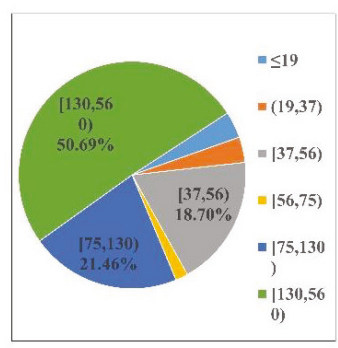

(c)

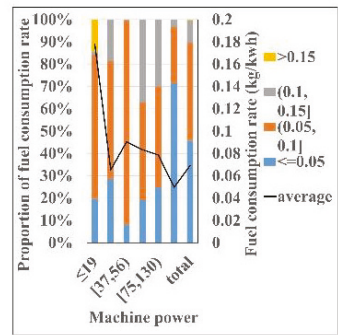

(f)

Figure 2. The summary of the basic parameters and the proportion of the fuel consumption rate of the cargo-handling equipment in 2015: (a) Machine type; (b) Fuel type; (c) Machine rated power; (d) Machine emission standard; (e) Machine fuel consumption; (f) Machine fuel consumption rate.

The distribution of the energy types of cargo-handling equipment had a direct effect on the emissions. The energy types used in the machines included diesel fuel, electricity, liquefied petroleum gas (LPG), liquefied natural gas (LNG), etc. Among them (Figure 2b), the diesel-driven machinery, with a total of 3498 pieces, accounting for $89.46 \%$, predominated, followed by LPG-driven machinery, with a total of 155 pieces, accounting for $3.96 \%$. The third was electricity-driven machinery, with a total of 124 pieces, accounting for more than $3.17 \%$. The fuel types of the cargo-handling equipment were gradually being upgraded and updated, and the number of machines driven by LNG and electric power increased [35]. However, from the research results, in 2015, the integration of LNG and electric drive machinery was relatively low, and the fuel structure still needed to be improved. 
The rated power of cargo-handling equipment ranged from $8.8 \mathrm{kWh}$ to $438.5 \mathrm{kWh}$. Machines with a rated power in the range of $130-560 \mathrm{~kW}$ accounted for $50.69 \%$ of all machinery (Figure 2c), followed by those with a rated power in the range of $75-130 \mathrm{~kW}$, which accounted for $21.46 \%$. The third most predominant was that of $37-56 \mathrm{~kW}$, accounting for $18.70 \%$. It was obvious that, due to the large amount of port operations, machines needed to bear heavy loads, and the operation time was long. Therefore, the high-power machinery still accounted for the vast majority.

The emission standards of the cargo-handling equipment ranged from the China 0 to China $\mathrm{V}$ emission standards. The total number of machines adhering to the China II standards was 1386, accounting for $36.61 \%$ (Figure $2 \mathrm{~d}$ ). The second greatest proportion adhered to the China 0 standards, with a total of 790 pieces, accounting for $20.87 \%$. The third greatest proportion adhered to the China III standards, with a total of 690 pieces, accounting for $18.23 \%$. It can be seen that, in 2015 , the pollution control of non-road mobile machinery in China was not yet in line with international standards, and there was still a large amount of high-emission and high-pollution machinery in use.

With respect to energy consumption, cargo-handling equipment had a total fuel consumption of $45,575.51 \mathrm{t}$. The distribution of the fuel consumption of cargo-handling equipment (Figure 2e) did not correspond absolutely with that of the types of machines. Towing tractors accounted for $36.93 \%$ but consumed approximately $48.1 \%$ of fuel. Forklifts accounted for $32.58 \%$ but consumed approximately $16.99 \%$ of fuel. The discrepancy was caused by the combined influence of the different distributions of rated power and emission standards.

The fuel consumption rate of the cargo-handling machines involved in this study (Figure 2f) differed greatly from the average fuel consumption rate under the calibration conditions in the literature [36]. This occurred because the ratio of actual hourly fuel consumption to mechanical power was obtained in this research, which was quite different from the value of the fuel consumption rate under calibration conditions. According to this research, the average fuel consumption rate of the cargo-handling equipment was approximately $0.069 \mathrm{~kg} / \mathrm{kWh}$, which is close to the value reported by [20]. Among the machinery, approximately $90 \%$ of the machines had a fuel consumption rate of no more than $0.1 \mathrm{~kg} / \mathrm{kWh}$. Furthermore, the rate of half of the machines was no more than $0.05 \mathrm{~kg} / \mathrm{kWh}$ and that of only a few machines was higher than $0.15 \mathrm{~kg} / \mathrm{kWh}$. The distribution of the fuel consumption rates of the machines varied with their power range. Approximately $65 \%$ of the low-power machines (i.e., no more than $19 \mathrm{~kW}$ ) had a fuel consumption rate of $0.05-0.1 \mathrm{~kg} / \mathrm{kWh}$; conversely, more than $70 \%$ of the high-power machines (i.e., no less than $130 \mathrm{~kW}$ ) had a fuel consumption rate of less than $0.05 \mathrm{~kg} / \mathrm{kWh}$. Two parameters that directly determine the mechanical fuel consumption rate are mechanical rated power and hourly fuel consumption. According to the research, the hourly fuel consumption of the different machines was not very different, ranging from $0.30 \mathrm{~kg} / \mathrm{h}$ to $14.93 \mathrm{~kg} / \mathrm{h}$. However, the mechanical power varied greatly, ranging from $0.92 \mathrm{~kW}$ to $560 \mathrm{~kW}$. In general, except for the average fuel consumption rate of the low-power machines at approximately $0.18 \mathrm{~kg} / \mathrm{kWh}$, the machine fuel consumption rate of the other power segments hovered around $0.07 \mathrm{~kg} / \mathrm{kWh}$.

\subsection{Port-Related Emission Inventory}

\subsubsection{Cargo-Handling Equipment}

The emissions of $\mathrm{SO}_{2}, \mathrm{NO}_{X}, \mathrm{CO}, \mathrm{VOC}_{\mathrm{S}}, \mathrm{PM}, \mathrm{PM}_{10}, \mathrm{PM}_{2.5}, \mathrm{CO}_{2}, \mathrm{BC}$ and $\mathrm{OC}$ from the machines were $21.88 \mathrm{t}, 1811.22 \mathrm{t}, 1741.72 \mathrm{t}, 222.76 \mathrm{t}, 61.52 \mathrm{t}, 61.42 \mathrm{t}, 58.41 \mathrm{t}, 141,805.40 \mathrm{t}, 26.80 \mathrm{t}$ and $10.07 \mathrm{t}$, respectively (Table 1 ). 
Table 1. Emission inventory from different types of cargo-handling equipment in port.

\begin{tabular}{|c|c|c|c|c|c|c|c|c|}
\hline \multicolumn{2}{|c|}{$\begin{array}{l}\text { In-Port Sources of } \\
\text { Pollution }\end{array}$} & Forklift & Vehicles & $\begin{array}{c}\text { Other } \\
\text { Industrial } \\
\text { Machinery }\end{array}$ & $\begin{array}{l}\text { Hoisting } \\
\text { Machinery }\end{array}$ & $\begin{array}{l}\text { Towing } \\
\text { Tractor }\end{array}$ & $\begin{array}{c}\text { Total of } \\
\text { Machineries }\end{array}$ & $\begin{array}{c}\text { External } \\
\text { Container } \\
\text { Trucks }\end{array}$ \\
\hline \multicolumn{2}{|c|}{ Holding volume } & 1274.00 & 232.00 & 882.00 & 78.00 & 1444.00 & 3910.00 & - \\
\hline \multicolumn{2}{|c|}{ Fuel consumption/t } & 7743.54 & 876.67 & $13,848.27$ & 1185.81 & $21,921.23$ & $45,575.51$ & - \\
\hline \multirow{10}{*}{ Emission/t } & $\mathrm{SO}_{2}$ & 4.20 & 0.47 & 7.28 & 0.24 & 9.70 & 21.88 & - \\
\hline & $\mathrm{NO}_{x}$ & 372.24 & 48.49 & 621.47 & 40.59 & 728.42 & 1811.22 & $18,002.9$ \\
\hline & $\mathrm{CO}$ & 122.74 & 32.90 & 286.41 & 179.75 & 1119.91 & 1741.72 & 5308.05 \\
\hline & $\mathrm{VOC}_{\mathrm{S}}$ & 31.78 & 9.33 & 56.43 & 13.89 & 111.32 & 222.76 & 1134.57 \\
\hline & PM & 17.53 & 1.89 & 23.66 & 0.70 & 17.74 & 61.52 & - \\
\hline & $\mathrm{PM}_{10}$ & 17.53 & 1.80 & 23.66 & 0.70 & 17.74 & 61.43 & 711.12 \\
\hline & $\mathrm{PM}_{2.5}$ & 16.66 & 1.74 & 22.48 & 0.67 & 16.87 & 58.41 & 640.59 \\
\hline & $\mathrm{CO}_{2}$ & 24,459 & 2766 & 43,558 & 3441 & 67,581 & 141,805 & - \\
\hline & $\mathrm{BC}$ & 9.49 & 0.39 & 12.81 & 0.38 & 3.73 & 26.80 & - \\
\hline & OC & 3.00 & 0.28 & 4.05 & 0.12 & 2.63 & 10.07 & - \\
\hline
\end{tabular}

Due to the usage of vehicle diesel in cargo-handling equipment, the sulfur content was relatively low-generally no higher than $0.1 \%$. Therefore, the emissions of sulfur dioxide from cargo-handling equipment were low. In contrast, the emissions of $\mathrm{NO}_{X}$ were predominant. The different contributions of separate air pollutants were due to the general composition of diesel oil. Therefore, they were similar among different ports $[16,22,24,37]$. The emission contribution tended to be similar among the different air pollutants according to the distribution of the fuel consumption, though discrepancies still occurred (Figure 3).

For towing tractors, $\mathrm{CO}$ and $\mathrm{VOC}_{\mathrm{S}}$ had higher contributions than the others, while the particulate matter was lower. This result was similar to that of Zhang et al. [24] and Archana et al. [22]. Except for the machinery attributes, this was also caused by the usage of LNG, which had a higher proportion in towing tractors, according to the element investigation. However, the forklifts presented the opposite situation because they were driven mainly by diesel fuel, which can lead to large emissions of particulate matter. Overall, towing tractors, forklifts and other industrial machinery — with the most individual machines and, consequently, the greatest fuel consumption-played the predominant role in the emissions. The results from Zhu et al. [16], covering 21 provinces and cities with ports in China, showed that loaders and tractors were the most severe polluting sources. A significant reason for the difference was the terminal type. The port of Shanghai is the world's largest container port, while Zhu's research included a more complex cargo composition. 


\section{Machine emission contribution}

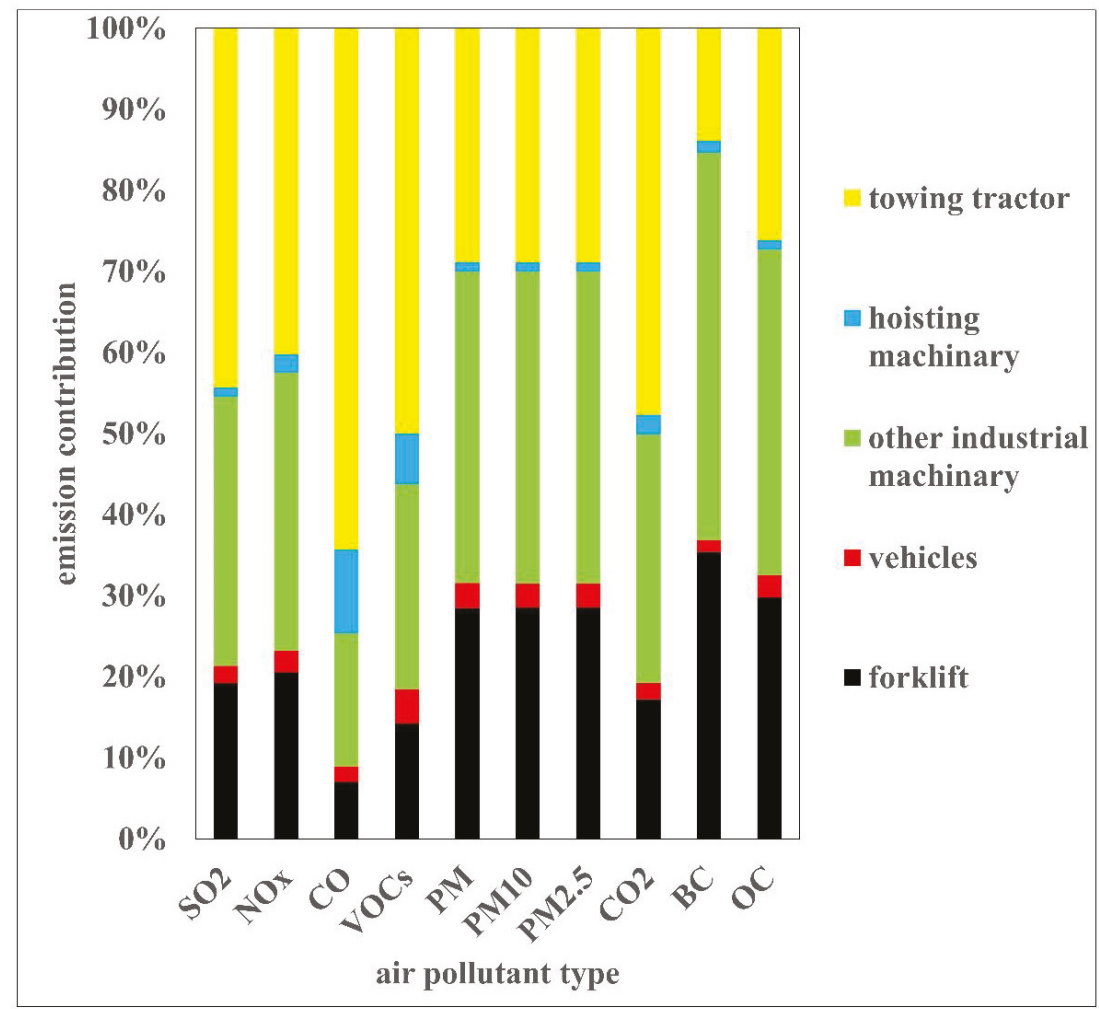

Figure 3. Emission contribution of different machine types in 2015 in the port of Shanghai.

The emissions of the port machinery are mapped in Figure 4. Most of these port enterprises were located near the Yangtze River estuary and along the Huangpu River. Among them, those in Luojing, Wusong, Waigaoqiao, Baoshan and Yangshan had a larger scale and higher levels of production activity. Therefore, we expected the pollution in these areas to be more severe than elsewhere. The general tendency of the spatial distribution was similar among the different pollutants (Figure 4), so $\mathrm{SO}_{2}$ was taken as an example (Figure 4a). The total emissions of $\mathrm{SO}_{2}$ were $21.88 \mathrm{t}$. Analogous to the distribution of port enterprises, the docks in Luojing, Wusong, Waigaoqiao, Laogang, Yangshan and along Huangpu River contributed significantly to the port emissions. Waigaoqiao contributed the most, and the peak was $6.96 \mathrm{t}$. 


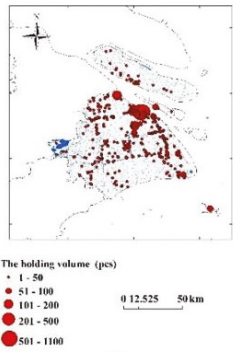

(a)
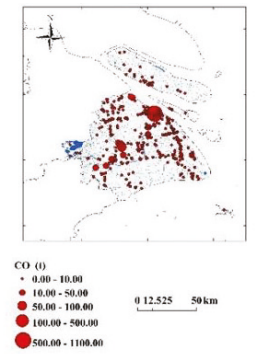

(e)

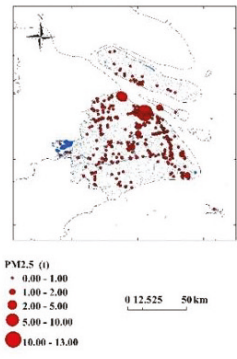

(i)
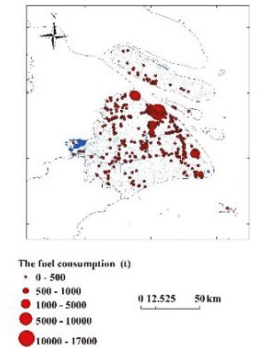

(b)
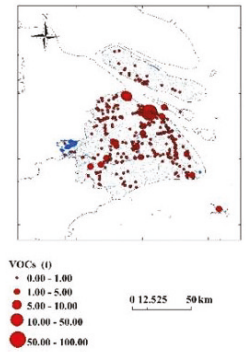

(f)
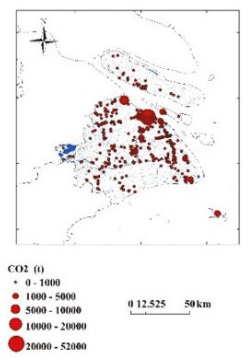

(j)
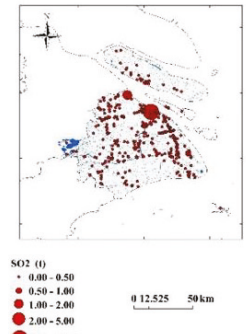

(c)
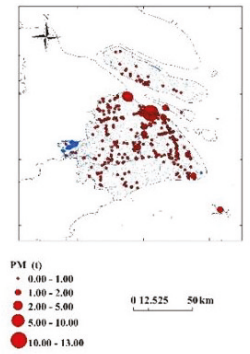

(g)
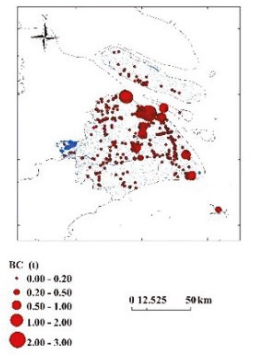

(k)
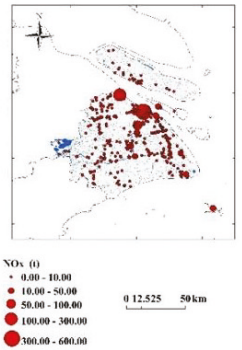

(d)
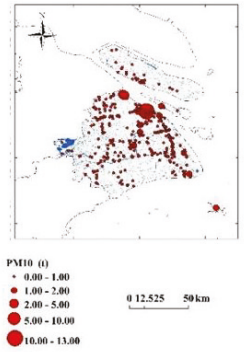

(h)

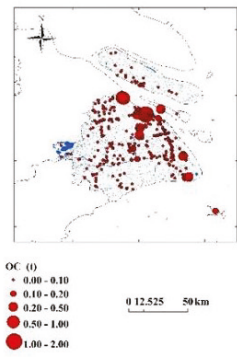

(l)

Figure 4. The spatial distribution of cargo-handling equipment volume, fuel consumption and emission flux: (a) cargo-handling equipment volume; (b) fuel consumption; (c) $\mathrm{SO}_{2} ;$ (d) $\mathrm{NO}_{\mathrm{X}}$; (e) $\mathrm{CO}$; (f) $\mathrm{VOC}_{\mathrm{S}}$; (g) PM; (h) $\mathrm{PM}_{10}$; (i) $\mathrm{PM}_{2.5}$; (j) $\mathrm{CO}_{2}$; (k) BC; (l) OC. The emission flux is given as $\mathrm{t}$.

\subsubsection{External Port-Related Container Trucks}

The emissions of $\mathrm{NO}_{X}, \mathrm{CO}, \mathrm{VOC}_{\mathrm{S}}, \mathrm{PM}_{10}$ and $\mathrm{PM}_{2.5}$ from external container trucks were 18,002.92 $\mathrm{t}$, 5308.05 t, 1134.57 t, $711.12 \mathrm{t}$ and 640.59 t, respectively (Table 1). Like the cargo-handling equipment, external container trucks basically used vehicle diesel, which has a low sulfur content. Therefore, the emissions of $\mathrm{SO}_{2}$ from external container trucks were not included in this study. The general tendency of the spatial distribution was similar among the different pollutants (Figure 5), so $\mathrm{NO}_{\mathrm{X}}$ was taken as an example (Figure 5c). 


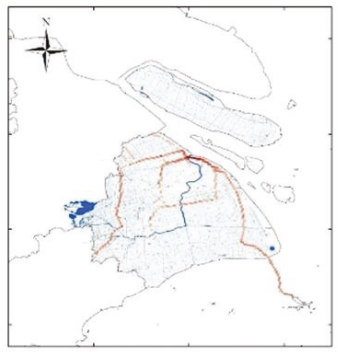

PM10 (t) $\square 0.00-0.50$ $1.00-2.00$

2.00-5.00

$2.00-5.00$

5.00 - 7.00

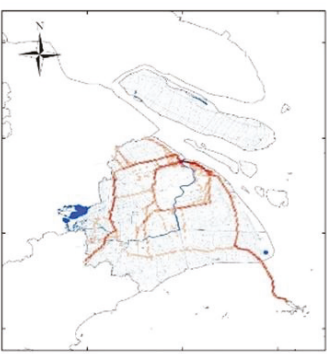

\section{PM2.5 (t)}

$\square 0.00-0.20$

$\square 0.20-0.50$

$0.50-1.00$

$1.00-3.00$
$3.00-6.00$

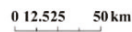

(a)

(b)

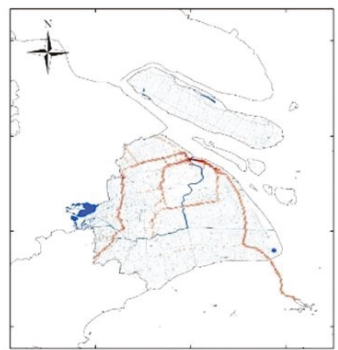

NOx (t)

$\square 0.00$ - 10.00

$\square 10.00-20.00 \quad 012.525 \quad 50 \mathrm{~km}$

$=20.00-50.00$

$50.00-100.00$

- $100.00-150.00$

(c)

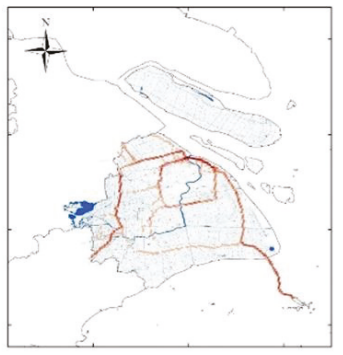

$\mathrm{CO}$ (t)

$\square .00-2.00$

$\square 2.00-5.00$

国.00 - 10.00

$10.00-25.00$

- $25.00-50.00$

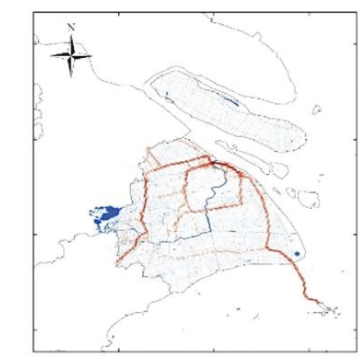

VoCs (t)

$\square 0.00-0.50$

$\square 0.50-1.00$

-2.00-5.00

- 5.00-10.00

(d)

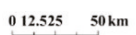

(e)

Figure 5. The spatial distribution of external port-related container trucks emissions: (a) $\mathrm{CO}$; (b) $\mathrm{NO}_{\mathrm{X}}$; (c) $\mathrm{PM}_{2.5} ;$ (d) $\mathrm{PM}_{10} ;(\mathbf{e}) \mathrm{VOC}_{\mathrm{S}}$. The emission flux is given as $\mathrm{t}$.

The total emissions of $\mathrm{NO}_{\mathbf{X}}$ were 18,002.92 $\mathrm{t}$. The emissions of trucks were mainly concentrated in Shanghai's suburban and outer ring road, on the G60 Shanghai-Kunming Highway in the direction of Hangzhou, in Zhejiang and on the S2 Hulu Highway in the direction of the Yangshan deep-water port. This spatial distribution met the traffic policy needs and the Shanghai road traffic flow. In accordance with traffic policies, container trucks were not allowed to enter central road sections in a particular period of the day. Therefore, the emissions inside the outer loop were much lower. In contrast, the emissions along the line-sources of the Shanghai outer ring road were generally higher. Regarding Shanghai's traffic flow, the Shanghai suburban and outer ring road, G60 Shanghai-Kunming Highway and S2 Hulu Highway were heavy-traffic routes in Shanghai's suburban areas. This enormous transportation burden leads to serious emissions, so the carrying capacity of different roads had a direct impact on the spatial distribution of emissions from external container trucks. Moreover, corresponding to the largest scale of the port enterprises in the Waigaoqiao area, the emissions peaked at $148 \mathrm{t}$ on the road sections in this area. As a result of the unique geographic location of the Waigaoqiao area, near the Shanghai outer ring road, the emissions in this area were more prominent than those in other regions. As far as the two sources of port-related pollution are concerned, the total amount of pollution discharged by trucks was much higher than that of machines, which was essentially 5-11-fold greater. 


\subsection{Air Quality Impact}

Among all pollution sources in Shanghai, the total port-related emissions (including cargo-handling equipment and external container trucks) constituted a relatively small proportion; e.g., the $\mathrm{NO}_{\mathrm{x}}$ emissions accounted for approximately $4 \%$, while the $\mathrm{VOC}_{\mathrm{S}}$ accounted for only $0.24 \%$ (Figure $6 \mathrm{a}$ ). However, because port-related sources were concentrated on the outer ring road and port area, they played an important role in port-surrounding areas with high-density populations. As such, $\mathrm{NO}_{\mathrm{X}}$ was taken as an example. The total emissions of $\mathrm{NO}_{\mathrm{X}}$ from all industries was approximately $500 \mathrm{kt}$ in 2015. The amount was higher in urban areas than in the suburbs (Figure 6b). This discrepancy was caused by the high emission contribution of on-road transportation inside the outer ring road. On the other hand, the emission shares were extremely high near terminal areas, such as Baoshan, Waigaoqian, Jinshan and some inland water areas. The peak reached 29,147 t near the Waigaoqiao terminal. Therefore, simulations were conducted to estimate the impact of the two types of port-related sources on air quality in Shanghai, including cargo-handling equipment and external container trucks. Because summer is the busiest period for shipping activity and port-related pollution [38,39], it was selected as a typical case to compare the diffusion and the impact on the air quality of the pollutants.

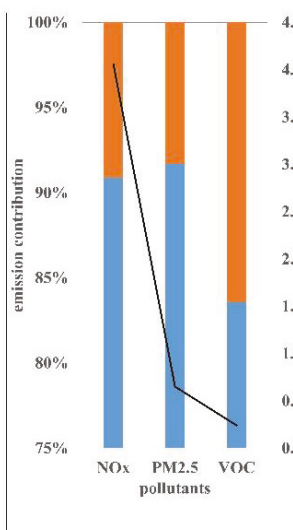

(a)

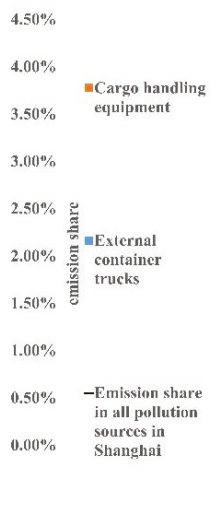

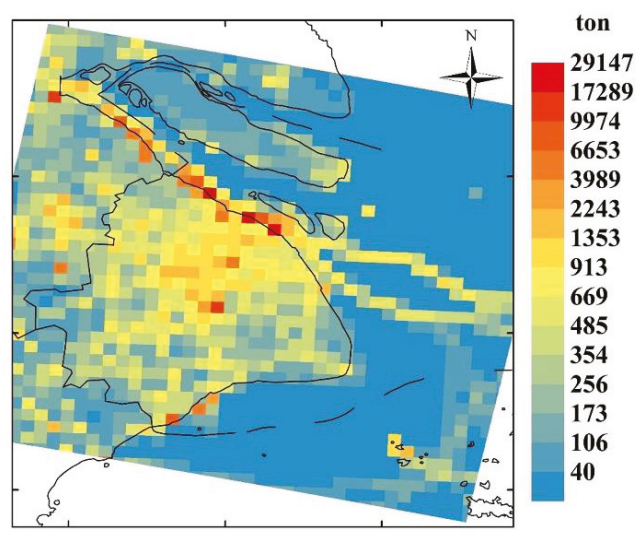

(b)

Figure 6. The total emission fluxes of port-related sources in Shanghai: (a) The emission contribution of cargo-handling equipment and external container trucks and their share in all pollution sources in Shanghai (\%); (b) The spatial distribution of annual $\mathrm{NO}_{\mathrm{X}}$ emission from all industries in Shanghai (t).

In the case of summer, the distributions of the concentration field for $\mathrm{NO}_{\mathrm{X}}$ and $\mathrm{PM}_{2.5}$ were similar (Figure $7 \mathrm{~b}, \mathrm{e}$ ). Because the numbers and activity of trucks were greater than those of the machines, the emissions were much higher. In addition, Shanghai is greatly affected by monsoons in the summer. Due to the influence of the monsoons, there could be a rapid spread of pollutants above most of the terminals located along the coast of the water-facing side, so the concentration was not high. The route of the trucks was generally inland, and the diffusion was slower than that of the machinery on the docks. In addition, the total emissions of trucks were 5-11 times those of the machinery. Therefore, the concentration of pollutants was higher along the main traffic route, including the suburban loop, outer loop, G60 Shanghai-Kunming Expressway and S2 Hulu Expressway. These traffic routes all converged near the Waigaoqiao port area, which guaranteed the heavy burden of freight transportation in Waigaoqiao, but also caused the maximum contribution of pollutants to be approximately $30.395 \mu \mathrm{g} / \mathrm{m}^{3}$ for $\mathrm{NO}_{\mathrm{X}}$ and approximately $1.346 \mu \mathrm{g} / \mathrm{m}^{3}$ for $\mathrm{PM}_{2.5}$. For $\mathrm{NO}_{\mathrm{X}}$, the concentrations along the main roads were essentially $5-10 \mu \mathrm{g} / \mathrm{m}^{3}$, while the concentrations in other regions were mostly less than $5.0 \mu \mathrm{g} / \mathrm{m}^{3}$. For $\mathrm{PM}_{2.5}$, the concentrations along the main roads were essentially $0.2-0.4 \mu \mathrm{g} / \mathrm{m}^{3}$, while the concentrations in other regions were mostly less than $0.2 \mu \mathrm{g} / \mathrm{m}^{3}$. 


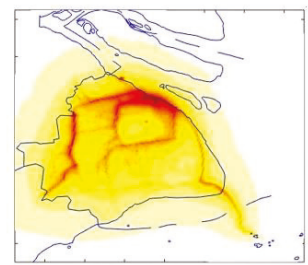

(a)

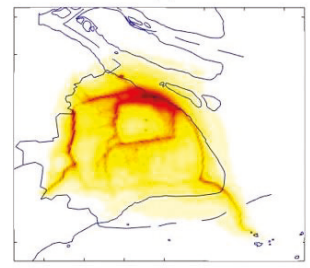

(d)

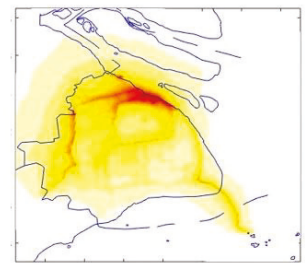

(b)

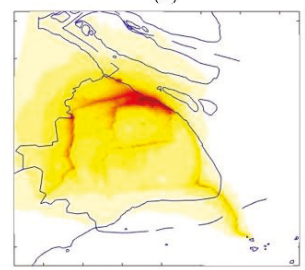

(e)

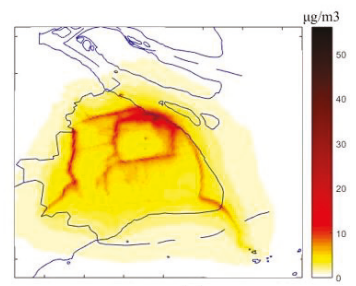

(c)

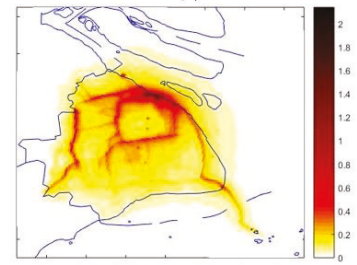

(f)

Figure 7. The simulated concentrations of $\mathrm{NO}_{X}$ and $\mathrm{PM}_{2.5}$ contributed by port-related sources in Shanghai: (a) Simulated $\mathrm{NO}_{\mathbf{X}}$ concentrations for annual average; (b) Simulated $\mathrm{NO}_{\mathrm{X}}$ concentrations in summer; (c) Simulated $\mathrm{NO}_{\mathrm{X}}$ concentrations in winter; (d) Simulated $\mathrm{PM}_{2.5}$ concentrations for annual average; (e) Simulated $\mathrm{PM}_{2.5}$ concentrations in summer; (f) Simulated $\mathrm{PM}_{2.5}$ concentrations in winter. The concentrations are given as $\mu \mathrm{g} / \mathrm{m}^{3}$.

The contribution of the pollutant concentrations varied greatly in the different seasons (Figure 7c-f). Due to the influence of the summer monsoon derived from the sea, the pollutants spread to the interior areas in the summer. In addition, the high wind speed of the summer monsoon brings a high diffusion rate of pollutants. Therefore, the impact of air quality from port-related sources was relatively small in the case of summer, with peaks of $30.4 \mu \mathrm{g} / \mathrm{m}^{3}$ for $\mathrm{NO}_{\mathrm{X}}$ (Figure $7 \mathrm{c}$ ) and $1.35 \mu \mathrm{g} / \mathrm{m}^{3}$ for $\mathrm{PM}_{2.5}$ (Figure 7e). In contrast, Shanghai is influenced by monsoons from the interior areas during the winter, so pollutants spread to the southeastern coastal areas. Moreover, the relatively low wind speed and wet deposition reduced the diffusion of contaminants. Therefore, even if the cargo volume in the summer was higher than that in the winter, the impact of air quality from the port-related sources in the winter was higher than that in the summer in this study. The peak of $\mathrm{NO}_{X}$ was $55.8 \mu \mathrm{g} / \mathrm{m}^{3}$ (Figure $7 \mathrm{~d}$ ) and the peak of $\mathrm{PM}_{2.5}$ was $2.14 \mu \mathrm{g} / \mathrm{m}^{3}$ (Figure $7 \mathrm{f}$ ), both of which were recorded in the Waigaoqiao area.

Generally, the impact of air quality differed by location with respect to the proportion in all industries. Near the large-scale ports such as Waigaoqiao port and the Yangshan deep-water port, compared with other industries, the port industry is relatively well developed. Therefore, the impact on air quality was greater from port-related sources than from other sources. As shown in Figure 8, it can be seen that in the port areas such as Waigaoqiao and Yangshan, the relative contributions of pollutant concentrations (i.e., the proportion in the whole industry) were large. For the average annual contribution of $\mathrm{NO}_{\mathrm{X}}$, the peak near Waigaoqiao reached $36.7 \%$ (Figure 8a), while the peak of $\mathrm{PM}_{2.5}$ reached $3.08 \%$ (Figure $8 \mathrm{~d}$ ). Similarly, the relative contribution along the main road of Shanghai traffic was also significant, especially along the route leading to Waigaoqiao and Yangshan. The relative contribution of $\mathrm{NO}_{X}$ at these traffic routes was approximately $25 \%$, while the relative contribution of $\mathrm{PM}_{2.5}$ was approximately $1.5 \%$. 


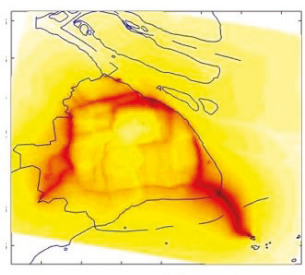

(a)

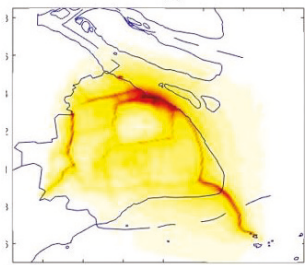

(d)

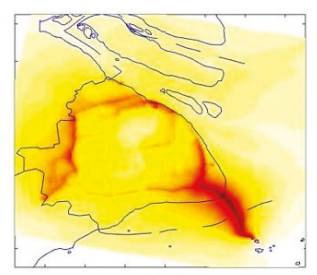

(b)

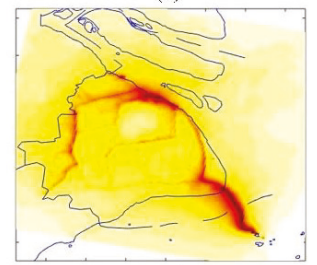

(e)

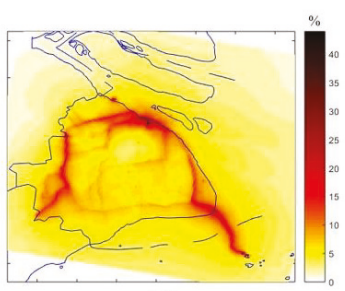

(c)

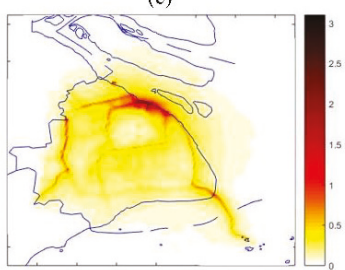

(f)

Figure 8. The proportions of port-related sources in all industries in Shanghai: (a) $\mathrm{NO}_{X}$ for annual average; (b) $\mathrm{NO}_{X}$ in summer; (c) $\mathrm{NO}_{X}$ in winter; (d) $\mathrm{PM}_{2.5}$ for annual average; (e) $\mathrm{PM}_{2.5}$ in summer; (f) $\mathrm{PM}_{2.5}$ in winter. The proportions are given as \%.

The seasonal differences in relative contributions were also obvious. For $\mathrm{NO}_{\mathbf{X}}$, due to the influence of the summer monsoon on the spread of pollutants, the relative contribution of concentration in the summer was lower than that in the winter (Figure 8b,c). However, the relative contribution of the S2 Hulu Expressway was higher in the summer than in the winter. This situation might be caused by the higher content of $\mathrm{NO}_{\mathrm{X}}$ in the exhaust emissions of external container trucks as compared to those of other sources. In addition, freight transportation in the summer was more frequent than that in the winter, resulting in the high-density discharge from trucks on the Hulu Expressway. For $\mathrm{PM}_{2.5}$, the important role of the summer monsoon on the diffusion can be clearly seen in Figure 8e. Moreover, due to the large amount of ground dust produced by other industries, such as construction, the relative contribution of port-related $\mathrm{PM}_{2.5}$ was relatively small and was mainly concentrated within the dense traffic routes of external container trucks, including the suburban loop, outer loop, G60 Shanghai-Kunming Expressway and S2 Hulu Expressway (Figure 8e,f).

\section{Discussions}

Our study of port-related emission inventories and environmental impact has suggested the importance of cleaner energy in the future. Clean energy, such as LNG and electricity, did not constitute a major portion of the energy structure in port-related activities in 2015. There is still some room for further improvements in optimizing the energy structure. The type of energy power at the port terminal has the most direct impact on the air pollutant emissions in a port area. The energy driving cargo-handling equipment, especially the horizontal transporting machines, should be changed from predominantly diesel fuel to predominantly electricity and LNG. Otherwise, the fuel quality of the diesel needs to be improved. Moreover, the proportion of clean energy, such as solar energy, wind energy and tidal energy, in the use of onshore electricity usage should be increased. With regard to the external container trucks, the energy use can be improved through the conversion of diesel oil to electricity hybrid and pure electric.

For the two different port-related sources, the emissions and environmental impacts of external container trucks occupied a prominent position. This is because the volume of external container trucks was large. In addition, the activity area and activity intensity of the external container trucks was much larger than those of the cargo-handling equipment. According to the impacts of port-related pollution on air quality in Shanghai, the proportions of terminals and main roads are more prominent 
due to the dense emissions in these areas. Therefore, besides the improvement of the energy structure, the control of the emissions of the external container trucks can be achieved through gradual policy development and the phasing out of vehicles with high energy consumption and high pollution levels, through the restriction of emission standards.

More importantly, the current major way to deliver shipping freight from port to city is by land trucks burning diesel oils, which contribute largely to air pollution in surrounding highway areas. In addition, the efficiency of truck transportation is relatively low. Previous studies [11,33] have shown that the conversion of land transportation to railway and waterway for multimodal transportation can effectively reduce the atmospheric pollution caused by external container trucks. There are large spaces for the use of railways or coasts and river waterways for freight transportation, which could significantly reduce the emissions from external port-related cargo delivery trucks if used. Therefore, the scale of railway transportation and waterway transportation must be gradually expanded and the proportion of land transportation reduced.

\section{Conclusions}

A systematic port-related emission inventory was constructed for the port of Shanghai, which included the port itself and the freight delivery land trucks outside the port. Diesel fuel dominated the fuel type of the machines and cargo delivery trucks in 2015. The emissions of $\mathrm{NO}_{\mathrm{X}}, \mathrm{CO}$, VOC $S, \mathrm{PM}_{10}$ and $\mathrm{PM}_{2.5}$ from port-related sources were 19,814.14 t, $7049.77 \mathrm{t}, 1357.33 \mathrm{t}, 772.55 \mathrm{t}$ and 699 t. Among all port-related sources, external container trucks generally produce more pollution than cargo-handling equipment. For $\mathrm{NO}_{\mathrm{X}}, \mathrm{CO}, \mathrm{VOC}_{\mathrm{S}}$ and $\mathrm{PM}_{2.5}$, the external port-related trucks accounted for $90.9 \%, 75.3 \%, 83.6 \%, 92.0 \%$ and $91.6 \%$.

Therefore, the annual emissions of different air pollutants were approximately 5 to 11 times that of the cargo-handling equipment. Under these circumstances, the environmental impact of pollution on air quality along the main city arteries was significantly higher than that in other areas in all cases in our research. Furthermore, in terms of the concentrations of air pollutants, the nearby port areas close to the main roads with container cargo traffic suffered most severely from port-related emissions. In this area, the average annual peak concentration of $\mathrm{NO}_{X}$ was approximately $30.40 \mu \mathrm{g} / \mathrm{m}^{3}$, accounting for $36.7 \%$ of all anthropogenic sources, while the peak of $\mathrm{PM}_{2.5}$ was approximately $1.346 \mu \mathrm{g} / \mathrm{m}^{3}$, accounting for $3 \%$.

Overall, the study implied it was necessary to promote the implementation of a combined green port policy in Shanghai, which could be made possible in the near future by optimizing the cargo delivery system from port to city and the energy structure used in the port, also by adding real-time monitoring systems to manage energy consumption and air pollutant emissions. Future green-port-related researches can focus on the following aspects: (1) To improve the energy structure of the port-related sources and reduce the usage of diesel oil; (2) To improve the choices of multimodal transport and explore the feasibility of railway and waterway transit; (3) To get access to the establishment of a monitoring system with high spatial and temporal resolution of the port areas.

Author Contributions: Conceptualization, Y.Z. (Yan Zhang); Data curation, Y.Z. (Yuyan Zhou), J.L., J.F., C.H. and W.G.; Formal analysis, Y.Z. (Yuyan Zhou), Y.Z. (Yan Zhang), S.L. and J.F.; Investigation, Y.Z. (Yuyan Zhou), Y.Z. (Yan Zhang), D.M., J.L., S.L., C.H., W.G. and H.Z.; Methodology, Y.Z. (Yuyan Zhou), D.M., J.L., J.F. and C.H.; Project administration, Y.Z. (Yan Zhang); Resources, D.M., J.L., W.L., Y.F., W.G. and H.Z.; Software, S.L. and J.F.; Supervision, Y.Z. (Yan Zhang); Writing—original draft, Y.Z. (Yuyan Zhou); Writing—review \& editing, Y.Z. (Yan Zhang), D.M., J.L., W.L., Y.F., C.H., W.G. and H.Z. All authors have read and agree to the published version of the manuscript.

Funding: This research was funded by the National Natural Science Foundation of China, grant number 21677038, and the Major Program of the Shanghai Committee of Science and Technology, China (17DZ120290; No. 19DZ1205009).

Acknowledgments: We want to thank the Shanghai Traffic Management Office for the investigated data and valuable advice. The opinions expressed in this article are the author's own and do not reflect the view of author affiliations. 
Conflicts of Interest: The authors declare no conflicts of interest. The funders had no role in the design of the study; in the collection, analyses, or interpretation of data; in the writing of the manuscript, or in the decision to publish the results.

\section{Appendix A}

Table A1: Selecting principles for cargo-handling equipment emission factors, Table A2: The emission factors of external container trucks.

Table A1. Selecting principles for cargo-handling equipment emission factors.

\begin{tabular}{ccccc}
\hline & First & Second & Third & Fourth \\
\hline Grading standard & Machine type & Fuel type & $\begin{array}{c}\text { Rated power } \\
(\mathrm{kw})\end{array}$ & Emission standard \\
& Forklift & Diesel & $\leq 19$ & China 0 \\
& Vehicles & Gasoline & $(19,37)$ & China 1 \\
& Hoisting & LNG & {$[37,56)$} & China 2 \\
Grading & machinery & LPG & {$[75,75)$} & China 3 \\
& Towing tractor & Electricity & {$[130,560)$} & China 4 \\
& Other industrial & Other fuel type & $\geq 560$ & China 5 \\
& machinery & & & \\
\hline
\end{tabular}

Table A2. The emission factors of external container trucks.

\begin{tabular}{|c|c|c|}
\hline Emission Standard & Air Pollutant & Emission Factor $(\mathrm{g} / \mathrm{km})$ \\
\hline China 1 & $\mathrm{CO}$ & 0.00 \\
\hline China 2 & $\mathrm{CO}$ & 0.00 \\
\hline China 3 & $\mathrm{CO}$ & 4.40 \\
\hline China 4 & $\mathrm{CO}$ & 2.50 \\
\hline China 5 & $\mathrm{CO}$ & 2.50 \\
\hline China 1 & VOC $_{S}$ & 0.00 \\
\hline China 2 & $\mathrm{VOC}_{\mathrm{S}}$ & 0.00 \\
\hline China 3 & $\mathrm{VOC}_{\mathrm{S}}$ & 1.16 \\
\hline China 4 & $\mathrm{VOC}_{\mathrm{S}}$ & 0.72 \\
\hline China 5 & $\mathrm{VOC}_{\mathrm{S}}$ & 0.72 \\
\hline China 1 & $\mathrm{NO}_{X}$ & 0.00 \\
\hline China 2 & $\mathrm{NO}_{X}$ & 0.00 \\
\hline China 3 & $\mathrm{NO}_{X}$ & 15.88 \\
\hline China 4 & $\mathrm{NO}_{X}$ & 13.77 \\
\hline China 5 & $\mathrm{NO}_{X}$ & 11.72 \\
\hline China 1 & $\mathrm{PM}_{2.5}$ & 0.00 \\
\hline China 2 & $\mathrm{PM}_{2.5}$ & 0.00 \\
\hline China 3 & $\mathrm{PM}_{2.5}$ & 0.77 \\
\hline China 4 & $\mathrm{PM}_{2.5}$ & 0.42 \\
\hline China 5 & $\mathrm{PM}_{2.5}$ & 0.26 \\
\hline China 1 & $\mathrm{PM}_{10}$ & 0.00 \\
\hline China 2 & $\mathrm{PM}_{10}$ & 0.00 \\
\hline China 3 & $\mathrm{PM}_{10}$ & 0.85 \\
\hline China 4 & $\mathrm{PM}_{10}$ & 0.46 \\
\hline China 5 & $\mathrm{PM}_{10}$ & 0.29 \\
\hline China 1 & $\mathrm{CO}_{2}$ & 0.00 \\
\hline China 2 & $\mathrm{CO}_{2}$ & 0.00 \\
\hline China 3 & $\mathrm{CO}_{2}$ & 894.17 \\
\hline China 4 & $\mathrm{CO}_{2}$ & 894.17 \\
\hline China 5 & $\mathrm{CO}_{2}$ & 894.17 \\
\hline
\end{tabular}




\section{References}

1. Chen, S. The Research on Evaluation of Green Port in Shanghai Port. Master's Thesis, Nanchang University, Nanchang, China, 2016.

2. Li, J.B.; Oh, Y.S. A Research on Competition and Cooperation Between Shanghai Port and Ningbo-Zhoushan Port. Asian J. Shipp. 2010, 26, 67-91. [CrossRef]

3. Mou, N.; Wang, C.; Yang, T.; Zhang, L. Evaluation of Development Potential of Ports in the Yangtze River Delta Using FAHP-Entropy Model. Sustainability 2020, 12, 493. [CrossRef]

4. Ren, J.; Dong, L.; Sun, L. Competitiveness prioritisation of container ports in Asia under the background of China's Belt and Road initiative. Transp. Rev. 2018, 38, 436-456. [CrossRef]

5. Johnson, T.; Rogan, E.; Pope, J. 2005 Green Port Annual Report; Maryland Port Administration: Baltimore, MD, USA, 2005.

6. Cannon, C.; Tomley, H. San Pedro Bay Ports Clean Air Action Plan 2017; Port of Los Angeles: San Pedro, CA, USA, 2017.

7. Bonner, A.; Snedden, P.; Mayson, J.; Haydon, S.; Smith, K.; Osborne, B. Ports of Auckland Annual Report 2017; Ports of Auckland Limited: Auckland, New Zealand, 2017.

8. Madalin, A.; Alina, M.; Daniela, S.; Ambroziu, D.; Ciprian, H. Annual Report-Port of Constanta 2015; Port of Constanta: Constanta, Romania, 2015.

9. Gonzalez Aregall, M.; Bergqvist, R.; Monios, J. A global review of the hinterland dimension of green port strategies. Transp. Res. Part D Transp. Environ. 2018, 59, 23-34. [CrossRef]

10. Yong, L.U.; Hao, H.U. Sydney Port's Practice in Green Port Development and China's Inspiration from it. Navig. China 2009, 32, 72-75.

11. Han, C.H. Air Pollution Reduction Strategies of World Major Ports. Int. Commer. Law Rev. 2010, 48, $27-56$.

12. Qin, C. Discussion on Setting up the Area of International Ship Emission Control Area in China. Energy Conserv. Environ. Prot. Transp. 2018, 14, 25-28.

13. Li, Y.; Zhang, X.; Lin, K.; Huang, Q. The Analysis of a Simulation of a Port-City Green Cooperative Development, Based on System Dynamics: A Case Study of Shanghai Port, China. Sustainability 2019, 11, 5948. [CrossRef]

14. Han, C.H. Green Port Strategies for Reducing Air Pollution in Port of Incheon. J. Korea Port Econ. Assoc. 2011, 27, 281-304.

15. Peng, C.Y.; Lin, C.G.; Jong, T.C. Emissions of particulate and gaseous pollutants within the Keelung harbor region of Taiwan. Environ. Monit. Assess. 2005, 109, 37-56. [CrossRef]

16. Li, Z.; Feng, C.J.; Ya, D.J. Air Pollution and Control of Cargo Handling Equipments in Ports. In Proceedings of the 2018 International Conference on Green Energy and Environment Engineering, Kitahiroshima, Japan, 27-29 August 2018; Wang, Y., Ed.; E D P Sciences: Les Ulis, France, 2019; Volume 93.

17. Isakov, V.; Barzyk, T.; Arunachalam, S.; Snyder, M.; Venkatram, A. A Community-Scale Modeling System to Assess Port-Related Air Quality Impacts; Springer Int Publishing Ag: Cham, Switzerland, 2016; pp. 385-390.

18. Arunachalam, S.; Brantley, H.; Barzyk, T.M.; Hagler, G.; Isakov, V.; Kimbrough, E.S.; Naess, B.; Rice, N.; Snyder, M.G.; Talgo, K.; et al. Assessment of port-related air quality impacts: Geographic analysis of population. Int. J. Environ. Pollut. 2015, 58, 231-250. [CrossRef]

19. International, I. Current Methodologies in Preparing Mobile Source Port-Related Emission Inventories. In Final Report for US Environmental Protection Agency; US Environmental Protection Agency: Washington, DC, USA, 2009.

20. Li, D.; Wu, Y.; Zhou, Y.; Du, X.; Fu, L. Fuel Consumption and Emission Inventory of Typical Construction Equipments in China. Chin. J. Environ. Sci. 2012, 33, 518-524.

21. Samaras, Z.; Zierock, K.H. OFF-ROAD VEHICLES-A COMPARISON OF EMISSIONS WITH THOSE FROM ROAD TRANSPORT. Sci. Total Environ. 1995, 169, 249-255. [CrossRef]

22. Agrawal, A.; Aldrete, G.; Anderson, B.; Muller, R.; Ray, J. Inventory of Air Emissions for Calendar Year 2013; Starcrest: Longbeach, CA, USA, 2014.

23. Fu, M.; Ge, Y.; Tan, J.; Zeng, T.; Liang, B. Characteristics of typical non-road machinery emissions in China by using portable emission measurement system. Sci. Total Environ. 2012, 437, 255-261. [CrossRef]

24. Zhang, Y.; Peng, Y.-Q.; Wang, W.; Gu, J.; Wu, X.-J.; Feng, X.-J. Air emission inventory of container ports' cargo handling equipment with activity-based "bottom-up" method. Adv. Mech. Eng. 2017, 9, 1-9. [CrossRef] 
25. Shon, Z.-H. Emissions of Ozone Precursors from a Biogenic Source and Port-related Sources in the Largest Port City of Busan, Korea. Asian J. Atmos. Environ. 2015, 9, 39-47. [CrossRef]

26. Kean, A.J.; Sawyer, R.F.; Harley, R.A. A fuel-based assessment of off-road diesel engine emissions. J. Air Waste Manag. Assoc. 2000, 50, 1929-1939. [CrossRef]

27. Tan, H.; Liu, J.; Shen, Y.; Fang, Y. Emission Inventory of Air Pollutants from Cargo Handling Equipments. Environ. Sci. Manag. 2013, 38, 82-87.

28. Fan, X.; Xia, Z.; Li, C. An Improved Method for Building an Emission Inventory for Cargo Handling Equipment and Its Application. Res. Environ. Sci. 2017, 30, 628-635.

29. Dragović, B.; Tzannatos, E.; Tselentis, V.; Meštrović, R.; Škurić, M. Ship emissions and their externalities in cruise ports. Transp. Res. Part D Transp. Environ. 2018, 61, 289-300. [CrossRef]

30. Huang, L.; Wen, Y.; Geng, X.; Zhou, C.; Xiao, C. Integrating multi-source maritime information to estimate ship exhaust emissions under wind, wave and current conditions. Transp. Res. Part D Transp. Environ. 2018, 59, 148-159. [CrossRef]

31. López-Aparicio, S.; Tønnesen, D.; Thanh, T.N.; Neilson, H. Shipping emissions in a Nordic port: Assessment of mitigation strategies. Transp. Res. Part D Transp. Environ. 2017, 53, 205-216. [CrossRef]

32. Smailys, V.; Rapalis, P.; Strazdauskiene, R.; Esmantaite, V.; Kaunas University Technology Press. Air Pollution by NOx from Ships Passing Klaipeda Port Channel. In Transport Means 2013; Kaunas University Technology Press: Kaunas, Lithuania, 2013; pp. 97-100.

33. Bailey, D.; Solomon, G. Pollution prevention at ports: Clearing the air. Environ. Impact Assess. Rev. 2004, 24, 749-774. [CrossRef]

34. Feng, J.; Zhang, Y.; Li, S.; Mao, J.; Patton, A.P.; Zhou, Y.; Ma, W.; Liu, C.; Kan, H.; Huang, C.; et al. The influence of spatiality on shipping emissions, air quality and potential human exposure in the Yangtze River Delta/Shanghai, China. Atmos. Chem. Phys. 2019, 19, 6167-6183. [CrossRef]

35. Lu, J.; Huang, C.; Hu, Q.-Y.; Yang, Q.; Jing, B.L.; Xia, Y.; Lu, B.; Tang, W.; Lou, S.R.; Tao, S.K.; et al. Air Pollutant Emission Inventory of Non-road Machineries in Typical Cities in Eastern China. Environ. Sci. 2017, 38, 2738-2746.

36. Xie, Y.; Ji, W. The Study of Factors Affecting the Limits in the Standard of Non-road Diesel Engine Fuel Consumption Limits. Diesel Engine 2010, 32, 1-4.

37. Xu, J.; Feng, X.; Jiang, L. Research of Air Pollutants from Cargo Handling Equipments. J. East China Jiaotong Univ. 2014, 31, 12-17.

38. Fan, Q.; Zhang, Y.; Ma, W.; Ma, H.; Feng, J.; Yu, Q.; Yang, X.; Ng, S.K.; Fu, Q.; Chen, L. Spatial and Seasonal Dynamics of Ship Emissions over the Yangtze River Delta and East China Sea and Their Potential Environmental Influence. Environ. Sci. Technol. 2016, 50, 1322-1329. [CrossRef]

39. Jalkanen, J.P.; Brink, A.; Kalli, J.; Pettersson, H.; Kukkonen, J.; Stipa, T. A modelling system for the exhaust emissions of marine traffic and its application in the Baltic Sea area. Atmos. Chem. Phys. 2009, 9, 9209-9223. [CrossRef]

(C) 2020 by the authors. Licensee MDPI, Basel, Switzerland. This article is an open access article distributed under the terms and conditions of the Creative Commons Attribution (CC BY) license (http://creativecommons.org/licenses/by/4.0/). 

Article

\title{
Masterplanning at the Port of Dover: The Use of Discrete-Event Simulation in Managing Road Traffic
}

\author{
Geoffrey C. Preston ${ }^{1}$, Phillip Horne ${ }^{2}$, Maria Paola Scaparra ${ }^{1,3}$ and Jesse R. O'Hanley ${ }^{1,3, *}$ \\ 1 Kent Business School, University of Kent, Canterbury CT2 7FS, UK; cliff.preston_75@btinternet.com (G.C.P.); \\ m.p.scaparra@kent.ac.uk (M.P.S.) \\ 2 Dover Harbour Board, Harbour House, Marine Parade, Dover CT17 9BU, UK; \\ phillip.horne@doverport.co.uk \\ 3 Centre for Logistics and Heuristic Optimisation, University of Kent, Canterbury CT2 7FS, UK \\ * Correspondence: j.ohanley@kent.ac.uk
}

Received: 29 December 2019; Accepted: 27 January 2020; Published: 3 February 2020

\begin{abstract}
The Port of Dover is Europe's busiest ferry port, handling $£ 119$ billion or $17 \%$ of the UK's annual trade in goods. The Port is constrained geographically to a small area and faces multiple challenges, both short- and long-term, with managing the flow of five million vehicles per year to/from mainland Europe. This article describes some of the work that the Port is doing to minimize the impact of port road traffic on the local community and environment using discrete-event simulation modeling. Modeling is particularly valuable in identifying where future bottlenecks are likely to form within the Port due to projected growth in freight traffic and comparing the effectiveness of different interventions to cope with growth. One of our key findings is that space which can be used flexibly is far more valuable than dedicated space. This is supported by the much greater reduction in traffic congestion that is expected to be achieved given a $10 \%$ increase in freight traffic by reallocating space at the front of the system to temporarily hold vehicles waiting to pass through border control and check-in compared to extending the amount of space for ferry embarkation at the rear of the system. The importance of flexible space has implications for port design that can be applied more broadly. Modeling is also useful in identifying critical thresholds for vehicle processing times that would cause the system to become overwhelmed. Increasing the check-in time by just three to five minutes, for example, would completely exceed the Port's capacity and produce indefinite queueing. This finding has important implications for Brexit planning. From a wider context, the research presented here nicely illustrates how simulation can be used to instill more evidence-based thinking into port masterplanning and support "green port" and other corporate sustainability initiatives.
\end{abstract}

Keywords: port masterplanning; corporate sustainability; traffic flow modeling; discrete-event simulation

\section{Introduction}

Port masterplanning is the process by which ports determine and communicate their medium- to long-term strategic plans. Masterplanning is vital for linking a port's strategy to over-arching local and regional transport strategies and ensuring that a port meets its commercial, social, and environmental objectives [1]. Integration of "green port" policies aimed at reducing emissions of air pollutants and greenhouse gasses from logistic operations, in particular, is increasingly being seen as a core element of port masterplanning [2-4]. In this regard, port masterplanning is linked intrinsically to the three pillars of corporate sustainability (i.e., balancing economic growth with environmental and social considerations) $[5,6]$.

A general challenge associated with masterplanning is that port infrastructure is often complex, expensive and long-lived. At the same time, decisions to build or repurpose infrastructure is often made with limited knowledge of future business trends, technology, and environmental regulations. 
From this perspective, port masterplanning is best viewed as a process of complex decision-making under uncertainty. To help address this, techniques from the field of operations research (OR) are becoming ever more popular for structuring and supporting the development of port masterplans. Simulation modeling is especially well suited for addressing problems at all levels of planning, including operational, tactical, and strategic, for which uncertainty and time are key features [7]. Indeed, the World Association for Waterborne Transport Infrastructure (PIANC) advocates the use of simulation across a range of port functions, such as vessel maneuvering, tide and sedimentation analysis, and traffic flow prediction [8]. Note that a number of different simulation approaches can be adopted (e.g., system dynamics, discrete-event, agent-based, and mixed), with each method having its strengths and weaknesses. Selection of a particular method to use depends in part on the type of problem being modeled, the granularity of available data, and the degree of abstraction needed to address questions of interest.

A number of timely reviews have appeared in the literature recently presenting overviews of the application of OR methods in port and maritime planning [9-15]. A particularly good review of how simulation models are applied in ports and container terminals is presented by Dragović et al. [14], who trace the evolution of methods used and the breadth of problem areas addressed since the 1960s. Of the 219 articles evaluated by Dragović et al., the majority focus on container stack loading and unloading, which is discussed in more depth in a study by Lehnfeld and Knust [15]. Another notable finding is the sheer variety of simulation techniques and software used, with discrete-event simulation being the most common type of framework (e.g., [16]) but with agent-based models also frequently employed (e.g., [17]). An entire section of the review is devoted to port traffic, specifically marine vessels. Examples mentioned include modeling ferry traffic of Aegean ports given seasonally varying demand [18], modeling safety and vessel interactions in San Francisco Bay [19], and detailed modeling of ferry maneuvers at the Port of Dover [20]. The Dragović et al. review concludes that simulation modeling is a pre-requisite of effective port development planning due to the degree of complexity of port systems [14].

For modeling vehicle traffic within ports, agent-based simulation tends to be the methodology of choice. For example, causes and possible solutions to traffic congestion at the Port of Chennai are analyzed by Rajamanickam and Ramadurai [21] using the agent-based microsimulation environment PTV Vissim. The authors of this study find vehicle document processing to be a limiting step in the system and propose both technological and structural solutions to mitigate congestion. Similarly, Demirci [22] developed a whole-port simulation model to identify processing bottlenecks and possible investments to improve cargo handling, warehousing, and transport operations at Trabzon Port in Turkey. The simulation explicitly models both shipping vessels and cargo loading/unloading vehicles (e.g., trucks and forklifts). In addition to more land-side focused modeling studies, other whole-port modeling tools are described in the literature, including Portsim, a discrete-event model developed primarily for military logistics planning [23] and a general hybrid discrete-event and agent-based framework for modeling cargo facilities implemented in AnyLogic and Java [24].

The focus of the current study is the Port of Dover in the UK. The Port of Dover is Europe's busiest ferry port, handling upwards of $£ 119$ billion or $17 \%$ of the UK's annual trade in goods along a $180 \mathrm{~km}$ trade expressway [25]. As a roll-on-roll-off (aka ro-ro) ferry port, the Port of Dover faces multiple challenges with managing the flow of over 10,000 vehicles per day to/from mainland Europe. Ferry operations are situated on the Port's Eastern Docks, which are constrained geographically to a small area bounded by cliffs to the north, the sea to the east and south, and the town of Dover and major road links to the west (Figure 1). What is more, the Port operates in a highly dynamic environment. This includes both short-term operational stressors (e.g., delayed ferry movements caused by storms, variable staffing levels, labor strikes, and heightened security in response to acts or threats of terrorism) and long-term strategic stressors (e.g., projected growth of freight traffic and the possibility of additional border and customs checks on vehicles following Brexit). With little recourse 
to increase its existing footprint, it is vital that the Port finds smarter ways of doing things if it is to maintain and grow the ferry business.

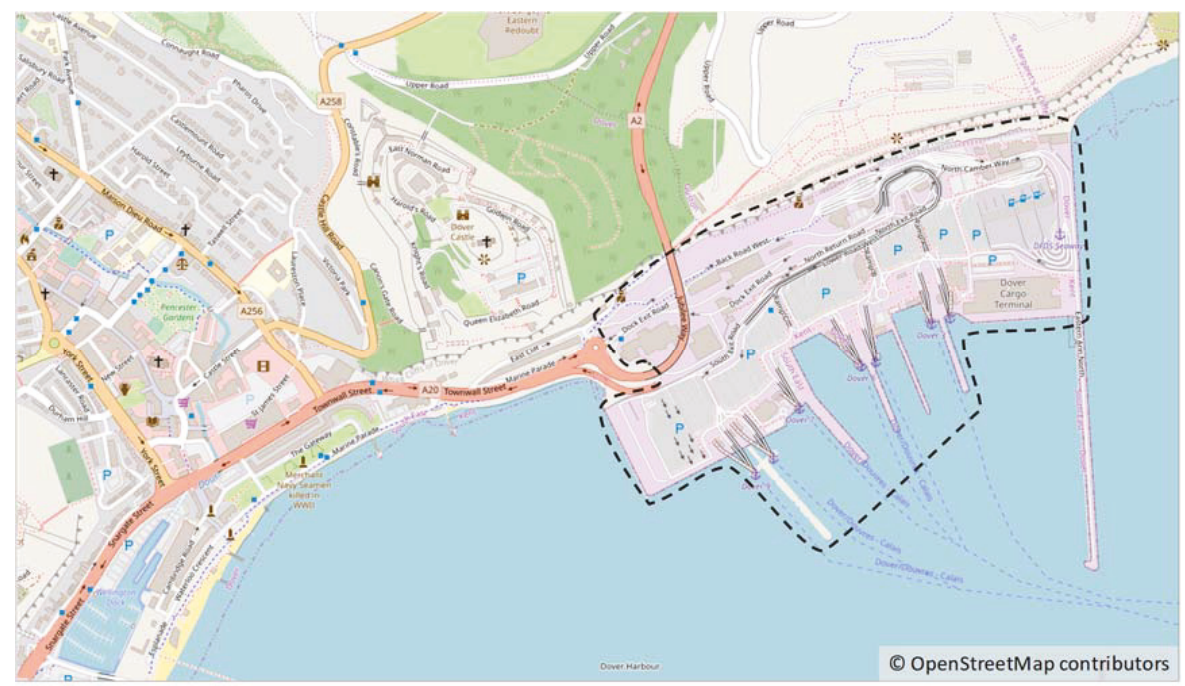

Figure 1. Aerial view of the Port of Dover Eastern Docks (Source: [26]). The black dashed line roughly marks out the physical boundary of the Eastern Docks.

In an effort to instill more evidence-based thinking into its masterplanning exercise, the Port of Dover has over the past few years invested in the development of simulation and other OR methodologies to inform operational policies and capital investment decisions. This article describes some of the work that the Port is doing to minimize the impact of port road traffic on the local community and environment using a whole-port discrete-event simulation model to improve traffic flow forecasting and identify the best use of space to reduce traffic congestion.

Road traffic at the Port of Dover has previously been the subject of various simulation studies. Roadknight and colleagues report findings of two studies involving application of the microscopic traffic flow simulation software Vissim $[27,28]$. A key advantage of traffic flow simulators is the high level of detail that can be ascribed to individual driver behavior and choices. For example, using Vissim, Roadknight et al. were able to simulate how traffic divides over a set of parallel weigh-bridges by defining simple rules of thumb for driver behavior rather than assigning weigh-bridge choice probabilistically [27]. However, as the authors point out, difficulties can arise when simulating large systems made up of many interdependent entities due to high data requirements and the likelihood that small errors in model design can result in highly inaccurate outputs.

Given the stochastic nature of the system, simulation provides a valuable tool to address both the short-term operational needs of the Port of Dover as well as investigate long-term strategic choices. Where agent-based and discrete-event models have been explicitly compared, agent-based models are typically judged as being more accurate [29]. For the current study, however, discrete-event simulation was adopted given the flexibility it offers in terms of quickly reconfiguring the model to analyze different possible future scenarios and its reliance on a minimal set of assumptions about the Port's physical layout and the movement of traffic.

The Port system has some interesting features from a queuing theory perspective. Queuing theory mainly focuses on stable queues in which arrival rates are less than service rates, resulting in stable and predictable behavior over time. In contrast, the Port of Dover has arrival rates that are non-stationary but vary systematically within each day. Since the Port operates efficiently overall, these arrival rates 
can transiently exceed processing rates, resulting in queues which move rhythmically from sub- to super-saturated and back. As pointed out by Newell [30], queue behavior where arrival rates and service rates are closely matched is particularly chaotic and therefore harder to predict.

In what follows, we describe the construction and validation of a discrete-event simulation model of the Port of Dover and its application in both short-term and long-term planning. Key findings of our study are intended to yield general insights that can be used to guide sustainability initiatives and infrastructure decisions at other ports. As a bit of context, modeling originally began in late 2015 with the goal of identifying potential bottlenecks in the system driven by anticipated growth in freight traffic and the development of possible interventions to reduce queuing traffic. The model has subsequently been adapted to explore possible implications for the Port regarding the UK's decision in 2016 to leave the European Union (i.e., Brexit) and support post Brexit planning. The full ramifications of Brexit are currently unknown. However, modeling provides a convenient means for carrying out "what-if" analysis in the absence of reliable information on future traffic volumes or required changes to vehicle processing.

The work presented here is noteworthy in several respects. First, our study stands out within the literature by focusing on road traffic in a ro-ro ferry port rather than the usual container port. Second, whereas simulation is most often used to help streamline existing operations, an additional primary aim of our investigation is to examine how simulation can support strategic, long-term planning and investment tied to port masterplanning. Finally, as part of our analysis, we address sustainability issues by considering a key performance indicator (i.e., Dover Traffic Assessment Project (TAP), discussed below) that relates to the impact of traffic queues on the local community and the environment.

\section{Materials and Methods}

\subsection{Study Area}

The Port of Dover is a large roll-on-roll-off ferry port located in Dover, southeast England that provides one the two main modes of transport (along with Eurotunnel) for road vehicles traveling between the UK and mainland Europe. The Port handles three main vehicle types: large freight vehicles (or lorries), passenger cars/motorcycles, and coaches, which drive onto ferries under their own power and drive off at their destination. Currently, there are two ferry operators at the Port of Dover, P\&O Ferries and DFDS Seaways, which run cross-channel services to Calais and Dunkirk in France. Up to 5 million vehicles travel through the Port annually.

The Port system is moderately complex, with multiple traffic types, arrival rates which have within-day, weekly, and seasonal variations, and a series of manned check points, each of which is preceded by space for queuing traffic (Figure 2). The Port is best thought of as a "system of systems" [31], in which the overall behavior of the system emerges from the interactions among its component processes and queues.

There are two main entrances to the Port: the A20, which approaches the Port along the coast from Folkestone to the west, and the A2, which approaches the Port inland from Canterbury to the northeast. The majority of freight vehicles and coaches arrive from the A20. The A2 has a mixture of traffic but is made up mainly of passenger cars. After arriving at the Port, vehicles are required to pass French border control, better known as Police aux Frontières (PAF), and other security checks before making their way to check-in booths to collect boarding passes for their designated ferry service. Vehicles wait for ferries in the assembly area next to the docks. The final stage of journey through the Port is ferry embarkation or "uplift" (i.e., removal of vehicles from the system) when a ferry enters the Port, docks, unloads incoming vehicles, loads outgoing vehicles, and then departs.

Immediately inside the port entrance is a highly flexible space called the "buffer zone" for temporarily holding vehicles waiting to pass through PAF and/or check-in. The buffer zone has the capacity for 220 lorries or around 600 passenger cars/motorcycles. Traffic is directed at the port entrance using electronic signs above individual lanes within the buffer zone so subsets of vehicles (either type 
of vehicle or those booked on a particular ferry service) can be selectively held in the buffer zone or allowed to bypass it directly to PAF.

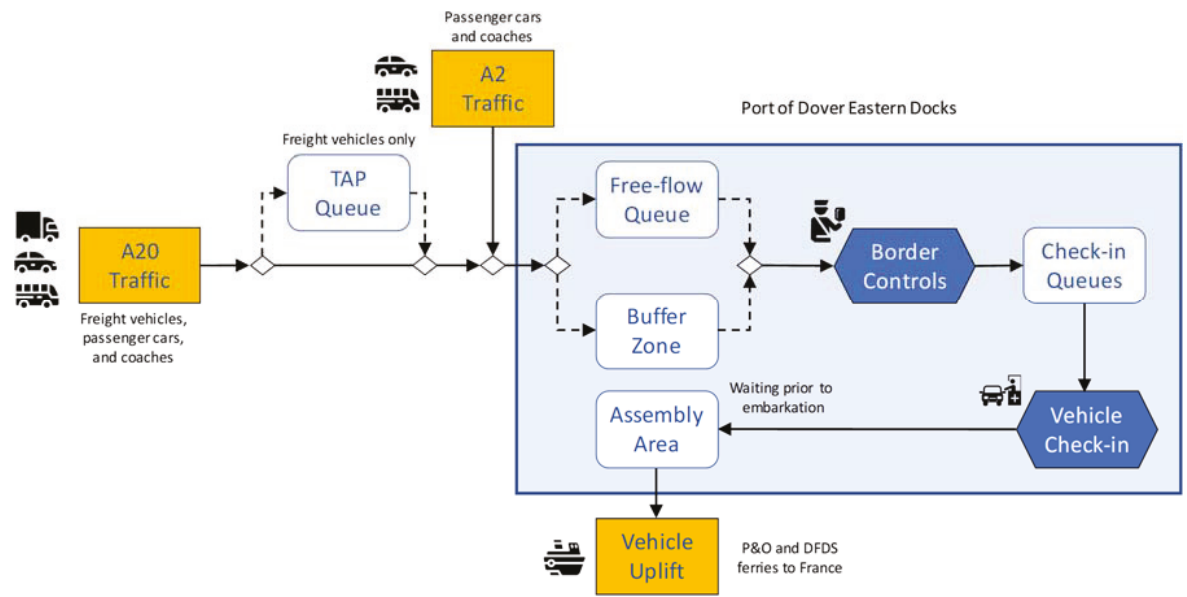

Figure 2. Simplified schematic of the Port of Dover Eastern Docks. Figure adapted from [32]. TAP = Traffic Assessment Project.

Under extreme conditions, such as prolonged periods of bad weather or labor strikes, the M20 motorway, which freight and other vehicles travel along prior to joining the A20, is sometimes closed to traffic and used as a giant lorry park. Operation Stack, as it is commonly known, is rare. In 2015, there were 31 days of Operation Stack, but none from 2016 to 2019. It is estimated that Operation Stack cost the UK economy $£ 250$ million per day [33]. In 2019, Operation Stack was replaced by Operation Brock, which introduced a contraflow system to buffer freight traffic on the M20. At the start of 2020, however, permanent barriers used to operate the contraflow system have started to be removed.

In April 2015, Highways England implemented a local traffic management system, known as the Dover Traffic Assessment Project (TAP), to control freight traffic approaching the Port along the A20. The main purpose of TAP is to reduce congestion of Dover's local road network and improve air quality within the town and avoid the necessity of triggering Operation Stack/Brock. TAP, which is composed of a series of traffic lights to regulate flow along the left lane of the A20, is only put into operation when needed due to heavy congestion within the Port. Passenger cars/motorcycles and coaches are not held in the TAP queue, so they get preferential access to the Port when TAP is in place.

\subsection{Model Development and Validation}

A discrete-event simulation model of the Port of Dover Eastern Docks was developed using the Simul8 software package. The model considers only outbound traffic (i.e., traffic traveling from the UK to France) as outbound flow is effectively independent and does not compete for resources or space. The reason for this is that under the Le Touquet agreement, UK and French border controls are juxtaposed, with French controls located in the UK and UK controls located in France. Consequently, there are relatively few checks on inbound traffic and little or no queuing. Figure 3 shows an annotated flow diagram of the simulation model. The various components of the model are described in Table 1. Main input data to the model include the following. 


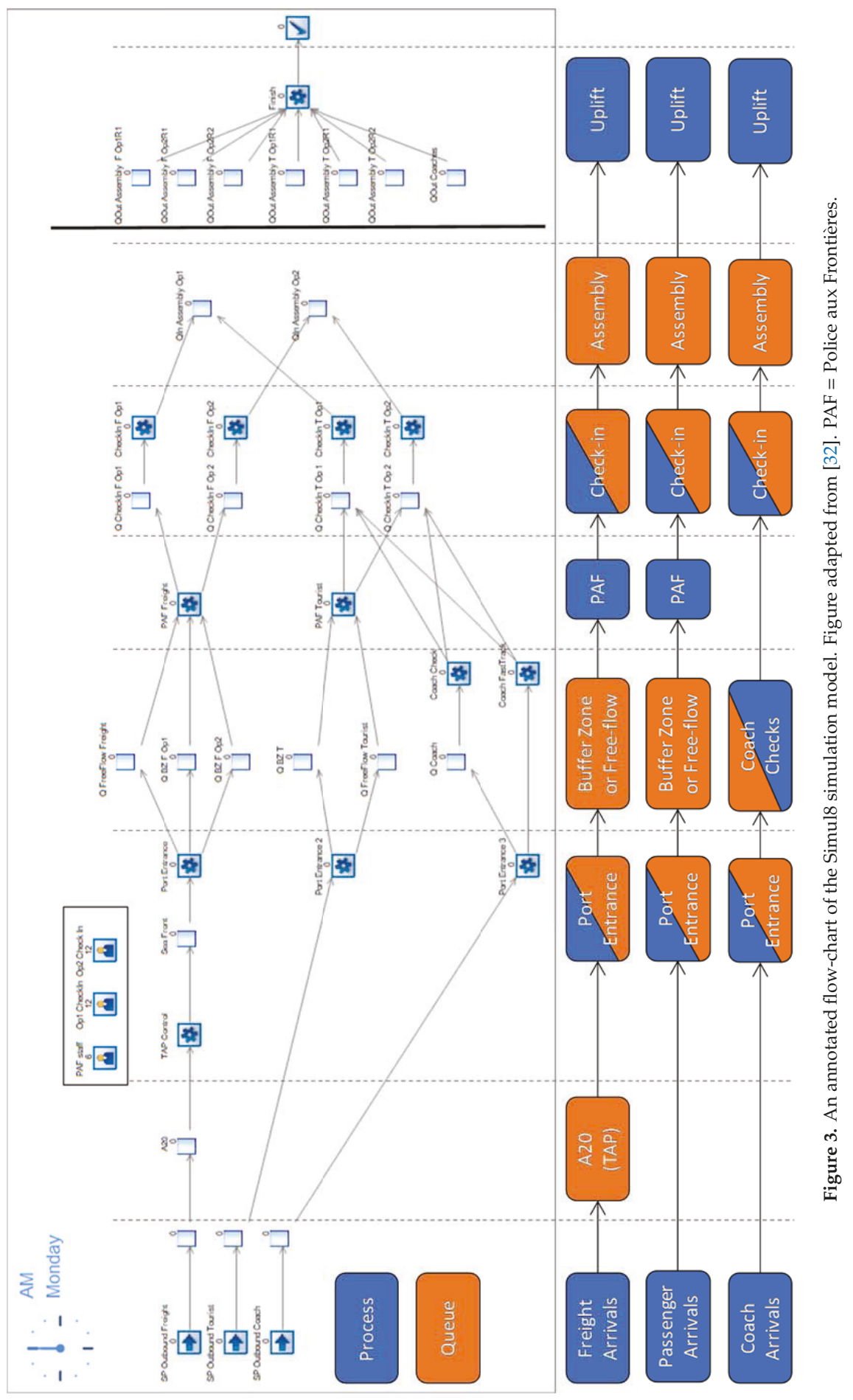


Table 1. Main components of the simulation model.

\begin{tabular}{|c|c|c|}
\hline & Component & Description \\
\hline \multirow[t]{2}{*}{ Transient Entities } & Ferries & $\begin{array}{c}\text { Ferry vessels differentiated by ferry operator } \\
\text { (P\&O and DFDS), destination (Calais and } \\
\text { Dunkirk) and uplift capacity. }\end{array}$ \\
\hline & Road Vehicles & $\begin{array}{l}\text { Road vehicles differentiated by vehicle type } \\
\text { (freight vehicle, passenger car/motorcycle, coach), } \\
\text { intended ferry operator and destination. }\end{array}$ \\
\hline \multirow{4}{*}{ Resident Entities } & PAF & $\begin{array}{l}\text { French border control (aka PAF) and other } \\
\text { security checks. }\end{array}$ \\
\hline & Coach Checks & $\begin{array}{l}\text { Separate border control and other security checks } \\
\text { for coaches. }\end{array}$ \\
\hline & Check-in Booths & $\begin{array}{c}\text { Check-in booths specific to ferry operator. Can be } \\
\text { reallocated to different traffic types dynamically } \\
\text { depending on demand. }\end{array}$ \\
\hline & Ferry Uplift & $\begin{array}{l}\text { Ferry uplift is specific to ferry vessel } \\
\text { and destination. }\end{array}$ \\
\hline \multirow{6}{*}{ Queues } & TAP & Queuing freight traffic on the A20 due to TAP. \\
\hline & Buffer Zone & $\begin{array}{l}\text { Area for temporarily holding vehicles waiting to } \\
\text { pass through PAF. }\end{array}$ \\
\hline & Free-flow Queue & Queue for free-flowing traffic approaching PAF. \\
\hline & Coach Queue & $\begin{array}{l}\text { Queue for coaches waiting for border control and } \\
\text { other security checks. }\end{array}$ \\
\hline & Check-in Queue & Queue for vehicles in front of check-in booths. \\
\hline & Assembly Area & $\begin{array}{l}\text { Marshalling area for vehicles waiting to board } \\
\text { ferries. Segregated by ferry operator. }\end{array}$ \\
\hline
\end{tabular}

- The capacity of each queue or holding area in the model is measured in freight equivalent units (FEUs), with $1 \mathrm{FEU}$ equal to $18 \mathrm{~m}$ of road space (including free space in front and behind a vehicle). Coaches are estimated as $1 \mathrm{FEU}$, while passenger cars and motorcycles are specified as $1 / 3$ of an FEU (6 $\mathrm{m}$ of road space).

- Parametric distributions for process times were fit to data collected from both manual samples (stopwatch estimates) and automatic loggers where available (e.g., logs of check-in booth gate raises). Distributions were derived using Stat::Fit software and the best fitting distributions chosen based on $p$-values of the Kolmogorov-Smirnov test.

- Half-hourly arrival rates for each traffic type are based on historical patterns.

- Ferry schedules and vessel capacities are based on schedules currently in use as well as analysis of historical schedules and vehicles carried.

In reality, ferries take tens of minutes to load and unload. In the simulation, however, embarkation is modeled as an instantaneous event at the time of ferry departure. Vehicles chosen for embarkation is based on a first-come-first-serve basis according to time of check-in, a protocol that more or less matches current practice.

The primary key performance indicator (KPI) chosen for the simulation study was the predicted number of TAPs per week. This is a convenient proxy for days on which the Port's capacity to handle inbound traffic is exceeded for whatever reason. TAP events have significant implications for Port staff, since TAP and buffer zone queues must be actively monitored and traffic systematically conveyed from TAP to the buffer zone. In addition, Port police are needed to provide traffic control at the front of the TAP queue. TAP is also well-known to local and national agencies. Finally, TAP is a vital metric from a sustainability perspective, since it is both a social measure of inconvenience to local stakeholders (i.e., congestion of local roads near the A20) and an indirect environmental measure since it involves stop-start queuing freight traffic that could otherwise be at rest with engines switched off. We therefore assume that TAP reduction is one of the main enablers for the Port to meet its social and environmental objectives.

Secondary KPIs monitored in the simulation were: (i) total time in system starting from entering the extended Port system (approximately 6.3 miles from the entrance to the Port) and ending at 
embarkation; (ii) use of the buffer zone, which provides an indicator that the system is near or at capacity; and (iii) emissions of $\mathrm{CO}_{2}$ (a primary greenhouse gas) and $\mathrm{NOx}$ (a regulated air pollutant) produced by freight vehicles in the TAP queue. Estimates for $\mathrm{CO}_{2}$ and $\mathrm{NOx}$ are derived by calculating the average speed for each freight vehicle in the TAP queue and then applying the UK Department for Transport speed-emissions curves [34]. As a conservative approach, we used parameter values for 34-40 metric ton articulated heavy goods vehicles (HGVs) fitted with diesel engines meeting the Euro VI emission standard. This class of HGVs corresponds to the most common type of articulated freight in 2020 and the most fuel efficient [35].

Verification and validation of the model was performed using Sargent's schema as a guide [36]. Verification consisted of a line-by-line check of the model code and systematic checks and documentation of each entity in the simulation to ensure they behaved as intended. "White-box" testing was conducted by varying simulation inputs and confirming the simulation responded appropriately (e.g., increasing daily volumes of traffic to observe progressive saturation of queues and monotonic increases in traffic queuing outside the Port). Verification tests were run independently by two of the authors (G.C.P. and J.O'H.), one of whom did not work on model implementation (J.O'H.). Face validity was confirmed by demonstrating the working simulation to Port operational staff, who confirmed the correct sequence of operations and that no key features were absent.

Additional operational validation work was carried out to ensure the simulation model was suitable for decision support purposes. First, outputs of the simulation model were compared with a simple, deterministic system dynamics model developed in-house by the Port for estimating total traffic in the system (i.e., traffic that has entered the system, expressed in FEUs, but not yet embarked). The system dynamics model (implemented in Excel) is designed to represent the Port only at a very high level. It combines vehicle arrival patterns with ferry arrival/departure schedules to identify periods during which waiting traffic is likely to be held within the Port and the amount of traffic held. Despite its very different underlying methodology, the discrete-event simulation model is able to reproduce outputs very similar to the system dynamics model (Figure 4), but has the added advantage (given its much greater level of detail) of showing where queues are located in the Port, which traffic types are queuing for which ferry services, and when TAP events are likely to occur.

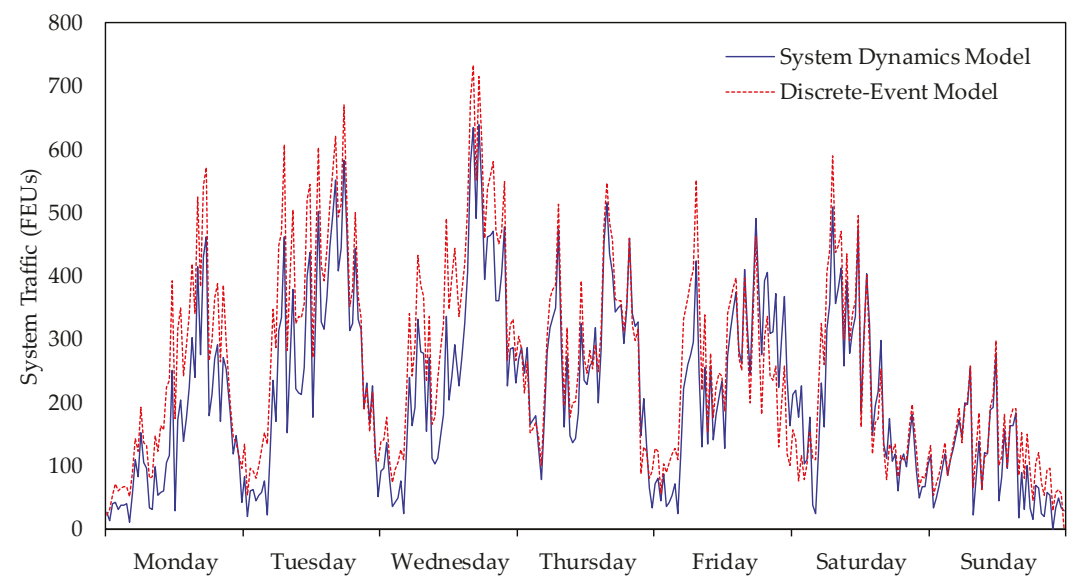

Figure 4. Comparison of number of vehicles in the Port system, measured in freight equivalent units (FEUs), for the systems dynamics model and the discrete-event simulation model given inputs for a typical week. The Pearson correlation coefficient for the two time series displayed is 0.94 .

Second, the simulation model was compared against real-time traffic monitoring data collected by the Port. One of these systems includes Blip Systems BlipTrack sensors, which monitor traffic flows by 
sensing mobile phone and Global Positioning System (GPS) signals. A typical freight week from April 2016 was used as a benchmark by comparing simulated transit times against sampled BlipTrack dwell times and cumulative ferry uplift. Additionally, weeks with known vessel refits, check-in computer system failures, or slow processing at PAF were used to check that the model was sensitive to observed stressors. Figure 5 shows the results of such an event, in which a late-afternoon reduction in the number of available check-ins triggers first use of the buffer zone, then an extended period of TAP, which eventually clears by mid-evening. Comparison of simulated dwell times with sampled BlipTrack dwell times on the A20 for the day in question shows that the model correctly identifies the start and end of TAP and closely approximates maximum dwell time in each half-hour period and the overall pattern of rise and fall of dwell times. Note that BlipTrack segregates traffic into fast and slow streams, so free-flowing traffic is not recorded. The stretch of road takes about 8-9 min to cover, hence a value of $8.6 \mathrm{~min}$ is shown for BlipTrack outside the TAP event (i.e., 15:30-17:00 and 21:00-22:30).

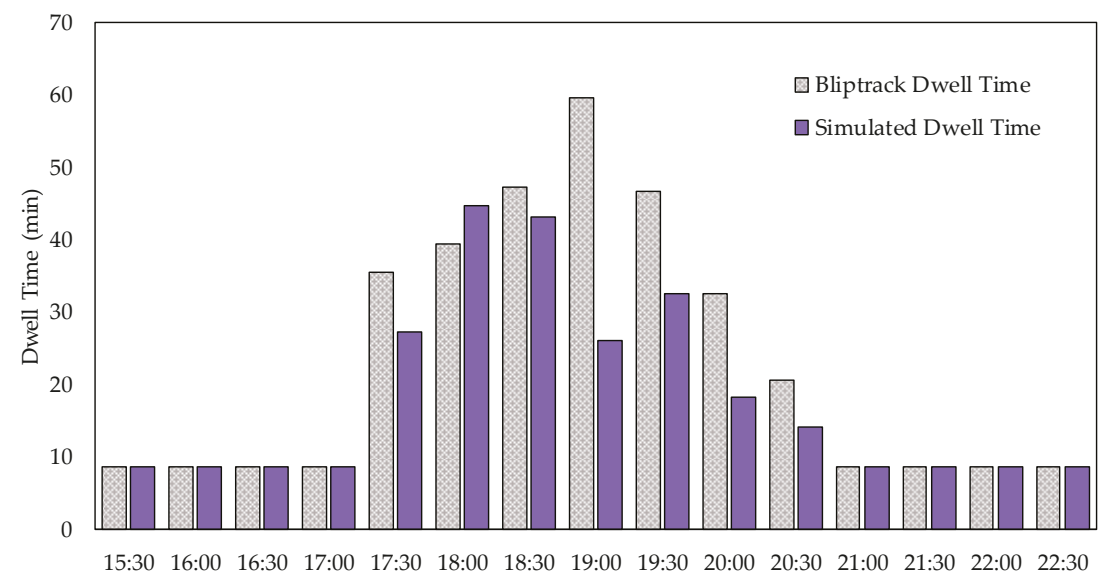

Figure 5. Comparison of simulated dwell times in the TAP queue with observed dwell times from BlipTrack during a TAP event on the evening of 2 February 2016.

The simulation model can be run over two basic time intervals. A one-week version of the model is quick to run and modify, affords a greater number of trials, which improves the precision of statistical analyses, and gives outputs comparable with the system dynamics model. Results reported in this paper are based on a one-week runtime. Alternatively, the model can be run over a full year (actually 48 weeks as the first two and last two weeks of the year must be excluded, since they are atypical and distort year-to-year comparisons). A one-year run is slow to execute and not ideal for conducting multiple trials but has the advantage in that it provides an estimate of the number of TAP days per year, which is better for communicating results to external stakeholders.

\section{Results}

\subsection{Anticipated Impact of Freight Traffic Growth}

At the time the Port of Dover's last masterplanning cycle was initiated, the volume of freight traffic was steadily increasing over time. In just the two-year period 2013-2015, freight grew by $30 \%$ [25], bringing concerns about environmental sustainability and the feasibility of maintaining business growth of this level to the fore.

The first set of simulation experiments were designed to assess the capacity of the Port system to cope with increased freight traffic. As baseline for comparison, the week of 18 April 2016 was chosen to represent a moderately heavy freight week. This was the Port's fifth busiest week for freight 
that year but typical in the sense that no extraordinary events or weather conditions prevailed, and within-week and within-day arrival patterns were not out of the ordinary. Since the focus of our analysis is on infrastructure planning rather than driver behavior, the ferry schedule was set to the highest frequency of sailings seen in 2016, while staffing at both PAF border controls and check-in booths was set to the number of service channels available (rather than constrained by actual staffing). Traffic flow was simulated for this baseline scenario and then again for a $10 \%$ growth in freight vehicles by simply multiplying the instantaneous arrival rates for freight traffic by 1.1. This was considered a sensible choice given trends in freight traffic growth in preceding years. Tourist and coach traffic were left unchanged.

Figure 6 shows a single one-week run of the simulation for both the baseline and 10\% freight growth scenarios. At baseline, a typical high-freight week with no unusual circumstances is easily handled by the Port. Traffic has a mid-week peak of around 900 FEUs and some use of the buffer zone on Wednesdays but no instances of TAP. In contrast, with a 10\% growth of freight, queuing traffic peaks to over 1100 mid-week, with three activations of the buffer zone and two instances of TAP.

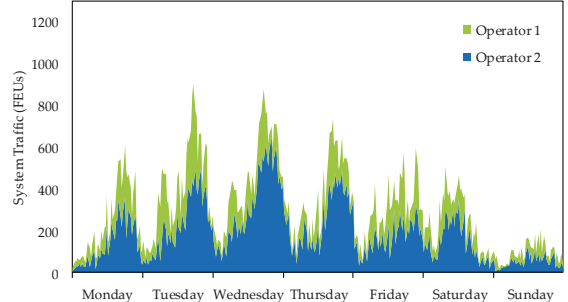

(a)

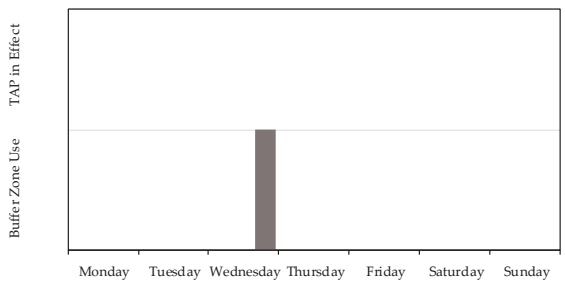

(c)

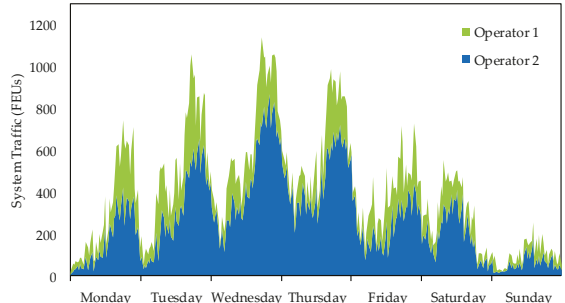

(b)

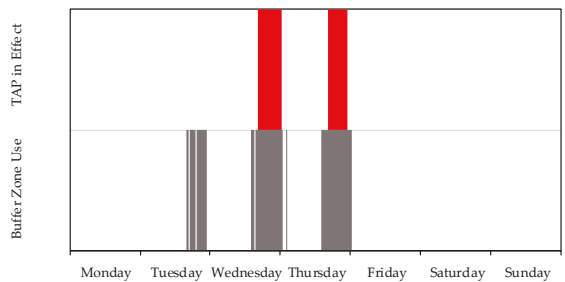

(d)

Figure 6. (a) Simulated Port traffic by ferry operator (blue and green) over a typical week under baseline conditions and (b) following a 10\% increase in freight traffic, along with (c) buffer zone (grey) and TAP use (red) under baseline conditions and (d) following a 10\% increase in freight traffic.

Summary results comparing the base case and 10\% freight growth scenarios given 100 simulation runs are provided in Table 2. These results tell a similar story to Figure 6. Given 10\% freight growth, vehicles remain in the system an average of 25\% longer, rising from 89 to $111 \mathrm{~min}$. More importantly, the number of weekly TAPs increases significantly, going from near zero to 1.6 per week, while $\mathrm{CO}_{2}$ and NOx emissions rise by $12 \%$. The consequence is that there are periods when 223 freight vehicles are queuing in TAP, equating to approximately 2.5 miles of queuing traffic, as well as an excess of 5.4 $\mathrm{kt}$ of $\mathrm{CO}_{2}$ and an excess of $3.5 \mathrm{~kg}$ of NOx emitted per week. Note that excess emissions represent the levels of emissions over and above what is expected following a $10 \%$ increase in vehicle numbers and is expressed simply as projected $\mathrm{CO}_{2}$ and $\mathrm{NOx}$ emissions minus 1.1 times baseline $\mathrm{CO}_{2}$ and NOx emissions. 
Table 2. Traffic flow metrics for the base case and $10 \%$ growth in freight traffic scenarios. Values reported are means over 100 simulation runs along with $95 \%$ confidence interval half-widths.

\begin{tabular}{|c|c|c|c|c|c|c|c|c|}
\hline \multirow[b]{2}{*}{ Scenario } & \multirow[b]{2}{*}{$\begin{array}{l}\text { Time in } \\
\text { System } \\
\text { (min) }\end{array}$} & \multicolumn{2}{|c|}{ Buffer Zone } & \multicolumn{5}{|c|}{ TAP Queue $^{1}$} \\
\hline & & $\begin{array}{l}\text { Max Size } \\
\text { (FEUs) }\end{array}$ & $\begin{array}{c}\text { Max Dwell } \\
\text { (min) }\end{array}$ & $\begin{array}{l}\text { No. TAPs } \\
\text { (per wk) }\end{array}$ & $\begin{array}{l}\text { Max Size } \\
\text { (FEUs) }\end{array}$ & $\begin{array}{l}\text { Max Dwell } \\
\text { (min) }\end{array}$ & $\begin{array}{c}\mathrm{CO}_{2} \\
(\mathrm{kt} / \mathrm{wk})\end{array}$ & $\begin{array}{c}\text { NOx } \\
\text { (kg/wk) }\end{array}$ \\
\hline Baseline & $88.6 \pm 0.3$ & $90.8 \pm 7.0$ & $43.4 \pm 3.6$ & $\begin{array}{c}2.0 \times 10^{-2} \\
\pm 2.8 \times 10^{-2}\end{array}$ & $68.6 \pm 0.6$ & $8.5 \pm 0.1$ & $246.4 \pm 0.3$ & $167.6 \pm 0.2$ \\
\hline$+10 \%$ Freight & $111.0 \pm 0.6$ & $203.6 \pm 1.2$ & $105.5 \pm 1.4$ & $1.6 \pm 0.1$ & $222.7 \pm 15.7$ & $57.0 \pm 4.1$ & $276.4 \pm 1.0$ & $187.9 \pm 0.6$ \\
\hline
\end{tabular}

${ }^{1}$ Note that in the simulation model, the TAP queue doubles as a section of road and as a queue for holding freight vehicles during TAP events. Minimum dwell time in the TAP queue is $8.5 \mathrm{~min}$ and corresponds to free-flowing traffic.

\subsection{Interventions to Manage Freight Growth}

Having quantified the impacts of a relatively modest increase in traffic volume, our next step was to identify and evaluate possible interventions to mitigate these impacts. Realistic interventions for dealing with a $10 \%$ freight growth scenario include increasing the number of PAF and check-in booths, adding space to the assembly area, adding space to the buffer zone, and increasing ferry uplift. Interventions that increase the number of PAF/check-in booths or increase space for holding vehicles could either be achieved by re-purposing other areas within the Port (e.g., demolishing existing buildings to create space) or through costly reclamation of land from the sea. Table 3 reports the effectiveness of various interventions to deal with increased freight volumes. Excess emissions of $\mathrm{CO}_{2}$ and NOx for each intervention are displayed in Figure 7.

Table 3. Traffic flow metrics for potential interventions to manage $10 \%$ growth in freight traffic.

\begin{tabular}{|c|c|c|c|c|c|c|c|c|}
\hline \multirow[b]{2}{*}{ Scenario } & \multirow[b]{2}{*}{$\begin{array}{c}\text { Time in } \\
\text { System (min) }\end{array}$} & \multicolumn{2}{|c|}{ Buffer Zone } & \multicolumn{5}{|c|}{ TAP Queue $^{1}$} \\
\hline & & $\begin{array}{c}\text { Max Size } \\
\text { (FEUs) }\end{array}$ & $\begin{array}{c}\text { Max Dwell } \\
\text { (min) }\end{array}$ & $\begin{array}{l}\text { No. TAPs } \\
\text { (per wk) }\end{array}$ & $\begin{array}{c}\text { Max Size } \\
\text { (FEUs) }\end{array}$ & $\begin{array}{c}\text { Max Dwell } \\
(\mathrm{min})\end{array}$ & $\mathrm{CO}_{2}(\mathrm{kt} / \mathrm{wk})$ & NOx (kg/wk) \\
\hline No Intervention & $111.0 \pm 0.6$ & $203.6 \pm 1.2$ & $105.5 \pm 1.4$ & $1.6 \pm 0.1$ & $222.7 \pm 15.7$ & $57.0 \pm 4.1$ & $276.4 \pm 1.0$ & $187.9 \pm 0.6$ \\
\hline Double Resources & $110.2 \pm 0.6$ & $196.8 \pm 1.6$ & $102.7 \pm 1.7$ & $1.3 \pm 0.1$ & $184.2 \pm 15.3$ & $46.8 \pm 4.0$ & $273.9 \pm 0.7$ & $186.2 \pm 0.5$ \\
\hline+200 AA Spaces ${ }^{1}$ & $110.7 \pm 0.6$ & $169.2 \pm 6.5$ & $83.9 \pm 3.3$ & $0.5 \pm 0.1$ & $93.4 \pm 7.5$ & $17.5 \pm 2.5$ & $271.5 \pm 0.4$ & $184.7 \pm 0.2$ \\
\hline+200 BZ Spaces ${ }^{2}$ & $111.0 \pm 0.6$ & $281.8 \pm 8.7$ & $130.6 \pm 3.8$ & $\begin{array}{c}1.0 \times 10^{-2} \\
\pm 2.0 \times 10^{-2}\end{array}$ & $74.6 \pm 0.8$ & $8.8 \pm 0.3$ & $271.1 \pm 0.3$ & $184.4 \pm 0.2$ \\
\hline$+10 \%$ Ferry Uplift & $87.2 \pm 0.3$ & $138.6 \pm 7.7$ & $61.2 \pm 3.6$ & $0.2 \pm 0.1$ & $78.4 \pm 4.0$ & $10.6 \pm 1.2$ & $271.2 \pm 0.3$ & $184.5 \pm 0.2$ \\
\hline
\end{tabular}

${ }^{1}$ AA refers to the assembly area with additional space measured in FEUs. ${ }^{2}$ BZ refers to the buffer zone with additional space measured in FEUs.

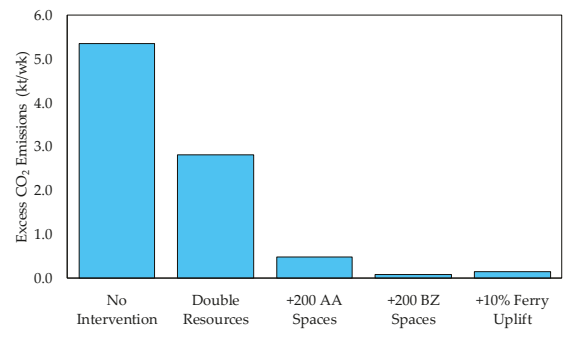

(a)

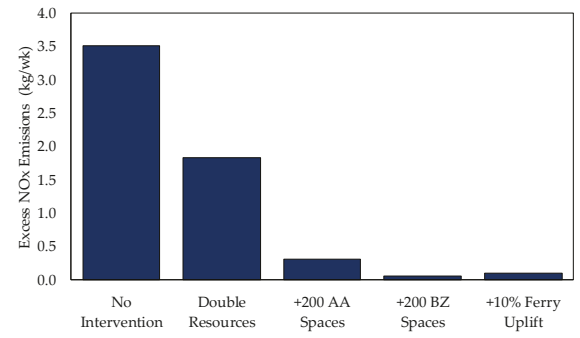

(b)

Figure 7. (a) Excess $\mathrm{CO}_{2}$ emissions per week and (b) excess $\mathrm{NOx}$ emissions per week for potential interventions to manage $10 \%$ growth in freight traffic. Note that $\mathrm{CO}_{2}$ emissions are measured in kilotons (kt) per week, while NOx emissions are measured in kilograms (kg) per week.

Some important insights are drawn from the results shown in Table 3 and Figure 7 . The first is that PAF and check-in are not significant constraints on the system given the rather modest change in traffic flow metrics in response to doubling PAF and check-in processing rates. Buffer zone usage and dwell time, for example, remain virtually unchanged. There is, however, a small drop in the number of TAPs per week (-0.3), a noticeable decrease in both TAP queue size ( -39 FEUs) and dwell time 
$(-10 \mathrm{~min})$, and a sizeable drop in excess emissions $\left(-2.5 \mathrm{kt}\right.$ of $\mathrm{CO}_{2}$ and $-1.7 \mathrm{~kg}$ of NOx per week). What this implies is that there is at present sufficient physical capacity to handle a $10 \%$ growth in freight traffic. It is merely the case that staffing levels within the Port may simply need to rise on certain days to keep pace with the increased volumes of freight vehicles.

A second key insight is that increasing space, either in the assembly area or buffer zone produces the desired effect of internalizing queues within the Port. Both interventions significantly reduce the number of TAPs per week, maximum TAP queue size, and excess emissions of $\mathrm{CO}_{2}$ and NOx. However, not all space is equal in terms of impact. Specifically, increasing space for vehicles in the buffer zone is much more effective at reducing queuing outside the Port than increasing space in the assembly area (Table 3, Figures 7 and 8). Compared to the no intervention scenario, adding 200 FEU spaces to the assembly area reduces the expected number of TAPs per week from 1.6 to 0.4 (an order of magnitude decrease), while adding 200 FEU spaces to the buffer zone reduces this to 0.01 (two orders of magnitude decrease). Over a month, this translates to approximately two TAPs by adding 200 spaces to the assembly area versus zero TAPs by adding the same amount of space to the buffer zone. Meanwhile, maximum TAP queue size is reduced from 223 to 93 freight vehicles ( -130 FEUs) by adding 200 spaces to the assembly area and all the way down to 75 freight vehicles ( -148 FEUs) by adding 200 spaces to the buffer zone. In terms of excess emissions of $\mathrm{CO}_{2}$ and $\mathrm{NOx}$, these fall from $5.4 \mathrm{kt}$ and $3.5 \mathrm{~kg}$ per week, respectively, to $0.5 \mathrm{kt}$ and $0.3 \mathrm{~kg}$ per week ( $91 \%$ reduction) by adding 200 spaces to the assembly area and even further to $0.1 \mathrm{kt}$ and $0.1 \mathrm{~kg}$ per week (97-98\% reduction) by adding 200 spaces to the buffer zone.

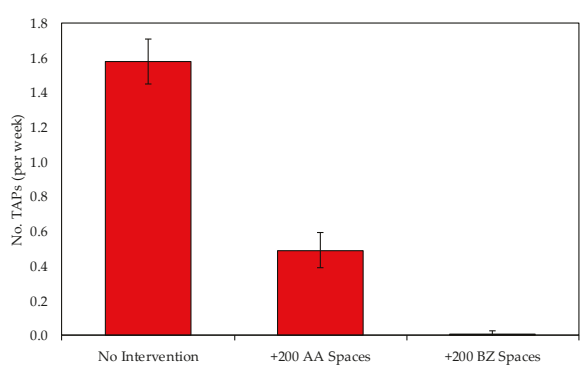

(a)

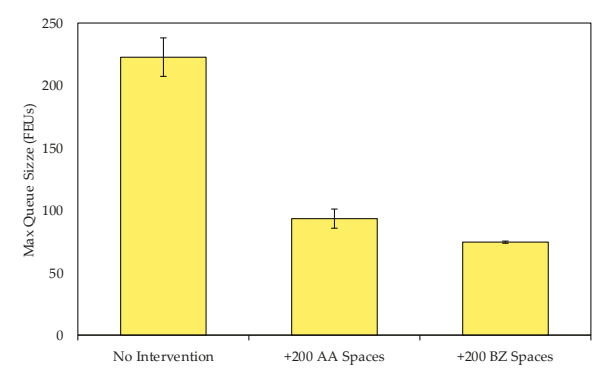

(b)

Figure 8. (a) Expected number of TAPs per week and (b) maximum size of the TAP queue for the no intervention, add space to the assembly area (AA) and add space to the buffer zone (BZ) planning scenarios in response a $10 \%$ growth in freight traffic.

Intuitively, this sort of result makes sense due to the flexible nature of the buffer zone, which can be used to buffer any single operator's traffic or a specific type of traffic, thus allowing other vehicles to bypass the queue. The assembly area, on the other hand, is located low in the chain of steps for processing vehicles through the system and, therefore, does nothing to alleviate transient queues caused by the fluctuation of processing rates at steps higher in the chain (e.g., at PAF or check-in). Indeed, a proportion of real-life TAPs are caused by issues at border control or check-in (e.g., due to computer system failures or slower processing associated with heightened security levels). These types of events are not captured in the simulation model, which suggests that the results shown here underestimate the value of buffer zone space at the front of the Port.

A final, perhaps unsurprising, finding is that increasing ferry uplift is perhaps the best solution for dealing with increased freight volumes in the long-term. Increasing uplift in step with traffic demand is the only intervention that minimizes queuing both in and outside the Port. Compared to increasing buffer zone space, increasing uplift by $10 \%$ not only produces similar maximum TAP queue sizes (78 vs. $75 \mathrm{FEUs})$, maximum TAP dwell times (10.6 vs. $8.8 \mathrm{~min}$ ) and excess $\mathrm{CO}_{2}$ emissions (0.2 kt vs. $\left.0.1 \mathrm{kt}\right)$, but also results in the lowest usage of the buffer zone (both in terms of maximum queue size and dwell 
time) among the interventions considered. In addition, unlike any of the other scenarios, increased ferry uplift also reduces overall time in the system from 110-111 min (all other scenarios) to $87 \mathrm{~min}$. On the other hand, while it should be pointed out that increasing ferry uplift does result in a slightly higher number of TAPs per week compared to adding space to the buffer zone intervention (less than 0.2 vs. 0.01 ), over a month the overall number of TAPs remains small (approximately 0.7 per month).

It is worth mentioning that in the current model, increased uplift was implemented by simply increasing the capacity of each vessel by $10 \%$. We acknowledge that adding larger vessels to the fleet would place additional strains on the assembly area and buffer zone, since larger numbers of vehicles would be arriving and waiting for the next (larger) vessel. Alternatives such as increasing the frequency of sailings or adding a few additional vessels, however, would mitigate against this to a large extent.

Additional testing of the simulation model assuming a 30\% growth in freight traffic (results not reported here) only further reinforces the importance of ferry uplift. Increasing uplift by $30 \%$ is sufficient to handle increased traffic of this magnitude without the need for additional space or new infrastructure. However, a 30\% increase in freight traffic without a concomitant increase in uplift would exceed the physical capacity of the Port.

\subsection{Sensitivity Analysis of Check-in Processing Times}

As illustrated by the analysis above, Port infrastructure and processes are sufficient to handle present-day freight volumes. Furthermore, a 10-30\% increase in growth could be accommodated by increasing buffer zone space within the Port and/or increasing ferry uplift. Under such circumstances, neither PAF nor check-in would form a bottleneck as long as processing rates remain the same.

As part of robust masterplanning, one might want to challenge the assumption that processes will not change in the future. While the majority of changes such as increased digitization and automation tend to improve throughput, there are two possible scenarios which could make processing times worse: (1) sustained increase in security, which would result in increased time for border control checks, and (2) expanded administrative requirements at check-in, for example filling in additional customs documentation as part of a post Brexit world. It is hard to forecast what changes in processing times might be, particularly for the latter scenario, since there is not any reliable data on which to base projections. Sensitivity analysis, however, provides a vital tool for investigating potential impacts over a range of possible changes to model inputs.

To this end, the effect of increased time to process vehicles at check-in was investigated on top of a $10 \%$ growth in freight traffic. As in the previous analyses, it is assumed that there are no restrictions on the availability of check-in booths (i.e., all booths are manned continuously throughout the week) and that up to $80 \%$ of them are devoted to freight. Results are shown in Figure 9.

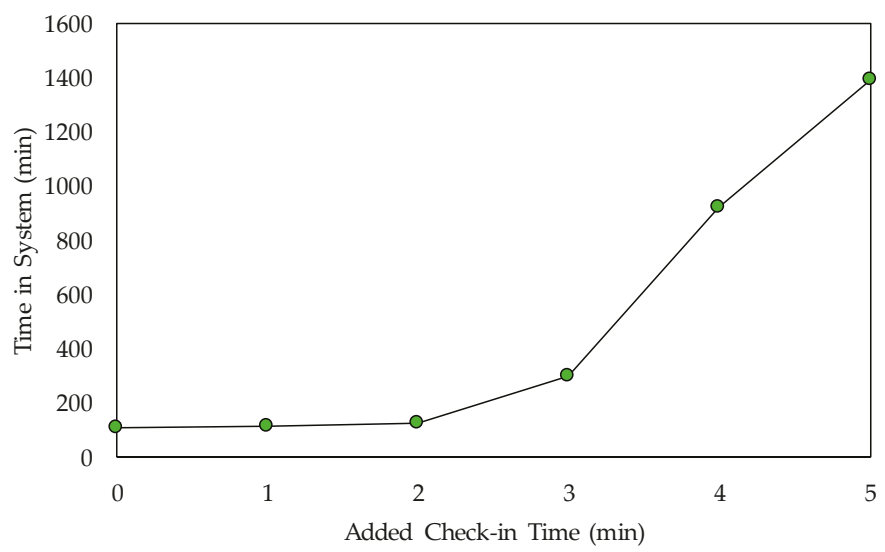

Figure 9. Time in system as a function of average check-in time given $10 \%$ growth in freight. 
If processing times at check-in booths increased by one minute, average time in the system would be little affected, increasing by just two minutes. Increasing check-in times by two minutes would also appear to be tolerable, with an average time in system going up by 14 min. However, this underestimates the true impact since it is assumed that staffing is unconstrained and queues are initially empty at the start of each one-week run of the model. In reality, staffing may be less than ideal and there may be carry-over of vehicles from week-to-week once large queues form. Indeed, separate full year model runs that incorporate carry-over indicate that even a two-minute increase in processing times produces considerable queuing and long delays for freight traffic. In any case, what is perfectly clear is that increasing processing time by just three minutes is sufficient to increase time in the system to almost $300 \mathrm{~min}$, which not only exceeds the Port's capacity, but also exceeds the capacity of TAP and necessarily triggers Operation Stack/Brock. Adding a full five minutes to check-in time, meanwhile, causes average time in the system to reach almost $1400 \mathrm{~min}(>23 \mathrm{~h})$ and produces queues that never clear. To put these figures in context, the waiting time at the "frictionless" Norway-Sweden border is reported to be on the order of eight minutes [37].

\subsection{Additional Uses of the Model}

Whilst the primary focus of the present modeling study is on long-term infrastructure planning, it should be noted that the model can just as easily be used to examine the potential effects of shorter-term stressors on the system and evaluate appropriate tactical mitigation strategies. One such stressor is annual ferry refit, in which a vessel is removed from service temporarily for planned maintenance and upgrading. Results showing the impact of a vessel refit are shown in Figure 10 and Table 4.

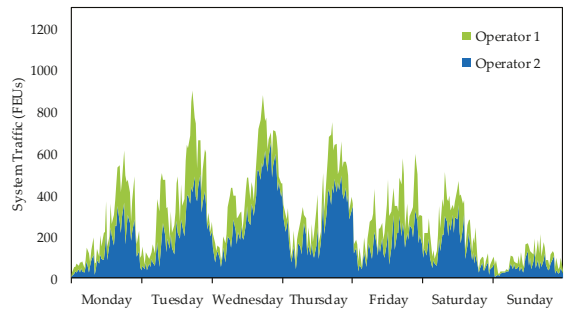

(a)

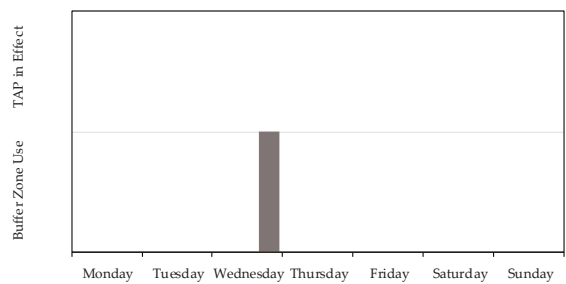

(c)

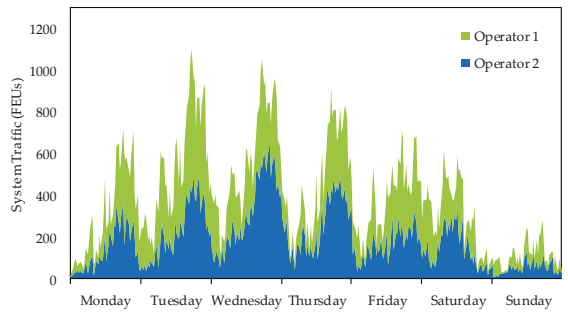

(b)

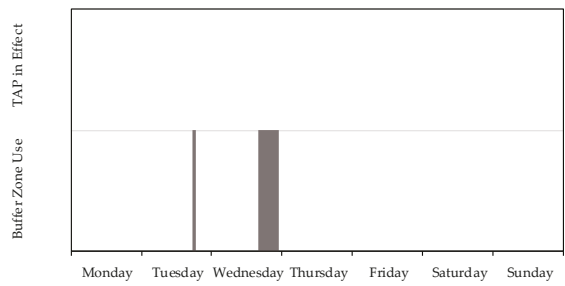

(d)

Figure 10. (a) Simulated Port traffic by ferry operator (blue and green) over a typical week under baseline conditions and (b) during a ferry vessel refit, along with (c) buffer zone (grey) and TAP use (red) under baseline conditions and (d) during a ferry vessel refit.

As seen, the system is only moderately affected by a vessel refit. While the total number of vehicles in the system does increase during a vessel refit (see Figure 10), going from a peak of approximately 900 to 1100 FEUs, TAP would not be expected to occur and there is only limited additional use of the buffer zone (one day for normal conditions, two days for vessel refit). Overall, traffic metrics for the 
two scenarios are similar (see Table 4), with the only significant difference being that total time in the system increases by $25 \%$ (from 89 to $111 \mathrm{~min}$ ).

Table 4. Traffic flow metrics for the base case and vessel refit scenarios.

\begin{tabular}{|c|c|c|c|c|c|c|}
\hline \multirow[b]{2}{*}{ Scenario } & \multirow[b]{2}{*}{$\begin{array}{c}\text { Time in } \\
\text { System (min) }\end{array}$} & \multicolumn{2}{|c|}{ Buffer Zone } & \multicolumn{3}{|c|}{ TAP Queue } \\
\hline & & $\begin{array}{l}\text { Max Size } \\
\text { (FEUs) }\end{array}$ & $\begin{array}{l}\text { Max Dwell } \\
\text { Time (min) }\end{array}$ & $\begin{array}{l}\text { No. TAPs } \\
\text { (per wk) }\end{array}$ & $\begin{array}{c}\text { Max Size } \\
\text { (FEUs) }\end{array}$ & $\begin{array}{l}\text { Max Dwell } \\
\text { Time (min) }\end{array}$ \\
\hline Baseline & $88.6 \pm 0.3$ & $90.8 \pm 7.0$ & $43.4 \pm 3.6$ & $\begin{array}{c}2.0 \times 10^{-2} \\
\pm 2.8 \times 10^{-2}\end{array}$ & $68.6 \pm 0.6$ & $8.5 \pm 0.1$ \\
\hline Vessel Refit & $111.4 \pm 0.6$ & $95.9 \pm 6.2$ & $44.9 \pm 3.3$ & $\begin{array}{c}1.0 \times 10^{-2} \\
\pm 2.0 \times 10^{-2}\end{array}$ & $68.6 \pm 0.6$ & $8.5 \pm 0.1$ \\
\hline
\end{tabular}

In principle, changes to the port infrastructure or operations could be investigated, similar to the analysis carried out in Section 3.2, to help identify appropriate strategies to minimize disruption at the Port during vessel refits in combination with other incidents causing short-term reduction in system capacity (e.g., staff shortages and/or extended security checks) to ensure the Port continues to meet its economic, social and environmental goals.

\section{Discussion}

This study describes how simulation modeling and analysis are being used at the Port of Dover to address economic, social, and environmental trade-offs involved with port masterplanning. It contributes to the scientific literature by focusing on road traffic in a ro-ro port and by providing basic insight into the interplay between the use of space and processes that influence port performance.

The study initially began during a period of high uncertainty for the Port, brought about by incidences of terrorist attacks in France, a spike in illegal migration, and the Brexit vote, which focused attention on understanding the implications of potential new border control, customs, and inspection regimes. The tensions involved in port masterplanning have been pointed out previously $[38,39]$. Investing in new infrastructure has repercussions that are long lasting, but decisions often need to be taken during periods of uncertainty during which forecasts vary widely. This highlights the value of options-based valuation, which emphasizes the importance of phasing, deferring, abandoning or adapting projects. Although the analysis presented here does not employ options valuation, our work has nevertheless stimulated 'options thinking' among senior managers at the Port and reinforced the need to adapt to changing opportunities and threats [40].

The discrete-event simulation approach used here is valuable for gaining high-level insights about traffic flow patterns and where and why queues build up in a system. One limitation of using discrete-event simulation is that it does not represent interactions between moving vehicles as well as agent-based models do. Further work using detailed agent-based models of specific areas of the system might help to verify that interventions identified with our discrete-event model for improving traffic flow perform as expected. Alternatively, developing a system dynamics approach might be appropriate for larger-scale modeling of cross-channel traffic flows by incorporating Eurotunnel and possibly other ports in the UK and continental Europe. Another interesting line of research would be to model an expanded set of interventions aimed at reducing queuing traffic, including implementation of the "dry port" concept [41]. Dry ports are used to move certain seaport functions inland and are shown to be effective in alleviating space constraints and improving environmental performance [42].

A noteworthy aspect of our study is the use of a queuing metric (TAP) as the primary KPI, both as a measure of overall system efficiency and as a measure of local community and environmental sustainability. The ability to use TAP to hold freight outside the Port is an immensely valuable means of managing port traffic. At the same time, reducing occurrences of TAP when possible reduces inconvenience to the local community and reduces direct staff cost of active traffic management. Minimizing traffic queues also helps to reduce the environmental impacts of port traffic, including air pollutant and $\mathrm{CO}_{2}$ emissions, which will be vital in the future as the Port strives to meet its 
environmental obligations and become a "green port" [43]. The use of TAP as a KPI contrasts with other simulation studies dealing with port investment planning (e.g., [44]), which use more typical financial metrics like EBITDA (earnings before interest, tax, depreciation and amortization). The TAP metric, by comparison, relates directly to two of the three pillars of sustainability (social and environmental), which can then be traded off against the third (economic) by considering investments needed to reduce TAP.

One of the main benefits of the research presented here is in discovering and illustrating some guiding principles that can be applied to port masterplanning more generally. As an example, our analysis of the Port of Dover showed the critical role of ferry uplift (i.e., the rate at which vehicles are removed from the system by ferries) as the main determinant of overall queuing in and transit through the system. Increased uplift is only achieved by adding more ferries and services of the current vessel type or by replacing some portion of the fleet with larger ferries, which might even require fewer services. Which is preferable would depend on a more detailed financial analysis of the costs involved and the environmental impacts.

One of the key messages we wish to emphasize is the value of flexibility. Specifically, space that can be used flexibly, either for multiple traffic types, ferry operators, or activities, is far more valuable than dedicated space, which cannot be readily switched to meet fluctuations in demand. This is clearly illustrated by the far greater reduction in traffic congestion that could be achieved by increasing buffer zone space to hold vehicles at the front of the system compared to increasing assembly area space for embarkation at the rear of the system. With added buffer zone space, transient increases in arrivals (immediately upstream of the buffer zone) and short-term reductions in processing speed at border controls or check-ins (downstream from the buffer zone) can both be accommodated for by space at the front of the system. Generalizing beyond this, it seems logical that under conditions of uncertainty, layouts and buildings that can be changed and re-purposed, provide greater value and resilience than permanent or fixed structures.

Looked at more generally, a potentially useful way to interpret our findings is within the context of the theory of constraints [45,46]. The guiding approach of our analysis was to look for those constraints which, if lifted, would have the largest effect on system performance. Interestingly, while ferry uplift is an obvious constraint governing total traffic throughput, relaxing constraints on space within the Port can be equally effective at reducing TAP and traffic congestion.

Finally, our analysis confirmed that the ability of the Port to clear traffic out of the system is strongly influenced by vehicle processing times. Even moderate increases in check-in times are not sustainable given the Port's current physical capacity. The practical implication of this is to emphasize the extent to which technological improvements, such as automated check-in and license plate recognition, may be essential to speed up processing and improve future traffic fluidity.

Author Contributions: Conceptualization, G.C.P., P.H., M.P.S., and J.R.O.; methodology, G.C.P. and J.R.O.; software, G.C.P.; validation, G.C.P. and J.R.O.; writing-original draft preparation, G.C.P. and J.R.O.; writing-review and editing, G.C.P., P.H., M.P.S., and J.R.O.; project administration, P.H. and J.R.O.; funding acquisition, P.H., M.P.S., and J.R.O. All authors have read and agreed to the published version of the manuscript.

Funding: This research was funded in part by Innovate UK through a Knowledge Transfer Partnership (KTP).

Acknowledgments: We wish to thank former Port of Dover CEO Tim Waggott, Port of Dover General Manager of Engineering Rikard Bergstrom, former Port of Dover General Manager of Strategy and Risk Timothy Godden, Innovate UK KTP Advisor Terry Corner, and the University of Kent Innovation and Enterprise team for all their contributions. Our gratitude also goes to the many colleagues at Port of Dover who provided data, advice, and assistance throughout the project and to three anonymous reviewers for very helpful comments made on an earlier draft of this paper.

Conflicts of Interest: The authors declare no conflicts of interest. 


\section{References}

1. Guidance on the Preparation of Port Master Plans. Department for Transport Port, 2008. Available online: https:/infrastructure.planninginspectorate.gov.uk/wp-content/ipc/uploads/projects/ TR030001/TR030001-001984-121026_TR030001\%20Port\%20master\%20plan\%20guidance.pdf (accessed on 13 December 2019).

2. Li, N.; Chen, G.; Govindan, K.; Jin, Z. Disruption management for truck appointment system at a container terminal: A green initiative. Transp. Res. Part D Transp. Environ. 2018, 61, 261-273. [CrossRef]

3. Wan, C.; Zhang, D.; Yan, X.; Yang, Z. A novel model for the quantitative evaluation of green port development-A case study of major ports in China. Transp. Res. Part D Transp. Environ. 2018, 61, 431-443. [CrossRef]

4. Bjerkan, K.Y.; Seter, H. Reviewing tools and technologies for sustainable ports: Does research enable decision making in ports? Transp. Res. Part D Transp. Environ. 2019, 72, 243-260. [CrossRef]

5. Lim, S.; Pettit, S.; Abouarghoub, W.; Beresford, A. Port sustainability and performance: A systematic literature review. Transp. Res. Part D Transp. Environ. 2019, 72, 47-64. [CrossRef]

6. Dushenko, M.; Bjorbaek, C.T.; Steger-Jensen, K. Application of a sustainability model for assessing the relocation of a container terminal: A case study of Kristiansand Port. Sustainability 2018, 11, 87. [CrossRef]

7. Günther, H.O.; Kim, K.H. Container terminals and terminal operations. OR Spectr. 2006, 28, 437-445. [CrossRef]

8. PIANC, MarCom WG 158: Masterplans for the Development of Existing Ports (2014). Available online: https://www.pianc.org/publications/marcom/masterplans-for-the-development-of-existing-ports (accessed on 29 January 2020).

9. Stahlbock, R.; Voß, S. Operations research at container terminals: A literature update. OR Spectr. 2008, 30, 1-52. [CrossRef]

10. Angeloudis, P.; Bell, M.G.H. A review of container terminal simulation models. Marit. Policy Manag. 2011, 38, 523-540. [CrossRef]

11. Woo, S.H.; Pettit, S.J.; Kwak, D.W.; Beresford, A.K.C. Seaport research: A structured literature review on methodological issues since the 1980s. Transp. Res. Part A Policy Pract. 2011, 45, 667-685. [CrossRef]

12. Kim, K.H.; Lee, H. Container terminal operation: Current trends and future challenges. In Handbook of Ocean Container Transport Logistics; Lee, C.-Y., Meng, Q., Eds.; Springer: Basel, Switzerland, 2015; pp. 43-73.

13. Steenken, D.; Voß, S.; Stahlbock, R. Container terminal operation and operations research-A classification and literature review. In Container Terminals and Automated Transport Systems: Logistics Control Issues and Quantitative Decision Support; Günther, H.-O., Kim, K.H., Eds.; Springer: Berlin, Germany, 2005; pp. 3-49.

14. Dragović, B.; Tzannatos, E.; Park, N.K. Simulation modeling in ports and container terminals: Literature overview and analysis by research field, application area and tool. Flex. Serv. Manuf. J. 2017, 29, 4-34. [CrossRef]

15. Lehnfeld, J.; Knust, S. Loading, unloading and premarshalling of stacks in storage areas: Survey and classification. Eur. J. Oper. Res. 2014, 239, 297-312. [CrossRef]

16. Carteni, A.; de Luca, S. Tactical and strategic planning for a container terminal: Modeling issues within a discrete event simulation approach. Simul. Model. Pract. Theory. 2012, 21, 123-145. [CrossRef]

17. Garro, A.; Monaco, M.F.; Russo, W.; Sammarra, M.; Sorrentino, G. Agent-based simulation for the evaluation of a new dispatching model for the straddle carrier pooling problem. Simulation 2015, 91, 181-202. [CrossRef]

18. Darzentas, J.; Spyrou, T. Ferry traffic in the Aegean islands: A simulation study. J. Oper. Res. Soc. 1996, 47, 203-216. [CrossRef]

19. Merrick, J.R.W.; Van Dorp, J.R.; Blackford, J.P.; Shaw, G.L.; Harrald, J.; Mazzuchi, T.A. A traffic density analysis of proposed ferry service expansion in San Francisco Bay using a maritime simulation model. Reliab. Eng. Syst. Saf. 2003, 81, 119-132. [CrossRef]

20. Khatiashvili, S.; Bakeev, C.; Fidler, M. Application of simulation modeling to harbour operations. Proc. Inst. Civ. Eng. Marit. Eng. 2006, 159, 121-128. 
21. Rajamanickam, G.D.; Ramadurai, G. Simulation of truck congestion in Chennai port. In Proceedings of the 2015 Winter Simulation Conference, Huntington Beach, CA, USA, 6-9 December 2015; Yilmaz, L., Chan, W.K.V., Moon, I., Roeder, T.M.K., Macal, C., Rossetti, M.D., Eds.; pp. 1904-1915.

22. Demirci, E. Simulation Modeling and Analysis of a Port Investment. Simul. Trans. Soc. Model. Simul. 2003, 79, 94-105.

23. Howard, D.L.; Bragen, M.J.; Buake, J.F.; Love, R.J. PORTSIM 5: Modeling from a seaport level. Math. Comput. Model. 2004, 39, 715-731. [CrossRef]

24. Kondratyev, M. An object-oriented approach to port activity simulation. Int. J. Simul. Process Model. 2015, 10, 1-9. [CrossRef]

25. Annual Report and Account, Port of Dover. Dover Harbour Board, 2015. Available online: https: //www.doverport.co.uk/downloads/DHB_Annual_Report\%20and\%20Accounts\%202015_WEB.pdf (accessed on 13 December 2019).

26. Planet Dump. OpenStreetMap Contributors. 2017. Available online: https://planet.openstreetmap.org (accessed on 13 December 2019).

27. Roadknight, C.; Aickelin, U.; Sherman, G. Validation of a microsimulation of the Port of Dover. J. Comput. Sci. 2012, 3, 56-66. [CrossRef]

28. Roadknight, C.; Aickelin, U. Extending a microsimulation of the Port of Dover. In Proceedings of the Operational Research Society Simulation Workshop, Worcestershire, UK, 27-28 March 2012; Tjahjono, B., Heavey, C., Onggo, S., van der Zee, D.-J., Eds.; pp. 165-170.

29. Ceballos, G.; Curtis, O. Queue analysis at toll and parking exit plazas: A comparison between multi-server queuing models and traffic simulation. In Proceedings of the ITE 2004 Annual Meeting and Exhibit, Lake Buena Vista, FL, USA, 1-4 August 2004.

30. Newell, G.F. Applications of Queueing Theory; Chapman \& Hall Ltd.: London, UK, 1971.

31. Caballini, C.; Sacone, S.; Siri, S. The port as a system of systems: A system dynamics simulation approach. In Proceedings of the 7th International Conference on System of Systems Engineering, Genoa, Italy, 16-19 July 2012; pp. 191-196.

32. Preston, C.; Horne, P.; O’Hanley, J.; Scaparra, M.P. Traffic modelling at the Port of Dover. Impact 2018, 1, 7-11. [CrossRef]

33. Operation Stack. Available online: https://www.roads.org.uk/articles/operation-stack (accessed on 27 December 2019).

34. Boulter, P.G.; Barlow, T.J.; McCrae, I.S. Emissions factors 2009: Report 3-Exahust emission factors for road vehicles in the United Kingdom. TRL Report for Department for Transport. 2009. Available online: https://assets.publishing.service.gov.uk/government/uploads/system/uploads/attachment_data/file/ 4249/report-3.pdf (accessed on 24 January 2020).

35. Vehicle Fleet Composition Projections (Base 2018), National Atmospheric Emsissions Inventory. 2018. Available online: https://naei.beis.gov.uk/data/ef-transport (accessed on 24 January 2020).

36. Sargent, R. Verification and validation of simulation models. J. Simul. 2012, 7, 12-24. [CrossRef]

37. Cellan-Jones, R. Frictionless Borders: Learning from Norway. BBC News, 29 September 2017. Available online: https://www.bbc.co.uk/news/technology-41412561 (accessed on 27 December 2019).

38. Taneja, P.; Ligteringen, H.; Walker, W.E. Flexibility in port planning and design. Eur. J. Transp. Infrastruct. Res. 2011, 12, 66-87.

39. Taneja, P.; Walker, W.E.; Ligteringen, H.; Van Schuylenburg, M.; Van Der Plas, R. Implications of an uncertain future for port planning. Marit. Policy Manag. 2010, 37, 221-245. [CrossRef]

40. Steffens, P.R.; Douglas, E.J. Valuing technology investments: use real options thinking but forget real options valuation. Int. J. Technoentrepreneursh. 2007, 1, 58-77. [CrossRef]

41. Roso, V.; Woxenius, K.; Lumsden, K. The dry port concept: Connecting container seaports with the hinterland. J. Transp. Geogr. 2009, 17, 338-345. [CrossRef]

42. Korovyakovsky, E.; Panova, Y. Dynamics of Russian dry ports. Res. Transp. Econ. 2011, 33, 25-34. [CrossRef]

43. The Blueprint for Our Success-Corporate Social Responsibility Report, Port of Dover. Dover Harbour Board, 2018. Available online: https:/www.doverport.co.uk/administrator/tinymce/source/Annual\%20Reports/ DHB1052\%20CSR\%20Report\%202018\%20v4...\%20FINAL.pdf (accessed on 13 December 2019). 
44. Lagoudis, I.N.; Rice, J.B.; Salminen, J.B. Port investment strategies under uncertainty: The case of a Southeast Asian multipurpose port. Asian J. Shipp. Logist. 2014, 30, 299-319. [CrossRef]

45. Goldratt, E.M.; Cox, J. The Goal: Excellence in Manufacturing; North River Press: Croton-on-Hudson, NY, USA, 1984.

46. Ikeziri, L.M.; de Souza, F.B.; Gupta, M.C.; de Camargo Fiorini, P. Theory of constraints: review and bibliometric analysis. Int. J. Prod. Res. 2019, 57, 5068-5102. [CrossRef]

(C) 2020 by the authors. Licensee MDPI, Basel, Switzerland. This article is an open access article distributed under the terms and conditions of the Creative Commons Attribution (CC BY) license (http://creativecommons.org/licenses/by/4.0/). 

Article

\title{
The Method to Decrease Emissions from Ships in Port Areas
}

\author{
Vytautas Paulauskas $^{1, *}$, Ludmiła Filina-Dawidowicz ${ }^{2}$ and Donatas Paulauskas ${ }^{3}$ \\ 1 Klaipeda Shipping Research Centre, Klaipeda University, V. Berbomo str. 7-5, LT-92219 Klaipeda, Lithuania \\ 2 Faculty of Maritime Technology and Transport, West Pomeranian University of Technology, Szczecin, Ave. \\ Piastów 41, 71-065 Szczecin, Poland; ludmila.filina@zut.edu.pl \\ 3 Maritime Engineering Department, Klaipeda University, H. Manto g. 84, LT-92294 Klaipeda, Lithuania; \\ paulauskasd75@gmail.com \\ * Correspondence: vytautaskltc@gmail.com
}

Received: 1 May 2020; Accepted: 25 May 2020; Published: 27 May 2020

\begin{abstract}
Nowadays great attention is being paid to the ecological aspects of maritime transport functioning, including the problem of pollution and emission of poisonous substances from ships. Such emissions have a significant impact on the environment and sustainable operation of ports, especially those located close to intensive waterways. A decrease in emissions from ships may be achieved by implementing different methods, among others, through the use of environmentally friendly fuels, electrical and hybrid vehicles, as well as through the improvement of port approach and inside navigational channels, optimization of the transport processes organization, etc. However, the size of the influence of ships' crew and ports pilots' qualification on the possibility to decrease the emissions from ships during maneuvering in port areas remains a question. This article aims to develop a method to assess the possible decrease of the emissions from ships in ports, considering human factor influence. The method has been developed and verified on the selected case study example. The influence of ships' crew and ports pilots' qualification on time spent on maneuvering operations by ships in port areas and consequently the volume of emissions has been investigated. The research results show that for the set conditions it is possible to reduce emissions from ships up to $12.5 \%$. For that reason, appropriate education and training are needed to improve the qualifications of decision-makers performing ship maneuvers at ports areas.
\end{abstract}

Keywords: maritime transport; emission from ships; sustainable port; energy sources; ship's crew and port pilots qualification; green shipping; environmentally friendly fuels

\section{Introduction}

Maritime transport is extremely important for the world and regional economy; some countries, like those located on islands, are dependent on goods delivered by sea. From 1970 until 2019 the world population increased from 3.7 billion up to over 7.7 billion, but at the same time global maritime trade increased from 2.6 billion tons up to 11 billion tons (in 2018) [1]. In early 2019, the total world fleet constituted 95,402 ships, accounting for 1.97 billion dead-weight tons. Moreover, the carrying capacity grew by $2.61 \%$, compared with the beginning of 2018 (Table 1). It is forecasted that ship number and size will continue to grow [1].

Nowadays, much attention is paid to the issues of the negative impact of shipping on the environment. It is assumed that maritime transport emits around 940 million tons of $\mathrm{CO}_{2}$ annually, being responsible for about $2.5 \%$ of global greenhouse gas (GHG) emissions [2-4]. The negative impact of shipping on the environment is concentrated essentially in selected areas: close to big ports (e.g., Shanghai, Rotterdam, Hamburg, and others), main waterways (e.g., Suez and Panama channels), 
approach channels or rivers (e.g., Elbe river providing the Hamburg port, Yangtze river-to Shanghai port), and other areas [5-9].

Table 1. World fleet by principal vessel type 2018-2019 (thousand dead-weight tons) [1].

\begin{tabular}{cccc}
\hline Principal Types & $\mathbf{2 0 1 8}$ & $\mathbf{2 0 1 9}$ & Percentage Change 2019/2018 \\
\hline Oil tankers & 562,035 & 567,533 & 0.98 \\
Bulk carriers & 818,921 & 842,438 & 2.87 \\
General cargo ships & 73,951 & 74,000 & 0.07 \\
Container ships & 253,275 & 265,668 & 4.89 \\
Gas carriers & 64,407 & 69,078 & 7.25 \\
Chemical tankers & 44,457 & 46,297 & 4.14 \\
Offshore vessels & 78,269 & 80,453 & 2.79 \\
Ferries and passenger ships & 6922 & 7097 & 2.53 \\
Other/not available & 23,946 & 23,929 & -0.07 \\
World total & $1,926,183$ & $1,976,491$ & 2.61 \\
\hline
\end{tabular}

The International Maritime Organization (IMO) constantly pays a lot of attention to the issues of reduction of emissions from ships, especially decrease of sulfur $\left(\mathrm{SO}_{\mathrm{x}}\right)$, nitrogen $\left(\mathrm{NO}_{\mathrm{x}}\right)$, carbon dioxide $\left(\mathrm{CO}_{2}\right)$, particulate matter (PM), and other substances [2,4]. In 2008 the Sulfur Emission Control Areas (SECA) in the Baltic Sea started to be created, then they covered the North Sea and the English Channel. In 2012 similar Emission Control Areas (ECA) were created in the North American area, and the decision to decrease $\mathrm{SO}_{\mathrm{x}}$ in ships fuel was taken globally [4]. Ships' fuel sulfur requirements worldwide and in the ECA are presented in Figure 1.

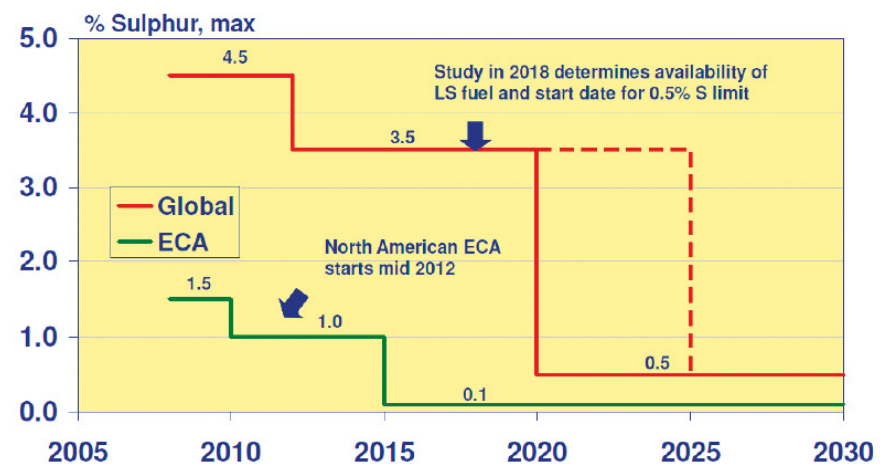

Figure 1. Ships' fuel sulfur requirements worldwide and in Emission Control Areas (ECA) [10].

This problem is recognized globally. For example, according to the European Union (EU) decision, the emission from ships should be decreased in 2020 not less than $20 \%$ (in comparison to 2005) and in 2030 not less than 30\%. Moreover, it is estimated that daily suboptimal operation of ships increases energy consumption up to $15 \%-18 \%$ caused by inappropriate decisions by the ship's crew, which influence the increase of emission from ships accordingly [1,11].

The conducted analysis of available literature revealed that green shipping development and environmental sustainability in seaports are frequently discussed research topics. The reviewed studies analyze technical and technological aspects of sustainable shipping, show organizational challenges and possible economic effects, assess the volume of pollution, and propose ways to decrease it [12-17].

Different regulations and approaches are implemented to reduce the volume of emissions. These approaches include, i.a., the decrease of emissions from vehicles using environmentally friendly fuels, optimization of ships' maneuvers in port approaches and internal navigational channels, by optimal design of the ports' terminals, as well as minimization of vehicle service time, improvement of ports' 
connection with hinterland, and others [18-29]. The implementation of a large number of these approaches requires significant financial outlays that may deal with investments in the development of ports' infrastructure, construction changes of ships, etc.

Conducted research studies also pay attention to human factor influence on navigation safety and ship operation [30-33]. However, it should be noted that the available literature positions do not present a detailed analysis of the influence of ships' crew and ports pilots' qualification on the possibility to decrease the emissions from ships during ships' maneuvering in seaports.

In this article the human factor influence on emissions from ships in port areas is analyzed in detail. It aims to develop a method allowing an assessment of the possible decrease in the emissions from ships, considering ships masters' and ports pilots' qualification. The research questions were formulated as follows:

1. Are the emissions from ships in seaports influenced by ships masters' and ports pilots' qualification?

2. What is the volume of emissions from ships that may be reduced during ships' maneuvering operations in port area depending on responsible person's qualification?

It is assumed that in case the maneuvers of ships will be done by operators with different qualifications, there will be differences in the volume of emissions created by ships. The proposed method is based on empirical data analysis and shows the way to analyze the data using dispersion and maximal dispersion methods. Its idea is to show that emissions from ships in ports may be reduced by employing ships' masters and ports' pilots with appropriate qualifications. The case study analysis is used to verify the method. Real data of ship sailing in seaports are considered, bearing in mind that ships' maneuvers are performed by different operators. Identified differences in ship sailing parameters allow an estimation of the emissions created by ships and share of possible emission reduction.

Section 2 of the paper presents the literature analysis. Section 3 describes the methodology used to conduct the research. The results of case study analysis are shown in Section 4. The paper is summarized by discussions, conclusions, and directions of future research, presented in Sections 5 and 6.

\section{Literature Analysis}

Emissions of poisonous substances are produced by different sectors of the economy and different approaches to estimate the volume of emissions are implemented [5,34-38]. This also applies to transport and logistics systems functioning in pursuit of sustainable development of these systems [39-43]. Direct and indirect gas emissions caused by water transport are noted, especially air pollution through various greenhouse gas emissions $\left(\mathrm{SO}_{2}, \mathrm{NO}_{\mathrm{x}}, \mathrm{CO}_{2}, \mathrm{PM}_{2.5}, \mathrm{PM}_{10}\right)$ [32,44-46].

Emission from ships has wide regulation framework. Stringent regulations were implemented by the IMO and the EU (i.e., within and beyond the SECA limits) to reduce the sulfur emissions of ships $[4,10,45]$. IMO has tasked its members to achieve a 70\% reduction in $\mathrm{CO}_{2}$ emissions by 2050, the decarbonization process is based on EU strategic documents, low-emission and zero-emission technologies [12]. Furthermore, the nitrogen emission control area (NECA) in the Baltic Sea and the North Sea is planned to be introduced in 2021 [15]. These and other restrictions significantly affect the functioning of shipping companies and seaports, as well as forces them into action measures to comply with environmental protection requirements [47].

Bouman et al. provided a comprehensive overview of the $\mathrm{CO}_{2}$ emission reduction potentials and measures and stated that emissions can be reduced by more than $75 \%$, based on current technologies and by 2050, through a combination of measures if policies and regulations are focused on achieving these reductions [48]. Available studies recognize the need for research result implications for the further development of policies addressing sustainability in shipping management [49], as well as combining instruments into policy packages, and emphasise the urgency of addressing technology and policy solutions for the maritime sector [50]. It is highlighted that management policies should depend 
on the internal and external environment of shipping companies [13]. Safe, secure, energy-efficient, affordable, reliable, climate-resilient, low-carbon, and rule-based maritime transport systems contribute to achieving an economically efficient and environmentally sound development [14,51].

Decreasing of emissions from shipping is the multipurpose task which links technical, technological, organizational, legal decisions, as well as human factor influence (employee education and training). In this regard, different approaches may be found in the literature [52]. In order to reduce emission volume in port areas and main international waterways, environmentally friendly fuels and renewable energy resources may be used $[2,3,19,20,22,24,28,37,53]$. In many cases, ships in ports use only permitted fuels (depending on fuel content). Improvements in ship structure, including used engines, are also investigated $[3,42,54-56]$. Slow steaming strategies have been introduced in most shipping lines and significantly decrease $\mathrm{CO}_{2}$ emissions from international shipping [16]. Moreover, simplified and composite ship fuel consumption models for ocean-going vessels were developed and facilitate the assessment of the fuel volume needed for ships [32,46,57-59]. It is also noted that modal shift policy is one of the ways to reduce emissions and should take into consideration environmental strategy and possible pollution reduction [60].

The analysis of the literature positions revealed that currently problems of decreasing the emissions from ships are applied to different shipping areas, however a lot of attention is paid to ships' service in seaports. Ports, as the important nodes of transport and logistics systems, make an effort to plan their territory optimally; however, it is not an easy task, especially when ports are located in cities or next to them [8,61-63]. It was estimated that in some specific harbor areas in Asia, ships can contribute up to $7 \%-26 \%$ to the local fine particulate matter concentrations [64]. Attention is paid to the need to develop approaches for green ports that have emerged within environmental management and give attention to the ecological issues [17]. This reinforces the belief that actions should be continued to reduce the volume of emissions in ports.

The complicated design of navigational approach and inside port channels sometimes need a lot of ships maneuvers that may be optimized [65,66]. Emissions from ships, especially observed in approaches to the ports and in ports areas, is influenced by the performed maneuvers and often requires changing the ship's engine power, which should be carried out by the ship's crew and port pilot with appropriate qualifications.

A comprehensive review of ships' maneuvers and environmental effects was conducted by Di Vaio et al. [67]. It was mentioned that in order to achieve high competitiveness in seaports in response to environmental and energy regulation, port authorities, users, and local communities have to invest considerable resources. The paper introduces managerial key performance indicators to support port authorities in their decision-making processes, considering inter-organizational relationships with shipping lines that aim to develop environmentally sustainable and energy efficient ports.

It should be noted that port configuration and ship maneuvering areas are different in particular ports $[26,66]$. Two main factors influence the emissions produced by ships in ports: types of maneuver operations made by ships and efficiency of tug assistance. On the one hand, ships sailing in port areas have to be safe. On the other hand, it is very important to optimize the time of ships' movement and minimize maneuvers inside the port that mainly depend on the responsible people's qualifications and health $[26,29,68]$. The reviewed research papers mention that these qualifications are influenced by the region seafarers come from [69] and affect the safety in maritime operations [30,70]. However, the influence of ships' crew and port pilots' qualification on the possibility to reduce the emissions from ships has not been analyzed in detail.

Corrigan et al. [31] stated that there is an increasing awareness of human factor influence in maritime transport and much more focused research is required concentrating on the specific complexities, constraints, and shared processes of port environments. It is also highlighted that maritime educational institutions around the world should be prepared to provide the skilled labor the industry will require to remain competitive [33].

On the basis of the conducted literature analysis it should be stated that: 
- $\quad$ the problem of decreasing the emissions from ships is up-to-date and further solutions in this field should be developed;

- $\quad$ there is a need to look for solutions to reduce the emissions from ships that will not require high volumes of investments;

- $\quad$ human factor influence on poisonous substance emissions from ships has been analyzed so far to a small extent.

This justifies the need to investigate the impact of ships' crew and port pilots' qualifications and decisions on ships' maneuver operations in port areas, as well as further search for ways to decrease emissions from ships.

\section{Materials and Methods}

The following methodology was used to develop the method aiming to assess the possible decrease of the emissions from ships (Figure 2). After the literature analysis the necessary data were collected to develop the method. The method was verified on the basis of Klaipeda port case study analysis. Then, the appropriate conclusions were drawn.

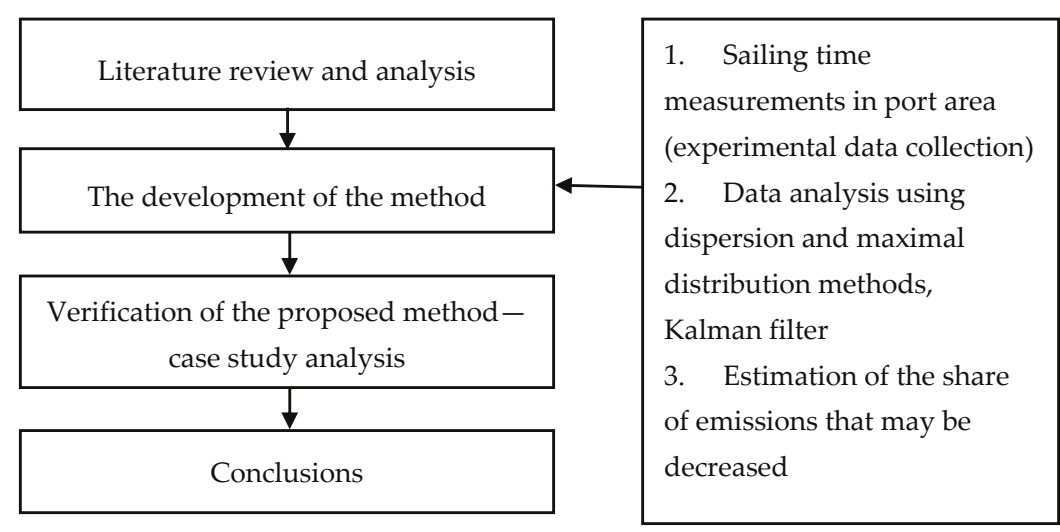

Figure 2. The methodology used to conduct the research.

To decrease the energy consumption, as well emissions from shipping activity, it is necessary to clearly understand ships' operation processes and have knowledge about emission sources, including transport means and port equipment operation, possibility to use the definite fuels for the different machines' functioning, as well as to know the methods of optimal holistic port and terminal design, and recognize the significance of the high qualifications of port staff and ships' crew.

Emissions from ships and other transport vehicles directly depend on the quantity and quality of fuel used. The main emissions from ships constitute: carbon dioxide $\left(\mathrm{CO}_{2}\right)$, nitrogen oxides $\left(\mathrm{NO}_{\mathrm{x}}\right)$, carbon monoxide (CO), sulfur oxides $\left(\mathrm{SO}_{\mathrm{x}}\right)$, and particulate matter (PM) [10].

Carbon dioxide and sulfur oxide emissions could be calculated as follows (Equations (1) and (2)):

$$
\begin{gathered}
\mathrm{CO}_{2}=k_{\mathrm{CO}_{2}} \cdot Q_{f}, \\
S O_{x}=k_{S O} \cdot Q_{f},
\end{gathered}
$$

where: $k_{\mathrm{CO}_{2}}$ is the carbon dioxide coefficient, which depends on fuel quality (for the high-quality diesel fuel this coefficient is between 3.0 and 3.2 and for the LNG (Liquefied Natural Gas) fuel this coefficient is between 2.1 and 2.3); $k_{S O}$ is the sulfur oxides coefficient, which depends on the fuel quality (sulfur 
percentage in fuel), for example, for $\mathrm{SO}_{\mathrm{x}}$ control areas it is 0.001 for diesel fuel and 0.0 for the LNG fuel; $Q_{f}$ is the quantity of fuel during ship sailing, which can be estimated as follows (Equation (3)):

$$
Q_{f}=\int_{0}^{T} k_{f} \cdot q_{f} \cdot N_{a v} \cdot d t
$$

where $k_{f}$ is the coefficient, which depends on the type of engine [10,71]; $q_{f}$ is the consumption of fuel for the definite engine $(\mathrm{kg} / \mathrm{kWh}), N_{a v}$ is the ship's engine's average power during the sailing period $(\mathrm{kW})$, which can be calculated using Equation (4):

$$
N_{a v}=\frac{\int_{0}^{t} N_{i} \cdot d t}{t},
$$

where $N_{i}$ is the instantaneous ship's main engine power $(\mathrm{kW})$; $t$ is the ship's sailing time.

Nitrogen oxides, carbon monoxide, and particulate matter emissions depend on the real engine power, type of fuel, and its quality, and can be assessed as follows (Equations (5)-(7)):

$$
\begin{gathered}
C O=k_{C O} \cdot N_{a v} \cdot t, \\
N O_{x}=k_{N O_{x}} \cdot N_{a v} \cdot t, \\
P M=k_{P M} \cdot N_{a v} \cdot t,
\end{gathered}
$$

where $k_{\mathrm{CO}}$ is the carbon monoxide coefficient, which depends on fuel quality and engine condition, for the high-quality diesel fuel and modern engines it varies between $0.005 \mathrm{~kg} / \mathrm{kWh}$ for diesel fuel and $0.003 \mathrm{~kg} / \mathrm{kWh}$ for LNG fuel; $k_{N O_{x}}$ is the nitrogen oxides coefficient, which also depends on fuel quality and engine state, for the high-quality diesel fuel and modern engines it is in the range of $0.008-0.0012$ $\mathrm{kg} / \mathrm{kWh}$ for diesel oil and $0.003-0.004 \mathrm{~kg} / \mathrm{kWh}$ for LNG fuel; $k_{P M}$ is the particulate matter coefficient, which depends on fuel quality and engine, for the high-quality diesel fuel and modern engines it varies between $0.0005-0.0006 \mathrm{~kg} / \mathrm{kWh}$ for diesel oil and about $0.0001 \mathrm{~kg} / \mathrm{kWh}$ for LNG fuel $[10,72]$.

As it was mentioned before, the staff (ships' crew and ports pilots') qualifications and behavior greatly influence the volume of emissions coming from ships. The time the ship spends on crossing the port area and maneuvering operations affects the fuel consumption and consequently the volume of produced emissions. In order to evaluate this influence, it is proposed to use experimental data and apply dispersion and maximal distribution methods for their analysis.

The developed method is focused on time and emission bands analysis. In order to calculate the size of random error or time bands, we use dispersion and/or "maximal distribution" mathematical methods. It was set that the size of random error $\left(e\right.$ or $\left.\Delta t_{P}\right)$ in the dispersion method is comparable with dispersion $\left(\sigma_{y}\right)[26,73,74]$. Dispersion method implementation to evaluate the ship's sailing time in port time bands can be expressed using Equation (8) [73,75]:

$$
\sigma_{y}^{2}=\frac{1}{n-1} \sum\left(t_{i}-t_{y}\right)^{2}
$$

where $n$ is the number of the measurements; $t_{i}$ is the particular measurement results (ship's sailing time in port area); $t_{y}$ is the mathematical expectation of the average sailing time, which can be calculated as follows (Equation (9)):

$$
t_{y}=\frac{\sum_{i=1}^{n} t_{i}}{n} .
$$

Finally, sailing time band with determined probability (e.g., 63\%-68\%) $\left(\Delta t_{P}\right)$ can be presented by random error (Equation (10)):

$$
e=\Delta t_{P}= \pm \sqrt{\sigma_{y}^{2}}
$$


Sailing time band $\left(t_{P}\right)$ may be calculated using the Equation (11):

$$
t_{P}=t_{y} \pm \Delta t_{P}
$$

Similarly, sailing time band can be estimated using the "maximal distribution" method. For the purpose of the research it can be expressed as follows (Equation (12)) [26,76]:

$$
t_{P}=t_{y} \pm P \prime \cdot \Delta t \cdot k_{t}
$$

where $P^{\prime}$ is the probability coefficient (it has been proposed that in the case of probability $63 \%-68 \%$, the coefficient should equal 1, in the case of probability $95 \%$, the probability coefficient should be 2 , and in the case of probability $99.7 \%$, the probability coefficient equals 3); $\Delta t$ is the difference between sailing times; $k_{t}$ is the coefficient, which depends on the number of measurements (the number of possessed data): in the case the number of data is 3 , this coefficient will be 0.55 ; in the case of data numbering 4, this coefficient will be 0.47 , and similarly depending on the number of obtained data $5-0.43 ; 6-0.395$; $7-0.37 ; 8-0.351 ; 9-0.337 ; 10-0.329 ; 11-0.325 ; 12-0.322$ and so on, but the minimum value of this coefficient could be about 0.315 , in the case the number of collected data will be more than 15 .

The proposed approach introduces a new way to calculate and analyze ships' sailing time. In particular, it deals with sailing time band (most probable interval) calculation on the basis of experimental (real) data using request filtration to receive sailing time calculated values that are as close as possible to the actual ship's sailing time. The probability of the ship's sailing time or differences between average and actual sailing time data are the stochastic processes, therefore, filtration is required. To evaluate the difference between expected and real data, we implement the Kalman filter (other filters also may be used), which may be assessed as follows (Equations (13) and (14)) [77]:

$$
x_{k}=A x_{k-1}+B u_{k}+\omega_{k}
$$

with observations $z_{k}$ :

$$
z_{k}=H x_{k}+v_{k}
$$

where $A, B, H$ are coefficients; $\omega_{k}, v_{k}$ are the sequence of noisy observations; $x_{k}, u_{k}$ are control vectors.

The same approach is implemented to analyze the emission bands for the particular substances. Comparing the experimental results preceded by dispersion and maximal distribution methods, it is possible to evaluate the share of emissions that may be decreased. It should be highlighted that the presented methodology may be implemented to analyze the emissions from any kind of ship operating in any port.

\section{Results of Case Study Analysis}

In order to verify the proposed method, the case study was considered. Klaipeda port was selected and LNG standard tankers' movement through the port area from approach channel up to ships' turning basin was examined. The vessel was navigated by the ship's master and port pilot. Additionally, the behavior of 10 operators, who had professional experience to navigate ships using simulators, was investigated. These operators took part in the experiment and used the "SimFlex Navigator" simulator to steer a similar ship on the selected route.

While investigating the emissions from ships sailing through the port area, the external forces caused by wind, current, waves, and shallow water effect, influencing the ship's maneuverability, were also taken into account. The experiment was conducted under the set conditions, typical for the big ships entering Klaipeda and other ports.

The experimental study was carried out in Klaipeda port in winter 2019 when an LNG Standard tanker (with a capacity about $150,000 \mathrm{~m}^{3}$ of LNG) entered the port and sailed to the LNG terminal (Figure 3). The ship's movement parameters as engine power and ship's speed were recorded by the ship's equipment; additionally, the ship's speed was measured by differential GPS and checked by AIS 
(Automatic Identification System). The sections of the vessel's sailing route are presented in Figure 4 . The sailing time was measured in particular measurement points.

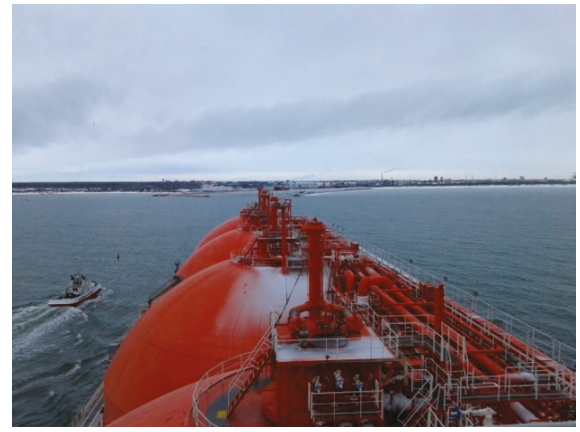

(a)

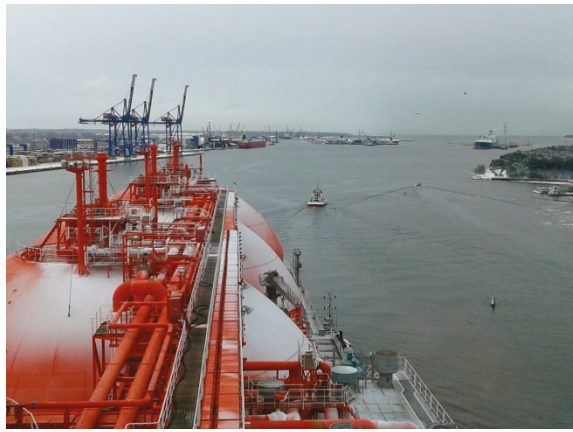

(b)

Figure 3. LNG Standard tanker: (a) measurement start position; (b) tanker passing the navigational channel of Klaipeda port.

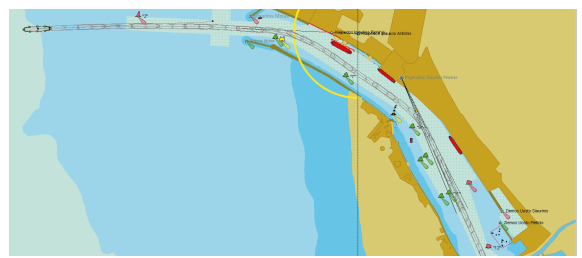

(a)

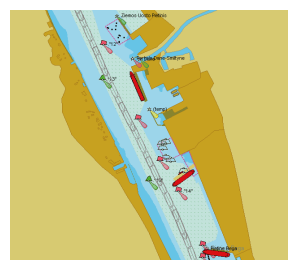

(b)

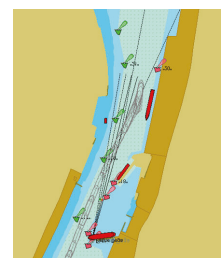

(c)

Figure 4. LNG Standard tanker sailing route: $(\mathbf{a}-\mathbf{c})$ route sections in the navigation channel of Klaipeda port.

The calculations for the specific case study were conducted under the set assumptions. The LNG Standard tanker that passed through the port area had the following parameters: length $(L)-290 \mathrm{~m}$, width $\left(B_{1}\right)-49 \mathrm{~m}$, draft $\left(T_{1}\right)-12 \mathrm{~m}$, displacement $\left(D_{1}\right)-125,000 \mathrm{t}$. Additionally, it was set that the block coefficient $(\delta)$ was 0.75 , ship's speed $\left(v_{1}\right)$ varied between 6 and 9 knots (from 3.1 up to $4.6 \mathrm{~m} / \mathrm{s}$ ), depth in port area $(H)$ was $14.5 \mathrm{~m}$. The LNG Standard tanker main sailing parameters, measured during the experiment performed by selected operators, are shown in Figure 5.

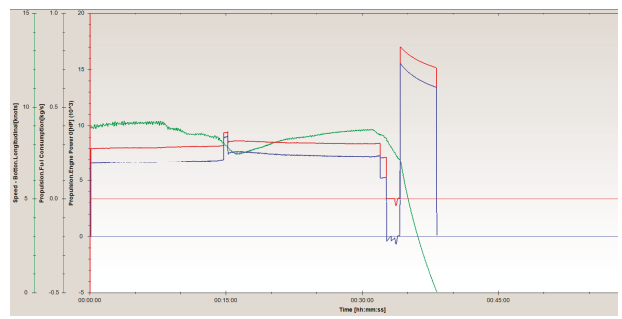

(a)

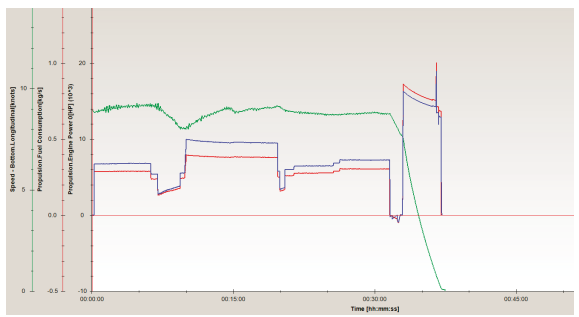

(b)

Figure 5. The LNG Standard tanker main sailing parameters $\left(v_{i}, Q_{f i}, N_{i}\right.$ as function of $\left.t\right)$, received during conducting the experiment: (a) ship steered by operator No. 4; (b) ship steered by operator No. 7. 
The settings used in the simulator were adjusted to external conditions measured during the performance of experimental study on the real ship. These settings included: wind direction SW, velocity $10 \mathrm{~m} / \mathrm{s}$, current out of port 0.5 knots, waves SW direction, height $1 \mathrm{~m}$ in approach channel and 0 inside port, shallow water effect ratio (ship's draft to depth) $\mathrm{T} / \mathrm{H}=0.82$. In total, over 100 similar experiments were performed using the simulator, among which 10 experiments on a real ship under similar external conditions (wind, current, waves, shallow effects) were carried out by different operators. By keeping identical sailing conditions for ships' maneuvers, it was possible to repeat the experiment and identify the behavior of different operators.

On the basis of the conducted measurements it was possible to compare and analyze the achieved results. The analysis covered experimental data received during the observation of 10 operators' behavior and real ship sailing. The selected investigated parameters after filtration by Kalman filter are presented in Table 2.

Table 2. Selected experimental data gained for LNG Standard tanker sailing in Klaipeda port, obtained from the "SimFlex Navigator" simulator and real ship.

\begin{tabular}{cccc}
\hline Operator & Sailing Time, $\boldsymbol{t}_{\boldsymbol{i}}, \mathbf{\text { min }}$ & Average Engine Power, $\boldsymbol{N}_{\boldsymbol{a v v}}, \mathbf{k W}$ & Used Fuel, $Q_{f}, \mathbf{k g}$ \\
\hline 1 & 37.5 & 6460 & 910 \\
2 & 38.2 & 6410 & 960 \\
3 & 36.9 & 6520 & 1020 \\
4 & 38.5 & 6420 & 980 \\
5 & 37.8 & 6460 & 950 \\
6 & 37.0 & 6610 & 1015 \\
7 & 39.2 & 6380 & 925 \\
8 & 38.1 & 6220 & 890 \\
9 & 36.7 & 6610 & 1050 \\
10 & 38.2 & 6510 & 990 \\
Real Ship & 37.5 & 6220 & 880 \\
\hline
\end{tabular}

On the basis of the received experimental results the emissions in the case of using the diesel oil with $0.1 \% \mathrm{SO}_{\mathrm{x}}$ content and LNG fuel (real LNG Standard tanker used LNG fuel) were calculated. Calculation results achieved using the methodology presented in the article are shown in Table 3.

Table 3. Emissions from LNG Standard tanker during sailing in Klaipeda port calculated for diesel oil/LNG usage, based on experimental results obtained from the "SimFlex Navigator" simulator and real ship.

\begin{tabular}{cccccc}
\hline Operator, No. & $\mathrm{CO}_{2}, \mathbf{k g}$ & $\mathrm{SO}_{\boldsymbol{x}}, \mathbf{k g}$ & $\mathrm{CO}, \mathbf{k g}$ & $\mathrm{NO}, \mathbf{k g}$ & $\mathbf{P M}, \mathbf{k g}$ \\
\hline 1 & $2821 / 2002$ & $0.91 / 0$ & $32.3 / 22.6$ & $6.5 / 4.5$ & $3.23 / 0.32$ \\
2 & $2976 / 2112$ & $0.96 / 0$ & $32.1 / 22.4$ & $6.4 / 4.5$ & $3.21 / 0.32$ \\
3 & $3162 / 2244$ & $1.02 / 0$ & $32.6 / 22.8$ & $6.5 / 4.6$ & $3.26 / 0.33$ \\
4 & $3038 / 2156$ & $0.98 / 0$ & $32.1 / 22.5$ & $6.4 / 4.5$ & $3.21 / 0.32$ \\
5 & $2945 / 2090$ & $0.95 / 0$ & $32.3 / 22.6$ & $6.5 / 4.5$ & $3.23 / 0.32$ \\
6 & $3146 / 2233$ & $1.02 / 0$ & $33.1 / 23.1$ & $6.6 / 4.6$ & $3.31 / 0.33$ \\
7 & $2868 / 2035$ & $0.93 / 0$ & $31.9 / 22.3$ & $6.4 / 4.5$ & $3.19 / 0.32$ \\
8 & $2759 / 1958$ & $0.89 / 0$ & $31.1 / 21.8$ & $6.2 / 4.4$ & $3.11 / 0.31$ \\
9 & $3255 / 2310$ & $1.05 / 0$ & $33.05 / 23.1$ & $6.6 / 4.6$ & $3.31 / 0.33$ \\
10 & $3069 / 2178$ & $0.99 / 0$ & $32.6 / 22.8$ & $6.5 / 4.6$ & $3.26 / 0.33$ \\
Real LNG tanker & $2759 / 1958$ & $0.89 / 0$ & $32.1 / 22.5$ & $6.4 / 4.5$ & $3.21 / 0.32$ \\
\hline
\end{tabular}

On the basis of the received experimental data, the mathematical expectation and bands (time and emission) for the specific ship operation were calculated using methods presented in the article. The achieved calculation results are presented in Tables 4 and 5. Dispersion and maximal distribution methods were used to assess the main ship's sailing and emission parameters. 
Table 4. Main ship's operation parameters and bands.

\begin{tabular}{cccc}
\hline Parameter & $\begin{array}{c}\text { Mathematical } \\
\text { Expectation }\end{array}$ & $\begin{array}{c}\text { Parameter's Band Received } \\
\text { by Dispersion Method }\end{array}$ & $\begin{array}{c}\text { Parameter's Band Received by } \\
\text { Maximal Distribution Method }\end{array}$ \\
\hline Sailing time, min & 37.9 & $37.1-38.7$ & $37.1-38.7$ \\
Engine power, kW & 6456 & $6346-6566$ & $6329-6583$ \\
Fuel consumption, kg & 962 & $908-1016$ & $910-1014$ \\
$\mathrm{CO}_{2}$ (diesel fuel), kg & 2991 & $2822-3160$ & $2830-3152$ \\
$\mathrm{CO}$ (LNG fuel), kg & 2116 & $1996-2236$ & $2002-2230$ \\
$\mathrm{CO}$ (diesel fuel), kg & 32.3 & $31.8-32.9$ & $31.7-32.9$ \\
$\mathrm{CO}$ (LNG fuel), kg & 22.6 & $22.2-23.0$ & $22.2-23.0$ \\
$\mathrm{NO} \mathrm{O}_{x}$ (diesel fuel), kg & 6.5 & $6.37-6.63$ & $6.37-6.63$ \\
$\mathrm{NO}$ (LNG fuel), kg & 4.5 & $4.41-4.59$ & $4.43-4.57$ \\
$\mathrm{PM}_{x}$ (diesel fuel), kg & 3.23 & $3.17-3.29$ & $3.16-3.30$ \\
$\mathrm{PM}$ (LNG fuel), kg & 0.32 & $0.30-0.34$ & $0.31-0.33$ \\
$\mathrm{SO}_{x}$ (diesel fuel), kg & 0.96 & $0.90-1.02$ & $0.91-1.01$ \\
$\mathrm{SO}_{x}$ (LNG fuel), $\mathrm{kg}$ & 0 & 0 & 0 \\
\hline
\end{tabular}

Table 5. The bands of the selected ship's sailing and emission parameters received by dispersion and maximal distribution methods.

\begin{tabular}{ccc}
\hline $\begin{array}{c}\text { Ship's Sailing and Emission } \\
\text { Parameters }\end{array}$ & $\begin{array}{c}\text { Parameter's Band Received by } \\
\text { Dispersion Method, \% }\end{array}$ & $\begin{array}{c}\text { Parameter's Band Received by } \\
\text { Maximal Distribution Method, \% }\end{array}$ \\
\hline Sailing time & 4.2 & 4.2 \\
Engine power & 3.4 & 3.9 \\
Fuel consumption & 11.2 & 10.8 \\
$\mathrm{CO}_{2}$ (diesel fuel) & 11.3 & 10.8 \\
$\mathrm{CO}_{2}$ (LNG fuel) & 11.3 & 10.8 \\
$\mathrm{CO}$ (diesel fuel) & 3.4 & 3.7 \\
$\mathrm{CO}$ (LNG fuel) & 3.5 & 3.5 \\
$N O_{x}$ (diesel fuel) & 4.0 & 4.0 \\
$N O_{x}$ (LNG fuel) & 4.0 & 3.1 \\
$P$ (diesel fuel) $_{P M}$ (LNG fuel) & 3.7 & 4.3 \\
$\mathrm{SO}_{x}$ (diesel fuel) & 6.5 & 6.2 \\
$\mathrm{SO}_{x}$ (LNG fuel) & 12.5 & 10.4 \\
& 0 & 0 \\
\hline
\end{tabular}

The achieved research results (Table 4) show that both methods for the band calculation (dispersion and maximal distribution methods) may be implemented for the analysis of ships' sailing and emission parameters. The difference between the results obtained using these two methods is less than $1 \%$. At the same time, the differences in particular operators' qualifications and behaviors could be observed. This demonstrates that decisions taken by operators significantly influence the ship's sailing time, affect ships' fuel consumption, and consequently volume of emission (Table 5).

It should be also mentioned that fuel type influences the emission volume. The research results made it possible to compare the emissions coming from the operation of ships using diesel and LNG fuels. Usage of fuels, like LNG, can decrease the volume of emissions from ships up to $30 \%$ and $\mathrm{SO}_{\mathrm{x}}$ emission up to $100 \%$. This underlines the effectiveness of their use in emission reduction.

\section{Discussion}

The research results reveal that qualifications of ports' pilots and ships' masters play a significant role in performing ships maneuvers, and consequently the volume of emissions from ships.

The number of conducted measurements during the case study analysis can be discussed. This number was limited, however, representative for the established research topic. The differences in operators' behavior while performing maneuvering operations were visible and proved that the level of pilots' qualification was different. Therefore, it should be stated that research results are satisfactory and allowed to answer the first research question—-the emission from ships in seaports is influenced 
by ships masters' and port pilots' qualification. In our future research we will try to extend the number of measurements and involve more qualified pilots, who will agree to take part in the study.

Conducted experimental results showed that the volume of emissions from ships may be reduced by $12.5 \%$ or even more. Some literature sources mention that the way of maneuvering the ship may influence the emission volume up to $15 \%-18 \%$ [72]. It should be noted that the research presented in this article was conducted for the specific ship and defined sailing conditions limited to the port area, that also influenced the results. However, it was possible to answer the second research question and assess the volume of emission from ships that may be reduced during ships' maneuvering operations in port area depending on responsible person qualification.

It should be highlighted that the research results were also influenced by external conditions that were founded during the study. Therefore, it will be reasonable to repeat experiment considering external conditions in different seasons and compare the results. On that basis, it will be possible to define the external conditions during which it is particularly important to have high qualifications of staff to make the right decisions and reduce the volume of emission.

Moreover, research results may have managerial implications. Seaports, as well as shipping companies, may change their procedures and introduce strict conditions of skill verification during employee hiring and professional work, in pursuit of reducing the volume of emissions at seaports. Companies may organize regular trainings and invest in employee education aiming at improving staff qualifications in supporting decision-making during maneuver operations. These activities may affect the development of companies' environmental policy in order to decrease the costs of ship operation, as well as emission volume.

The achieved results also proved that the maritime education quality is very important to obtain the necessary qualifications for ships operators. This justifies the need to raise the quality of professional education at the universities and increase the number of practical hours on simulators for seafarers, which will enable an increase in their qualifications and attractiveness on the labor market.

\section{Conclusions}

In shipping areas like ports, approach channels, and main waterways (Panama, Suez channels etc.), where intensive traffic is observed, the decrease of emissions from ships is very important for the sustainable development of ports. It influences not only people's health and quality of life, but also the surrounding environment.

The study presented in this article, aimed to develop a method to assess the possible decrease of emissions from ships, considering ships operators' qualification. This goal has been achieved. Study results show that qualification of the ship's masters and port pilots can influence the emission volume. This volume may be decreased up to $12.5 \%$ or even more.

Achieved results also allowed a comparison of the emissions coming from the operation of ships using diesel and LNG fuels. It was stated that the usage of more environmentally friendly fuels, like LNG, can decrease emissions from ships up to $30 \%$ and $\mathrm{SO}_{\mathrm{x}}$ emission up to $100 \%$.

The developed method presents a way to analyze empirical data and may be introduced in practice. It shows the role of operators' education and training, as well as justifies the need for regular improvement of staff qualifications. Moreover, the presented approach may be useful for seaports and shipping companies and may be implemented to assess the personal qualifications during the selection of staff responsible for ships' steering.

More detailed and complex investigations of external factors influencing the volume of emission coming from ships in port areas, like the type of tugs used, wind, and currents, will form the direction of our further research.

Author Contributions: Conceptualization, V.P. and D.P.; methodology, V.P.; software, V.P.; validation, V.P. and D.P; formal analysis, L.F.-D.; investigation, V.P., L.F.-D. and D.P.; resources, V.P. and D.P.; data curation, V.P. and D.P.; writing—original draft preparation, V.P. and D.P.; writing—review and editing, L.F.-D.; visualization, V.P., 
L.F.-D. and D.P.; supervision, V.P.; project administration, V.P.; funding acquisition, V.P. All authors have read and agreed to the published version of the manuscript.

Funding: This research received no external funding.

Acknowledgments: This article is based on the research conducted within the Interreg South Baltic project SB Transport LOOPS co-financed by the European Union from the European Regional Development Fund.

Conflicts of Interest: The authors declare no conflict of interest.

\section{References}

1. Review of Maritime Transport 2019, UNCTAD. 2020. Available online: https://unctad.org/en/ PublicationsLibrary/rmt2019_en.pdf (accessed on 25 May 2020).

2. Buhaug, Ø.; Corbett, J.J.; Eyring, V.; Endresen, Ø. Second IMO GHG Study, Technical Report; International Maritime Organization (IMO): London, UK, 2009.

3. Eyring, V.; Köhler, H.W.; Lauer, A.; Lemper, B. Emissions from international shipping: 2. Impact of future technologies on scenarios until 2050. J. Geophys. Res. 2005, 110, D17306. [CrossRef]

4. IMO. Amendments to the Annex of the Protocol of 1997 to Amend the International Convention for the Prevention of Pollution from Ships, 1973, as Modified by the Protocol of 1978 Relating thereto (MARPOL Annex VI). 2008. Available online: http://www.imo.org/includes/blastDataOnly.asp/data_id\%3D23760/176 (accessed on 25 May 2020).

5. Adamowicz, K. Assessment of the average rate of changes in atmospheric CO emissions in OECD countries. Arch. Environ. Prot. 2018, 44, 97-102. [CrossRef]

6. Brandt, J.; Silver, J.D.; Christensen, J.H.; Andersen, M.S.; Bønløkke, J.H.; Sigsgaard, T.; Geels, C.; Gross, A.; Hansen, A.B.; Hansen, K.M.; et al. Assessment of past, present and future health-cost externalities of air pollution in Europe and the contribution from international ship traffic using the EVA model system. Atmos. Chem. Phys. 2013, 13, 7747-7764. [CrossRef]

7. Colette, A.; Granier, C.Ø.; Hodnebrog, Ø.H.; Jakobs, H.; Maurizi, A.; Nyiri, A.; Bessagnet, B.; D’Angiola, A.; D'Isidoro, M.; Gauss, M.; et al. Air quality trends in Europe over the past decade: A first multi-model assessment. Atmos. Chem. Phys. 2011, 11, 11657-11678. [CrossRef]

8. Matthias, V.; Aulinger, A.; Backes, A.; Bieser, J.; Geyer, B.; Quante, M.; Zeretzke, M. The impact of shipping emissions on air pollution in the greater North Sea region-Part 2: Scenarios for 2030. Atmos. Chem. Phys. 2016, 16, 759-776. [CrossRef]

9. Streets, D.G.; Waldhoff, S.T. Present and future emissions of air pollutants in China: SO2, NOx, and CO. Atmos. Environ. 2000, 34, 363-374. [CrossRef]

10. IMO. Marine Engine Regulations; IMO: London, UK, 2015.

11. Air Quality Guidelines for Particulate Matter, Ozone, Nitrogen Dioxide and Sulfur Dioxide. Global Update 2005. WHO. 2006. Available online: http://whqlibdoc.who.int/hq/2006/WHO_SDE_PHE_OEH_06.02_eng.pdf (accessed on 1 November 2017).

12. Czermański, E.; Pawłowska, B.; Oniszczuk-Jastrząbek, A.; Cirella, G.T. Decarbonization of maritime transport: Analysis of external costs. Front. Energy Res. 2020, 8, 28. [CrossRef]

13. Yuen, K.F.; Wang, X.; Wong, Y.D.; Ma, F. A contingency view of the effects of sustainable shipping exploitation and exploration on business performance. Transp. Policy 2019, 77, 90-103. [CrossRef]

14. Benamara, H.; Hoffmann, J.; Youssef, F. Maritime transport: The sustainability imperative. Sustain. Shipp. A Cross Discipl. View 2019, 1-31. [CrossRef]

15. Karl, M.; Jonson, J.E.; Uppstu, A.; Aulinger, A.; Prank, M.; Sofiev, M.; Jalkanen, J.-P.; Johansson, L.; Quante, M.; Matthias, V. Effects of ship emissions on air quality in the Baltic Sea region simulated with three different chemistry transport models. Atmos. Chem. Phys. 2019, 19, 7019-7053. [CrossRef]

16. Cariou, $\mathrm{P}$. Is slow steaming a sustainable means of reducing $\mathrm{CO}_{2}$ emissions from container shipping? Transp. Res. Part. D Transp. Environ. 2011, 16, 260-264. [CrossRef]

17. $\mathrm{Wu}, \mathrm{X}$.; Zhang, L.; Yang, H.-C. Integration of eco-centric views of sustainability in port planning. Sustainability 2020, 12, 2971. [CrossRef]

18. Aulinger, A.; Matthias, V.; Zeretzke, M.; Bieser, J.; Quante, M.; Backes, A. The impact of shipping emissions on air pollution in the greater North Sea region-Part 1: Current emissions and concentrations. Atmos. Chem. Phys. 2016, 16, 739-758. [CrossRef] 
19. Bermúdez, F.M.; Laxe, F.G.; Aguayo-Lorenzo, E. Assessment of the tools to monitor air pollution in the Spanish ports system. Air Qual. Atmos. Health 2019, 12, 651-659. [CrossRef]

20. De Boer, W.P.; Slinger, J.H.; wa Kangeri, A.K.; Vreugdenhil, H.S.I.; Taneja, P.; Addo, K.A.; Vellinga, T. Identifying ecosystem-based alternatives for the design of a seaports marine infrastructure: The case of tema port expansion in Ghana. Sustainability 2019, 11, 6633. [CrossRef]

21. Di Vaio, A.; Varriale, L. Management innovation for environmental sustainability in seaports: Managerial accounting instruments and training for competitive green ports beyond the regulations. Sustainability 2018, 10, 783. [CrossRef]

22. González-Cancelas, N.; Serrano, B.M.; Soler-Flores, F. Seaport sustainable: Use of artificial intelligence to evaluate liquid natural gas utilization in short sea shipping. Transp. J. 2019, 58, 197-221. [CrossRef]

23. Langenus, M.; Dooms, M. Creating an industry-level business model for sustainability: The case of the European ports industry. J. Clean. Prod. 2018, 195, 949-962. [CrossRef]

24. Lozano, R.; Fobbe, L.; Carpenter, A.; Sammalisto, K. Analysing sustainability changes in seaports: Experiences from the Gävle Port Authority. Sustain. Dev. 2019, 27, 409-418. [CrossRef]

25. Pallis, A.A.; Vaggelas, G.K. Cruise Shipping and Green Ports: A Strategic Challenge. In Green Ports: Inland and Seaside Sustainable Transportation Strategies; Elsevier: Amsterdam, The Netherlands, 2018; pp. 255-273. [CrossRef]

26. Paulauskas, V. Ships Entering the Ports; N.I.M.S Publish House: Riga, Latvia, 2013; 240p, ISBN 9984-679-71-3.

27. Williams, J. The circular regeneration of a seaport. Sustainability 2019, 11, 3424. [CrossRef]

28. Ypsilantis, P.; Zuidwijk, R. Collaborative fleet deployment and routing for sustainable transport. Sustainability 2019, 11, 5666. [CrossRef]

29. Zalewski, P.; Montewka, J. Navigation safety assessment in an entrance channel, based on real experiments. In Proceedings of the 12th International Congress of the International Maritime Association of the Mediterranean (IMAM 2007), Varna, Bulgaria, 2-6 September 2007; pp. 1113-1117.

30. Sharma, A.; Nazir, S.; Ernstsen, J. Situation awareness information requirements for maritime navigation: A goal directed task analysis. Saf. Sci. 2019, 120, 745-752. [CrossRef]

31. Corrigan, S.; Kay, A.; Ryan, M.; Ward, M.E.; Brazil, B. Human factors and safety culture: Challenges and opportunities for the port environment. Saf. Sci. 2019, 119, 252-265. [CrossRef]

32. Heinrich, L.; Koschinsky, A.; Markus, T.; Singh, P. Quantifying the fuel consumption, greenhouse gas emissions and air pollution of a potential commercial manganese nodule mining operation. Mar. Policy 2020, 114, 103678. [CrossRef]

33. Simmons, E.; McLean, G. Understanding the paradigm shift in maritime education: The role of 4th Industrial Revolution technologies: An industry perspective. Worldw. Hosp. Tour. Themes 2020, 12, 90-97. [CrossRef]

34. Adam, M.; Schikowski, T.; Carsin, A.E.; Cai, Y.; Jacquemin, B.; Sanchez, M.; Vierkötter, A.; Marcon, A.; Keidel, D.; Sugiri, D.; et al. Adult lung function and long-term air pollution exposure. ESCAPE: A multicenter cohort study and meta-analysis. Eur. Respir. J. 2015, 45, 38-50. [CrossRef]

35. Anderson, J.O.; Thundiyil, J.G.; Stolbach, A. Clearing the air: A review of the effects of particulate matter air pollution on human health. J. Med. Toxicol. 2012, 8, 166-175. [CrossRef]

36. Bessagnet, B.; Colette, A.F.; Meleux, F.L.; Rouil, L.; Ung, A.; Favez, O.; Cuvelier, C.; Thunis, P.; Tsyro, S.; Stern, R.; et al. The EURODELTA III exercise-Model evaluation with observations issued from the 2009 EMEP intensive period and standard measurements in Feb/Mar 2009. Tech. Rep. 2014, 1, 2014.

37. Ignatavicius, G.; Toleikiene, M. Optimisation of the conservation of rare and vulnerable plant species in the perspective of climate change in Lithuanian (nature) reserves. Arch. Environ. Prot. 2017, 43, 61-73. [CrossRef]

38. Chen, Y.; Yu, J.; Li, L.; Li, L.; Li, L.; Zhou, J.; Tsai, S.-B.; Chen, Q. An Empirical Study of the Impact of the Air Transportation Industry Energy Conservation and Emission Reduction Projects on the Local Economy in China. Int. J. Environ. Res. Public Health 2018, 15, 812. [CrossRef]

39. Lindstad, H.; Verbeek, R.; Blok, M.; van Zyl, S.; Hübscher, A.; Kramer, H.; Purwanto, J.; Ivanova, O.; Boonman, H. GHG emission reduction potential of EU-related maritime transport and on its impacts, TNO innovation of life, CLIMA.B.3/ETU/2013/0015. Eur. Comm. CLIMA B 2015, 3, 1-95.

40. Gnap, J.; Varjan, P.; Durana, P.; Kostrzewski, M. Research on relationship between freight transport and transport infrastructure in selected European countries. Transp. Probl. 2019, 14, 63-74. [CrossRef]

41. Jonson, J.E.; Gauss, M.; Jalkanen, J.P.; Nyíri, A.; Johansson, L. EMEP model calculations of the effects of ship emissions in the Baltic Sea and the North Sea. Clean Shipp. Curr. 2014, 2, 21943-21974. 
42. Semenov, I.N.; Filina-Dawidowicz, L. Topology-based Approach to the Modernization of Transport and Logistics Systems with Hybrid Architecture. Part 1. Proof-of-Concept study. Arch. Transp. 2017, 43, 105-124. [CrossRef]

43. Soto, C.G. The potential impacts of global climate change on marine protected areas. Rev. Fish. Biol. Fish. 2002, 11, 181-195. [CrossRef]

44. Garg, C.P.; Kashav, V. Evaluating value creating factors in greening the transportation of Global Maritime Supply Chains (GMSCs) of containerized freight. Transp. Res. Part. D Transp. Environ. 2019, 73, 162-186. [CrossRef]

45. Bagoulla, C.; Guillotreau, P. Maritime transport in the French economy and its impact on air pollution: An input-output analysis. Mar. Policy 2020, 116, 103818. [CrossRef]

46. Agrawal, H.; Welch, W.A.; Miller, J.W.; Cocker, D.R. Emission measurements from a crude oil tanker at sea. Environ. Sci. Technol. 2008, 42, 7098-7103. [CrossRef]

47. Cullinane, K.; Bergqvist, R. Emission control areas and their impact on maritime transport. Transp. Res. Part. D Transp. Environ. 2014, 28, 1-5. [CrossRef]

48. Bouman, E.A.; Lindstad, E.; Rialland, A.I.; Strømman, A.H. State-of-the-art technologies, measures, and potential for reducing GHG emissions from shipping-A review. Transp. Res. Part. D Transp. Environ. 2017, 52, 408-421. [CrossRef]

49. Vejvar, M.; Lai, K.-H.; Lo, C.K.Y. A citation network analysis of sustainability development in liner shipping management: A review of the literature and policy implications. Marit. Policy Manag. 2020, 47, 1-26. [CrossRef]

50. Venturini, G.; Karlsson, K.; Münster, M. Impact and effectiveness of transport policy measures for a renewable-based energy system. Energy Policy 2019, 133, 110900. [CrossRef]

51. Wang, D.; Ding, R.; Gong, Y.; Wang, R.; Wang, J.; Huang, X. Feasibility of the Northern Sea Route for oil shipping from the economic and environmental perspective and its influence on China's oil imports. Mar. Policy 2020, 118, 104006. [CrossRef]

52. Novac, V.; Rusu, E. Air emissions from ships-Western black sea case study. Int. Multidiscip. Sci. Geoconference Surv. Geol. Min. Ecol. Manag. Sgem. 2019, 19, 813-819. [CrossRef]

53. Paulauskiene, T.; Bucas, M.; Laukinaite, A. Alternative fuels for marine applications: Biomethanol-biodiesel-diesel blends. Fuel 2019, 248, 161-167. [CrossRef]

54. Kušter Marić, M.; Ožbolt, J.; Balabanić, G. Reinforced concrete bridge exposed to extreme maritime environmental conditions and mechanical damage: Measurements and numerical simulation. Eng. Struct. 2020, 205, 110078. [CrossRef]

55. Hinostroza, M.A.; Xu, H.; Guedes Soares, C. Cooperative operation of autonomous surface vehicles for maintaining formation in complex marine environment. Ocean. Eng. 2019, 183, 132-154. [CrossRef]

56. Lion, S.; Vlaskos, I.; Taccani, R. A review of emissions reduction technologies for low and medium speed marine Diesel engines and their potential for waste heat recovery. Energy Convers. Manag. 2020, 207, 112553. [CrossRef]

57. Lang, X.; Zhang, C.; Jonasson, L.; Mao, W.; Eriksson, L.; Zhang, D. Comparison between full-scale measurements and theoretical fuel consumption model in a real arctic ship navigation. Proc. Int. Offshore Polar Eng. Conf. 2019, 1, 886-892.

58. Endresen, Ø.; Sørgård, E.; Sundet, J.K.; Dalsøren, S.B.; Isaksen, I.S.A.; Berglen, T.F.; Gravir, G. Emission from international sea transportation and environmental impact. J. Geophys. Res. D Atmos. 2003, 108, ACH 14-1-ACH 14-22. [CrossRef]

59. Le, L.T.; Lee, G.; Kim, H.; Woo, S.-H. Voyage-based statistical fuel consumption models of ocean-going container ships in Korea. Marit. Policy Manag. 2020, 47, 304-331. [CrossRef]

60. Pinchasik, D.R.; Hovi, I.B.; Mjøsund, C.S.; Grønland, S.E.; Fridell, E.; Jerksjö, M. Crossing borders and expanding modal shift measures: Effects on mode choice and emissions from freight transport in the Nordics. Sustainability 2020, 12, 894. [CrossRef]

61. Bieser, J.; Aulinger, A.; Matthias, V.; Quante, M.; Builtjes, P. SMOKE for Europe-adaptation, modification and evaluation of a comprehensive emission model for Europe. Geosci. Model. Dev. 2011, 4, 47-68. [CrossRef]

62. Lack, D.A.; Corbett, J.J. Black carbon from ships: A review of the effects of ship speed, fuel quality and exhaust gas scrubbing. Atmos. Chem. Phys. 2012, 12, 3985-4000. [CrossRef] 
63. Paulauskas, V.; Filina-Dawidowicz, L.; Paulauskas, D. Ships speed limitations for reliable maintenance of the quay walls of navigation channels in ports. Eksploat. I Niezawodn. Maint. Reliab. 2020, 22, 306-315. [CrossRef]

64. Sorte, S.; Rodrigues, V.; Borrego, C.; Monteiro, A. Impact of harbour activities on local air quality: A review. Environ. Pollut. 2020, 257, 113542. [CrossRef] [PubMed]

65. Pallotta, G.; Vespe, M.; Bryan, K. Vessel pattern knowledge discovery from AIS data: A framework for anomaly detection and route prediction. Entropy 2013, 15, 2218-2245. [CrossRef]

66. Tomczak, A. Safety evaluation of ship's maneuvers carried out on the basis of integrated navigational system (INS) indications. J. Kobin 2008, 4, 247-266. [CrossRef]

67. Di Vaio, A.; Varriale, L.; Alvino, F. Key performance indicators for developing environmentally sustainable and energy efficient ports: Evidence from Italy. Energy Policy 2018, 122, 229-240. [CrossRef]

68. Dachev, Y.; Lazarov, I. Impact of the marine environment on the health and efficiency of seafarers. Wseas Trans. Bus. Econ. 2019, 16, 282-287.

69. Kartal, Ş.E.; Uğurlu, Ö.; Kaptan, M.; Arslanoğlu, Y.; Wang, J.; Loughney, S. An analysis and comparison of multinational officers of the watch in the global maritime labor market. Marit. Policy Manag. 2019, 46, 757-780. [CrossRef]

70. Mou, J.M.; Chen, P.F.; He, Y.X.; Yip, T.L.; Li, W.H.; Tang, J.; Zhang, H.Z. Vessel traffic safety in busy waterways: A case study of accidents in western shenzhen port. Accid. Anal. Prev. 2019, 123, 461-468. [CrossRef] [PubMed]

71. Byun, D.W.; Ching, J.K.S. Science Algorithms of the EPA Models-3 Community Multiscale Air Quality (CMAQ) Modeling System; United States Environmental Protection Agency, Office of Research and Development: Washington, DC, USA, 1999.

72. Denier van der Gon, H.; Hulskotte, J. Methodologies for Estimating Shipping Emissions in the Netherlands; BOP Reports 500099012, Netherlands Environmental Assessment Agency, (PBL), PO BOX 303, 3720 AH Bilthoven, The Netherlands; Publication of the Netherlands Research Program on Particulate Matter: Bilthoven, The Netherlands, 2010.

73. Gunning, P.; Horgan, J.M.; Yancey, W. Geometric stratification of accounting data. Rev. Contad. Y Adm. 2004, 214.

74. Sitter, R.R.; Wu, C. Efficient estimation of quadratic finite population functions in the presence of auxiliary information. J. Am. Stat. Assoc. 2002, 97, 535-543. [CrossRef]

75. Plikusas, A.; Pumputis, D. Estimation of the finite population covariance using calibration. Nonlinear Anal. Model. Control. 2010, 15, 325-340. [CrossRef]

76. Tulasi, L.C.; Rao, A.R. Review on theory of constraints. Int. J. Adv. Eng. Technol. 2012, 3, 334-344.

77. Chauhan, S.; Patil, C.; Sinha, M.; Halder, A. Fuzzy state noise-driven Kalman filter for sensor fusion. Proc. Inst. Mech. Eng. Part. G J. Aerosp. Eng. 2009, 223, 1091-1097. [CrossRef]

(C) 2020 by the authors. Licensee MDPI, Basel, Switzerland. This article is an open access article distributed under the terms and conditions of the Creative Commons Attribution (CC BY) license (http://creativecommons.org/licenses/by/4.0/). 

MDPI

St. Alban-Anlage 66

4052 Basel

Switzerland

Tel. +41616837734

Fax +41 613028918

www.mdpi.com

Sustainability Editorial Office

E-mail: sustainability@mdpi.com

www.mdpi.com/journal/sustainability

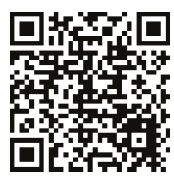



MDPI

St. Alban-Anlage 66

4052 Basel

Switzerland

Tel: +41 616837734

Fax: +41 613028918 